\title{
Role of demand in technical change
}

Citation for published version (APA):

Garcia-Torres, M. A. (2009). Role of demand in technical change. [Doctoral Thesis, Maastricht University]. Universitaire Pers Maastricht. https://doi.org/10.26481/dis.20090212mg

Document status and date:

Published: 01/01/2009

DOI:

10.26481/dis.20090212mg

Document Version:

Publisher's PDF, also known as Version of record

\section{Please check the document version of this publication:}

- A submitted manuscript is the version of the article upon submission and before peer-review. There can be important differences between the submitted version and the official published version of record.

People interested in the research are advised to contact the author for the final version of the publication, or visit the DOI to the publisher's website.

- The final author version and the galley proof are versions of the publication after peer review.

- The final published version features the final layout of the paper including the volume, issue and page numbers.

Link to publication

\footnotetext{
General rights rights.

- You may freely distribute the URL identifying the publication in the public portal. please follow below link for the End User Agreement:

www.umlib.nl/taverne-license

Take down policy

If you believe that this document breaches copyright please contact us at:

repository@maastrichtuniversity.nl

providing details and we will investigate your claim.
}

Copyright and moral rights for the publications made accessible in the public portal are retained by the authors and/or other copyright owners and it is a condition of accessing publications that users recognise and abide by the legal requirements associated with these

- Users may download and print one copy of any publication from the public portal for the purpose of private study or research.

- You may not further distribute the material or use it for any profit-making activity or commercial gain

If the publication is distributed under the terms of Article $25 \mathrm{fa}$ of the Dutch Copyright Act, indicated by the "Taverne" license above, 
The Role of Demand in Technical Change 
(C) 2008 M.Abraham García Torres

All rights reserved.

Cover artwork and design by M.Abraham García Torres

Prcpared with IATEX

Published by Universitaire Pers Maastricht

ISBN 9789052788029

Printed in the Netherlands by Datawyse Maastricht 


\title{
The Role of Demand in Technical Change
}

\author{
PROEFSCHRIFT
}

ter verkrijging van de graad van doctor aan de Universiteit Maastricht, op gezag van de Rector Magnificus, Prof. Mr. G.P.M.F. Mols, volgens het bosluit van het College van Decanen, in het openbaar te verdedigen op donderdag 12 februari 2009 om 12.00 uur

door M.Abraham García Torres

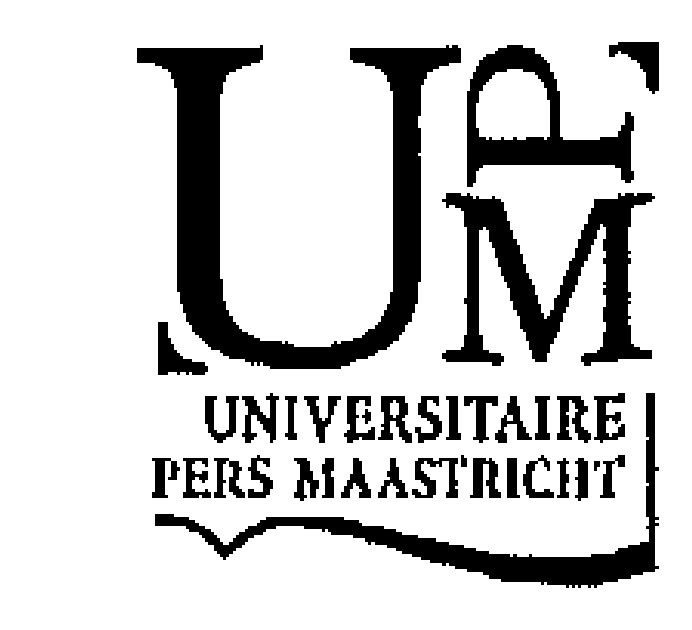




\section{Promotor:}

Prof. Dr. R. Cowan

Prof. Dr. P. Mohnen

Prof. Dr. L.L.G. Soete

Co-promotors:

Dr. T.H.W. Ziesemer

\section{Beoordelingscommissie:}

Prof. Dr. J. Mairesse, voorzitter

Prof. Dr. B. Verspagen

Prof. Dr. G. Duysters, Eindhoven University of Technology

Dr. A. van Zon 
"A mis padres y hermanos" 


\section{ABSTRACT}

This thesis analyses the role of consumer demand on technical change. Using a variety of techniques and approaches it discusses how successful innovations change consumers' options. While focusing on product innovation, the thesis is structured as four indepcndent papers.

We initially reflect from a microeconomic perspective on the evolution of preferences over time. A microcconomic model is introduced in which the consumer maximizes utility, taking decisions in which neu possibilities interact with earlier purchasing habits. Habit formation and the novelty associatcd with new goods are two concepts that explain this dynamic consumer behaviour. The model explains a situation in which technically good innovative products can fail due to a lack of novelty value.

Habit formation is analysed in a macroeconomic growth model. Working with non-homothetic preferences in a Dixit and Stiglizt framework, the model introduces creative destruction from the demand side. There are two sectors: a final goods sector and an $R \& D$ sector, the latter producing in each time period a blueprint for a new good which is superior to all existing previous ones in its capacity to generate habits. Each period's new good differs from all existing goods both vertically and horizontally. An interesting conclusion is that product innovation increases the marginal (and average) propensity to consume.

Demand is also studied from an evolutionary perspective by discussing its role in a National System of Innovations. Four dimensions of the system are quantified using composite indicators: creation of knowledge, human capital, and supply and demand innovation capacity. The innovation capacity relates to how well demand and supply are correlated with the other two dimensions. The evolution of fourteen European countries over ten years is discussed in an attempt to understand weak links in each country's system.

The last empirical chapter uses CIS data to determine whether government funding has any effect on the demand for new products. Using a minimum distance estimator, a system of simultaneous equations is created in which government funding affects the input side of innovation (R\&D) and the output side of innovation (demand for new products). We find some positive effect between receiving government funding and the amount of $R \& D$, however the effect of funding on demand for new products is much smaller, coming only indirectly through increased $R \& D$.

The main objective of the thesis, by giving these four viewpoints, is to open new areas of discussion on the role of demand on technical change. The principal conclusion of the thesis is that we need to incorporate human needs and their demand for innovations when discussing the economics of technical change. This can only be done by introducing a dynamic view of demand. 


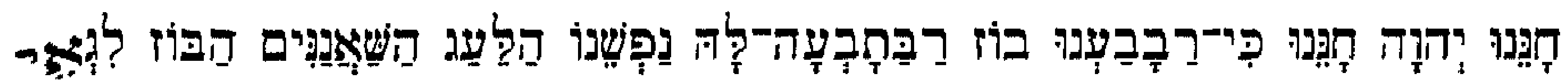

.. JMy spirit, which is upon you and My words that I have placed in your 2 , shall not move from your mouth or from the mouth of your seed and from o uth $^{\text {th }}$ your seed's sced"[...](Isaiah 59:21)

\section{ACKNOWLEDGEMENTS}

2r-king on this $\mathrm{Ph} . \mathrm{D}$ has been a great experience for me. However, many I felt I was fighting with darkness, some of which came from inside myself. nly weapon to fight against it was constant work. However many people, on occasions, helped me to walk far away from the negativity. To all of them, Ld like to express my thanks.

rst of all I would like to thank Luc Soete, who gave me the opportunity involved partially in projects to be able to carry out the Ph.D. Not only 3 find a way to financially support my research, but also enriched me with fruitful discussions at different stages of the process. Second, I would like naks Thomas Ziesemmer for his guidance and patience, checking the tedious lation of the models. From Pierre Mohnen I learned the wonderful insides plied econometrics. And to Robin Cowan I am grateful for being able to inate research that was done in very different directions. Without their help, Id have taken more than a few detours. I thank the members of my reading ittee; Jacques Mairesse, Geert Duysters, Bart Verspagen and Adrian van or their positive judgment and comments on the thesis. I would also like ank Dominique Forey for letting me be part of the CEMI-EPLF group in .nne.

am grateful to Corien Gijsbers, who not only help me with all sorts of listrative and housing matters but also became a very good friend. Eveline

- Braek's entry into the team made my life, as well as that of phd students more enjoyable. Ad Noten was always very kind and helpful when help was cl to find weird books or articles. I am also grateful to Dai Jones for the ent work on editing the thesis.

the adventure of being involve in projects I want to thank Hugo Hollanders, Bordoy, Ren Wintjes, Anthony Arunclel and Wendy Hansen for making me art of the MERIT team. 
But among the many books and articles that I have read while being a Plı.D student, there is one that was very special to me, a book of life in whose pages were those people that became my fostcr family. The fact that UNU-MERIT is such a rich cultural organization gave me the opportunity to come close to ideas that had been far away from me. Some of these pages were specially important for my work. The students where always more flexible compared to the professors when new ideas were to be discussed. In this sense I would like to thank Giulia Felice, for her moral support and understanding of my work; Bas Straathof (who not only discussed my ideas at a very early stage but also translated the summary of the thesis to Dutch and introduced me in Dr. Chaykoskys secret theorems), Bulat Sanditov and Yoseph Getachew. They were always there to discuss ideas, even if it was in the middlc of parties, dinners or over beers.I would like also to thank those students from my batch especially Teresa Caparas, Francisco Aguayo, Marcia de Mota Daros and Fulvia Farinelli for being part of my family since the first day we meet. The students that were there before I arrived, that helped me understand all kinds of issues related to my status as a new student. I would like to remember Elad Harison, Muge Ozman, Andreas Reinstaller, Noi Kwanjai, Branka Urem and Norman Dytianquin. I want to thank Semih Akomack for having an amazing amount of patience with me, and always being there when I needed him. Together with Ezequiel Tacsir, Fernando Santiago-Rodriguez and Marion Motari, we became part of the lunchtime hardcore team. Zacharias Babutsidze, Natalia Timus, Asel Doronova, Ekin Keskin, Bilal Mirza, Flavia Carvalho, Donatus Kosi Ayitey, Veronica Jazmin Guerrero, Shuan SandreGhazi, Lilia Stubrin and Daniel Vertesy for various reasons became very special people to me. I would also like to remember some of the students that visited MERIT and became part of my life, among them are Roberto Antonietti, Francesco Rentocchini, Giulia Panzani, Watu Wamae, Anabel Marin and Subash Sasidharan. I am also thankful to the students of the School of Governance, especially Maha Amed and Judit Vall. Not only inside the institute but also outside the wall of merit, the friendship of many people helped me in the times of difficulties, I would like to particularly thank Sonia Piedrafita, Susana Ravassa, Steven Jukes, Mu (Aye Mu Myint), Pilar Martinez and Ame Gabriel. I am also grateful to Susana Gonzalo Salgado for the support offered for this project at an early stage; Kino Majan, Monica Aranda and to Milagros Rojas. The list is much longer but I will stop here.

Last but not least, I would like to thank my parents Felix Garcia and Rafi Torres, my brother Felix and my sister Olga. Without their support this thesis would not have been finished. I dedicate this work to them.

M. Abraham Garcia-Torres Lausanne Switzerland, Winter 2008 


\section{Contents}

Abstract $\quad$ vii

Acknowledgements $\quad$ ix

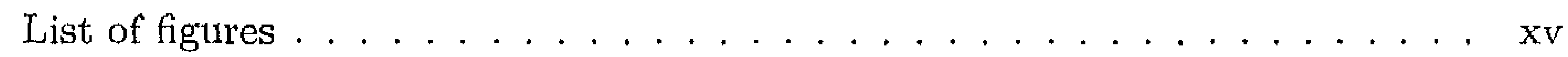

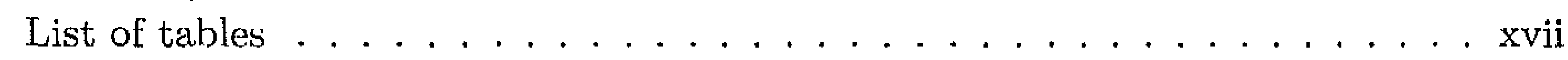

1 Introduction 1

1.1 J.M. Keynes . . . . . . . . . . . . . . . . . . . . . . . 2

1.2 L.L. Pasinetti . . . . . . . . . . . . . . . . 4

1.3 Thesis structure $\ldots \ldots \ldots \ldots \ldots$

2 Consumer behaviour: evolution of preferences and the search for novelty 9

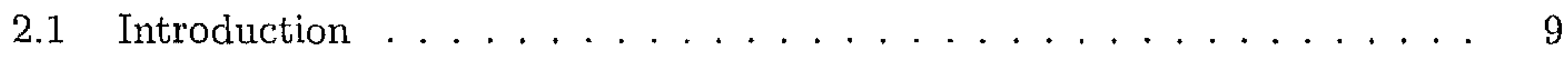

2.2 The dynamics of utility in the economic literature . . . . . . . . . 10

2.3 A new theory for consumer behaviour . . . . . . . . . . . 15

2.3.1 Evolution of preferences . . . . . . . . . . . 17

2.3 .2 The search for novelty . . . . . . . . . . . . . . 19

2.3 .3 Deciding what to buy . . . . . . . . . . . . . . . . 22

2.4 Formalization of the model . . . . . . . . . . . . . . . . . 24

2.4 .1 Utility maximization in one period . . . . . . . . . 25

Properties of the function . . . . . . . . . . 27

Elasticity of substitution . . . . . . . . . . . 27

2.4.2 Evolution of the dynamic subconscious process . . . . . . 28

2.4.3 One new good, four possible outcomes . . . . . . . . . . 30

2.4.4 Graphical analysis of the model . . . . . . . . . . . . . 32

2.4 .5 Extending the model . . . . . . . . . . . . . 35

2.5 Conclusions . . . . . . . . . . . . . . . . . . 36

3 Habit formation, demand and growth through product innovation $\quad 39$

3.1 Introduction . . . . . . . . . . . . . . . 39

3.2 Demand and growth in the economic literature . . . . . . . . . . . 42

3.3 The engine of growth: an infinite number of needs . . . . . . . . . . 48

3.4 The mathematical model . . . . . . . . . . . . . . 51

3.4.1 Time and the arrival of new products . . . . . . . . . 52

3.4 .2 Individuals . . . . . . . . . . . . . . . . 54

3.4.3 The production side of the economy . . . . . . . . . 58 
Firms producing final goods $\ldots \ldots \ldots \ldots$

The R\&D sector . . . . . . . . . . . . . . . 64

3.4 .4 The equity market $\ldots \ldots \ldots \ldots 67$

3.5 The general equilibrium . . . . . . . . . . . . . . 67

3.5.1 Transition to the equilibrium . . . . . . . . . 70

3.5.2 Analysis of the parameter of the model . . . . . . . . . 71

3.5.3 The Intertemporal Elasticity of Substitution (IES) and the

propensity to consume . . . . . . . . . . . . . . 74

The IES in the short run . . . . . . . . . . . 75

The IES in the long run . . . . . . . . . . . . 77

3.6 Conclusion . . . . . . . . . . . . . . . . . 77

4 National Systems of Innovation and the role of demand: a comparison $\begin{array}{ll}\text { across countries } & 81\end{array}$

4.1 Introduction . . . . . . . . . . . . . . . . . 81

4.2 Review of the literature . . . . . . . . . . . . . . 83

4.2 .1 The role of demand . . . . . . . . . . . . . 83

4.2.2 Attempts to quantify National Systems of Innovation . . . . . 87

4.3 Methodology to construct composite indicators . . . . . . . . . . . . 88

4.3 .1 Imputation . . . . . . . . . . . . . . . . . 91

4.3 .2 Normalization . . . . . . . . . . . . . . . . . . 91

4.3 .3 Weighting . . . . . . . . . . . . . . . . 92

4.3.4 Evaluation of performance based on the distance from the median 94

4.4 The economic implication of the indicators . . . . . . . . . . . . . . 99

4.4.1 The four dimensions and their variables . . . . . . . . . . . . 99

4.4.2 The four dimensions at the country level . . . . . . . . . . . . 102

4.4 .3 Weak links . . . . . . . . . . . . . . . . . . . . . . 104

4.4 .4 Country Groups . . . . . . . . . . . . . . . . 106

4.5 Conclusions . . . . . . . . . . . . . . . . . . 110

5 The impact of government funding on R\&D and innovation 111

5.1 Introduction . . . . . . . . . . . . . . . . . 111

5.2 Data . . . . . . . . . . . . . . . . . . . . . 112

5.2.1 Frequency of innovation in Austria in 1998-2000 . . . . . . . . 113

5.2.2 Distribution of various sources of government support for innovation . . . . . . . . . . . . . . . 114

5.3 Methodology . . . . . . . . . . . . . . . . . . . 115

$5.3 .1 \quad$ Econometric model . . . . . . . . . . . . . . . . 115

Box 1: Model equations . . . . . . . . . . . . . 117

Box 2: Asymptotic Least Squares . . . . . . . . . . . . . . 118

5.3 .2 Control variables . . . . . . . . . . . . . . 118

5.4 Results . . . . . . . . . . . . . . . . . . . . 121

5.5 Conclusion . . . . . . . . . . . . . . . 126

6 Conclusion $\quad 127$

6.1 Final remarks . . . . . . . . . . . . . . . . . . 128

$\begin{array}{ll}\text { Appendices } & \mathbf{1 3 1}\end{array}$ 
B Dynamic conspicuous consumption

B.1 System of equations for the dynamic problem with conspicuous consumption 136

C Technical Notes

C.1 Technical Notes . . . . . . . . . . . . . . . . . . . . . . . 137

C.1.1 STEP 1: Maximization of the static utility for prices of the within period in the long run . . . . . . . . . . . 137

C.1.2 STEP 2: Intratemporal utility maximization. The Euler Rule. . . 139

C.1.3 Evolution of quantities and profits over time as new innovations arrive . . . . . . . . . . . . . . . . . . 141

C.1.4 Calculus of the value of the sum . . . . . . . . . . . 145

The limit of the sum in the transition . . . . . . . . . . 145

C.1.5 Relation between salary ratios and income ratios . . . . . . . 147

C.1.6 Growth of the utility function in the long run . . . . . . . . . 147

D NSI 151

D.1 European National System of Innovation in four dimensions . . . . . . 151

D.1.1 Converging Countries . . . . . . . . . . . . . . . . . . . 151

D.1.2 Scandinavian Countrics . . . . . . . . . . . . . . 154

D.1.3 Low Knowledge . . . . . . . . . . . . . . . . . . . . 156

D.1.4 Strong Demand . . . . . . . . . . . . . . . . . . 158

$\begin{array}{ll}\text { Bibliography } & 160\end{array}$

$\begin{array}{ll}\text { Nederlandse samenvatting } & 171\end{array}$

$\begin{array}{lr}\text { Curriculum Vitae } & 173\end{array}$ 


\section{List of Figures}

2.1 Formation of decision utility . . . . . . . . . . . . . 23

2.2 Time and preferences evolution . . . . . . . . . . . . . . . 34

3.1 Time evolution between and within periods . . . . . . . . . . . 53

3.2 Arrival of innovations ....................... 54

3.3 Value of parameters, labour distribution and growth . . . . . . . . 73

3.4 Interaction of agents . . . . . . . . . . . . . 78

4.1 Mean and median: symmetric vs. skewed distributions . . . . . . . . . 90

4.2 Results of the mean distance to median approach . . . . . . . . . . . 95

4.3 Imputation techniques . . . . . . . . . . . . . . . 96

4.4 Normalization techniques . . . . . . . . . . . . . . . . . . 97

4.5 Weighting techniques $\ldots \ldots \ldots \ldots$. . . . . . . . . . . 98

4.6 Correlations among the four dimensions . . . . . . . . . . . . . . . 101

4.7 Netherlands - National System of Innovation . . . . . . . . . . . . . . 103

4.8 Ireland - National System of Innovation . . . . . . . . . . . . . . . . . 104

4.9 Spain - National System of Innovation . . . . . . . . . . . . . . . . . 105

4.10 Sweden - National System of Innovation . . . . . . . . . . . . . . 106

4.11 Countries presenting converging patterns . . . . . . . . . . . . . . 108

4.12 Scandinavian countries . . . . . . . . . . . . . . . . . . . . 108

4.13 Countries with a weak production of knowledge . . . . . . . . . . . 109

4.14 Countries presenting a strong demand . . . . . . . . . . . . . . . . . 109

5.1 Government Funds and Innovation Activity . . . . . . . . . . . . . . . 115

D.1 Austria - National System of Innovations . . . . . . . . . . . . . . 151

D.2 France - National System of Innovations . . . . . . . . . . . . . . . 152

D.3 Netherlands - National System of Innovations . . . . . . . . . . . . . . . 152

D.4 Italy - National System of Innovations . . . . . . . . . . . . . . . . 153

D.5 Sweden - National System of Innovation . . . . . . . . . . . . . . . 154

D.6 Finland - National System of Innovations . . . . . . . . . . . . . . . 154

D.7 Denmark - National System of Innovations . . . . . . . . . . . . . . 155

D.8 Ireland - National System of Innovations . . . . . . . . . . . . . . 156

D.9 Portugal - National System of Innovations . . . . . . . . . . . . 156

D.10 Greece - National System of Innovations . . . . . . . . . . . . . . 157

D.11 Germany - National System of Innovations . . . . . . . . . . . . . 157

D.12 United Kingdom - National System of Innovations . . . . . . . . . . 158

D.13 Spain - National System of Innovations . . . . . . . . . . . . . . 158 


\section{List of Tables}

3.1 Production of quantities for each good in each period of time . . . . . . 62

3.2 Evolution of profits . . . . . . . . . . . . . . . . 63

3.3 Comparison for the value of patents . . . . . . . . . 65

3.4 Calibration of parameters: Labor distribution and Growth rates . . . . . 74

4.1 Dimensions and variables . . . . . . . . . . . . . . . . . . . . . . . . . . 89

4.2 Different indicator outcomes . . . . . . . . . . . . . . . . . 94

5.1 Distribution of innovator types in Austria, 1998-2000 . . . . . . . . . 114

5.2 Distribution of government support among innovators, Austria, 1998-2000 114

5.3 Descriptive statistics on control variables, Austria, 1998-2000, CIS 3 . . . 120

5.4 Marginal effects of determinants of various sources of innovation support, Austria, 1998-2000, CIS 3, probit estimation . . . . . . . . . . . 121

5.5 Marginal effects of determinants of new to firm product innovations, Austria, 1998-2000, CIS 3, ALS estimation . . . . . . . . . . . . 123

5.6 Marginal effects of determinants of new to the market product innovations, Austria, 1998-2000, CIS 3, ALS estimation . . . . . . . . . . . . . . 124

C.1 Transformation in relative quantities to the quantity of the first good . . 141

C.2 Relatives quantities expressed in relation to the quantity of the first good 142

C.3 Total quantities in relation to the first good . . . . . . . . . . . . . . . . 142

C.4 Production of quantities in relation to the labour used in the sector of final goods . . . . . . . . . . . . . . . . . 143

C.5 Evolution of profits . . . . . . . . . . . . . . . . . . . . . 144 


\section{INTRODUCTION}

In a world like ours, where science and technology plays such an important role in the forward march of mankind, it is important to understand their impact on society. The subject can be studied in many ways: from a historical perspective, analysing the sociological changes that produces, delving into its economic implications, and so on. This thesis focuses on the economic implications of technical change.

In the past 60 years a huge research effort has been carried out to incorporate technological change into economics. One of the main conclusions from these studies is that technology increases productivity by reducing production costs. This form of technical change is known as "process innovation". Yet there is another form of technical change, known as "product innovation". When talking of process innovation we refer to the fact that technology has affected the means of production in a positive way; with product innovation we mean that technology have created a new product or service. The implications of this second form of technical change are less clear and more difficult to grasp. The root of these difficulties comes from facing another big problem in economics: demand, the theory of utility and the formation and evolution of preferences.

The thesis emphasises a point often neglected: innovations, if they are successful, change the habits and customs of a society. Such changes have an important bearing on the economy but are rarely discussed in relation with the effects of 
technical change.

The main topics of this research are: product innovation, demand, evolution of preferences, habit formation and growth. Before discussing demand in more detail the work of two economists will be mentioned: Keynes and Pasinetti. In doing so we shall also introduce our own motivations for writing the thesis. Keynes' ideas are important because of the prominent role given to demand in all his analysis and the influence they have had on economic theory. Thercfore wc shall introduce some of our ideas making use of the multiplier theory. Pasinetti on the other hand is the first, and one of the few, who has discussed in detail the importance of demand on technological change and its implications for economics.

\section{$1.1 \quad$ J.M. Keynes}

Nobody questions Keynes' influence. His ideas have permeated all discussions and are found in any introductory book on economics. Later we shall discuss these ideas in detail; here we introduce his ideas in a simple way, at the expense of some formality. We will make use of the multiplier theory, modifying it so it applies to the ideas of the thesis.

The multiplier theory, as found in any text book ${ }^{1}$, explains the effect on national income of an increase in demand. It states that at the macro level consumption is a constant proportion of the total income:

$$
C_{t}=c_{1} Y_{t-1}
$$

where $c_{1}$ is the (marginal and average) propensity to consume and is assumed to be constant. Investment is divided in two parts: an initial level of investment $I_{0}$, together with an increase in the investment, mainly explained as coming from public expenditure, that occurs in only a single period $\Delta I=G$. The increase in government expenditure produces an increase in total demand, the so-called "exogenous demand shock". In equilibrium total demand and total production must be equal. The final effect will be a rise in the level of national income produced by the increase in public expenditure. The logic is the following: for the economy an increase in government expenditure $(G)$ means an increase in investment that will then increase demand in that period. To satisfy the increase in demand, new workers will be hired. These new workers will also use part of their salaries on consumption. After a few periods of adjustment a new equilibrium will be reached. The increase in national income, $\Delta Y$, is proportional to the initial increase in $\Delta I$ :

$$
\Delta Y=\frac{1}{1-c_{1}} G
$$

The fraction $\frac{1}{1-c_{1}}$ is known as the multiplier. It relates the proportion of the

\footnotetext{
${ }^{1}$ For an analytical discussion see Appendix A.
} 
increase of government expenditure to the increase in the national income. We have described here a single shock in one period.

We develop the analysis in a different direction though, returning to the assumption that the marginal propensity to consume is constant. Keynes discusses six factors that affect this propensity: wage units, net incomes, capital-values, discount rate, fiscal policy and expectations about the future level of incomes. Some of these factors may affect the propensity to consume but he concludes the propensity is fairly stable. In his own words,

\footnotetext{
"Granted, then, that the propensity to consume is a fairly stable function, so that, as a rule, the amount of aggregate consumption mainly deponds on the amount of the aggregate income $[. .$.$] , changes in the propensity itself$ being treated as secondary [...]" (Keynes, 1936, p. 96)
}

Reading this, we understand that the multiplier is rooted on the assumption of a constant propensity to consume. However, we argue that the main effect of product innovation is an increasc in the (average and) marginal propensity to consume. This is true only if product innovation is the unique manifestation of technical change, isolated from any form of process innovation. If we consider only process innovation the effect will be the opposite since process innovation reduces production costs. But successful product innovation, meaning by successful that people really need the innovation, will increase the propensity to consume. The cletails of how that happens will be further discussed in the theoretical part of thesis.

At this point we revise the multiplier effect theory by allowing the propensity to consume to change. Suppose in our previous example that government expenditure is used in research and development (R\&D). As an effect of this expenditure a new product appears at time $t$. For example, consider mobile telephone technology. Although the process of diffusion is long, complicated, and mixed with process innovation, it is a clear example of an innovation leading to an increase in consumption. The macro effect of this technology from the consumption side can be seen as an increase in the propensity to consume from $c_{1}$ (before the technology is in the market) to $c_{2}$ (once the technology is completely diffused). Consumption before the new technology is in the market will be a constant proportion of national income:

$$
C_{t-1}=c_{1} Y_{t-2}
$$

In the initial situation (without the new technology) the consumption rate is $c_{1}$. At time $t$ a radical innovation arrives that makes everybody increase consumption to $c_{2}$ with $0<c_{1}<c_{2}<1$; at $\mathrm{t}$ consumption will be

$$
C_{t}=c_{2} Y_{t-1}
$$

In this case, which parallels the previous one, there is also an increase in gov- 
ernment expenditure $G$, which has an effect on total investment $G=\Delta I$. Now, however, we assume the increase in public expenditure is fully used in the $R \& D$ sector, leading in consequence to the arrival of the radical innovation. The increase in the level of national income will be

$$
\Delta Y=\frac{1}{1-c_{2}} G
$$

Comparing this situation with the previous one in which demand shock does not affect the propensity to consume, and whenever $c_{1}<c_{2}$,

$$
\frac{G}{1-c_{1}}<\frac{G}{1-c_{2}}
$$

Therefore we can conclude that the multiplier effect in the second case is higher. When public funding is used for $R \& D$, resulting in new products that are sought after by the society, it has a positive impact on the national level of income.

This idea is the core of the thesis. We believe that if consumption increases through product innovation we reach higher levels of income. In this example we were talking about changes in the level of national income which only occur in one period. Later in the thesis, we shall work with a flow of innovations which constantly increase marginal consumption rates. This example, although not very formal, is a good prelude to the ideas behind the thesis.

To continue with the introduction, we should like to resume the discussion on demand and technological change begun by Passineti more than twenty years ago.

\subsection{L.L. Pasinetti}

One of the richest discussions on the relationship between demand and technical change is presented by Pasinetti (1981). Taking a macroeconomic point of view he engages in deep speculation about the effects that demand may have on technical change. His ideas have been relevant throughout our work, therefore we consider we should introduce them here to elucidate the micro-motivations for writing this thesis.

Pasinetti presents the following logical relationship: technical change increases productivity, which means increasingly higher wages and profits or, more generally, an increasing per capita income at the disposal of the community. It follows that in each term technical change compels the individuals in the socicty to make new decisions about which commodities to choose when spending their increased income. He concludes that preferences may play a crucial role. Before going on, we would like the reader to refiect on the fact that Pasinetti is only considering process innovation in this argumentation about technical change. In this situation he thinks of technology as increasing productivity, therefore he is dealing with process innovation and it is through process innovation that per capita income is increased. 
He puts consumer preferences at the very centre of the economic discussion. No commodity will be sold, or even produced, if its (real or imagined) utility for the consumer is not sufficient to justify its cost. Few neoclassical growth models recognize the possibility that production can be unsold, and mostly by using very simplistic assumptions about demand. Now, in this situation where utility is concerned, Pasinetti's considerations are more on the lines of product innovation. Only if the commodity is appreciated by the consumer will it be successfully sold.

The key idea is that something needs to be sold to contribute to the wealth of the nation. And, as Pasinetti, we felt the need to understand consumer preferences and their evolution over time. Only after doing so could we start thinking about the implications of product innovation.

Pasinetti continues with the idea that it is necessary to understand proference evolution as income per capita increases. He engages in a discussion on technical change, Engel's law and consumer learning, from which he draws three conclusions:

- The proportion of income spent by the consumer differs from one commodity to another.

- There is an order in which things are chosen. First the consumer satisfies basic needs and only then will concentrate on other necds.

- There is a saturation level for any commodity.

We agree with Pasinetti's first and the second points. However, we shall consider decisions made in a society where all basic needs are covered. In such a case basic needs are no longer a major factor in the spending of increased income. We suggest that technology, through product innovation, is generating new needs in the society and that successful innovations are those that generate strong consumption habits once they are known by the society. Although we believe that there is a saturation level for the number of things consumed, we also argue that the amount of money used for any particular consumption has no limit. In this sense we do not believe in a saturation level; there is a limit on what a person may be able to eat, but there is almost no real limit on what the person may be able to spend on a dinner. This thought can be extrapolated to any new product, whether a fancy mobile phone or any other innovation. New innovations provide the consumer with new options on which to continually increase the amount of money spent on consumption.

Before concluding our comments on Pasinetti's work, it is worth outlining which changes he includes in demand when related to mathematical modelling. He assumes that there are different sectors in the economy and each sector has its own technical change rate. The preferences on demand are assumed to evolve exogenously in such a way that they absorb each sector's extra production. In other words, on the production side technical change increases production, on the demand sicle preferences evolve so that all extra production is consumed. Linking these ideas with the ideas presented in the previous scction, the multiplier remains 


\section{INTRODUCTION}

unchanged because the marginal propensity to consume is the same, before and after process innovation.

These ideas are the motivation for our research project. The intention of the thesis is not to give the final word on how things should be. On the contrary, we should be happy if the thesis fosters further research and discussion in this important field of demand and technical change.

\subsection{Thesis structure}

The thesis has two main parts: a theoretical one followed by more applied research. The applied part is mostly the result of the great collaboration I have experienced on various projects at UNU-MERIT, much of it at the European level. Sometimes the results of these projects were interesting for the discussion about demand and technical change. In other cases the results, although not directly related to the topic, were interesting in themselves.

The thesis is structured in four chapters, together with the introduction (this chapter) and the conclusion. Each chapter is really an independent article; most include a review of the literature.

\section{Theoretical part:}

Chapter Two, from a microeconomic perspective, discusses the evolution of consumer preferences. Collecting ideas about preferences and utility from the neoclassical school, it compares them with others arising from heterodox research. The work is rooted in the contributions by Scitosvky (1977), Berlyne (1974) and Bianchi (2002). Touching a little on psychology, the chapter tries to provide a view of a more flexible consumer and where product innovation can be understood. A simple model is introduced to update classical consumer decisions in a dynamic perspective. Two key concepts to understand this dynamic decision process are habit formation and novelty.

Chapter Three attempts to raise, at the macroeconomic level, the implications presented by the previous chapter. Focusing on one of the key concepts, habit formation, it sets up a growth model in which demand and technical change through product innovation are the main drivers of growth. The model's theory is located between Aghion and Howitt (1992) and Grossman and Helpman (1991), with the main implication being the increasing modification of the propensity to consume. This is achieved by introducing a flow of goods which are more eagerly sought, i.e. introducing goods which give higher utility to the consumers.

\section{Empirical part:}

Chapter Four, also at the macroeconomic level, uses the National System of Innovation approach. Starting with a discussion of how various authors see the role which demand plays in the system, it makes use of knowledge indicators to 
access different system performance measurements at the European level. An extensive presentation on the best method of building an index is found here, followed by a reflection on the dynamics of 14 European countries over a ten-year period. A classification grouping countries according to performance is presented as a conclusion.

Chapter Five studies the effects of public support on product innovation. Two forms of product innovation are studied: radical product innovation (new to the market) and incremental product innovation (new to the firm). The effects of receiving public funding is analysed at the input (level of $R \& D$ done by the firm) and at the output level (share of innovative sales). The main conclusion is that support has a strong effect on innovation inputs but only a weak indirect effect on consumer needs (measured in terms of innovation outputs).

Chapter Six as a conclusion gives a general overview of the whole thesis. 


\section{CONSUMER BEHAVIOUR: EVOLUTION OF PREFERENCES AND THE SEARCH FOR NOVELTY}

\section{$2.1 \quad$ Introduction}

As we have already commented in the introduction, the main focus of the thesis is product innovation. We reflect on its importance and the implications of the invention of products for the economy. We also want to study the effects of technical change from the final demand aspect, which means we need the consumer to consider new products in her maximizing decisions. And we need, as Pasinetti argued, to understand the evolution of preferences. How preferences change to allow the consumer to choose new goods while retaining some old habits. That is the aim of this chapter - to explore ideas that allow consumer theory to explain the choice and consumption of new goods, and the cohabitation of such decisions with the formation of habits.

Even though we acknowledge the importance of new consumption, it is incorrect to base consumer theory purely on new products. If our goal is to explain real behaviour, we must take into account that consumer decisions are an interaction of new possibilities with previous purchasing habits. When we follow the patterns of an individual's consumption we see that some goods are consumed several times. We also see that sometimes new things are bought to try them out. After trial, some goods will become habitually bought and others never again. 


\section{Consumer Behaviour}

Consumer theory, as it appears in text books, is not a useful theory when studying product innovation. It is a logical tool that only considers quantities and prices to explain a decision taken by an individual. Once the choice is made we can explain how the decision will change if prices change. The main problem arrives the second time the consumer must choose between the same goods. We have to assume that the person's preferences have not changed between these two occasions and so, if prices are also constant, the second decision must be exactly equal to the first one. This assumption is too strong and blocks the analysis of product innovation. Despite this fact, rather than negating the theory, we shall transform it to make it sufficiently flexible for our purposes.

Therefore we consider it worth dedicating this chapter to understanding and analysing preference evolution within the framework of technological change. Here, there will be not a final point on the state of consumer theory, but a first step toward some changes that need to be made to comprehend the importance of technology in the world economy.

Having said that, the main point of the chapter is the evolution of preferenccs - aiming to explain why old consumption patterns survive with new products. If this is our aim, there are some questions that need to be answered: Why and how do we develop consumption habits? Why do we consume new products? And how can these two actions be integrated into a single decision made by the consumer?

This chapter will not deal with the social dimension in consumer patterns although we acknowledge its importance. It will focus on the behaviour of an individual consumer. The work will be mainly looking at "inconspicuous" consumption patterns.

The chapter is organised as follows: in section 2.2 we review the literature concerning consumer behaviour, in section 2.3 the three main topics of habit formation, novelty and how to integrate both will be discussed, section 2.4 simplifies these ideas into a mathematical model and the last section, 2.5, provides a conclusion.

\subsection{The dynamics of utility in the economic liter- ature}

The purpose of this review of the litcrature is to analyse attempts to make economic theory more responsive to consumer behaviour. We focus particularly on understanding product innovation from the consumers' perspective. With this in mind, we shall first look at the origin of two main assumptions which are incompatible with innovations: fixed preferences and inter-temporal independence. The next step will be to analyse attempts to see how consumer behaviour is affected by either past or future consumption. Afterwards we discuss some criticisms made of consumer theory and try to locate our research in the literature.

The idea of fixed preferences follows from the theory of revealed preferences. It was proposed by Samuelson (1938) and it is one of the most restrictive 
ideas concerning consumer behaviour. He focused on the idea that when a consumer chooses a set of goods at a constant set of prices, she is revealing her preferences. Thus, assuming that her preferences are stable over time he argues that indifference curves are not very relevant, that a lot of information can be found from the consumer's elections independently of the existence of the utility curve. This information is more empirical and inductive than that derived from indifference curves. His main concern was the fact that utility can not be measured either in a cardinal or in an ordinal way; however, the consumer reveals her preferences every time she chooses something, and this is the information that economists should use. A deep view into the main issues he was dealing with will bring us to a discussion of whether utility can be measured. The impossibility of measurement is a central point of his discussion.

The issue of measuring utility brings us to the origin of the concept of utility, which goes back to Bentham and J.S. Mill. They introduced this concept, with the certainty that utility could be measured in a scientific way, as a result of processes of pleasures and pains. In thcir work they presented lists of sources of human pain and satisfaction. They argued that pleasure or pain could be measured depending on variables such as intensity, duration, certainty or uncertainty and propinquity or remoteness. After compiling an exhaustive list of human sources for pain and pleasure and the variables that control the level of satisfaction, they aimed to asscss the state of any individual. Their ideas were further discussed and worked out by the marginalists (Jevons, Walras and Menger), crystallizing into one important concept: decreasing marginal utility. It means that when people enjoy things, the more they have the better it is, but each extra unit of the same good adds slightly less utility than the previous unit did. The concept was still based implicitly on measurability. Using this concept, Marshall (1890) deduced demand curves, making a strong logical link with indifference curves. However, the idea that utility could be measured was soon problematic. At the beginning of the following century an influential economist, Robbins (1935), came to the conclusion that utility could be only measured in an ordinal way. His idea was more that, even though it was possible to order the preferences of the consumer, it was not possible to assign a number to an experienced pleasure. In a way he tries to move consumer theory from a theory based on values to a general logical choice. Hicks and Allen (1934a,b), taking Robbins' arguments, make a whole review of critical concepts derived from consumer choice: marginal utility, elasticity of substitution, expenditure curves, demand curves, complementarity... basically they conclude that these concepts can be used even if we measure utility in an ordinal way. To end this issue we refer to the work of a prestigious economist - and note how economic theory evolves in a circular manner. Since, in more recent research, the Nobel laureate Kahneman and his colleagues (1999) propose going back to Bentham, arguing that science now allows us to measure utility with accurate methods. In his work he suggested two ways of measuring utility: based either on reports made by the consumer or in physiological measurements (heart pressure, 


\section{Consumer Behaviour}

brain waves...). He suggests that in such a way we could move toward a more cxperimental consumer theory.

Thus the notion that one can measure the hedonistic pleasure that any good gives to an individual leads to the idea that utility can also be measured, whether in a cardinal (Bentham and Mills) or ordinal manner Robbins (1935). Hicks and Allen $(1934 \mathrm{a}, \mathrm{b})$ proved a demand curve can be derived from either case. However demand curves relate price and quantity for one single product. They are derived from indifference curves, which always relate a set of existing goods to levels of utility. The issue of the apparition of a now good, and how it affects indifferences curves and demand, was never discussed by these economists.

A second point, which is related to the stability of preferences, is the intertemporal independence assumption: preferences are affected by neither past nor future consumption. Under this assumption, what I consume today is not affected by what I consumed yesterday nor by something I will consume tomorrow. However this assumption is too unrcalistic and too strong. The consumcr is always the same person over time and a connection between decisions taken at different moments is to be expected. To illustrate the problems associated with the independonce assumption, some words from Samuelson, the economist who stated the thcory of revealed preferences:

"The amount of wine that I drank yesterday and will drink tomorrow can be expected to have effects upon my today's indifference slope between wine and milk." Samuelson (1952).

Some economists have tried to work on the relaxation of this idea. Two groups will be now discussed: scholars who try to sec how past experiences affect present decisions and others who look to the relation between present choices and future elections. In other words the utility is affected either by past consumption or by future consumption. Starting with past consumption affecting present decisions, the first attempt to break the assumption of temporal consumption independence came from Duesenberry (1949). He was trying to find more coherent and realistic ways to explain consumer behaviour. In his book one idea is highlighted: consumption is used to create a self image. Consumption patterns are explained by belonging to a peer group; he was thus able to explain why consumption patterns were so stable in the presence of a change in income. One idea that follows from his work, and that is relevant for us, is that consumption is determined by habits. Hence present decisions are a consequence of past experiences. $\mathrm{He}$ proposed to look at past consumption and presented the idea of habit formation. Some years later Pollak (1970) presented a first formal study of habit formation in consumer theory. He focused on linear utility functions and the implications of introducing lhabit formation into the consumer maximizing behaviour. He concluded that consumer theory is more responsive if past consumption is allowed to interfere with present decisions. His contribution was further worked by Rycler and Heal (1973). They looked at how habit formation affects the optimal path 
2.2. The dynamics of utility in the economic literature

of a neoclassical growth model. However, the literature concerning growth and habit formation will be presented in the next chapter. Therefore we return to contributions at the level of micro consumer theory.

The next point to consider is how future consumption affects present utility. The idea is not new, its roots going back to Jevons. The logic is the following: if somebody invites me to go to the cinema tomorrow, my utility is increased from the moment I am invited. However, future utility needs to be discounted to bring it to the present moment. In general this is done by using exponential functions. Ainslie $(1975,1991,1992)$ has written stremuously against this method of discounting future utilities. Instead he gives founded reasons for using a hyperbolic discounted function. To understand the importance of the matter it is worth looking at the argument made by Thaler (1981): asked to choose, a person might prefer to have one apple today than two tomorrow while at the same time preforring to have two apples within 51 days than one in 50 days. Most consumers will chose one apple today and two in fifty-one days. The hyperbolic function, being more concave than the exponential function, solves the problem. Despite the agreement on using a hyperbolic function when discounting, the value of the discount factor seems to depend very much on the empirical experiment. For a review of matters concerning discounting see Frederick et al. (2002).

As soon as future decisions become part of preference formation we have to take uncertainty into account. A general finding among economists and psychologists working with uncertainty decisions is the so-called loss-gain asymmetry. When the consumer is asked about the effect of a future gain she always overestimates its real utility, and when is questioned about a possible loss she underestimates it. For a group of researchers this is crucial, and it was first suggested by Markowitz (1952) that consumer theory should be based on gain and loss prospects instead of being based on choices of quantities depending on prices. Kahneman and Tversky (1979) incorporated this idea and they present a model of consumer decision-making under uncertainty. Their contribution solves Allais' paradox; decisions under uncertainty are not related to expected probability. They concluded that it is not the real probability that makes the consumer decide but the perceived uncertainty. When the consumer is discounting future outcomes the general conclusion is that losses are discounted at a lower rate than future gains. Tversky and Kahneman (1991) found that the ratio in which most consumers discount losses versus gains is almost constant, approximately one to two. They also point out that the key variable to look at is not general loss-gain but the relative gain. The consumer's initial situation determines her behaviour and the way she values things. Loewenstein and Prelec (1992) introduced a model that takes into account these irregularities. They work with a value based on deviation from an anticipated reference consumption. This function has different curvatures depending on whether the consumer is evaluating a positive or negative gain. With thcir work they are able to discuss the effect of 


\section{Consumer Behaviour}

the consumer's psychology on the economy. For example, they argue that the uncertainty the consunner faces about the future will reinforce business cycles. Another interesting conclusion is of the incapacity of the consumer to predict change in future utility. Loewenstein ct al. (2000) find that even if the consumer is able to predict the direction in which her utility will change, she systematically miscalculates the impact of the change. They explain that the real utility lies between her prediction and her current situation.

Before continuing, we collect and summarize some of the issues that have been tackled so far. Our goal is to understand product innovation from the consumer's perspective. We agree that decisions concerning old habits and new consumptions intertwine in coherent consumer behaviour. We consider the models of habit formation especially relevant and shall develop them further in the following sections, trying to look deeper into reasons relating past and present consumptions. Future consumption affects present decisions too, but the kind and level of uncertainty implied by the papers quoted so far, is not the central concern of our work.

Our ideas are closer to Witt (2001b), he recognized as one of the main problems concerning the theory of technological change the fact that we know too little about demand, in particular about the evolution of preferences. In his article he asks about the satiation of needs, and how is it possible that in developed societies income per capita has been continuously growing but demand is never satiated. His main conclusion is that one possible explanation could be that the patterns of consumer demand are becoming increasingly specialised. In this chapter, we are mostly concentrated in how new goods enter the consumer's decision.

We consider it an important issue that economic theory gives very little explanation for the consumption of new goods; there is no formal explanation that helps us understand such consumption. The only relevant attempt was Lancaster (1966). He argued that goods are consumed because of their characteristics and that new goods are recombinations of old characteristics; the combination of characteristics that the new goods offer is closer to the consumer's preferences than those of the old goods, hence the new goods are bought. The main problem of this approach, as is mentioned by Swann (2002), is that the question of why we consume new goods is simply reworded as why we consume new characteristics of goods. Following Lancaster's ideas, Stigler and Becker (1977) suggest comparing the consumer to a firm. In this approach the consumer is treated as if he were producing utility in a firm whose inputs are characteristics. Thereby they succeed in presenting a more dynamic consumer. However, the question of why we consume new characteristics is left without answer. More successful although less formal is the explanation given by Scitosvky (1977); the consumer necds change in what she consumes simply because she needs novelty to reach well-being and comfort. Following his ideas, and merging them with the previous ones, we find useful the work done by Bianchi $(1998,2002)$. She argues that novelty is a relevant 
2.3. A new theory for consumer behaviour

factor in the inputs that the consumer is using to maximize utility. Both Scitosky and Bianchi acknowledge in their work the research concerning novelty done by Berlyne (1974). He was working on novelty and the reaction of humans towards novelty. One of the most important conclusions from his research in behavioural psychology is the so-called Wund Curve. It is an inverted U-shaped curve that plots hedonistic reaction against novelty. Things too new or too old offer a low hedonistic satisfaction, the peak being somewhere between the two extremes.

We believe it necessary to develop further a sound theory that integrates some of the results produced by economists and psychologists working in fields close to behavioural psychology. Some of these results are so crucial that we need to provide more detail, enabling the reader to get a clearer view why individuals consume new products. Hence the next section, in which we shall discuss in depth some of these results and link them to economic theory, in particular to consumer theory.

\subsection{A new theory for consumer behaviour}

Decisions concerning consumption cover a broad spectrum of goods and services: a car, a ticket for the cinema, a dinner in a restaurant, new shoes, a Picasso picture.... The reasons behind these decisions may well be quite different; the reason for going to the cinema is a probably very different from that which pushes you to buy a new car.

The first thing we need to understand is that there are two different activities that the consumer is continually repeating: buying and using. Buying means using money to get something. Using means getting utility out of direct contact with the object or service. One important issue in our argument is at what moment the consumer maximizes her utility; when buying or when using? In some cases these two actions are connected in time and they follow one from another; for example, drinking a cup of coffee in the cafeteria, where the actions of buying and using the good are linked in time. In this case, there is also a unique relation between the two actions: you buy one coffee and you can only use it once. In other cases, the two actions are neither so simultaneous nor are they in unique one-to-one relationships. Take a knife as an example; you buy it once and you may use it many times. The two actions are separated in time and are not bilateral.

We believe that the concept of "consumer utility space" can help us to understand consumer behaviour. We shall define this theoretical space as one that contains the object or service so that the consumer can extract some utility from it. It is not a physical space. Some examples may help to explain how we use this concept. Tomatoes in your refrigerator are inside the utility space, those in the supermarket are not. The films at the cinema are outside the utility space, the specific film for which you bought a ticket is inside it. Books in the library are outside, the book borrowed from the library is inside. Whatever we can use and 


\section{CONSUMER BEHAVIOUR}

get some utility from will be inside. Our consumer is able by direct contact to intellectually or physically cnjoy things within the space.

First we should anlayse how goods enter into this utility space. We suggest two possille ways:

- market provision, which basically means the consumcrs buy a good,

- non-market provision, for which we find various possibilities: home-made produce, loans, heritage, gifts...

Then we can describe three main reasons why the good leaves the space:

- The good disappears, such as food when eaten or the cinema film when it finishes. After nsing it once, it no longer exists

- The good breaks or gets too old to be used. An example would be an old computer

- We get jaded from using the good. This might happen in differcnt ways, slowly (boredom) or quickly (dislike). Envisage the boredom of an outmoded t-shirt or the foodstuff whose taste wo dislike from the very first trial.

These distinctions may appear redundant. However they are important variables which may explain product innovation and economic growth. Take a hypothetical case, that the average lifespan of electrical house appliances is under the control of the manufacturer. Think about an electrical appliance which most people already consune habitually, for cxample a refrigerator, and then imagine a cartel which decides to reduce the average life of refrigerators. If such a decision were taken and implemented it would have a positive impact on the growth of the country. However, this discussion is outside our scope and will be left for future research.

But to return to the previous point - once we have the good inside the consumer's utility space we can study the formation and evolution of preferences. This will be the main subject of subsection 2.3.1. However in the subsequent subsections, 2.3.2 and 2.3.3, we are more restrictive and focus on only one kind of good. Goods, and when we say goods we mean also services, of one single use. We define a single-luse good as one, provided by the market, that the consumer buys (gets inside her consumer utility space) and uses (gets utility) before it leaves the space. For a single-use good the three parts of this process occur within each time period.

We discuss the evolution of a preference for a single good in the next subsection. The use of a good is compared to the exposure of an individual to a constant extemal stimulus. We argue that conclusions from behavioural psychology are valid when considering consumcr behaviour. Novelty and its relevance for consumer choices will be the focus of the subsection that follows and in subsection 2.3.3 the two previous points will be integrated into a single process of decision as made by a consumer. 
2.3. A new theory for consumer behaviour

\subsubsection{Evolution of preferences}

We concentrate on the evolution of preferences for one good which is already inside the utility space. We will make a categorical definition of a good and fix periods of time as follows: a short period in which the individual will consume the good, followed by a long period of time with no consumption. The break in consumption will be called the "time interval" between consumptions. Once the good and the period are defined we can study how this good affects the consumer, or in other words how preferences for this good evolve. Firstly we analyse the evolution of reactions of an individual who is repeatedly exposed to an external stimulus. Secondly we adjust the results from psychological behaviour to corsumer utility, arguing that consumption of a good is an external stimulus. We then analyse some important differences for consumer behaviour.

To understand the evolution of reactions that an individual has towards a stimulus, we follow the research done by Solomon (1980). He was looking at the way individuals react to exposure for a few seconds to an external stimulus when followed by a long period without exposure. He focused on the evolution of reactions to the repetition of the experiment. Working with both positive and negative stimuli, Solomon measured reactions using physiological indicators: excitement, blood pressure, heart activity ${ }^{1}$.... As an example of his animal cxperiments, he worked with young ducklings and studied their reactions (agitated movements and high peak sounds) to the presence of a moving mother duck (a positive stimuli). He studied how reactions evolved when the cycle of exposure followed by a long period without exposure was repeated. Other experiments involved dogs, monkeys, and humans.

As a result of his experiments the "Opponent process" theory was formullated. This theory states that if an individual is exposed over a period of time to a stimulus repeated at constant intervals, the effect of the stimulus will decrease over time. He argues that the impact of the stimulus on hedonistic perception depends on three variables: the length of the time intervals without exposure, the memory of the individual and the quality of the stimulus. The stimulating effect depends on these three variables as follows:

- Time interval between exposures: the longer the interval the greater the effect of the stimulus in the next repetition.

- The memory of the individual: the greater the capacity of the individual to remember past expcriences the lower the effect of the stimulus in each repetition.

- The quality of the stimulus: an increase in the quality of the stimulus will cause an increase in the experienced hedonistic perception.

The consumption of a good can be considered a concrete example of the broad definition of an external stimulus. Thus the consumption of the good gencrates

\footnotetext{
${ }^{1}$ More recent research explains these reactions based on the endorphins. See for example Ito and Cacioppo (1999)
} 
in the brain a positive reaction which is perceived by the consumer as an increase in her hedonistic situation. To study the evolution of preferences we need to examine the relation between exposure of the individual to the same stimulus with the evolution in the perceived level of pleasure. Assuming our consumer is only affected by the consumption of a single good from within her consumer utility space, we shall considcr how the threc 'opponent process' variables alter this consumption. The utility that the consumer dcrives from something inside her space (i.e. the increase in her hedonistic level) will be called "experienced utility". How does experienced utility change as we modify the three variables, one variable at a time, while, as above, the individual consumes a good for a short period of time followed by a long break? Starting with the length of time interval between consumptions: if the time interval is sufficiently long for her memory to hardly evoke the last experience then the consumer will be able to enjoy the next consumption almost as she did the first time. As the time interval decreases the consumer will begin to develop an aversion to that specific good. If the intermissions are very short she may even develop an aversion strong enough to prevent the good's use for the rest of her life. If the avcrsion is not too strong, a long period of rest, a long break, might be enough to allow her to enjoy the good again.

Concerning the second variable, if our period of study is the consumer's whole lifespan then memory may play an important role. The better the consumer's memory the faster the level of experienced utility will decrease. For this case imagine two individuals, one adult (normal memory) and one old person (lower memory). Both being exposed to the same good for identical periods, the adult's level of expcrienced utility will decrease faster than that of the old person. Proving, as Scitovsky points out, that habit formation in elderly populations is stronger than that among younger adults. Scitovsky refers to cxperiments done concerning the diet of one group of old people versus another of adults. These two groups can be consuming the same thing, or doing the same thing, but reach boredom at different times, with adults becoming bored sooner than elderly people.

The third point is that an increase in the good's quality, ceteris paribus, will induce an increase of experienced utility.

At this stage, it is worth recalling classical consumer theory, and reflecting that the theory is only based on an increase in the quantity consumed. It statcs that greater quantity always causes a positive effect on the experienced utility but each extra unit consumed will have less effect (decreasing marginal utility). The classical theory presents an analysis of one single variable affecting the level of experienced utility: increases in quantity. But the analysis of the repetition of consumption of identical quantities at unchanging prices has always been ignored.

There is one important difference between a consumer theory and a behavioural psychology one. In the second case we are studying reactions to an external situation which is not determined by the individual. A consumer, however, has freedom to choose her own exposure to the good, thus setting up her own experimental en- 
2.3. A new theory for consumer behaviour

vironment. So we can postulate that the consumer subconsciously learns how to consume the good in the sense that, given a quality of the good and a stable memory, she learns to set the right time interval between consumptions in order to experience utility. In section 2.4 , the model will assume fixed time intervals, constant memory and equal quality of a good while we give the consumer freedom to choose the good's quantity according to her experienced utility.

Concluding, three main factors explain the evolution of preference for a good: the time between each consumption, the memory of the consumer and the good's quality. Separate consumers may be exposed to the same consumption of a single good and may have very different levels of experienced utility; however the cvolution itself of their preferences towards that good will follow similar patterns.

The next section concerns novelty, an important idea that explains how a good enters the consumer utility space.

\subsubsection{The search for novelty}

The focus of the previous section was the evolution of preferences and experienced utility, in particular the evolution of utility when neither quantity nor prices change. We were thinking about a situation in which the consumer has direct contact with goods and is learning from past experiences. While considering habit formation we were following the studies begun by Duesenberry, as noted in our review of the literature. We also know from the literature that several writers on economics try to explain present consumption as being influenced by future discounted utility (among many others: Jevons, Ainslie (1975), Thaler (1981), Tversky and Kahneman (1986), Loewenstein and Prelec (1991) and Ramsey (1928)). From their work we understand that consumers are able to improve their hedonistic situation by imagining that they are using goods and therefore deriving utility from future consumption. However here we shall be more precise in our interpretation. We are not looking at the impact that future consumption of old goods will have on the present consumer. Our main viewpoint is the present impact on utility that unused goods have on present decisions and that the idea of buying new goods raises the present level of utility. In the current section we argue that consumers search for a different form of utility, one derived from novelty. However our purpose is not to define novelty but rather to see how crucial it is to understanding consumer behaviour. Therefore we concentrate on a description of what we mean rather than on its definition.

To introduce this idea we quote Adam Smith:

"The imagination and memory [...] fluctuated to no purpose from thought to thought, and we remain still uncertain and undetermined where to place it, or what to think of it. It is this fluctuation and vain recollection, together with the emotion [...] that they excite, which constitute the sentiment properly called Wonder, and which occasion that staring and 


\section{Consumer Behaviour}

sometimes that rolling of the cyes, that suspension of the breath, and that swelling of the heart, which we may all observe, both in ourselves and others, when wondering at some new object, and which are the natural symptoms of uncertain and undetermined thought". ${ }^{2}$

Although Adam Sinith was describing the reaction of the scientist when ho finds something new, it is easy for the reader to imagine the same sensation of wonder applied to a consumer. And we, as consumers, have all observed these reactions both in ourselves and in others. The idea of possessing a new car, a new house, a digital camera, a new pair of shocs or even a new jacket.. The list of objects is long that may produce similar feelings of wonder. Consumers may be excited by different objects or idcas but it would be difficult to find a consumer that has not ever expcrienced such sensations. Bianchi's research (1998) presents these thoughts well. She argues that novelty is an important input determining the utility of a consumer.

This sensation of novelty is occasionally very strong and at others quite mild. We are happy to pay for a portion of this novclty, as in the case of a "news"paper where the utility does not come so much from reading the paper itself as from the feeling of getting some novelty. If we reconsider the previous discussion about the definition of goods, we could define the good as the "newspaper", the consumer developing the habit of buying a newspaper every day. However if we define the good as "the new" then every day it is a different good. This point is important because it means that the consumer gets utility from what she does not know and is also willing to pay for it.

We now present two relevant results concerning novelty; as in the previous subsection they are part of psychological research. Presenting Berlyne's work, we will discuss how people react toward different degrees of novelty, but beforehand we will also mention results by Hebb (1955). Hebb's explanations of brain cell activity are very relevant for our own discussion. His main conclusion is that humans need a certain amount of novelty in their environmental stimuli to feel well. As an example, Hcbb set up an experiment in which individuals were asked to fill in a questionnaire of basic questions about culture as well as performing basic mathematical exerciscs. Afterwards they were asked to spend several hours in an empty white room before filling in an equivalent questionnaire. The majority of the individuals scored very poorly in the second test. He explains that to be able to perform intellectual activities the brain needs a certain amount of external stimulus. He was studying the relation between the activity of brain cells, neurons, and the feeling of well-being in humans. Arising from his studies he proposed a theory based on "arousal" due to environmental stimuli. He concluded that a person needs changing stimuli in order to feel well. His conclusion is interesting for us, bccause some changes in stimulus may come from goods that the consumer has in her consumer utility space, while other's may be created by the market. The

\footnotetext{
${ }^{2}$ Essays on Philosophical Issues: History of Astronomy p. 39
} 
2.3. A new theory for consumer behaviour

second case provides a reason why a consumer buys new things. So far economists have been interested in studying a single set of goods and the effect that these goods have on the consumer's utility. Our argument is that the curiosity, and therefore the utility, of the consumer is raised by the idea of buying a novel good.

If consumers need novelty we should determine the degrees of novelty, and understand how changes in the degree of novelty affect consumers' utility. The research presented by Berlyne (1974) brings some light to the issue of novelty and the level required by individuals. He studied the reaction of humans when exposed to novel objccts. One example, among many experiments that he made, was to show drawings, for example of a tree, changing the degree of novelty in each drawing from a very basic tree shape to a futuristic image, passing by very detailed drawings. People were asked to choose which one they preferred; the majority chose one between the two extremes. Based on his experiments he concluded that positive perception of the novelty by the individual follows an inverted U-shaped curve, the so-called "Wund-curve". The individual will dislike exposure to things either extremely original or too little so. He also reaches a similar conclusion to the one presented by Solomon: if a person is exposed for a long time to an extreme novelty, the initial clislike may with repetition turn to pleasure. Think for example how new fashions arisc; at first very few people use the article but with time its consumption becomes massive.

Psychology, then, gives us two main ideas concerning novelty: we need a certain amount of it to feel good and the level of it that we choose is never extreme.

Still, as economists, novelty is important because it can explain why a consumer buys new goods. The utility she gets from a new item comes not from her personal experience but from imagining how well she could feel in the future. Lancaster (1966) argued that new goods are bought because they fit the intrinsic characteristics better. However, many economists, such as Swann (2002), recognise this replaces the question of why we consume new goods by why we consume new characteristics. We believe it is a matter of the good's definition. Taking a mobile phone as an example, we could think of it as a telephone with a new characteristic. Lancaster's argument is that the new good offers us the possibility to talk almost everywhere. Combining the two characteristics allows one to talk to distant people while being free to move about. This optimal new combination makes one buy the good. Our line of argument is different. When confronted with a telephone characteristic such as "the capacity to talk without having a fixed connection" Lancaster's theory cannot offer us an explanation because the characteristic is entirely new, not intrinsic. The question then becomes why we think we shall get some utility out of something we can never have experienced before. Our explanation is that the consumer buys the new good/characteristic because of the excitement produced in her imagination by the idea of using it. We believe that one buys new things because of their novelty value. This novelty produces in us so much pleasure that we pay for it.

In the next subsection we shall study how novelty and habit formation form a whole, how these two concepts are interrelated to maximise utility. 


\subsubsection{Deciding what to buy}

We lave talked about the consumer's two principal activities: huying and nsing. Classical theory in summary, states that the two are joined in time and that the consuner maximizes her utility between a fixed set of goods to result in an optimal combination of quantities according to prices and preforences. We propose the combiner's choices are explaned by a mixture of novelty and past experiences or habits and that what our ronsumer will he maximinge is a mixtme of past and future expectation: we shall call it "deecision ntility". This decision utility is not derived from direct contanct with the goods but from an blending of what she learned from the past and what she is experting in the future. Docision utility will dotermine what the consumer buys. Hor purchase will enable her to uso the goods and rach a level of perceived utility.

In a case where the consumer is subject to a budget constrant, let us analyse two situations: as election between habits, and as a situation where a new good appears and interferes with the old habits. In a case where the selection is based only on old goods, the consumer has information on each of them. She knows how much experienced utility each good gives her. In the hypothetical case in which all prices are equal, those goods with higher experienced utility will be bought in higher quantities. Experienced utility will affect decision utility. With differing prices, defining the marginal decision utility as the increase in the decision utility generated by the last mit of good, the selection of goods will be done in such a way that the ratio between the marginal decision utility and prices are equal for all selected goods.

In the second case, in which a new good appears, the novelty associated with the good will be compared to the experienced utility of old goods. The budget will be redistributed accordingly to reach an equilibrium at the point:

$$
\frac{D U_{1}^{\prime}\left(E U_{1}, 0\right)}{P_{1}}=\ldots=\frac{D U_{n}^{\prime}\left(E U_{n}, 0\right)}{P_{n}}=\frac{D U_{n+1}^{\prime}\left(0, N_{n+1}\right)}{P_{n+1}}
$$

The formula attempts to explain that the consumer increases her hedonistic level not only from things that she knows about (experienced utility) but also from novelty. Both enter the decision of how much of each good to buy. In the formula experienced utility is given by commodities numbered 1 to $n$, while novelty in this formula is given by commodity $n+1$. Our argument in this section is that the consumer forms her "decision utility" based on a mixture of "experienced utility" and "novelty". She chooses quantities so that her optimal decision makes all these ratios equal. The terms experienced utility and decision utility are borrowed from Kahmeman et al. (1997) ${ }^{3}$.

\footnotetext{
${ }^{3}$ Kahmeman is talking about instant utility and remembered utility. If the instant utility comes out of direct contint with the good, the remembered utility will be the retrospective reports that the brain of the individual is projecting. Here we will be considering only one past period which is affecting onr present decision utility, so I use experienced utility as that bascd on some physical experienced contact with the good
} 


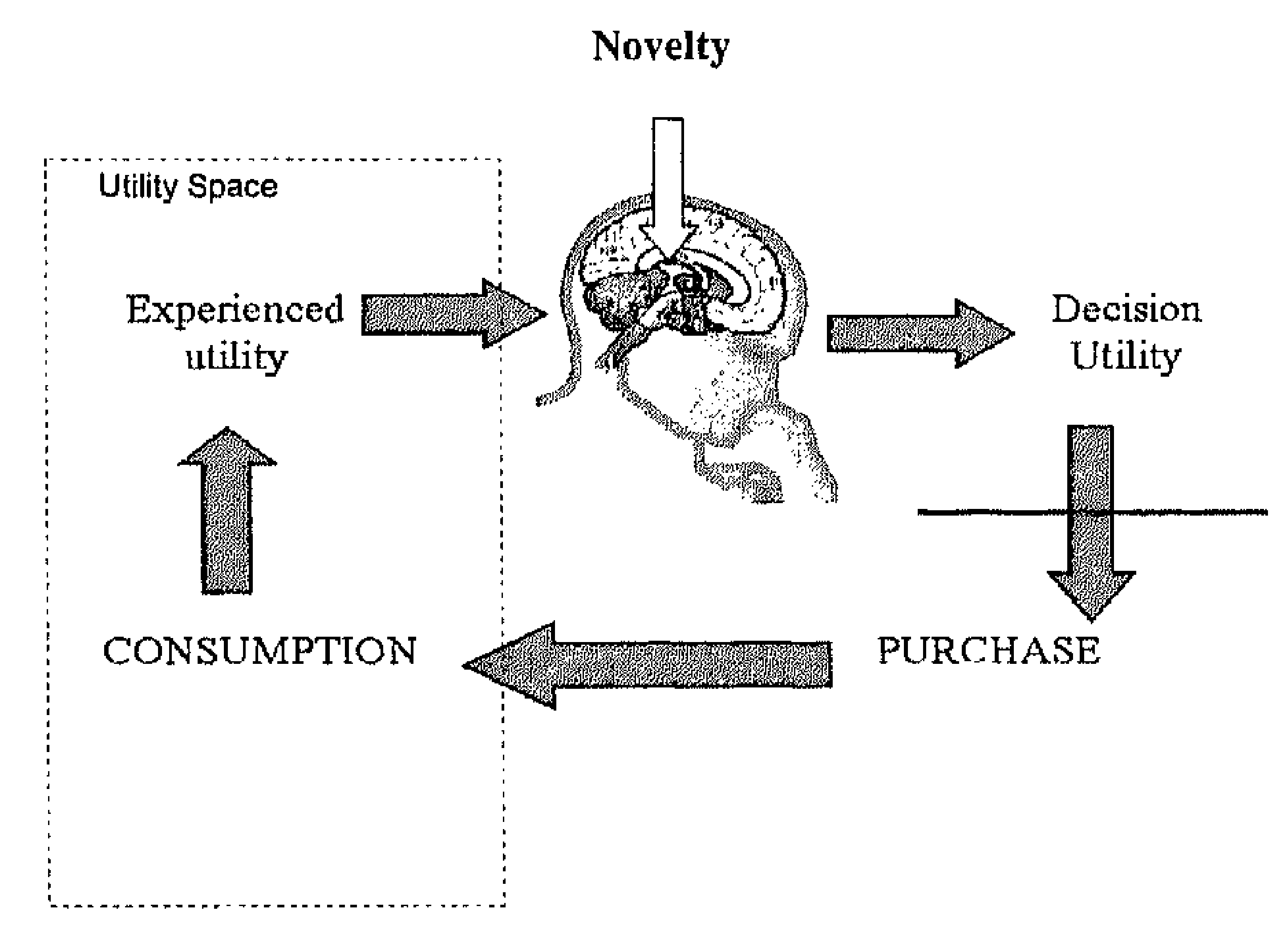

Figure 2.1: Formation of decision utility

Figure 2.1 attempts to clarify the whole process of deciding what to buy. Although we know there are other ways of getting goods into the utility space, I focus attention on market provision and, for simplicity, on goods with a single use. With a mixture of novelty and experienced utility the consumer will form her decision utility. Depending on prices and budget constraints she will get some quantity of each good, experience utility out of them and once again start the whole process.

It is worth highlighting one idea related to the new product. The first time the consumer buys the new good her hedonistic level is increased even though the rise does not come from direct contact with the good. As is the case for the old and known goods, the increase in this hedonic perception is a blending in the consumer's imagination. We have called this increase novelty.

We shall now classify goods according to how the consumer's decisions evolve. To do this we fix a long period and study the series of sequential decisions for a single good taken by the consumer during this time. The analysis shows four possible categories:

- Addictions: An addiction is the consumption of a good which in the long run will require all the consumer's income. Examples of such addictions are drugs, compulsive gambling... Socially accepted lesser addictions like drinking tea or coffee, smoking, and so forth are considered as habits.

- Eternal Habits: In this category we find goods which the consumer has learnt to consume and of which some quantity will always be chosen during the period studied even if new goods become available.

- Temporary Habits: The consumption of such a good will give the consumer utility for some time but it will be excluded from her preferences upon arrival of 


\section{Consumer Behaviour}

a new good. She will consume the good for a time but before our period finishes will banish it from her shopping basket.

- Novelty consumptions: The consumer buys such goods out of curiosity and will enjoy them until the novelty disappears. Once the novelty has worn off the consumer no longer uses the good.

We should like to reflect here on how new products are analysed in an environment of technical change. New products are in gencral better than earlier ones and the greater the number of new products the better it will be for the economy. The lack of a demand perspective hampers the distinction between innovations. We are not talking about a demand pull versus an innovative supply push. We are, however, interested in introducing into the discussion the real utility generated by an innovation and how effective this utility is in generating a habit in the consumer. We hope the rcader sees clearly that a new product which becomes an eternal habit is not the same as a new product which becomes simply a temporal habit. The distinction can only be studied when demand plays a role. The value of an innovation, and its contribution to the wealth of the economy, depends on its capacity to be needed by the consumer. In other words, by the capacity of the good to develop a habit in the consumer. Habit in the long term is a major determinant. However a certain degree of novelty is crucial, otherwise the whole innovation could be wasted.

What is especially relevant for us is that consumer behaviour is explained by decision utility - the utility that she maximizes before making a purchase. This decision utility is a blend of novelty and experienced utility. Novelty is important in the first purchase; it helps us to understand the initial consumption of a new good. By studying the evolution of preferences over a fixed period we can classify them according to the trajectory they follow. This is further explained in the next section.

\subsection{Formalization of the model}

In this section we present a mathematical model rooted in classical consumer theory. The objective is to make the consumer more dynamic by introducing habit formation and novelty into the formation of preferences. Improving the dynamic behavior of our theoretical consumer gives us a routine in which new products are part of the maximising decision of the consumer, thus creating a theory that can be used to analyse technical change when we focus only on product innovation.

Although it is impossible to introduce all the complexity of the consumer into one formal model, the principal components discussed in the previous sections will be considered. As in any formal model, we deal with a stylization of the real consumer behaviour. Only goods of a single use will be considered. The model consumer, though affected by past consumptions, will maximise her utility in each period without considering the fact that her current consumption may 
2.4. Formalization of the model

affect her future decisions. She maximises over quantities, not over her habit formation. There are two principal reasons for doing this: one conceptual and the other technical. First we consider that such consumer behaviour is closer to reality, that any consumer maximising her situation uses past experiences when making decisions but does not consider the effects of present decisions on her future habits. In this way, preferences evolve subconsciously, not under consumer control. The technical reason is that the model has an analytical solution; omitting this assumption will force us to use simulation techniques. The solutions obtained will be used in chapter 3 when further discussing the implications of demand and growth. Such discussions will be difficult to handle using simulations. Therefore we model a myopic consumer in the sense that her past experiences affect present decisions, but the latter do not control the effect on her future choices.

The static maximization of the consumer will be the first part of the section. Afterwards we will analyse the utility function that is used and its propertics. The next step will be, linking the four categories of habit formations into the model, to study the dynamic subconscious process of the individual and to clerive important conclusions for new products and habit formation. We finalise the section by suggesting possible extensions of the model.

The consumer chooses over a vector of goods $\vec{x}=\left(x_{1}, x_{2}, \ldots, x_{n}\right)$. Prices are given, so she will choose the quantities that maximize her decision utility function, defined as:

$$
\mathrm{U}(\vec{x})=\left(\sum_{\mathrm{i}=1}^{\mathrm{n}}\left(x_{i}-z_{i}\right)^{\alpha}\right)^{1 / \alpha}
$$

with $0<\alpha<1$ and $\left(x_{i}-z_{i}\right)>0$

The term $x_{i}$ represents the quantity of the good, and $z_{i}$ is the subsistence level of the good $i$. This level is formed by past experience and/or novelty. The terms $x_{i}$ and $z_{i}$ are always positive, $x_{i}$ because it is a quantity and $z_{i}$ because we only study goods, assuming any positive quantity of good will produce non-negative experienced utility. In a way, our function is the familiar CES modified by the $z_{i}$ term. Or we could describe the function as a Stone-Geary function nested in a CES. ${ }^{4}$ We now explain the solution of the static problem.

\subsubsection{Utility maximization in one period}

Formally the consumer faces the following maximization problem:

\footnotetext{
${ }^{4}$ Another more classical form when dealing with similar problems in economics could be a CES with depreciating coefficients. This approach would explain the continuous decrease in utility given by the same good over time, but it would not permit the inclusion of information about novelty or past experience. This function offers us the flexibility necessary to further work on demand and technology.
} 


$$
\begin{array}{ll}
\max & \left(\sum_{\mathrm{i}=1}^{\mathrm{n}}\left(x_{i}-z_{i}\right)^{\alpha}\right)^{1 / \alpha} \\
\text { s.t. } & \sum_{\mathrm{i}=1}^{\mathrm{n}} x_{i} p_{i}=E
\end{array}
$$

The static solution for this problem is:

$$
x_{i t}^{*}=z_{i t}-\frac{p_{i}^{\xi}}{\Sigma p_{j}^{\xi+1}}\left(\Sigma p_{j} z_{j t}-E\right)
$$

with $\xi=\frac{1}{\alpha-1}$

The solution can be rewritten in the following way:

$$
x_{i t}^{*}=z_{i t}+\psi \frac{\left(E-\Sigma p_{j} z_{j t}\right)}{p_{i}}
$$

In this way it can be understood, with $\psi$ being a price index, that the level of consumption will be equal to the minimum "subsistence" consumption $z_{i t}$ plus a fraction $\psi$ of the maximum amount of $z_{i t}$ that could be bought using the free disposable budget.

In the usual consumer problem, the marginal utility of each good tends toward infinity as the quantity consumed decreases toward zero. In such a setting all existing goods will be consumed even in infinitesimally small quantities. But we are interested in studying how new goods enter consumer preferences. To understand the introduction of a new good we shall specify that, on the first occasion, the consumer buys at least one full unit of it. If the maximization process give us a solution which is less than one, we shall assume that the consumer does not sufficiently appreciate the good so does not buy it. Such docisions lead to some goods not being consumed. To implement this consumer behaviour we follow an algorithm: if any of the resulting quantities fall below one, we shall eliminate that good and then repeat the process to maximize utility. Should the quantity chosen of two or more goods simultaneously be less than one, we eliminate first the good whose quantity is the smallest and repeat the process. If in doing so the other good now reaches a value greater than one, it will be retained, otherwise it, too, is omitted and we continue. We reason that the consumer weighs up all her possible options and if she cannot buy at least one first full unit she will buy none of this good at all and redistribute her income among other products.

By amending the classical theory, we derive that the following rule will be satisfied at equilibrium, 


$$
\frac{\left(x_{1}-z_{1}\right)^{\alpha-1}}{p_{1}}=\frac{\left(x_{2}-z_{2}\right)^{\alpha-1}}{p_{2}}=\ldots=\frac{\left(x_{n}-z_{n}\right)^{\alpha-1}}{p_{n}}
$$

In words, for cach good the consumer is comparing marginal decision utilities divided by prices, such that in equilibrium the ratios are equal. The $z_{i}$ terms act like a minimum desired level, holding information of how much pleasure she has previously received from consumption of each good. The maximum decision utility is achieved at the point where the last unit of income expended on each good, is such that distance from each good corrected by past experiences given by the good and divided by prices is equal.

\section{Properties of the function}

The first derivative of the decision utility with respect to the quantities is positive, and the second negative. As in the classical model, we have a marginal decision utility function which is positive but decreasing. Since $z_{i}$ is awkward and rarely used in the literature, it is worth analysing its relation to decision utility and to marginal decision utility. The effect of an increase in $z_{i}$ in the decision utility function will be:

$$
\frac{\partial U}{\partial z_{i}}=-\left(x_{i}-z_{i}\right)^{(\alpha-1)} U^{(1-\alpha)}
$$

The sign of this derivative is negative, since by assumption $\left(x_{i}-z_{i}\right)>0$. The idea behind the negative sign is that the higher our desire for a good, the worse off we shall be. If we increase this habit formation term, other things remaining equal, the current utility decreases.

The next equation presents the effect of this term in the marginal decision utility for that specific good:

$$
\frac{\partial^{2} U}{\partial x_{i} \partial z_{i}}=(1-\alpha)\left(x_{i}-z_{i}\right)^{(\alpha-1)}\left(x_{j}-z_{j}\right) U^{(1-2 \alpha)}
$$

This term is always positive because the more accustomed you are to a good, the more value you give to each extra unit of it compared to other goods.

\section{Elasticity of substitution}

To conclude the analysis of this function, we calculate the elasticity of substitution between two goods:

$$
\frac{d \ln \left(x_{1} / x_{2}\right)}{d \ln \left(U_{x 1} / U_{x 2}\right)}=\frac{1}{\alpha-1} \frac{\frac{1}{x_{1}}-\frac{1}{x_{2}}}{\left(\frac{1}{x_{1}-z_{1}}-\frac{1}{x_{2}-z_{2}}\right)}
$$

This proves that unless the two values of $z_{i}$ are equal to zero this function no longer presents constant elasticity of substitution. In other words, we will be 


\section{Consumer Behaviour}

working with non-homothetic preferences and that an increase in income will not be distributed proportionately among all goods.

\subsubsection{Evolution of the dynamic subconscious process}

Having studied the static maximization, we now analyse the dynamics of the evolution of subconscious preferences. The term $z_{i}$, as before, contains information on experienced utility and novelty. These concepts play a significant role in both short-term and long-tcrm equilibrium. We explain expcrienced utility, then novelty and the way these two terms affect $z_{i}$. A set of dynamic equations will be set up to describe quantities bought over time depending on the evolution of preferences.

Working with non-homothetic preferences implies that increases in income will not be equally distributed among all goods. This point is a cornerstone of our research. Basically we are always working with goods which differ from each other in their capacity to produce experienced utility. If the same quantity of two goods is consumed, the experienced utility will be different for each one, each unit of consumption of each good producing differing amounts of experienced utility. To derive the level of experienced utility produced by the total quantity consumed of one specific good, we multiply this total quantity by a goods-specific coefficient, whose range is from 0 to 1 . This coefficient is an inner characteristic of the good and does not change over time. The consumer chooses the quantity but the characteristic is exogenous to the model. In our model experienced utility has the following analytical form:

$$
E U_{i t}=c_{i} x_{i t-1}
$$

with $0 \leq c_{i} \leq 1$.

The term $c_{i}$ is the intrinsic capacity that the good has to produce experienced utility. This term is goods-specific, and it is constant over time. The actual level of experienced utility of the good $i$ depends on $c_{i}$ and on the past period quantity $x_{i t-1}$.

Novelty will be modelled so that it decreases with time :

$$
N_{i t}=N_{i} \sigma^{t}
$$

with $\sigma<1$. This parameter controls the depreciation of novelty over time $t$, which is initially zero. The whole term measures how much the idea of consuming the good excites the consumer, and how this feeling loses its power over time. Later in the discussion we present an initial situation in which the consumer has already consumed something. Even though in the past these 'old goods' may have had some novelty, in the present the novelty is assumed to be zero.

In a general case the good has both novelty and experienced utility:

$$
z_{i t}=c_{i} x_{i t-1}+N_{i} \sigma^{(t-1)}
$$


2.4. Formalization of the model

For simplicity we will concentrate here on only two goods: $x_{1}$, the old one (with no novelty) and $x_{2}$, a new one (with no experienced utility for the first maximization period).

Introducing the definition of the $z_{i}$ term presented by the previous equation in the static solution 2.5 will provides a system of differential equations. By studying the dynamics, the next subscction will extend the possible outcomes for any new good that appears in the consumer's life.

The dynamics of preference evolution are presented, concentrating on the simplest case. Considering only one old good $\left(x_{1}\right)$ and one new one $\left(x_{2}\right)$, their respective parameters $z_{i}$ at each moment of time are $z_{1 t}=c_{1} x_{1 t-1}$, $z_{2 t}=c_{2} x_{2 t-1}+N \sigma^{t-1}$. Substituting these values in the solution 2.5 gives us the following system of simultaneous differential equations:

$$
\left[\begin{array}{l}
x_{1 t} \\
x_{2 t}
\end{array}\right]=\left[\begin{array}{cc}
c_{1}\left(1-\frac{p_{1}^{\xi+1}}{\theta}\right) & -c_{2} \frac{p_{2} p_{1}^{\xi}}{\theta} \\
-c_{1} \frac{p_{1} p_{2}^{\xi}}{\theta} & c_{2}\left(1-\frac{p_{2}^{\xi+1}}{\theta}\right)
\end{array}\right]\left[\begin{array}{c}
x_{1 t-1} \\
x_{2 t-1}
\end{array}\right]+\left[\begin{array}{c}
\frac{E p_{1}^{\xi}-N p_{2} p_{1}^{\xi} \sigma^{t-1}}{\theta} \\
\frac{E p_{2}^{\xi}-N p_{1} p_{2}^{\xi} \sigma^{t-1}}{\theta}
\end{array}\right]
$$

with $\theta=p 1^{\xi+1}+p 2^{\xi+1}$. The system presents an analytical solution wlich for each good is equal to:

$$
\begin{aligned}
& x_{1 t}=A \lambda^{t}+B N \sigma^{t-1}+\frac{\frac{p 1^{\xi}}{\left(c_{1}-1\right)}}{\sum \frac{p i^{\xi+1}}{\left(c_{i}-1\right)}} E \\
& x_{2 t}=A^{\prime} \lambda^{t}+B^{\prime} N \sigma^{t-1}+\frac{\frac{p 2^{\xi}}{\left(c_{2}-1\right)}}{\sum \frac{p i \xi^{\xi+1}}{\left(c_{i}-1\right)}} E
\end{aligned}
$$

with $\lambda=\frac{c_{1} p 2^{\xi+1}+c_{2} p 1^{\xi+1}}{p 2^{\xi+1}+p 1^{\xi+1}}<1$

The terms A, B, A' and B' are constants. Their values depend on the initial value we want to analyse. For a hypothetical casc in which in the first period all income is used on the first good, and nothing on the new good, the values of these constants are as follows:

$$
\begin{aligned}
& A=\frac{E}{p_{1} \lambda}-\frac{p_{1}^{\xi}\left(c_{2}-1\right)}{\lambda \vartheta} \\
& B=\frac{1}{N}\left[\frac{p_{1}(\lambda-1)\left(c_{2}-1\right)}{\vartheta}+\frac{E\left(c_{1}-1\right)}{p_{1}}-\frac{p_{1}^{\xi}\left(E\left(c_{1}-1\right)+N p_{2}\right)}{p_{1}^{\xi+1}+p_{2}^{\xi+1}}\right] \\
& A^{\prime}=\frac{-p_{2}^{\xi}\left(c_{1}-1\right)}{\lambda \vartheta} \\
& B^{\prime}=1+\frac{p_{2}^{\xi}\left(c_{1}-1\right)(\lambda-1)}{N \vartheta}-\frac{p_{2}^{\xi}\left(E\left(c_{1}-1\right)+N p_{2}\right)}{N\left(p_{1}^{\xi+1}+p_{2}^{\xi+1}\right)} \\
& \vartheta=p_{1}^{\xi+1}\left(c_{2}-1\right)+p_{2}^{\xi+1}\left(c_{1}-1\right)
\end{aligned}
$$




\subsubsection{One new good, four possible outcomes}

In this section we study how a new good enters into the utility space of $t h$ consumer and, if it does, how and why it remains there. As we said brin : the maximization is done in repetitive steps with the condition that the solutir, for any good is greater than unity. Any good whose chosen quantity is lesin thik one will be eliminated and the income redistributed among the other goods.

The cntrance of a new good deserves special attention so an example with $t h_{1}$ easiest case will be analysed step by step. Initially the consumer only has one and we wish to know whether or not she buys a new product. We also want t, know if she will continue to buy this product in the future. The initial conditine for each good, and the value for their respective $z$ terms, are the following:

- The consumer expends all her income on the old good so she consumes $l: /$. units of it. The experienced utility will be $c_{1} E / p_{1}$. Because this good is an "hls one the novelty is zero. Therefore the habit formation is equal to $z_{11}=c_{1} E / 1 \mathrm{r}$.

- For the second good, since it is a new good its experienced utility will be $2 x \cdot$ r and the only parameter will be the novelty. $z_{21}=N$.

Taking equation 2.5 and defining it for each good we have:

$$
\begin{aligned}
& x_{11}=z_{11}-\frac{p_{1}^{\xi}}{0}\left(p_{1} z_{11}+p_{2} z_{21}-E\right) \\
& x_{21}=z_{21}-\frac{p_{2}^{\xi}}{\theta}\left(p_{1} z_{11}+p_{2} z_{21}-E\right)
\end{aligned}
$$

with $\theta=p_{1}^{\xi+1}+p_{2}^{\xi+1}$

If we substitute the habit formation part for each good we have the first solutin, for the next period; for $t=1$, we will have

$$
\begin{aligned}
& x_{11}^{*}=\frac{E c_{1}}{p_{1}}-\frac{p_{1}^{\xi}}{\theta}\left(p_{1} E c_{1}+p_{2} N-E\right) \\
& x_{21}^{*}=N-\frac{p_{2}^{\xi}}{\theta}\left(p_{1} E c_{1}+p_{2} N-E\right)
\end{aligned}
$$

If $x_{21}^{*}<1$ then the consumer will buy no first unit of the new good and sink will still expend all her income on the old good. Given the rest of parameters. i is the level of initial novelty that determines the consumption of the first unit $\mathrm{c}$ good. The minimal level of novelty needed for the consumer to get a first full uni 1 is:

$$
N^{*} \geq 1+\frac{p_{2}^{\xi}}{\theta}\left(E\left(c_{1}-1\right)+p_{2}\right)
$$

Any value of novelty below this means the consumer is perhaps interested is the good but not enough to buy the first whole unit. As initial consumption ihw": not depend on experienced utility, novelty is the only variable that controls it other things being equal. 
The next important question is, if the consumer buys a first unit, whether she will continue to buy it. In other words, whether or not she redistributes her income between two goods. By studying the solution presented by equations 2.13 and 2.14 we can answer this question. With $\lambda=\frac{c_{1} p 2^{\xi+1}+c_{2} p 1^{\xi+1}}{p^{\xi+1}+p 1^{\xi+1}}<1$ and $\sigma<1$, when $t$ goes to infinity the system has the following long-term solution :

$$
\begin{aligned}
\bar{x}_{1}^{*} & =\frac{\frac{p 1^{\xi}}{\left(c_{1}-1\right)}}{\sum \frac{p i^{\xi+1}}{\left(c_{i}-1\right)}} E \\
\overline{x_{2}^{*}} & =\frac{\frac{p 2^{\xi}}{\left(c_{2}-1\right)}}{\sum \frac{p i^{\xi+1}}{\left(c_{i}-1\right)}} E
\end{aligned}
$$

The long-term solution does not depend on novelty, but on the capacity the good has to provide experienced utility. It depends on the parameter $c_{2}$. If we are interested in knowing whether the second good will become a new habit then we should find the conditions for which the solution is $\overline{x_{2}^{*}} \geq 1$.

A relevant result of this study is that although a good may have a long-term solution (in our example $\overline{x_{2}^{*}}$ ) greater than unity it might not have enough novelty value to be tried a first time. According to the values of novelty and experienced utility three interesting cases are possible:

- $N \geq N^{*}$ and $\overline{x_{2}^{*}} \geq 1$. This is the case of a successful innovation which will give utility to the consumer in the long run.

- $N \leq N^{*}$ and $\overline{x_{2}^{*}} \geq 1$. In this case, the innovation was potentially successful but the consumer never took an interest in it, possibly due to a failure in the marketing of the innovation.

- $N \geq N^{*}$ and $\overline{x_{2}^{*}} \leq 1$. This is a tested innovation that is found to give so little experienced utility that in the long run the consumer will go back to her old consumptions.

To conclude this section and to link its ideas, we reflect that up to now we have concentrated on the perspective of the consumer. So far, when we referred to novelty we assumed it to be an inner curiosity of the consumer. However, looking at things from the firm's viewpoint might bring different insights into the discussion. Should a firm wish to introduce a new good in a market, it is vital to raise the perceived level of novelty of its product. In solution 2.17 we can see good reason for a firm to do marketing and publicity; it is one of the best ways to raise perceived novelty. Otherwise, even if the good is technologically superior or useful to the consumer, it may never be sold. We consider it crucial that studies of technological change should include the marketing perspective and we return to the subject in the conclusion of this chapter. 


\subsubsection{Graphical analysis of the model}

Figure 2.2, presenting four graphs, attempts to illustrate the concepts being discussed. The first three panels plot the quantity of each good over time in three different situations. In the first case we plot a successful innovation, case 2 is for a good which will not be chosen on a long-term basis and case 3 is that of an addiction. In panel 4 of the figure we plot, using indifference curves, the different situations in time at which the consumer might be.

In our graphs consumer income is equal to 1000; there are two goods, one old $\left(x_{1}\right)$ and one new $\left(x_{2}\right)$. The old good's price is $p_{1}=10$, the price for the new one is $p_{2}=5$. Varying the values of $c_{i} s$, the proportion of experience utility achieved by the consumer for each unit of good, and novelty; changes both the dynamics and the steady state.

The first panel of figure 2.2 is the case of a successful innovation. Initially the consumer buys a lot of this good, generating a peak in consumption at $\mathrm{C}$. As the novelty value drops towards zero the consumer still finds this good useful but at a lower level of consumption, point $\mathrm{B}$, where the long-term stable consumption level is reached.

Panel 2 is an cxample of a temporary consumption. The novelty for this product is high and thercfore the person consumes it for a period, but as time passes she goes back to the original situation.

The next case is an addiction, in which the new good gives so much experienced utility that the consumer decides to use all her income on the new good. This is presented in the third panel.

The last item of the figure, the fourth panel, is an attempt to reconcile this theory with the classical consumer theories. This presents indifference curves that show the marginal decision utility that each combination of goods has at each moment of time. The curves represent different combinations of quantities from both goods, for which the consumer will be equally happy when making the decision. In our case the curves change over time as does the quantity chosen for each good. The lines A, B, C, D in the three previous panels represent situations in which the indifference curves are A, B, C or D. Still, as in the classical case, the solution for each moment of time is given by the point where the indifference curves are tangential to the budget constraint. In our case the curves move over time, though always tangential to the budget line, until the consumer reaches a long-term solution.

To clarify panel 4 let us compare it to the different situations described by panel 1. At the beginning only the old good is bought, which in panel 1 is marked by line $\mathrm{A}$. In the fourth panel this is represented by indifference curve $\mathrm{A}$, in which only the old good is consumed. The next line rightwards in panel 1 is line $\mathrm{C}$, a situation that in the indifference map is represented by $C$. Line B and indifference curve $B$ are similar. Panel 1 represents total quantities and changes in time. The dynamics in the indifference curves are expressed by movements of this curve over time as habits form. In the case of the panel 1 , the evolution of the indifference 


\subsection{Formalization of the model}

curves over time is represented in panel 4 , starting in indifference curve A, moving towards $\mathrm{C}$ and reaching equilibrium in $\mathrm{B}$. 


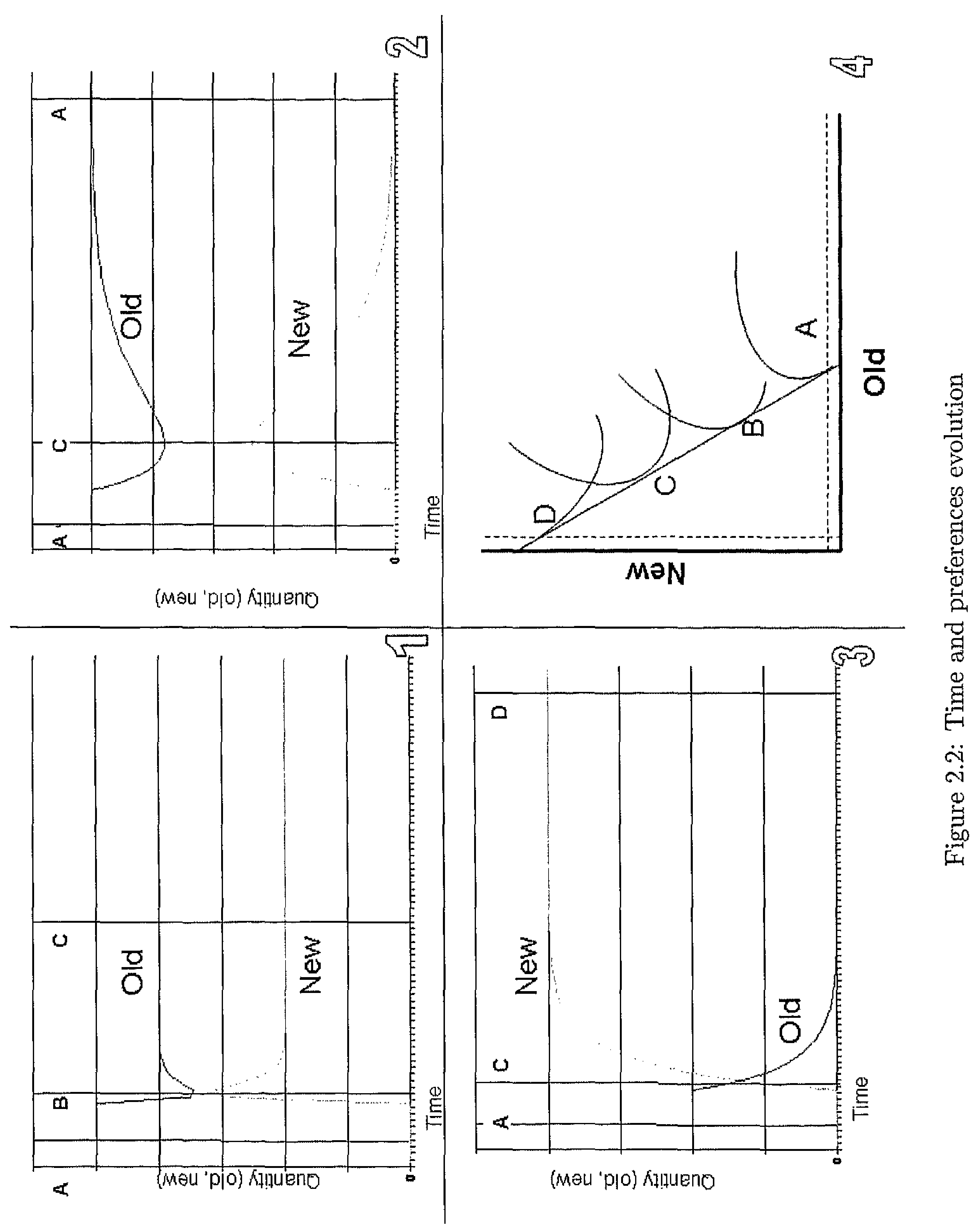


2.4. Formalization of the model

\subsubsection{Extending the model}

Although we concentrate mainly on inconspicuous consumption, in this section we allow the consumer to be partially influenced by societal choices, presenting a discussion based on long-term solutions. We assume here that consumers are not all equal and that our consumer is different from the rest of the society. We will be treating the society as one single big consumer. Acknowledging the importance of an initial level of novelty, and assuming that this level is reached, we look at the relationship between the solution for the society and that of the individual. Formally we remodel $z_{i}$ to be:

$$
z_{i t}=\phi\left(c_{i} x_{i t-1}\right)+(1-\phi)\left(\eta_{i} X_{i t-1}\right)
$$

The $c_{i}$ parameter captures the inner capacity of the good to produce experienced utility in the consumer. $x_{i t-1}$ is the amount of good previously consumed. The value of the $\phi$ parameter controls the extent to which the consumer is influenced by society. A value of $\phi=0$ represents an outward-looking consumer, whose preferences are completely determined by society - a case of pure conspicuous consumption. At the other extreme, a value of $\phi=1$ brings us back to the consumer presented in earlier sections, whose preferences are determined only by her experienced utility - an inward-looking consumer. The whole society is treated as a one big single consumer whose decisions are not controlled by our consumer. The $\eta_{i}$ parameter, in a way parallel to $c_{i}$, accounts for the level of experienced utility felt by society as a whole for the consumption of each unit of goods. In principle, it is only interesting to study the case in which $\eta_{i}$ is different from $c_{i}$, and is less than $1^{5}$. A capital $X$ is used to denote the quantity consumed by society, $X_{i t-1}$ is the past consumption of the society for good $i$. We assume that the individual consumer does not have the power to change social decisions although these decisions affect her.

When $\phi \neq 1$, the question that we have studied before, the buying of the first unit of good and the habit formation of the consumer is affected by societal decision. Using the habit formation of equation 2.20 , we work as in the previous sections by constructing the system of dynamic equations in $x_{1}, x_{2}, X_{1}, X_{2}$ (The system of equations is presented in appendix B.1)

When it comes to novelty, we assumc that the level is high enough to allow our individual consumer to buy one first unit. We could also present a cliscussion on how novelty in this partially conspicuous model is affected. However, we shall leave that for future research as there are many assumptions which could be considered (for example: whether the good is new only for the consumer, new for all of the society; each possible combination will give a different solution). What becomes more interesting, and easier to track, is the effect of society on long-term solutions.

\footnotetext{
${ }^{5}$ If it is equal to one, the society will be in a situation of being in a total addiction, which does not make much economics sense, though it is possible to study mathematically.
} 
For the whole society the long run solution will be:

$$
\bar{X}_{2}^{*}=\frac{\frac{p 2^{\xi}}{\left(\eta_{2}-1\right)}}{\sum \frac{p i \xi+1}{\left(\eta_{i}-1\right)}} E S o c
$$

The long-term solution for the consumer in this new case will be:

$$
\frac{\frac{p_{2}^{\xi}}{\left(c_{2}-1\right)}}{\phi \sum \frac{p_{i}^{\xi+1}}{\left(c_{i}-1\right)}} E+(1-\phi) \frac{\frac{p_{2}^{\xi}}{\left(e_{2}-1\right)}}{\phi \sum \frac{p_{2}^{\xi+1}}{\left(c_{1}-1\right)}} E S O C
$$

or, simplifying,

$$
\frac{\frac{p_{2}^{\xi}}{\left(c_{2}-1\right)}}{\phi \sum \frac{p_{1}^{\xi+1}}{\left(c_{2}-1\right)}}(E+(1-\phi) E S O c)
$$

One inmediately notes that the long-term solution for the single consumer is not affected by the $\eta_{i}$ parameter. It is only the long-term amount of the good bought by society $\left(\bar{X}_{2}^{*}\right.$ see equation 2.21 ) that really affects the decision of the individual consumer. The importance of this finding is that it opens up a way to connect the result of our consumer with the conspicuous consumption literature. It would be interesting to analyse the effect of an outward-looking consumer at the macro level, but this is outside the scope of our research.

\subsection{Conclusions}

The main motivation of the thesis is to analyse and study the effects of product innovation on the economy. By product innovation we mean neither improvements in quality nor the effect that new products have on production. We attempt to calculate the direct effect that an innovative product has on final demand. A major constraint was that classical utility maximization does not consider this factor; explanations such as that of Lancaster offer little flexibility when studying product innovation.

In the chapter we have attempted to incorporate ideas from behavioural psychology so that the consumption theory and its conclusions correspond more closely to real human behaviour. Therefore, together with this chapter's study of novelty, we use results from behavioural economics to build a theoretical framework flexible enough to explain habit formation and consumption of new goods and so to construct a more responsive consumer. By incorporating the two concepts with the idea that the consumer is maximizing decision utility we can understand why we consume new things and how we form our prefcrences. When the maximization process is studied over time, continually repeated as by a real consumer, it clarifies the evolution of preferences. The chapter describes four possible outcomes: addiction, eternal habit, temporary habit and consumption of novelty. 
Of special importance for technical change is that the value of innovation should be linked to the utility given to the consumer over a long period of time. Until now the value of an innovation has been approximated by the number of citations assigned to a patent or by analysing the percentage of sales due to innovative items at the company level. However, to our knowledge, no one has tried to calculate the value of an innovation based on the utility given to a consumer. Our concept allows one to relate closely the value of an innovation to the level of experienced utility.

Independently of an innovation's potential to generate new habits, the new good must present a minimum threshold of novelty. An innovation that remains unknown to consumers but has the potential to generate experienced utility may become a failure. Even very good innovations may require marketing effort to increase their novelty value so that they can in turn increase the well-being of society.

Satiation also requires discussion. The ideas we present are based on a consumer who already has all their basic necds covered but is nonetheless looking for new things. When demand and technology are discussed by Pasinetti (1981) or Witt (2001a) the focus is on satiation of needs as income per capita increases. There is always a hierarchy of needs that are satisfied as incomes rise. Without denying the importance of such relations we believe that today's developed-world decisions concerning innovations arc not related to increasing income. The consumer will have already covered her basic needs but will still consider innovations such as an ipod or a mobile phone. We wish to understand the introduction and use of new products once all basic needs are covered. Engel's Laws may be useful to analyse developing economies but we do not consider them the best explanation for product innovation nowadays. When a consumer in a developed economy is choosing an innovation it is hardly ever a case of covering a primary need.

In our next chapter we shall come closer to a question presented by Witt (2001b). He wonders how it is possible that in developed societies income per capita grows continuously but demand is never satisfied. In a setting similar to that presented in this chapter, we shall continuously introduce new goods which consumers always want. Our idea is to present a growth model in which the effect of technology is to generate a flow of innovations which creates strong habits in consumers. We show a mechanism to explain Witt's observation that expenditure increases without demand being satiated. 


\section{HABIT FORMATION, DEMAND AND GROWTH THROUGH PRODUCT INNOVATION}

\subsection{Introduction}

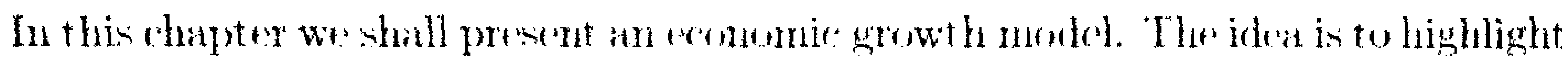

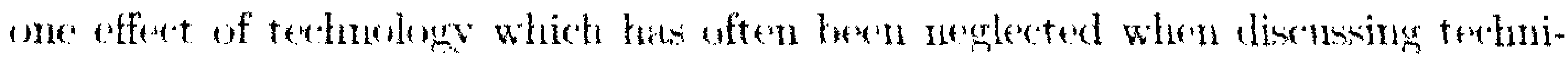

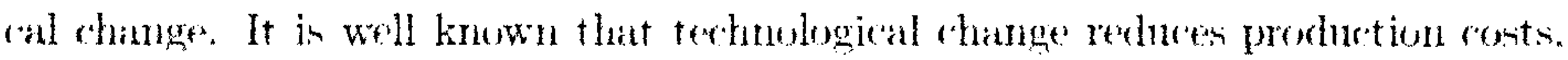

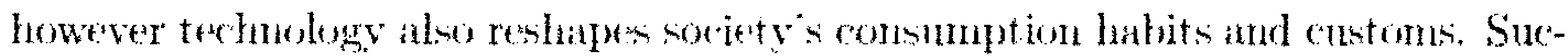

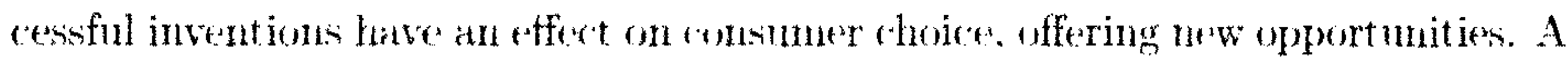

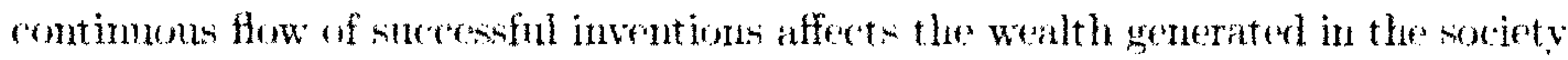

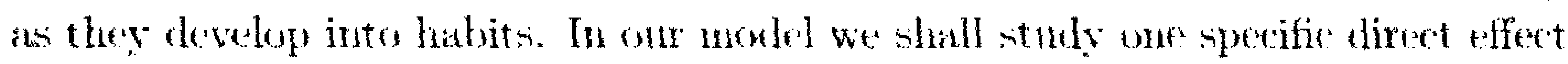
of technology on final demand the creation of new needs. One mordel imblates this affect from process innovation to dearly understand its affects althongh we know product innowation never happens in isolation. The main motivation is to reflect on the fact that tedminal dhange does net just redure production costs but also generutes nededs and reshapes preferenees in the society.

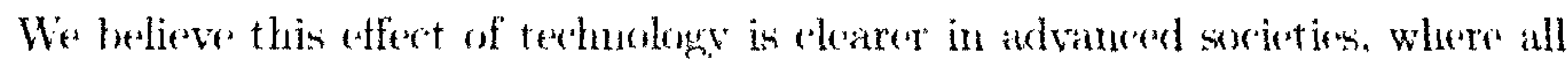
batsic neods are coverel. Every gear a mass of imovet ions comes onte the market. somes of which will hecome habits for at propurtion of the populat ion and others will

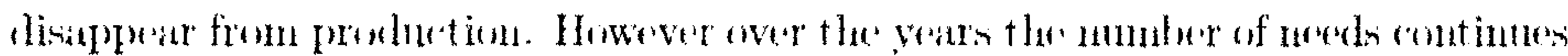

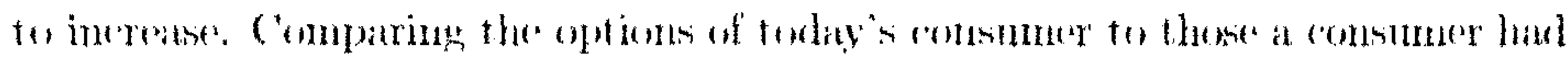




\section{Habit Formation, Demand and Growth}

a hundred years ago, the number and variety has increased. However, not only the absolute number of options has increased, today's consumer also considers more items to be essential than our grandparents did. This is the focus of the chapter: to study how this increase in needs affects economic growth.

In real life, technical change through introduction of final good inventions is very chaotic with many innovations generated at the same time, strongly affected by continuous natural selection. Some of the year's many inventions will become habits, others will disappear. We shall concentrate on the innovations that become consumer habits; these we consider are the real innovations. In reality there is no relation between the habits generated by one years innovations, and the habits created by the next. However we assume that in each period a single innovation will be introduced and this innovation will create a habit stronger than earlier ones. In the previous chapter preference evolution was introduced. It was argued that to understand preference evolution two key factors need to be taken in consideration: habit formation and novelty. Both are relevant, however in this chapter the main attention will be on habit formation. From the conclusions of the previous chapter, we know that a certain amount of novelty has to be perceived by the consumer at the beginning of the life of a product. In this chapter the assumption is that all new goods reach this level. We shall discuss the macroeconomic effects of product innovation, concentrating on habit formation and economic growth.

In this chapter when we talk about growth we are not referring to physical growth of the output. Our point is that, given a more active role of the demand, it is possible to have growth of added value and utility without increasing the amount of physical objects produced. We will work with a single production input: labour. In equilibria the total amount of labour is fixed and all industries have the same constant production coefficient. In this sense the total final quantity of goods produced by the economy will be constant. The variety of final goods is constantly changing, even after equilibria is reached, and so the total value of the production will be constantly increasing. New goods are superior to previous ones in their capacity to form habits and also have higher income elasticity than old goods. In the equilibrium the total value of the production will be increasing, while the physical amount produced will be constant. This growth is possible because each time a new good arrives the utility of individuals is increased.

Behind most economic growth theories is the assumption that what matters most is the total physical production. Economists have attempted to discover the reasons that explain increase in physical output, either modelling ways to increase factor accumulation or providing reasons that explain reduction in production coefficients. In both cases it is a matter of producing more; in this sense we argue that most economic growth theorics are biased towards supply. The dynamics of the demand in these theories are extremely simple, assumed in most cases to be equal to supply and that all production is bought.

Papers that study how technical change affects demand and growth can be divided into two groups, those in which new products bear a horizontal relationship to existing goods and those with a vertical relationship: 
- In the case of a horizontal relationship technology increases the varicty of products, all of which contribute equally in evcry moment of time to the general utility.

- When talking of a vertical relationship we mean the quality/utility of each existing good is increased by technology.

Our model combines both ideas. In each period we have both horizontal and vertical relationships to existing goods because in the period we introduce a new good of superior utility. Our interpretation of increase in utility is that the habit or need of the new product is superior to that of earlier ones.

In the third chapter of their book, Grossman and Helpman (1991), present a variety of models where technology affects the demand, increasing the variety of goods and therefore growth. We discuss the first two presented there since our model can be compared with both. In the first model, presented in the first section of the book, they treat technology as an entirely private product where entreprencurs invest resources in order to devclop unique goods. An ordinary production function relates input (primary factors of production) to output (blueprints for new goods). Product designs are assumed to be proprietary information, either because their details can be kept secret or because patents effectively deter unauthorized uses. Each new product substitutes imperfectly for existing brands, and innovators cxploit limited monopoly power in the product market. The assumption is that the potential for developing new products is unlimited; however in this model growth ultimately ceases. Even if the resource cost of creating new goods does not rise, the economic return on invention may decline as the number of products increases. In the model presented in the next section of the quoted chapter, they modify the innovation process to treat a part of the innovation as knowledge capital, which is considered a public good. This modification allows them to present a self-sustaining process of endogenous innovation. We work within a similar framework, with the distinction that each good gives a higher utility on the demand side and a higher profit is associated to it on the supply side. Therefore our profit rate for each future good is constantly increased, making retaining the $R \& D$ sector and investing in it worthwhile. Our specification allows us also to present a self-sustaining process of endogenous growth, not by introducing knowledge capital as a public good but by introducing a more relevant role of the demand. Since each new variety has a higher utility it also has associated higher profits that do not reduce the economic return of the final good sector.

The chapter is structured as follows: in section 3.2 we discuss the state of the issue and review the literature, in section 3.3 we explain the reasons and ways in which demand affects growth, section 3.4 formalizes the discussion presenting the different agents of our model and section 3.5 discusses the cquilibrium; the chapter's last section draws a conclusion. 


\section{Habit Formation, Demand and Growth}

\subsection{Demand and growth in the economic litera- ture}

The industrial revolution made one idea clear: machines and capital are able to produce more with less people. It is a supply-driven effect. The main idcas behind the recognized growth theories, especially after Solow (1956), are biased toward the supply side. The theories concentrate on factor accumulation and productivity and the conditions that can increase them. For process innovation anything that increases productivity through a reduction of costs or an increase in the quality of production factors will be translated into higher growth rates. The mechanism causing this to happen varies with the model. We shall briefly review the main sources of growth for each of them:

- Solow (1956) assumes that more savings are transformed into more investment. Investment basically means more capital and more machinery in the production process. The notion is that with more capital transformed into machinery the same people can produce more. Capital presents decreasing returns to scale, therefore in the steady state growth is determined by two main sources, the growth of technology and the growth of the population.

The strongest criticism made of this model was that the factors explaining growth were outside the model. As a reaction the endogenous growth literature was born in which each model gives a different reason to explain increased production:

- Arrow (1962) presents the idea of knowledge spillover. Knowledge generated can be used in many different places without increasing the cost, therefore it will increase total output.

- Lucas (1988) introduces the argument of human capital. It is not just a question of more machinery or more spillovers, but the fact that more highly qualified people will be able to produce better and more. He presents two main methods for generation of human capital: schooling and practical experience.

- Romer (1990) reflects on the increasing complexity of production processes. He argues that innovation affects the number of inputs used during production so that we are able to produce more. Thus innovation generates more inputs, which in turn enhances productivity.

- Aghion and Howitt (1992) introduce the Sclumpeterian concept of creative destruction in their model: a new production process makes its predecessors obsolete. In a way it is not the increasing number of goods but better production processes which generates growth.

The role of demand in these theories is very simple; it is always made to equal the supply. The dynamics of demand are neglected and it is left to passively absorb all production. All the cases previously discussed assumed homothetic preferences. It is interesting to note that demand was much more important in 
3.2. Demand and growth in the economic literature

the economic discussion before Solow wrote his article. Previous theories were much more concerned with the interaction of supply and demand, allowing for different dynamics in both sides. For cxample, Harrod (1939) presented a model of growth in which the key driver of the growth process is the level of the community's income. Income dynamics determine the supply and demand of savings. And then in Domar (1946) we find a rich discussion about the determinants of the growth of production (increase in the working population, labour productivity...) together with a presentation of different determinants for the growth of demand (increase in the national income...). In addition he analysed cases in which the rate of growth of each determinant is different. However the only things remaining in the text books from these earlier ideas is that they use a Leontieff production function, a criticism made by Solow (1956). Only some ideas introduced by Ramsey (1928), when he was looking for a theory of savings, seem to remain from the exogenous growth model. In his article, savings are not a constant proportion of production but depend on decisions made by consumers.

Recently some new growth theories have taken an interest in the role of demand. Three main interrelated branches can be distinguished in the literature: the causality from growth and savings, the relevance of habit formation, and the importance of different new products. As we have commented earlier in the section, the majority of growth theories take the view that production is too low. Anything increasing production is assumed to be good. More production means more income, and more income generates increased savings that are assumed to be transformed into investment. This higher investment increases productivity and we start a new loop, convinced that more savings generate more growth. One possible explanation for this conviction is that the dynamics of demand are never acknowledged by any of the theories.

If demand drives the growth process, then a reduction in savings, which irnplies an increase in consumption, will generate more growth and consequently more savings. But the direction of causality is changed, no longer leading from more savings to growth, but from more growth to savings. Carroll and Weil (1994) present some empirical evidence about this. They use a sub-sample of 68 countries from the Summer and Heston data base, making a cross-sectional analysis, and bring empirical evidence to prove that periods of high incomes are followed by periods of high savings. They also exploit American household data from the Panel Study of Income Dynamics (PSID) and other sources to investigate whether expectations of growing incomes will generate higher saving rates - they find some positive evidence. Having studied both macro and micro levels they conclude that causality goes from growth to savings. In Carroll et al. (2000), we find a theoretical model supporting the empirical evidence. Consumers maximize in a Ramsey framework a Constant Relative Risk Aversion (CRRA) utility function which has been modified to introduce habits. The model is based on the presence of habit formation in consumption patterns and they show that in a standard endogenous growth framework the presence of habits is sufficient to show growth- 


\section{Habit Formation, Demand and Growth}

to-savings causality. ${ }^{1}$ They study how changes in habit formation persistence might affect the steady state growth. Falkinger and Zweimuller (1997) present a different point of view which is more related to Engel's laws: higher incomes give a greater possibility to spend more on luxury goods than low incomes. They present some empirical evidence based on data provided from the United Nations Comparison Project (ICP). From their study of 27 countries they drew two main conclusions, stating inequality affects growth negatively. The reason given is that high income inequalities imply that less people can afford luxury goods, which therefore has a negative effect on growth. They also test the hypothesis that increasing the number of goods has a positive impact on productivity levels and reject it. Attanasio et al. (2000), using data from the World Bank, attempts to study Granger causality between the three relevant variables: growth, investment and savings. Granger causality studies how a variable (the one caused) correlates with the lagged values of the others. The most robust result is a negative relation from investments to growth.

Demand is modelled in the growth literature in such a way that goods are preferred in a proportional manner. An increase in consumer income proportionally affects the total consumption of each good. These are so-called homothetic preferences. As soon as this assumption is disregarded, demand plays a much more determinant role in growth models. One interesting result is presented by Echevarria (1997). She is working with non-homothetic preferences and sectoral change. She presents a general Solow model with three sectors, agriculture, manufacture and services. Each sector has a clifferent exogenous rate of technical change, therefore the productivities are different. Depending on the phase of development of the country, the sectoral composition moves from agricultural to service sector. Because preferences are not homothetic the composition of the demand affects the growth rate of the country. While she focused on differences in international growth rates, Kongsamut et al. (2001) in a similar theoretical work based on sectoral change, are able to reconcile Kaldor stylized facts with the massive reallocation of labour from agriculture and manufacture to the service sector. They show that a balanced growth path exists only under complex and restrictive knife-edge parameters of both technology and preferences. Similarly Felice and Bonatti (2004) present a model with two sectors: a stagnant service sector and a manufacturing sector with AK production function. Working with nonhomothetic preferences they analyse different patterns of demand for each sector. The role of demand, i.e. the proportion of expenditure devoted by individuals to the manufacturing and stagnant sectors, becomes crucial in determining whether the economy displays perpetual growth or stagnancy.

One of the possible reasons for reversing the causality from growth to savings is the presence of non-separable time preferences or, in other words, habit formation

\footnotetext{
${ }^{1}$ Even though in most growth models savings and total output normally move in the same direction, they study the variation of the saving function with respect to the growth rate. The sign of the first derivative of the saving function with respect to growth rate can be changed by the presence of habits.
} 
3.2. Demand and growth in the economic literature

processes. The idea was first presented by Duesenberry (1949). In his book he reflects that past consumption shapes today's preferences. The first formal studies of habit formation and growth come from Pollak (1970) and Ryder and Heal (1973). They focused their efforts on explaining the relations between past consumption and preference formation at the individual level. In Osborn (1988) we find some empirical evidence about the relevance of habit formation. He uses consumption data for durables in the UK. In an attempt to explain consumer behaviour, he rejects the hypothesis of the life cycle. He concludes that habit formation with seasonal adjustment is the best way to explain the consumer's patterns.

When working with preference formation the notion of conspicuous consumption plays a prominent point. Van de Stadt ct al. (1985) work with two forms of annual data about Dutch households. They incorporatc two ideas, the idea that habit formation is relevant and that individual consumption depends on the average consumption level of the society. As an approximation they find that the consumption level of the society explains $1 / 3$ of the consumption pattern, the remaining $2 / 3$ being explained by individual past habit formations. A microeconomic model that could explain this pattern was presented in section 2.4.5. One of their main conclusions is that habit formation is too important to be neglected in cross-sectional analysis. Some research has been done in this area on the important criteria when modelling non-separable time preferences. Three options are obscrved in the literature: a) inward-looking preferences, in which case the consumer is affected only by her own past consumption (habit formation), b) the consumer behaviour is determincd by society's consumption level (also called "catching up with the Joneses") or c) a mixture of the two. We shall focus for this review of paper only on the first and third options; the second one has a strong connection with conspicuous consumption literature and is therefore outside the scope of this chapter. Carroll et al. (1997) study two separate models: one concerned only with inward-looking habit formation, and the other based only on societal habit formation. They study how negative shocks to capital, savings and growth affect the transition to the steady state under the two assumptions about preference formation. They conclude that the decline in growth rate will be less if habit formation is cletermined by outward-looking preferences. Carroll et al. (2000) focus on the intensity of habit formation, comparing weak habits to strong ones. The higher the persistence of habits, the higher the impact on growth and on reversing the causality from growth to saving. The preceding two models are endogenous growth models with the simplest AK production function. Alvarez-Cuadrado et al. (2004), present a similar model but introduce a production function that presents decreasing returns to scale on capital. This is an interesting way of modelling preference evolution wherein habit formation is a geometric mean of individual past consumption and the consumption level of the society. They compare three cases: normal time-separable preferences, catching up with the Joneses and habit formation. Their findings concur with the rest of the literature, that non-time-separable preferences affect the dynamics of growth. When catching up with the Joneses, the differences in growth arise from a con- 


\section{Habit Formation, Demand and Growth}

sumption externality, in the case of inward-looking habit formation they arise from the fact that individuals smooth consumption. Alonso-Carrera et al. (2004) analyse a model with a standard neoclassical production function exhibiting constant returns to scale. The equilibrium exhibits transitional dynamics driven by both habit formation and decreasing returns on capital. They show that to see some effect of societal consumption level on growth, it has to affect habit formation dynamics. They find two main ways to treat this effect: either by modelling society's average consumption as a consequence of its past consumption level ${ }^{2}$ or by affecting the habit formation process of each individual.

In the previous paragraph consumption was taken at the individnal level; there was no distinction at product level. The role of new goods and their effects on growth was first studied by Grossman and Helpman (1991) in the third chapter of their book, as we have already commented in the introduction. They used the framework generated by Judd (1985), which was a study of patent length versus the number of goods. In their model using Dixit and Stiglitz (1977) monopolistic competition, they determined the optimal number of different goods for a society. Two opposing driving forces permit equilibrium. On the one hand consumers love variety, on the other hand firms face monopolistic competition, so the higher the number of new goods, the lower individual profits become.

However in their model goods are different but symmetric. Engel's laws provide one method of removing the symmetry so as to understand the importance of having different products. New products are assumed to be more expensive, therefore when they are introduced only higher-income consumers can afford them. If these new products are a source of growth, a more unequal distribution of incomes has a negative effect on growth. Goods follow a hierarchy from basic needs to luxury goods. Zweimuller (2000) set up a theoretical model collecting some of these concepts. In a framework similar to Grossman and Helpman (1991), consumers differ in their initial assets. Goods are demanded hierarchically, with new goods showing higher income elasticity. He shows that inequality affects growth because it discourages innovation. If relatively few consumers have high income, then demand for the new good is expected to be low, and so innovators are discouraged because they can not get back the sunk costs of innovation. Foellmi and Zweimuller (2002) present in a similar framework a model in which Kaldor facts and sectoral production and employment changes are reconciled. Goods are preferred in a hierarchical way; as the economy grows there is a shift of labour from necessities to luxury goods. In equilibrium the industries taking on more labour coexist with those shedding it; nonetheless macroeconomic aggregates grow at a constant rate. Foellmi and Zweimuller (2004) analysing the monopolistic competition model, come to the conclusion that, if preferences are not homothetic, then income distribution will always affect growth through markups and diversity of goods.

\footnotetext{
${ }^{2}$ In a way this is habit formation for the entire society. The whole society is treated as a single individual.
} 
A different argument is presented by Aoki and Yoshikawa (2002). They reflect that in neoclassical growth theories the main constraint is diminishing returns on capital and add the argument that demand saturation is also determinant. Each good presents an S-shaped diffusion process at different states; they conclude that demand saturation constrains steady state growth. Greenwood and Uysal (2004) introduce the argument of demand on new goods in a sectoral change model. They present three sectors: agriculture, a capital-producing sector and a "new goods" sector, each growing at a different exogenous rate. They conclude that as the economy grows and incomes rise consumers demand new goods because of a love of variety. A negative consequence of this effect is that the relevance of the agriculture sectors always decreases. Benhabib and Bisin (2000) present an intcresting point: the interaction of monopoly power with marketing strategies can create negative welfare effects. Also, following a Grossman and Helpman (1991) framework, firms do marketing. Marketing expenditure affects preference formation through income elasticities. They present different ways in which preferences are affected by marketing strategies. They studied how the Dixit and Stiglitz (1977) monopolistic competence could be affected by marketing power. Similarly, Ravn et al. (2006) focused on the effect of habit formation on different products; they called it the "Deep Habit" formation process. They argue that in a habit formation framework firms may adjust their pricing strategies to habits, so giving rise to the countercyclical mark-up process empirically evidenced.

The main difference in our model from the rest of the literature is the approach toward technical change. In our model there is a flow of innovations, each innovation being superior to the previous one in its capacity to satisfy the consumer. Technical change for us means only product innovation; process innovation does not exist so production coefficients are always constant. In this way it differs from models dealing with sectoral change (Kongsamut et al. (2001); Echevarria (1997); Felice and Bonatti (2004); Greenwood and Uysal (2004)). In these models it is always assumed that sectors differ in the intensity with which technology affects production coefficients. We study the presence of habit formation at the product level, thus differing from Carroll et al. (1997, 2000); Alvarez-Cuadrado et al. (2004); Alonso-Carrera et al. (2004), who treat consumption at aggregate level. The flow of innovations is such that all goods are basic necessities (income elasticity is always positive and equal to one), so modelling innovation to generate needs not luxury goods (in opposition to Zweimuller (2000); Foellmi and Zweimuller $(2002,2004)$ ). We have no saturation level for any of the goods; in this we differ from Aoki and Yoshikawa (2002). Despite the fact that marketing has an important role in the introduction of innovations, the success of the innovation depends on its own capacity to satisfy the consumer; we do not allow firms to affect preferences through marketing investments. In this aspect our work differs from Benhabib and Bisin (2000). Ravn ct al. (2006) study habit formation in conditions where decisions are maximized by both consurners and firms. We have simplified their framework to assume that neither firms nor consumers have the capacity to do this. Ravn et al. also considered that habits are under conscious control but 


\section{Habit Formation, Demand and Growth}

our assumption is that habits develop at the subconscious level as was explained in Chapter 2. Our main motivation is to prove that, in a model excluding process innovation but in which habits are considered, product innovation can increase the marginal propensity to consume in the economy.

\subsection{The engine of growth: an infinite number of needs}

To introduce the motivation of the chapter, let us start by quoting Galbraith (1958) and his formulation of dependence effect:

"As the society becomes increasingly affluent, wants are increasingly created by the process by which they are satisfied. Increases in consumption, the counterpart of increases in production, act by suggestion or emulation to create wants."

"The Affluent Society" p.135

Although Galbraith was talking about economic change in general, we would like to apply his thoughts to technological change in particular. We shall arguc that nowadays, when technology plays such a prominent role in advanced societies, a part of technological change is concentrated on the generation of new needs. In this chapter we present a model in which modern societies are able to grow by creation of new wants.

In models such as that presented by Zweimuller (2000), Focllmi and Zweimuller $(2002,2004)$ the main argument is that new products are always luxury goods and only part of the society can afford them. Our view of the process is slightly different in the sense that we believe the real impact of an innovation occurs when it becomes a necessity for the whole society. Therefore in our model an innovation is considered to be such only if it is a necessity for the whole population. The products considered here will be neither luxury nor basic goods; the income elasticity for all the goods considered will be strictly positive and equal to one. We feel product innovation has its biggest impact on society when innovations are used and needed by the majority of the population.

The main motivation is our belief that technological change is generating habits in our lives and that, if we study from a historical point of view the life of a representative consumer in a developed country over the last hundred years, we observe that the number of things bought has increased over the years. Beforc going into the details of model let me present some examples in which we can see needs being generated. The phenomenon is not a rapid process, but a very slow and subtle one and therefore hard to recognize. We would like to reflect on one example comparing intergenerational consumption patterns. 
3.3. The engine of growth: an infinite number of needs

In this comparison we highlight one process: how an innovation becomes a necessity. We are not talking of Engel's laws, by which an increase in income produces a greater increase in luxury goods (the relationship of this state of affairs and growth has been analysed by Falkinger and Zweimuller (1997); Foellmi and Zweimuller $(2002,2004)$ ). We focus on the fact that what was a luxury innovation for our grandparents is for us a need. Your grandmother as a child probably considered a refrigerator to be a luxury. Nowadays it is a necessity found in the majority of homes. Now supposing we ask if you need a new gadget, which uses biotechnology and could make your life easier, your answer could be yes or no. But if we ask whether you could live without this gadget, the answer will be affirmative. If we went back in time to when the refrigerator was invented and asked our grandparents whether they could live without a refrigerator, the answer would also be affirmative. Nowadays the majority of people would reply to the same question in the negative. But why this change in the answer within two generations? Habit formation. We are so accustomed to refrigerators that we can no longer live without them. What was a luxury innovation for our grandparents has become a need for the world.

The refrigerator is just one example of many other goods and services that are constantly becoming considered more necessary and less luxurious. This evolution is the effect of technical change when it is observed from the demand side: an increase in goods and services that are being used by people. Nobody would argue that a refrigerator is a basic human need such as food or shelter. In this sense the refrigerator is not essential for human life. If a developed society by some means reached a crisis in which refrigerators could no longer be bought, the general utility of such a society would decrease but it would not directly effect the survival of the society. The new situation of the society will be considered as underdeveloped when compared with the earlier one because we associate economic development with more and more things being available to consumers. As time passes and economic development continues, some of these goods become standard needs for people. Thus in the absence of crises economic evolution implies an increase in consumer habits, which in turn implies an increase in the general utility of the society. During this process the things being needed and produced increase in value and so the wealth of the economy is constantly being raised.

Innovations are classified in the technical change literature as incremental or radical. Radical innovations are ones that change the entire production process, while incremental ones make only minor changes within a technological paradigm. This classification shows the supply-side bias of the technical change literature. We would argue that a radical innovation is one that in the long run can become a habit for a large proportion of the population. An incremental one would be important for a smaller proportion or for a short period of time. In this chapter we will mainly focus on this type of radical innovations.

Considering the flow of innovations, each innovation is superior to the previous one as it has a higher capacity to generate consumer utility. This will allow monopolies to earn higher profits on the latest innovations. Profits will be related 
to earlier ones in a constant fixed relation. In the real world, innovations with higher capacity to increase utility arrive in a haphazard way. In the model we have assumed that they arrive in order so as to derive an analytical solution. A less orderly manner could be studied using individual-based simulations, however this is left for further research.

Our model fits into the endogenous growth literature, which has been strongly criticized as being unrcalistic. Jones $(1995 a, b)$, working with some empirically criticized R\&D-driven models, argucs that population is growing in most countries of the world and that some models under these circumstances produce explosive growth. His criticism could also be applicable to the model we present, however our concern is not to produce a realistic description of the world but to model a phenomenon which has not been studied by many people. Theorctical modelling is used to prove that under some assumptions an increase in the needs of the population, coming through technical change, generates growth. The population is always willing to buy more; the means by which this happens will be explained in the next sections. However we emphasise that $R \& D$ is aimed at new goods, not to develop new production processes.

With no process innovation and a constant amount of inputs, the total produced amount in equilibrium will always be the same. The source of growth comes from introducing new varieties with increasing utility. Domand, because it reaches higher utility values will be willing to pay more. Therefore even though the total produced amount is constant in equilibria, the value of the production keeps on rising. To clarify this point we first give an example of how this happens and then see how it differs from normal inflation. Imagine a country where all chairs are painted in a single colour, either red or white. The price of each chair is one unit. A designer imagines red and white striped chairs. She patents the idea, produces the good, and decides to sell the new striped model at the price of two units. The cost of the input is the same. For every unit she is able to sell there will be an increase in the value of the sector's sales. A new idea, in this case a new manner of painting chairs, has generated a new good for which some consumers are prepared to pay a higher price. The value given by demand is higher thereby generating growth. This is how growth occurs; there is an increase in added value but not in the quantity produced, which remains constant. In our model the variety of the goods is constantly increasing, each of them with a stronger habit; and it is this that produces the price rise and increased value of the production - a combination of the consumer "love of varicty" and a "superior utility" of each new variety.

One could argue that this is just inflation, but in the model we are introducing unrelated new goods. Inflation is defined as the increase in prices of a constant basket of goods. In our model the basket of goods will be changing so the rising prices cannot be described as inflation. The model's higher prices are a result of the overall rise in the level of society's utility. Therefore we have an increase in the total nominal value and an increase in individuals' well-being. 
3.4. The mathematical model

\subsection{The mathematical model}

In this section we present a model to show it is possible to have growth both in the utility function and in the nominal value of the production even with constant inputs and without cost reductions. Growth comes through the introduction of goods that are increasingly sought after by the population. People are willing to pay more for the latest innovations since they know they will experience higher utility. As well as the number of goods and the total added value produced by the economy, the utility experienced by the population always grows. First we shall briefly introduce all the different parts of the model, then describe in more detail the decisions taken by agents in each step before ending with the general equilibrium.

Technological change is represented in this model by product innovation; the arrival of a new innovation will determine a new period. There are two types of agent: individuals, who maximize utility, and firms, which produce in two sectors: final goods and R\&D. The distribution of people between these two sectors will be an exogenous decision taken by the economy; in both sectors it will be held constant. The amount of labour devoted to R\&D will determine how much of a habit (increase in the utility) each new good becomes.

\section{- Individuals}

- Individuals maximize their utility function deciding on:

* How much of each product to consume $\left(x_{1}, x_{2} \ldots\right)$,

* How much to save $\left(s_{t}\right)$.

- Each individual inelastically supplies one unit of labour every period.

- Firms

Using labour as the only input will work on two sectors:

- A production sector of final goods,

- An R\&D sector producing blueprints.

These agents interact in four different markets:

- A final goods market where each product is sold at price $p_{i t}$.

- A blueprint market.

- A labour market with a homogeneous price $w_{t}$.

- An equity market that is regulated by the interest rate $r_{t}$

We now present the decisions that are made by each of these agents in each market in the short rum. Later we shall give a definition of the long run equilibrium. 


\subsubsection{Time and the arrival of new products}

The arrival of innovations is a deterministic process. The arrival of a new innovation defines the beginning of a new period; only one innovation is possible per period. The method of modelling technological change is similar to that of Aghion and Howitt (1992), but has no uncertainty and is applied to product innovation rather than process innovation.

In the previous chapter it has been extensively discussed how people develop laabits. We mentioned several options and several possible outcomes (see chapter 2 ). Once an innovation appears there is an adjustment time which allows consumers to decide on an optimal quantity to buy based on priccs and habits. As was explained, this is a long process. In the previous chapter it was also shown that sooner or later the consumer will reach a stable solution if no external shocks appear.

Figure 3.1 defines two terms which we shall use later when introducing further assumptions. A 'period' begins when an innovation arrives. The time span from this arrival to the arrival of the next innovation we shall define as the time "between periods". Immediatcly after the new innovation has arrived up to the moment at which the next one appears we shall designate as time "within a period". As an analogy we can imagine now innovations arrive at the start of each year (between periods) although the consumer makes decisions on a daily base (within a period). The decisions taken by the consumer during 'within the period', assuming a large number of (possibly daily) subperiods, will assurc us that the consumer has developed habits for existing goods and that she knows exactly how to distributc her income among the existing goods. The proportions at the end of the time within the period will be constant for each existing good. Thus at the end of the year, due to daily decisions, the consumer will have stabilised the distribution of her income, and be buying a constant proportion of each good, although different for each of them. It is important to grasp the distinct meaning of these designations of 'between periods' and 'within a period'.

The previously stable equilibrium of allocation of resources will be broken by the arrival of the next innovation. In this model we concentrate only on these shocks. In effect we shall be working with a flow of interrelated innovations. New innovations need time to be brought to market, during which the consumer will have repeatedly bouglt the good (each purchase ending a subperiod) and gradually developed this consumption into a habit. Every time a new innovation arrives the consumer will be in equilibrium, so that we can use the solution presented in the previous chapter (Equation 2.18).

Products differ in their capacity to generate experienced utility in the consumer. The term $c_{i}$ is the intrinsic capacity that the good has to produce experienced utility. In this model innovation is defined as the arrival of a new good which has higher $c_{i+1}$ than all the previous $c_{i}$ s present in the market. The procedure is similar to that of Aghion and Howitt (1992). According to them the arrival of a new innovation contributes in a fixed proportion to production cost 


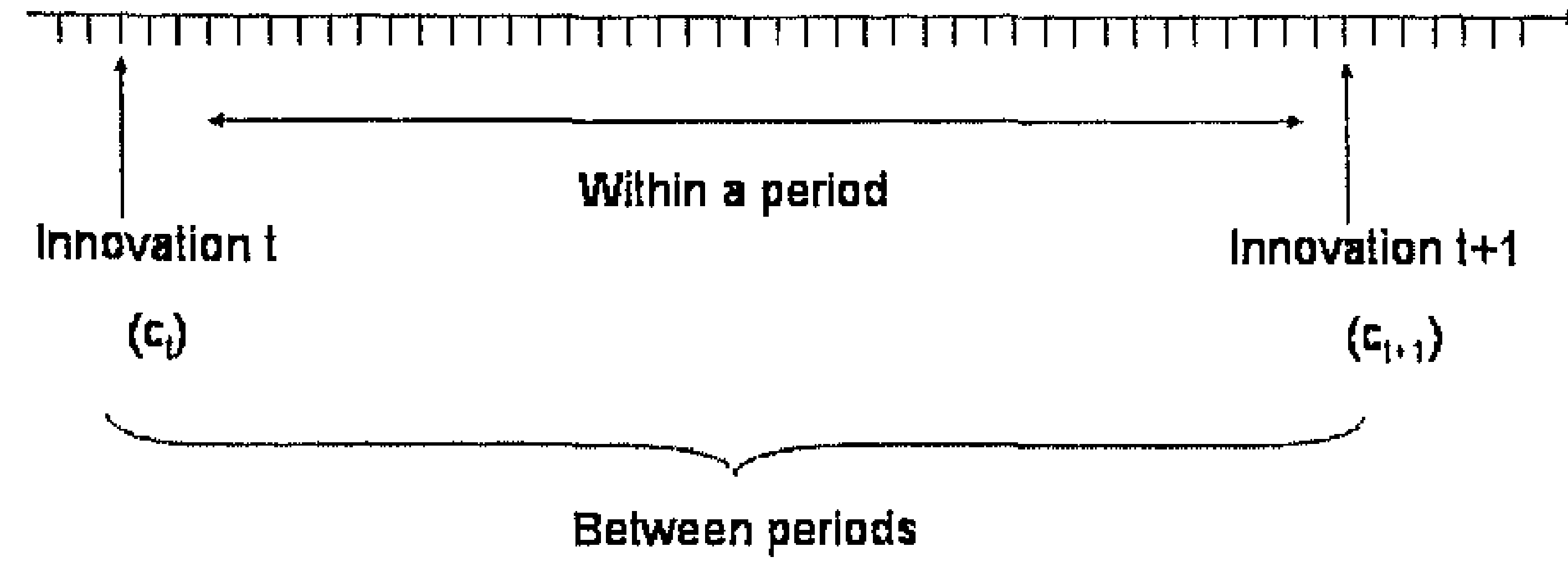

Figure 3.1: Time evolution between and within periods

reduction. In our case it will increase the capacity of the now good to be needed by the population. Our model also differs from theirs in that innovations arrive with certainty. There is a relation between the last $c_{i}$ and $c_{i+1}$; every time an innovation arrives it will happen such that:

$$
\frac{1}{c_{i+1}-1}=\gamma \frac{1}{c_{i}-1} \quad \text { with } \quad \gamma>1 \text { and } c_{i}<1 i=1,2,3 \ldots
$$

This is also the definition of technological change in this model. Solving for $c_{i+1}$ we have:

$$
c_{i+1}=\frac{\gamma+c_{i}-1}{\gamma}
$$

$\gamma$ in this model is not a parameter but variable ${ }^{3}$ defining the relation between the last innovation and the previous one. Is defining the jump in the utility and it is related to the total labour devoted to R\&D. The solution of the system, will prove that this variable is always in equilibrium larger than one. And if $\gamma>1$ then:

$$
\lim _{i \rightarrow \infty} c_{i+1}=1
$$

\footnotetext{
${ }^{3}$ For simplicity we will assume that in principle the system is in equilibrium, i.e. there is a constant distribution of labour between our two sectors. If the system is outside the equilibrium, in each period until the equilibrium is reached we will have a different $\gamma$. This case will bo analysed after the equilibrium is defined in subsection 3.5.1. We will afterwards study this case allowing for different $\gamma \mathrm{s}$. That will be section. This is done for simplicity of the algebra.
} 


\section{Habit Formation, Demand and Growth}

The arrival of new innovations is a deterministic process. In every time step we have a new innovation. The contribution of the latest innovation compared to the previous one is known, because it is known the amount of labour devoted to R\&D in the manner discussed in subsection 3.4.3. All members of society know that innovations are going to arrive so this will affect their savings decisions.

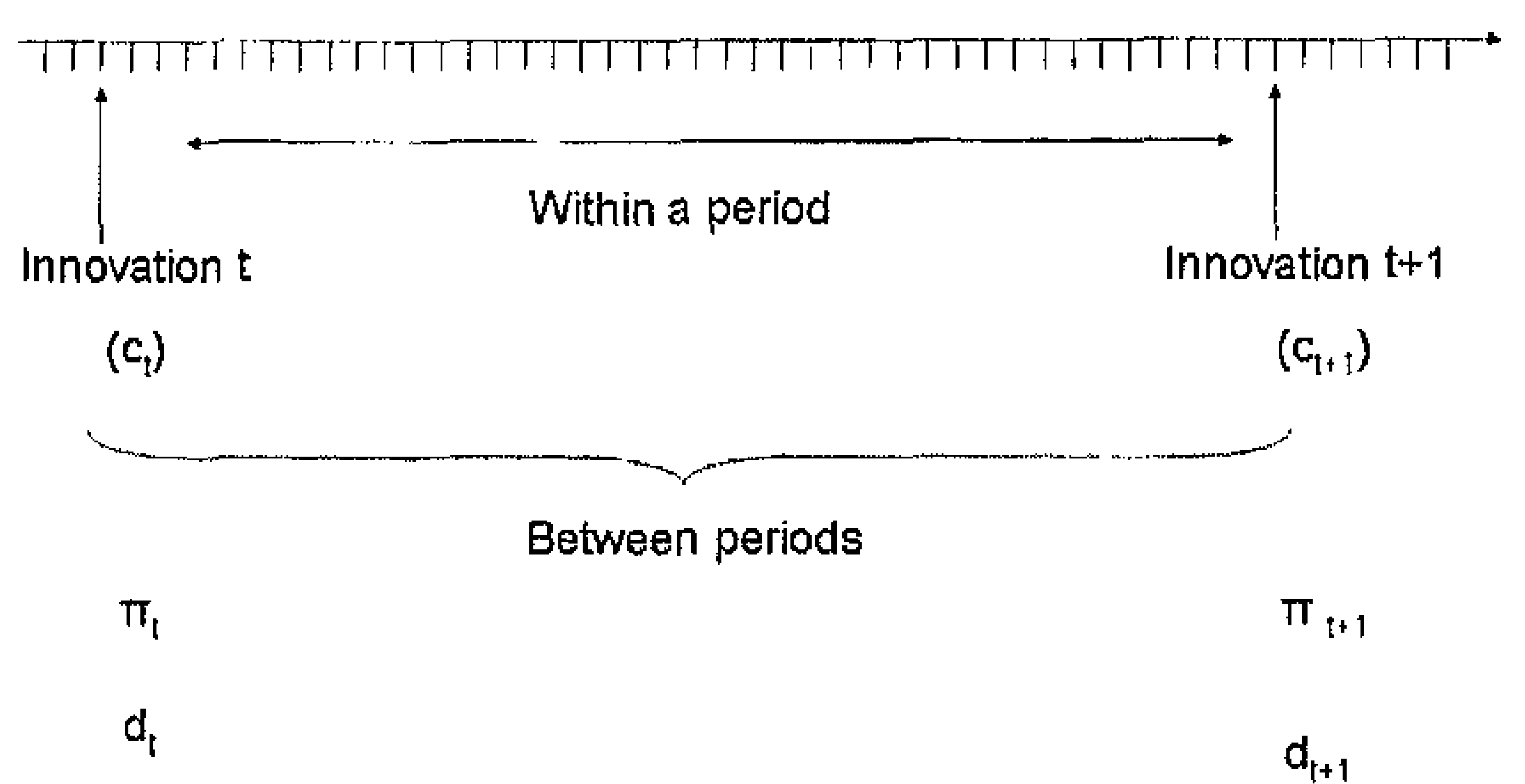

Figure 3.2: Arrival of innovations

Figure 3.2 depicts the events happening in every time step. As soon as the patent is sold the monopolist starts producing the new good.

\subsubsection{Individuals}

Modelling time and the arrival of innovations in the manner presented in the previous section, and assuming individuals only choose present quantities, i.e. they do not have control over their habit formation, we can assume intertemporal separability of lifetime utility between periods and apply two stage budgeting. In the first stage we will derive a solution within the period where the budget is constant, and in the second we will treat the dynamic problem of optimal allocation of lifetime expenditure between time periods.

\footnotetext{
${ }^{4}$ From section 2.5, wo know that the consumer needs some time to develop habits. We also know that the novelty associated with that good has to rise in order for the consumer to buy the first unit. Therefore we will assume that, even though the good is produced, in the first period it will produce no profits because all bencfits will be used, in the form of marketing expenditure, to raise its novelty. The concept is as follows: the R\&D sector comes up with an idea and also markets the product to raise the novelty value to the required minimum level. They will sell the product to generate some profits. To keep things as simple as possible we will assume that the total profit after paying for marketing expenditures is zero. When they start getting monopoly income the product's patent will be bought by a final goods firm and from this time on it is the final goods firm which earns monopoly income.
} 
3.4. The mathematical model

We could allow individuals to have control over their habit parameter and maximize according to it. This procedure has been taken by Ravn et al. (2006). However the problem does not have any analytical solution in such a situation; it is solved by computer simulation. For the sake of simplicity and clarity we assume that individuals know the evolution of technology even though we allow them no control over the habit formation process. The notion is that an individual's decision to buy is based on past experience but in this decision they do not takc into consideration that the present choice will affect their future preferenccs. In this sense the individual is myopic. However, individuals adjust their savings because they know the flow of innovations will provide superior products in the future.

The separability assumption is also used by (Grossman and Helpman, 1991, Chapter 3), and Foellmi and Zweimuller (2004). They work with a static demand, the situation that we shall arrive at since we impose a sufficiently large number of within subperiods to allow us to include the same assumptions.

For simplicity and without lost of generality, it is assumed that the population is constant and that each individual represents an adult working momber of the current generation. Thus there is a fixed and large number (normalized to be one) of identical adults who take into account the welfare and resources of their actual and prospective clescendants. Indeed, following Barro and Sala-i Martin (1995), this intergenerational interaction is modelled by imagining that the current generation maximizes utility and incorporates a budget constraint over an infinite future. That is, although individuals have finite lives, the model considers immortal extended families ("dynasties"). We do not allow individuals to engage in Ponzi games. In the first step individuals reach the within periods solution; in the second step they maximize intertemporal utility.

Step 1 The problem for the representative agent within the period is:

$$
\begin{aligned}
\underset{x_{i \tau}}{\operatorname{Max}} & \left(\sum_{\mathrm{i}=1}^{\mathrm{t}}\left(x_{i \tau}-c_{i} x_{i \tau-1}\right)^{\alpha}\right)^{1 / \alpha} \\
\text { s.t } & \sum_{\mathrm{i}=1}^{\mathrm{t}} x_{i \tau} p_{i \tau}=E_{l}
\end{aligned}
$$

The individual can only choose her actual consumption, how much of each good she wants according to the price, such that $x_{i \tau}$ is the quantity of the good $i$ in the subperiod $\tau$. The consumer is too small to influence the price; she is a price taker. Within the periods the budget is constant. The end of the sum is t, because the number of varieties present in each within period is t. Only between periods will budgets change; this will be explained later. The consumer decides on the actual quantity she wants to have for this period. She is myopic in the sense that she does not maximize controlling for the effect that the present consumption 


\section{Habit Formation, Demand and Growth}

might have in the future ${ }^{5}$. This assumption is made, as previously explained, to be able to find an analytical solution avoiding simulations. For the changes in time between periods the letter $t$ is used and for changes within periods we use $\tau$. We sum across goods because in each innovation lifespan interval the number of goods is equal to $t$.

For the solution in the long-term of the within period, $\tau$ tends to $t:^{6}$

$$
x_{i t}^{*}=\frac{\frac{p_{i t}^{\xi}}{\left(1-c_{i}\right)}}{\sum_{\mathrm{j}=1}^{\mathrm{t}} \frac{p_{j t}^{\xi+1}}{\left(1-c_{\jmath}\right)}} E_{t}
$$

with $\xi=\frac{1}{\alpha-1}$ and $0<\alpha<1$, accounting for the elasticity of substitution between the individual's past experienced utility consuming good $i, c_{i} x_{i \tau-1}$. and her present desired consumption level.

The solution within periods could be written as follows, knowing how parameter $\gamma$ determines the relation in the flow of innovations and that equation 3.1 defines how one innovation relates to the previous one:

$$
x_{i t}^{*}=\frac{\gamma^{i-1} p_{i t}^{\xi}}{\sum_{\mathrm{j}=1}^{\mathrm{t}} \gamma^{j-1} p_{j t}^{\xi+1}} E_{t}
$$

The income elasticity within the period is equal to?

$$
\varepsilon_{E t}=\frac{d x_{i t}}{d E_{t}} \frac{E_{t}}{x_{i t}}=1
$$

Step 2 The individual faces the following intertemporal maximization or maximization between time steps:

$$
\max \sum_{t=1}^{\infty} \beta^{t} U_{t}
$$

The parameter $\beta$ controls the discounting of utility over time, taking values between zero and one. The closer it gets to zero, the less the individual values future consumption. By assumption new innovations only arrive when the consumer is already in equilibrium within the period and, taking into consideration

\footnotetext{
${ }^{5}$ In mathematical terms she is maximizing her utility according to $x_{i \tau}$, she has no control in $\tau$ over $x_{i \tau-1}$

${ }^{6}$ This is a similar solution to that obtained in the previous chapter presented by equation number 2.18

7$$
\varepsilon_{E t}=\frac{d x_{i t}}{d E_{t}} \frac{E_{t}}{x_{i t}}=\frac{\gamma^{i-1} p_{i t}^{\xi}}{\sum_{\mathrm{j}=1}^{\mathrm{t}} \gamma^{j-1} p_{j t}^{\xi+1}} \frac{E_{t}}{\frac{\gamma^{i-1} p_{i t}^{\xi}}{\sum_{\mathrm{j}=1}^{\mathrm{t}} \gamma^{j-1} p_{j t}^{\xi+1}} E_{t}}=1
$$ 
the evolution of technology presented by equation 3.1, the maximization can be rewritten in the following way:

$$
\begin{aligned}
\max _{\substack{\left(x_{1 t} \ldots \ldots x_{t t}\right) \\
s_{t}}} & \sum_{t=1}^{\infty} \beta^{t}\left(\left(1-c_{1}\right)\left(\sum_{i=1}^{t} \gamma^{(i-1) \alpha} x_{i t}^{\alpha}\right)\right)^{1 / \alpha} \\
\text { s.t. } & \sum_{i=1}^{t} x_{i t} p_{i t}+s_{t}=d_{t}+\Pi_{t}+w_{t} \\
& d_{t+1}=\left(1+r_{t}\right) s_{t} \\
& \lim _{t \rightarrow \infty} \lambda_{t} d_{t}=0
\end{aligned}
$$

where $\sum_{\mathrm{i}=1}^{\mathrm{t}} x_{i t} p_{i t}$ is the individual's total expenditure in time $\mathrm{t}$ and $s_{t}$ the amount she wants to save in the same period. This decision is taken at the beginning of each period of time, with expenditures and savings being readjusted each new period. Individual savings of assets $d_{t}$ are in the form of ownership of firms or loans. Negative loans represent debts. Households can lend or borrow from other households but in equilibrium the net loans of a representative consumer will be zero. Because both forms of assets, shares and loans, are assumed to be perfect substitutes as stores of value they must pay the same real rate of return $r_{t}$. As income at the beginning of the period, an individual has the value of their assets $d_{t}$, the salary $w_{t}$ and the redistribution of profits in form of dividends $\Pi_{t}$. The level of savings in this period is determined, depending on $r_{t}$, by the amount of assets they wish to hold at the beginning of the next period $d_{t+1}$.

Using the definition of the indirect utility function we arrive to the following general Euler rule (see appendix C.1.2):

$$
\frac{\left(\sum_{i=1}^{t+1}\left(\frac{\gamma^{i-1} p_{i t}^{\xi}}{\sum_{i=1}^{t+1} \gamma^{i-1} p_{i t}^{\xi+1}}\right)^{\alpha}\right)^{1 / \alpha}}{\left(\sum_{i=1}^{t}\left(\frac{\gamma^{i-1} p_{i t}^{\xi}}{\sum_{i=1}^{t} \gamma^{i-1} p_{i t}^{\xi+1}}\right)^{\alpha}\right)^{1 / \alpha}}=\frac{1}{\left(1+r_{t}\right) \beta}
$$

This equation explains how the consumer decides to allocate resources over time. Consumers choose quantities but, because we have used the indirect utility function, the solution's quantities are written in terms of prices. Prices are determined by firms; this is discussed in the next subsection. The first fraction relates the consumption of next year to that of this year. The increase or decrease depends on the interest rate and on the $\beta$ parameter. Changes on these parameters will affect to the selected quantity of each good in each period. If the interest rate rises consumers will prefer to save more for the future. The discount rate for 


\section{Habit Formation, Demand and Growth}

future consumption is represented in our model by the parameter $\beta$; as it increases future consumption will have a greater weight in the present decision and present consumption will decrease.

We choose the numeraire in such a way that expenditure on the first good is always equal to one in each period,

$$
p_{1 t} x_{1 t}=1 \forall t .
$$

Making use of the solution 3.7 and the solution of prices from the next section, the Euler rule can be expressed as ${ }^{8}$ :

$$
\left(\frac{1+\gamma^{\alpha}+\ldots+\gamma^{\alpha(t)}}{1+\gamma^{\alpha}+\ldots+\gamma^{\alpha(t-1)}}\right)^{1 / \alpha} \frac{E_{t}}{E_{t+1}} \frac{p_{t}}{p_{t+1}}=\frac{1}{\left(1+r_{t}\right) \beta}
$$

\subsubsection{The production side of the economy}

Two diffcrent sectors interact in the economy, one sector producing final goods in a monopolistic competence market and another sector producing blueprints.

\section{Firms producing final goods}

Each final goods firm produces a different good using as input both labour and a blueprint for a product design. This latter has been bought from the R\&D sector, which has patented the rights to this innovation. Product designs are assumed to be proprietary information either because their details can be kept secret or because patents effectively deter unauthorised use. The production firm starts exploiting monopoly rights and earning monopoly profits in the period in which they buy the patent.

Each known variety is produced by a different single atomistic firm. This assumption can be justified in one of two ways. First, the government may grant long-term patents to the original inventors of innovative products. Alternatively, we may suppose that imitation is costly and that firms engage in ex-post price competition. In this case, no entrepreneur would ever invest resources to copy a brand that is already available on the market. A copier would earn zero profits in Bertrand competition with the original innovator and so would be unable to recoup a positive cost of imitation.

Each individual firm behaves as a monopolist in imperfectly competitive markets. Latecomers, because they buy a better brand, will derive higher profits. By assumption firms have no control over habit formations. Each firm maximizes its profit in each period; the optimal solution is for the firm to charge monopoly prices. Firms are sufficiently small so as not to influence other firms' prices. (The subsection on behaviour of firms parallels that presente by (Grossman and Helpman, 1991, Chapter 3, p.49-52)). We assume that all products are manufactured subject to a common constant returns to scale technology.

\footnotetext{
${ }^{8}$ For technical notes dealing with the mathematical steps see appendix C.1.2
} 
The production function of the firm is:

$$
x_{i t}=a L_{i t}
$$

All firms have the same production technology, which remains constant in all periods and is equal to $a$. This parameter accounts for the marginal cost of production of each unit of good. It is assumed that the parameter accounts for paying back the entrepreneur in some way. Each unit of labour $L_{i t}$ is paid at the wage rate $w_{t}$.

Assuming that firms maximize profits in the framework of monopolistic competition, we can define a firm's profit as:

$$
\pi_{i t}=p_{i t} x_{i t}-\frac{w_{t}}{a} x_{i t}
$$

With the solution of the static utility for the prices (see Appendix C.1.1) and the solution obtained by equation C.14 we arrive at: ${ }^{9}$

$$
\pi_{i t}=\frac{\gamma^{(i-1)(\alpha-1)} x_{i t}^{\alpha-1}}{\sum_{j=1}^{\mathrm{t}} \gamma^{(j-1)(\alpha-1)} x_{j t}^{\alpha}} x_{i t} E_{t}-\frac{w_{t}}{a} x_{i t}
$$

or

$$
\pi_{i t}=\frac{\gamma^{(i-1)(\alpha-1)} x_{i t}^{\alpha}}{\sum_{j=1}^{\mathrm{t}} \gamma^{(j-1)(\alpha-1)} x_{j t}^{\alpha}} E_{t}-\frac{w_{t}}{a} x_{i t}
$$

We will assume that the number of firms is big enough for a decision taken by one firm to have no influence on any other firm ${ }^{10}$. Calculating the derivative with respect to the quantity we find:

$$
\frac{\partial}{\partial x_{i t}} \pi_{i t}=\alpha \frac{\gamma^{(i-1)(\alpha-1)} x_{i t}^{\alpha-1}}{\sum_{j=1}^{\mathrm{t}} \gamma^{(j-1)(\alpha-1)} x_{j t}^{\alpha}} E_{t}-\frac{w_{t}}{a}=0
$$

Taking into account the definition of the prices given by equation C.14 and

\footnotetext{
${ }^{9}$ In subsection 3.4 .2 we have done exactly the same but the solution was presented as the resultant quantity in function of the prices. For the convenience of the algebra we express prices in function of the quantities consumed. To arrive at this solution see Appendix C.1.1

$$
p_{i t}=\frac{\gamma^{(i-1)(\alpha-1)} x_{i t}^{(\chi-1}}{\sum_{j=1}^{\mathrm{t}} \gamma^{(j-1)(\alpha-1)} x_{j t}^{\alpha}} E_{t}
$$

${ }^{10}$ We assume that the economy starts from a situation in which there is one theoretical single good $x_{11}$. This good represents a set of goods all with equal habit formation parameter $c_{1}$. In this sense we start from a stable solution similar to the final solution presented by (Grossman and Helpman, 1991, p. 43-54). In their model they increase variety but all goods are symmetric, a stable solution in which no economic growth is discussed. Our initial good, $x_{11}$, may be thought of as their resultant set of goods.
} 


\section{Habit Formation, Demand and Growth}

solving for $p_{i t}$ we have:

$$
p_{i t}=\frac{w_{t}}{a \alpha}
$$

Using the Amaroso-Robinson condition that prices are markups of costs:

$$
\pi_{i t}=\frac{w_{l}}{a}\left(\frac{1-\alpha}{\alpha}\right) x_{i t}
$$

An important conclusion is that prices arc independent of the quantitics wh and also independent of the $\gamma$ parameter. Prices will be equal for all goods imm! they increase at the same rate as wages. However, profits are dependent on the " lit rametcr $\gamma$ through $x_{i t}$ which changes with time, meaning with each new innovit in arrival.

$$
\pi_{i t}=w_{t}\left(\frac{1-\alpha}{\alpha}\right) L_{i t}
$$

Now we can study the distribution of labour among final goods firms.

Using the solution presented by Eq 3.7 we can study the relation betwint quantities $x_{1 t}^{*}$ and $x_{2 t}^{*}$, where the stars stand for the long-term solution of the within period:

$$
\begin{aligned}
& x_{1 t}^{*}=\frac{p_{1 t}^{\xi}}{\sum_{i} \gamma^{(i-1)} p_{i t}^{\xi+1}} E_{t} \\
& x_{2 t}^{*}=\frac{\gamma p_{2 t}^{\xi}}{\sum_{i} \gamma^{(i-1)} p_{i t}^{\xi+1}} E
\end{aligned}
$$

Since prices are equal for all goods (solution 3.16) in each period:

$$
\begin{array}{r}
x_{1 t}^{*}=\frac{p_{t}^{\xi}}{\sum_{i} \gamma^{(i-1)} p_{t}^{\xi+1}} E_{t} \\
x_{2 t}^{*}=\frac{\gamma p_{t}^{\xi}}{\sum_{i} \gamma^{(i-1)} p_{t}^{\xi+1}} E_{t} \\
x_{2 l}^{*}=\gamma x_{1 t}^{*}
\end{array}
$$

Having a single linear production function (equation 3.14), similar for all fituil good sectors, and knowing the relation between the quantities produced in carts. interval given by solution 3.7, we can arrive at the distribution of labour arrmim final goods: 


$$
\begin{aligned}
x_{1 t}^{*} & =a L_{1 t} \\
x_{2 t}^{*} & =a L_{2 t}=\gamma a L_{1 t} \\
x_{3 t}^{*} & =a L_{3 t}=\gamma^{2} a L_{1 t} \\
\cdots & \\
x_{i t}^{*} & =a L_{i t}=\gamma^{(i-1)} a L_{1 t} \\
L_{F G t} & =\sum_{i} L_{i t}
\end{aligned}
$$

And the distribution of labour for each sector will be:

$$
L_{i t}=\frac{\gamma^{i-1}}{\sum_{i=1}^{t} \gamma^{i-1}} L_{\text {Final Goods }}
$$

where $L_{F i n a l}$ Goods or $L_{F G}$ will be the total amount of labour devoted by the economy to the production of final goods. We will assume that the system is in equilibrium first, therefore we know how many workers are devoted to final production and how many to $R \& D$ is a constant proportion. When referring to individual goods, in each period therc will be a different amount of labour and the time subscript is needed. Taking as an example the amount of labour employed by the good 2 in the periods $t=3$ and $t=4$ :

$$
\begin{aligned}
& L_{23}=\frac{\gamma}{1+\gamma+\gamma^{2}} L_{\text {Final Goods }} \\
& L_{24}=\frac{\gamma}{1+\gamma+\gamma^{2}+\gamma^{3}} L_{\text {Final Goods }}
\end{aligned}
$$

The individual firm's profit will be equal to:

$$
\pi_{i t}=w_{t}\left(\frac{1-\alpha}{\alpha}\right) \frac{\gamma^{i-1}}{\sum_{i=1}^{t} \gamma^{i-1}} L_{\text {Final Goods }}
$$

and the total profits in the economy:

$$
\Pi_{t}=w_{t}\left(\frac{1-\alpha}{\alpha}\right) L_{\text {Final Goods }}
$$

It is interesting to study the relation between quantities produced and profits as time evolves.

Table 3.1 attempts to describe what is happening in this economy. In the first period there is one single good $x_{11}$. All labour devoted to final goods will be busy producing this single good. In the next period a new good, $x_{22}$, will appear and a proportion of the labour which was earlier producing good 1 will shift to the 


\begin{tabular}{|r||rrrrrrr|}
\hline Sector & $\begin{array}{r}\text { Time } \\
\mathbf{1}\end{array}$ & $\mathbf{2}$ & $\mathbf{3}$ & {$[\ldots]$} & $\mathbf{t}$ & $\mathbf{t + 1}$ & {$[\ldots]$} \\
\hline \hline 1 & $x_{11}$ & $x_{12}$ & $x_{13}$ & $\ldots$ & $x_{1 t}$ & $x_{1 t+1}$ & $\ldots$ \\
2 & & $x_{22}$ & $x_{23}$ & $\ldots$ & $x_{2 t}$ & $x_{2 t+1}$ & $\ldots$ \\
3 & & & $x_{33}$ & $\ldots$ & $x_{3 t}$ & $x_{3 t+1}$ & $\ldots$ \\
{$[\ldots]$} & $\ldots$ & $\ldots$ & $\ldots$ & $\ldots$ & $\ldots$ & $\ldots$ & $\ldots$ \\
$\mathbf{i}$ & & & & $\ldots$ & $x_{i t}$ & $x_{i t+1}$ & $\ldots$ \\
$\mathbf{i}+1$ & & & & $\ldots$ & & $x_{i+1} t+1$ & $\ldots$ \\
{$[\ldots]$} & $\ldots$ & $\ldots$ & $\ldots$ & $\ldots$ & $\ldots$ & $\ldots$ & $\ldots$ \\
\hline
\end{tabular}

Table 3.1: Production of quantities for each good in each period of time

production of good 2. If the system is in equilibria in the distribution of labor, the total quantity of labour devoted to final goods and the production coefficients are fixed, the total quantity of good 1 produced in time period 2 will diminish to $x_{12}$. The table presents a diagonal structure, a consequence of the idea that in each time period an innovation is introduced and produced by the economy. Using some definitions given by previous formulas (see Appendix C.1.3) the evolution of profits over time as new goods appear is represented in the following table (3.2). In the next section we will explain that the value of the patent depends on the flow of profits, therefore a similar table will be introduced to explain the relation between the value of a patent and that of the subsequent one. 


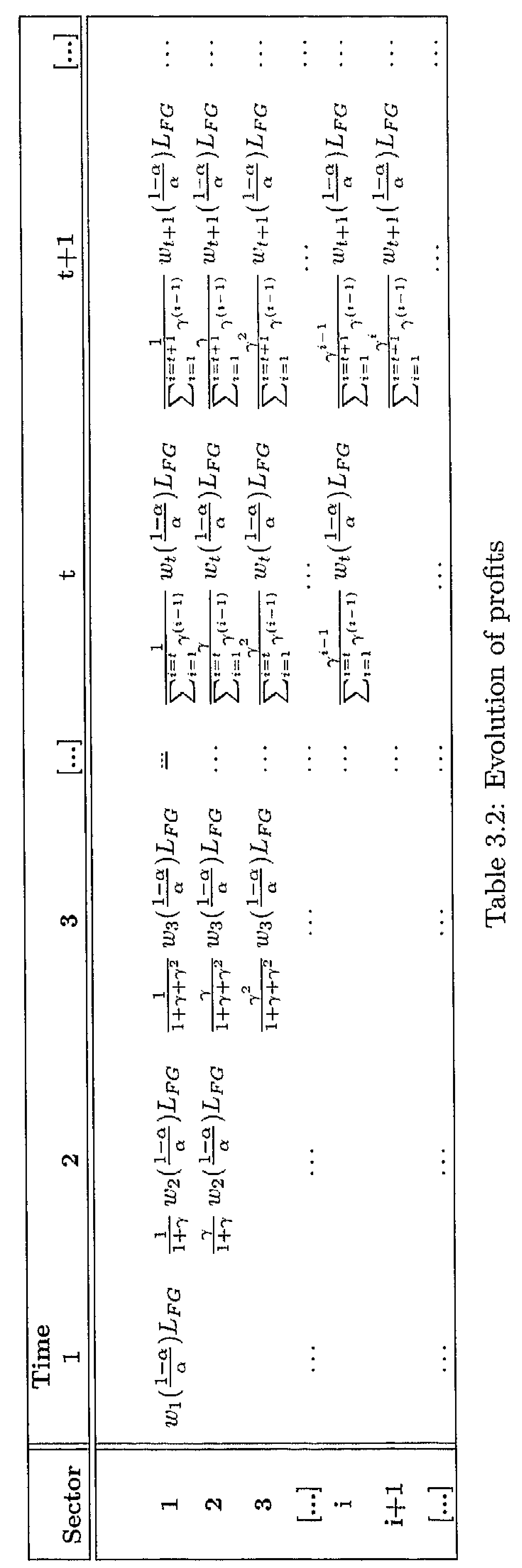




\section{Habit Formation, Demand and Growth}

\section{The R\&D sector}

We treat $R \& D$ as an ordinary economic activity that requires input resources. The sector produces blueprints using only labour as input. The production function has constant returns to scale in the number of blueprints produced although each blueprint will have a higher value than the previous one. Each blueprint is sold to a monopolist that will exploit its monopoly income from the innovation in the final goods market. The value of each innovation is the sum of the discounted future profits. In each period an innovation materialises and there is a new asset in the economy.

The R\&D sector has incomes that depend on the value of newly created innovations. The value of an innovation is the present value of the future profits generated by this specific innovation. Every time a new blueprint is bought a whole new sector $(i)$ starts producing:

$$
\begin{aligned}
& d_{i+1}=\frac{\pi_{i+1 t+1}}{\left(1+r_{t+1}\right)}+\frac{\pi_{i+1} t+2}{\left(1+r_{t+1}\right)\left(1+r_{t+2}\right)}+\frac{\pi_{i+1 t+3}}{\left(1+r_{t+1}\right)\left(1+r_{t+2}\right)\left(1+r_{t+3}\right)}+\ldots+0 \\
& d_{i+1}=\sum_{j=1}^{\infty} \frac{\pi_{i+1 t+j}}{\prod_{t=1}^{j}\left(1+r_{t+\ell}\right)}
\end{aligned}
$$

The relationship between the value of a patent and that of the subsequent patent can be easily seen:

$$
d_{i+1}=\gamma d_{i}
$$

As an example we compare the value of two patents $d_{1}$ and $d_{2}$ in $t=2$. Table 3.3 is a reformulation of the previous table 3.2. Comparing the two highlighted rows we see that in $t=2$ the present value of the flow of profits for the second good is $\gamma$ times superior to the discounted value of the profits for the first good:

$$
d_{2}=\gamma d_{1}
$$




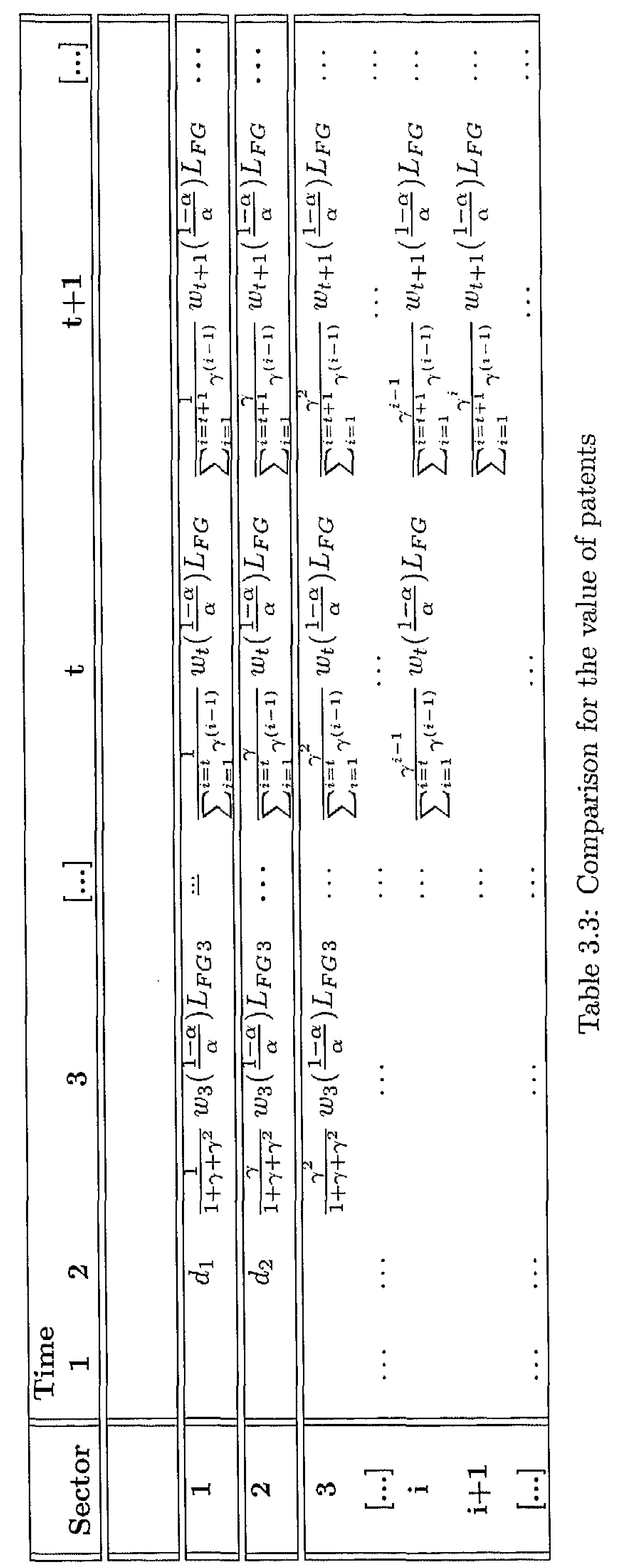




\section{Habit Formation, Demand and Growth}

We now concentrate on the production in the R\&D sector which in every period of time produces a single blueprint using as unique resource a fixed and constant amount of labour. Each produced blueprint has its own different value which depends on the future profits of the innovation. The total profit of the sector will depend on revenues $d_{i+1}$ and total costs of producing the innovation will depend on the total labour used and on the salary level $w_{t} L_{R \& D}$. Even though we have so far assumed that the system is in equilibria, a higher amount of labor in the sector is related to a superior utility jump. In subsection 3.4.1 when the arrival of innovation in relation to time was explained the equation, gives the necessary relation between the $c_{i}$, so that the utility jump given by the last good is $\gamma$ times bigger in relation to the previous good,

$$
c_{i+1}=\frac{\gamma+c_{i}-1}{\gamma}
$$

Let us compare the situations of two hypothetical closed economies with the same population each of them making a different technological effort. The first economy (1), having a total amount of labor in the R\&D equals to $L_{R \& D}^{(1)}$, and the second economy (2) doing a superior effort $L_{R \& D}^{(2)}$.

$$
\begin{array}{ll}
L_{R \& D}^{(1)}: \quad c_{1}^{(1)} \stackrel{\gamma^{(1)}}{\longrightarrow} c_{2}^{(1)} \stackrel{\gamma^{(1)}}{\longrightarrow} \ldots . c_{t}^{(1)} \stackrel{\gamma^{(1)}}{\longrightarrow} c_{t+1}^{(1)} \\
L_{R \& D}^{(2)}: \quad c_{1}^{(2)} \stackrel{\gamma^{(2)}}{\longrightarrow} c_{2}^{(2)} \stackrel{\gamma^{(2)}}{\longrightarrow} \ldots c_{t}^{(2)} \stackrel{\gamma^{(2)}}{\longrightarrow} c_{t+1}^{(2)}
\end{array}
$$

If one economy has more people working during the same period of time, the flow of innovations generated by this economy will have associated higher utility jumps. If $\gamma$ is measuring this jump, it is expected that if $L_{R \& D}^{(1)}<L_{R \& D}^{(2)}$ then $\gamma^{(1)}<\gamma^{(2)}$. In other words superior innovative effort will be related to a superior flow of innovations which will be associated to superior increases in utility.

The production function of the R\&D sector is relating inputs to outputs. Our only input is labour and by the assumptions in the utility side we know that the output per period will be always equal to one. Only one innovation at the time is possible and the output of the $R \& D$ will be always an idea. At the macroeconomic level howcver superior economic efforts are related to superior outputs, this relation is not a normal production function, but a translation of the research effort made by the economy, this iclea is capture by the next equation

$$
\gamma=\phi L_{R \& D}
$$

Where the parameter $\phi$ transforms the innovative inputs of the economy $L_{R \& D}$ during a period to the total impact that such innovation will have in the economy $\gamma$. However equation 3.23 is not a normal production function, but a relation between the effort done and the impact that this effort has in the economy.

After we have discussed this issue we present the profits of the R\&D sector. In each period of time the sector will produce a new innovation, that will have 
a value of $d_{i+1}$. This new innovation as it has been explained in will be $\gamma$ times bigger than the previous one, therefore the total ravenue of the $R \& D$ sector can be written as:

$$
d_{i+1}=\gamma d_{i}=\phi L_{R \& D} d_{i}
$$

And the total profit, will be total ravenues minus total costs $w_{t} L_{R \& D}$,

$$
\phi L_{R \& D} d_{i}-w_{t} L_{R \& D}
$$

The sector will maximize the profits making marginal revenues equal marginal costs,

$$
\phi d_{i}=w_{t}
$$

Rearranging terms:

$$
d_{i}=w_{t} / \phi
$$

\subsubsection{The equity market}

Equity holders expect to enjoy capital gains (or suffer capital losses) on their ownership shares. In a perfect-foresight equilibrium these expected gains or losses must match the change that actually occurs in the value of the firm. We let $d_{t}$ denote the value of a claim to the infinite stream of profits that accrues to a newly invented innovation. If such an amount is invested in the $R \& D$ sector the arbitrage in capital markets ensures equality between this yield and that from a similar amount on a riskless loan. The return of an investment on a riskless loan of size $d_{t}$ will be $d_{t} r_{t}$. The expected gains in the sector producing blueprints will be a new patent $d_{i+1}$ and the profit associated with this patent $\pi_{i+1}$. The arbitrage condition of the equity market will be:

$$
d_{i} r_{t}=d_{i+1}-d_{i}+\pi_{i+1}
$$

which means that, if we save one unit $d_{i}$, the increase in the value of the savings $d_{i} r_{t}$ has to be equal to the value gencrated by an investment of the same unit $d_{i}$ made in the $\mathrm{R} \& \mathrm{D}$ sector $\left(d_{i+1}+\pi_{i+1}\right)$. In equilibrium the value generated by investments in $R \& D$ must be equal to the value generated by a riskless loan.

\subsection{The general equilibrium}

We clefine a balanced growth path as the moment at which wages and prices (and therefore expenditures) grow at the same stable rate. This constant rate will be the growth rate of the economy in the balanced growth path. Before continuing with the solutions we recall the results already presented in the previous section:

1. We start with the Euler rule presented by equation 3.13. From the solution presented in equation 3.16 we know that prices are equal across goods in each 


\section{Habit Formation, Demand and Growth}

time period. We will choose the numeraire so that expenditure on the initial quantity will be equal to one in every period:

$$
p_{1 t} x_{1 t}=1 \quad \forall t .
$$

Taking into consideration these two previous equations, equation 3.13 can be written as (see appendix C.1.2):

$$
\left(\frac{1+\gamma^{\alpha}+\ldots+\gamma^{\alpha(t)}}{1+\gamma^{\alpha}+\ldots+\gamma^{\alpha(t-1)}}\right)^{1 / \alpha} \frac{E_{t}}{E_{t+1}} \frac{p_{t}}{p_{t+1}}=\frac{1}{\left(1+r_{t}\right) \beta}
$$

Solving for $r_{t}$,

$$
r_{t}=\frac{1}{\beta\left(\frac{1+\gamma^{\alpha}+\ldots+\gamma^{\alpha(l)}}{1+\gamma^{\alpha}+\ldots+\gamma^{\alpha(t-1)}}\right)^{1 / \alpha}} \frac{E_{t+1}}{E_{t}} \frac{p_{t+1}}{p_{t}}-1
$$

2. From the maximization of profits equation 3.20 we have:

$$
\pi_{i t}=w_{t}\left(\frac{1-\alpha}{\alpha}\right) \frac{\gamma^{i-1}}{\sum_{i=1}^{t} \gamma^{i-1}} L_{\text {Final Goods }}
$$

The profit of the last good invented in the subsequent period will be $i=t+1$, in $t+1$

$$
\pi_{i+1, t+1}=w_{t+1}\left(\frac{1-\alpha}{\alpha}\right) \frac{\gamma^{t}}{\sum_{i=1}^{t+1} \gamma^{i-1}} L_{\text {Final Goods }}
$$

3. From the labour market condition we find that the total labour of the economy has to equal the number of people employed in each sector:

$$
L=L_{R \& D}+L_{F G}
$$

Normalizing total labour to one wc have that:

$$
1=L_{R \& D}+L_{F G}
$$

4. Taking the labour constraint into consideration, maximizing the R\&D sector as shown in equation 3.26 gives:

$$
d_{i}=w_{t} / \phi
$$


Now we start with the arbitrage condition of the equity markets:

$$
d_{i} r_{t}=d_{i+1}-d_{i}+\pi_{i+1}
$$

Solving for $r_{t}$ we have

$$
r_{t}=\frac{d_{i+1}-d_{i}}{d_{i}}+\frac{\pi_{i+1}}{d_{i}}
$$

Knowing that each innovation is $\gamma$ times superior to the previous one:

$$
\begin{aligned}
& r_{t}=\frac{\gamma d_{i}-d_{i}}{d_{i}}+\frac{\pi_{i+1}}{d_{i}} \\
& r_{t}=(\gamma-1)+\frac{\pi_{i+1}}{d_{i}}
\end{aligned}
$$

Substituting in equation 3.31 the solution for $r_{l}$ that comes from the value obtained by the Euler rule (equation 3.27), the solution from the R\&D sector 3.30 , and the maximization of profits from final goods (cquation ??) produces:

$$
\frac{1}{\beta\left(\frac{1+\gamma^{\alpha}+\ldots+\gamma^{\alpha(t)}}{1+\gamma^{\alpha}+\ldots+\gamma^{\alpha(t-1)}}\right)^{1 / \alpha}} \frac{E_{t+1}}{E_{t}} \frac{p_{t+1} \frac{E_{t+1}}{E_{t}}\left(\frac{1-\alpha}{\alpha}\right) \frac{\gamma^{t}}{\sum_{t=1}^{t+1} \gamma^{i-1}} L_{F G}}{p_{t} / \phi}
$$

Having defined the balanced growth path (as the moment at which wages and prices grow at the same stable rate), when $t$ goes to infinity we can introduce the value of the limits given by solutions C.21 and C.22 (see appendix C.1.4). The only thing constantly growing in each period is the total value of the patents which, using the results of section 3.4 .3 , is:

$$
\frac{d_{i+1}-d_{i}}{d_{i}}=\frac{\gamma d_{i}-d_{i}}{d_{i}}=(\gamma-1)
$$

Since the number of people devoted to final goods is constant, total expenditures can be expressed as:

$$
E_{t}=p_{t} X^{* *}=p_{t} a L_{F G}^{* *}
$$

Calculating the growth rate of expenditures:

$$
\frac{E_{t+1}-E_{t}}{E_{t}}=\frac{p_{t+1} a L_{F G}^{* *}-p_{t} a L_{F G}^{* *}}{p_{t} a L_{F G}^{* *}}=\frac{p_{t+1}-p_{t}}{p_{t}}=(\gamma-1)
$$




\section{Habit Formation, Demiand and Growth}

When we are in the long-term balanced growth path we have:

$$
\frac{w_{t+1}-w_{t}}{w_{t}}=\frac{p_{t+1}-p_{t}}{p_{t}}=\frac{E_{t+1}-E_{t}}{E_{t}}=\frac{d_{t+1}-d_{t}}{d_{t}}=\gamma-1
$$

and $\frac{E_{t+1}}{E_{t}}=\frac{p_{t+1}}{p_{t}}=\gamma$

Solving the previous equation 3.32 in the long run(using the limits of appendix C.1.4), substituting $\gamma=\phi L_{R \& D}=\phi\left(1-L_{F G}\right)$ and rearranging terms provides the following equation:

$$
L_{F G}^{2}-\frac{\phi-1}{\phi} L_{F G}+\frac{(1-\beta)}{\beta} \frac{\alpha}{(1-\alpha) \phi^{2}}=0
$$

Solving for $L_{F G}$

$$
L_{F G}^{* *}=\frac{\frac{\phi-1}{\phi}+\sqrt{\left(\frac{\phi-1}{\phi}\right)^{2}-4 \frac{(1-\beta)}{\beta} \frac{\alpha}{(1-\alpha) \phi^{2}}}}{2}
$$

This solution gives us the proportion of labor that will assurc a constant rate of growth, which will be equal to,

$$
g^{* *}=(\gamma-1)=\phi L_{R \& D}^{* *}-1=\phi\left(1-L_{F G}^{* *}\right)-1
$$

\subsubsection{Transition to the equilibrium}

So far, we have assumed that there is a constant proportion of labour in each scctor, in this subsection we study transition to the equilibria. By assuming a constant proportion of labour in the $R \& D$ sector in all periods, we were getting a constant $\gamma$. If the economy starts from a distribution of labour different than the one given by equation 3.34, it will mean that in the first periods while the labour is adjusting we will get a different $\gamma$. Let us analyse a situation in which the labour in the $R \& D$ sector is different than the one in equilibria, assuming that there is free mobility of labour between the two sectors equation tell us that the in a moment of time in which the marginal productivity of labour in the two sectors will be equal,

If the economy starts from a situation in which $L_{R \& D}^{t} \neq L_{R \& D}^{* *}$, and we will assume that it takes $n$ periods to reach the equilibrium, in such a situation then we will have an array of gammas like, 


$$
\begin{aligned}
& \gamma_{(2)}=\phi L_{R \& D, t=2} \\
& \gamma_{(3)}=\phi L_{R \& D, t=3} \\
& \ldots \\
& \gamma_{(n)}=\phi L_{R \& D, t=n} \\
& \gamma_{(* *)}=\phi L_{R \& D, t=n+1} \\
& \cdots \\
& \gamma_{(* *)}=\phi L_{R \& D, t=\infty}
\end{aligned}
$$

Where $\gamma_{* *}$ is the parameter that corresponds to $L_{R \& D}^{* *}$. We discuss now how our equilibrium will be affected by such a change, we focus on cquation 3.32 , and in the changes that different $\gamma \mathrm{s}$ will have,

$$
\frac{1}{\beta\left(\frac{1+\gamma^{\alpha}+\ldots+\gamma^{\alpha(t)}}{1+\gamma^{\alpha}+\ldots+\gamma^{\alpha(t-1)}}\right)^{1 / \alpha}} \frac{E_{t+1}}{E_{t}} \frac{p_{t+1} \frac{E_{t+1}}{E_{t}}\left(\frac{1-\alpha}{\alpha}\right) \frac{\gamma^{t}}{p_{t}}-1=(\gamma-1)+\frac{\gamma_{i=1} \gamma^{i-1}}{p_{t} / \phi}}{w_{t}}
$$

In this equation, the variation introduce will affect the fractions $\left(\frac{1+\gamma^{\alpha}+\ldots+\gamma^{\alpha(t)}}{1+\gamma^{\alpha}+\ldots+\gamma^{\alpha(t-1)}}\right)^{1 / \alpha}$ and $\frac{\gamma^{t}}{\sum_{i=1}^{t+1} \gamma^{i-1}}$ which will be then be transformed into,

$$
\begin{gathered}
\left(\frac{1+\gamma_{(2)}^{\alpha}+\left(\gamma_{(2)} \gamma_{(3)}\right)^{\alpha} \ldots+\left(\gamma_{(2)} \gamma_{(3)} \ldots \gamma_{(n)} \gamma_{(* *)}^{(t-n) \alpha}\right)}{1+\gamma_{(2)}^{\alpha}+\left(\gamma_{(2)} \gamma_{(3)}\right)^{\alpha} \ldots+\left(\gamma_{(2)} \gamma_{(3)} \ldots \gamma_{(n)} \gamma_{(* *)}^{(t-n-1) \alpha}\right)}\right)^{1 / \alpha} \\
\left(\frac{\left(\gamma_{(2)} \gamma_{(3)} \ldots \gamma_{(n)} \gamma_{(* *)}^{(t-n)}\right)}{1+\gamma_{(2)}+\left(\gamma_{(2)} \gamma_{(3)}\right) \ldots+\left(\gamma_{(2)} \gamma_{(3)} \ldots \gamma_{(n)} \gamma_{(* *)}^{(t-n-1)}\right)}\right)^{(t)}
\end{gathered}
$$

In appendix C.1.4 we calculate the value of this two limits which are equal to $\gamma_{(* *)}$ and $\gamma_{(* *)}-1$. Therefore such variation will not affect the general equilibria, since the value of the limits is not affected by this change, neither will it bo any of the other assumptions or relations presented in the previous section. Having different $\gamma \mathrm{s}$ will only make it harder to follow up what is happening in the model.

\subsubsection{Analysis of the parameter of the model}

In this subsection we explain how will the change in the value of the parameter affect our solution, we will focus on the solution of $L_{R \& D}^{* *}$ and the general growth of the economy $g^{* *}$. 


$$
\begin{gathered}
L_{R \& D}^{* *}=1-\frac{\frac{\phi-1}{\phi}+\sqrt{\left(\frac{\phi-1}{\phi}\right)^{2}-4 \frac{(1-\beta)}{\beta} \frac{\alpha}{(1-\alpha) \phi^{2}}}}{2} \\
g^{* *}=(\gamma-1)=\phi L_{R \& D}^{* *}-1
\end{gathered}
$$

The next two figures 3.3 represents the value of the distribution of labou $R \& D$ and growth in equilibrium, for different parameters. To curves are re: sented in a 3 dimensional plot for $\alpha=0.5$ and $\alpha=0.75$. In table 3.4 a calibra: of the value of the parameters for $\alpha=0.5$ is presented. In graphs in can be served that higher values of $\alpha$, with evcrything else constant translates into hi $\varepsilon$ values of growth. The parameter $\alpha$ is related to the elasticity of substitutio: the CES function, the higher this parameter the easier that consumers will sw to new imnovations. Our $\beta$ is related to the consume's preferences of present , sumption versus future consumption. The closer this parameter is to one, lower the growth rate of the economy. Because the lower this parameter is less consumers will want to go for present consumption, and will postpone , sumption for future periods. The last parameter $\phi$ affects negatively to gror this parameter regulates the marginal productivity of labour in the $R \& D$, if parameter is higher it will be need it less labour in this sector that will go to production of final goods. The change in this parameter affects in two way the growth rate, since the growth rate of the economy is the one presentec equation 3.39. If $\phi \uparrow$ goes up, the quantity will be affected by two movem. $\phi(\uparrow) L_{R \& D}^{* *}(\downarrow)-1$, resulting in a total decreasing effect that dominates. This is case in the range for which the parameters have an economic value. All this ef can be observed in the graphs and tables. 

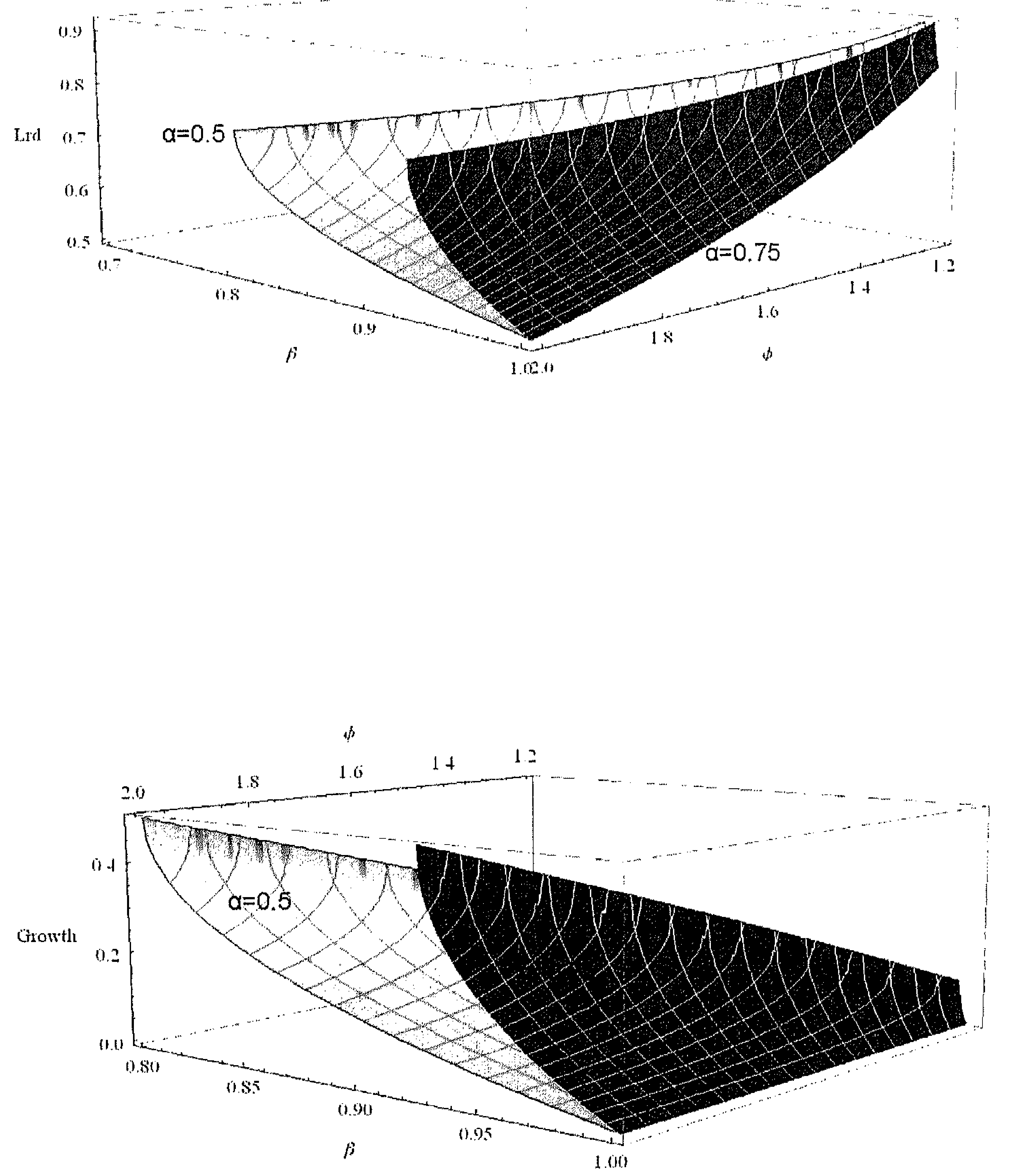

Figure 3.3: Value of parameters, labour distribution and growth 
3. Habit Formation, Demand and Growth

\begin{tabular}{|r||rrrrrrrr|}
\hline$L_{R \& D}^{* *}$ & $\beta$ & & & & & & & \\
& 0,90 & $\mathbf{0 , 9 1}$ & $\mathbf{0 , 9 2}$ & $\mathbf{0 , 9 3}$ & $\mathbf{0 , 9 4}$ & 0,95 & $\mathbf{0 , 9 6}$ & $\mathbf{0 , 9 7}$ \\
\hline \hline $\boldsymbol{\phi}$ & & & & & & & & \\
$\mathbf{1 , 6 7}$ & 0,75 & 0,72 & 0,70 & 0,68 & 0,66 & 0,65 & 0,64 & 0,62 \\
$\mathbf{1 , 7 7}$ & 0,67 & 0,65 & 0,64 & 0,63 & 0,61 & 0,60 & 0,59 & 0,59 \\
$\mathbf{1 , 8 7}$ & 0,61 & 0,60 & 0,59 & 0,58 & 0,57 & 0,57 & 0,56 & 0,55 \\
$\mathbf{1 , 9 7}$ & 0,57 & 0,56 & 0,56 & 0,55 & 0,54 & 0,53 & 0,53 & 0,52 \\
$\mathbf{2 , 0 7}$ & 0,54 & 0,53 & 0,52 & 0,52 & 0,51 & 0,51 & 0,50 & 0,50 \\
$\mathbf{2 , 1 7}$ & 0,51 & 0,50 & 0,50 & 0,49 & 0,49 & 0,48 & 0,48 & 0,47 \\
$\mathbf{2 , 2 7}$ & 0,48 & 0,48 & 0,47 & 0,47 & 0,46 & 0,46 & 0,45 & 0,45 \\
$\mathbf{2 , 3 7}$ & 0,46 & 0,45 & 0,45 & 0,44 & 0,44 & 0,44 & 0,43 & 0,43 \\
$\mathbf{2 , 4 7}$ & 0,44 & 0,43 & 0,43 & 0,43 & 0,42 & 0,42 & 0,42 & 0,41 \\
$\mathbf{2 , 5 7}$ & 0,42 & 0,41 & 0,41 & 0,41 & 0,40 & 0,40 & 0,40 & 0,40 \\
$\mathbf{2 , 6 7}$ & 0,40 & 0,40 & 0,39 & 0,39 & 0,39 & 0,39 & 0,38 & 0,38 \\
\hline \hline$g^{* *}$ & $\beta$ & & & & & & & \\
& 0,90 & 0,91 & 0,92 & 0,93 & $\mathbf{0 , 9 4}$ & 0,95 & $\mathbf{0 , 9 6}$ & 0,97 \\
\hline \hline $\boldsymbol{\phi}$ & & & & & & & & \\
$\mathbf{1 , 6 7}$ & 0,26 & 0,20 & 0,16 & 0,13 & 0,10 & 0,08 & 0,06 & 0,04 \\
$\mathbf{1 , 7 7}$ & 0,18 & 0,15 & 0,13 & 0,11 & 0,09 & 0,07 & 0,05 & 0,04 \\
$\mathbf{1 , 8 7}$ & 0,15 & 0,13 & 0,11 & 0,09 & 0,07 & 0,06 & 0,05 & 0,03 \\
$\mathbf{1 , 9 7}$ & 0,13 & 0,11 & 0,09 & 0,08 & 0,07 & 0,05 & 0,04 & 0,03 \\
$\mathbf{2 , 0 7}$ & 0,11 & 0,10 & 0,08 & 0,07 & 0,06 & 0,05 & 0,04 & 0,03 \\
$\mathbf{2 , 1 7}$ & 0,10 & 0,09 & 0,08 & 0,06 & 0,05 & 0,04 & 0,03 & 0,02 \\
$\mathbf{2 , 2 7}$ & 0,09 & 0,08 & 0,07 & 0,06 & 0,05 & 0,04 & 0,03 & 0,02 \\
$\mathbf{2 , 3 7}$ & 0,08 & 0,07 & 0,06 & 0,05 & 0,04 & 0,04 & 0,03 & 0,02 \\
$\mathbf{2 , 4 7}$ & 0,08 & 0,07 & 0,06 & 0,05 & 0,04 & 0,03 & 0,03 & 0,02 \\
$\mathbf{2 , 5 7}$ & 0,07 & 0,06 & 0,05 & 0,05 & 0,04 & 0,03 & 0,02 & 0,02 \\
$\mathbf{2 , 6 7}$ & 0,07 & 0,06 & 0,05 & 0,04 & 0,04 & 0,03 & 0,02 & 0,02 \\
\hline \hline$\alpha$ & 0,50 & & & & & & & \\
\hline
\end{tabular}

Table 3.4: Calibration of parameters: Labor distribution and Growth rates

\subsubsection{The Intertemporal Elasticity of Substitution (IES) and the propensity to consume}

We commented already that the utility function we have introduced in the model has non-homothetic preferences. Increases in income are not equally distributed over the different goods. (See chaptcr 2, solution 2.9). This utility function presents the characteristic of creating a new product in every new time interval. The Intertemporal Elasticity of Substitution (IES) is the relative variation in consumption levels related to the variation in relative changes in the utility. To be able to appreciate these changes we shall have to calculate the IES at the product level, and add it using the expenditures function.

To demonstrate that the marginal propensity to consume increases we shall 
calculate the IES in the short run ( $\left.I E S_{s r}\right)$ and also in the very long run when $\mathrm{t}$ goes to infinity $\left(I E S_{l r}\right)$. Three hypothetical cases are possible:

- Case 1: $I E S_{s r}=I E S_{l r}$

Savings are constant over time. As income increases constant proportions are devoted to savings and consumption. In such a case the propensity to consume is also constant over time. This is the classical result of homothetic preference models.

- Case 2: IES $S_{s r}<I E S_{l r}$

As incomes grow people save an increasing proportion of their incomes. In this case the marginal propensity to consume decreases with time.

- Case 3: IES $S_{s r}>I E S_{l r}$

People save less and less as income grows. In other words they consume an increasing proportion of their incomes. Therefore the marginal propensity to consume increases with time.

\section{The IES in the short run}

Our utility function is:

$$
\left.\left(\sum_{i=1}^{t} \gamma^{(i-1) \alpha} x_{i}^{\alpha}\right)\right)^{1 / \alpha}
$$

Let us calculate for a simple case with three goods. The utility function in this case will be:

$$
\left(x_{1}+\gamma^{\alpha} x_{2}^{\alpha}+\gamma^{2 \alpha} x_{3}^{\alpha}\right)^{1 / \alpha}
$$

Here we can calculate the IES for each good, such that:

$$
\begin{aligned}
& I E S_{x 1}=-\frac{U^{\prime}\left(x_{1}\right)}{U^{\prime \prime}\left(x_{1}\right) x_{1}}=\frac{1}{1-\alpha} \frac{x_{1}+\gamma^{\alpha} x_{2}^{\alpha}+\gamma^{2 \alpha} x_{3}^{\alpha}}{\gamma^{\alpha} x_{2}^{\alpha}+\gamma^{2 \alpha} x_{3}^{\alpha}}= \\
& =\frac{1}{1-\alpha} \frac{x_{1}+\gamma^{\alpha} x_{2}^{\alpha}+\gamma^{2 \alpha} x_{3}^{\alpha}}{x_{1}+\gamma^{\alpha} x_{2}^{\alpha}+\gamma^{2 \alpha} x_{3}^{\alpha}-x_{1}} \\
& I E S_{x 2}=-\frac{U^{\prime}\left(x_{2}\right)}{U^{\prime \prime}\left(x_{2}\right) x_{2}}=\frac{1}{1-\alpha} \frac{x_{1}+\gamma^{\alpha} x_{2}^{\alpha}+\gamma^{2 \alpha} x_{3}^{\alpha}}{\gamma^{\alpha} x_{2}^{\alpha}+\gamma^{2 \alpha} x_{3}^{\alpha}}= \\
& =\frac{1}{1-\alpha} \frac{x_{1}+\gamma^{\alpha} x_{2}^{\alpha}+\gamma^{2 \alpha} x_{3}^{\alpha}}{x_{1}+\gamma^{\alpha} x_{2}^{\alpha}+\gamma^{2 \alpha} x_{3}^{\alpha}-\gamma^{\alpha} x_{2}^{\alpha}} \\
& I E S_{x 3}=-\frac{U^{\prime}\left(x_{3}\right)}{U^{\prime \prime}\left(x_{3}\right) x_{3}}=\frac{1}{1-\alpha} \frac{x_{1}+\gamma^{\alpha} x_{2}^{\alpha}+\gamma^{2 \alpha} x_{3}^{\alpha}}{x_{1}+\gamma^{\alpha} x_{2}^{\alpha}}= \\
& =\frac{1}{1-\alpha} \frac{x_{1}+\gamma^{\alpha} x_{2}^{\alpha}+\gamma^{2 \alpha} x_{3}^{\alpha}}{x_{1}+\gamma^{\alpha} x_{2}^{\alpha}+\gamma^{2 \alpha} x_{3}^{\alpha}-\gamma^{2 \alpha} x_{3}^{\alpha}}
\end{aligned}
$$




\section{Habit Formation, Demand and Growth}

The general case, in any fixed $t$, and for any good $\mathrm{j}$, is:

$$
I E S_{x_{j}}=\frac{1}{1-\alpha} \frac{\sum_{i=1}^{t} \gamma^{(i-1) \alpha} x_{i}^{(k}}{\sum_{i=1}^{t} \gamma^{(i-1) \alpha} x_{i}^{(\alpha}-\gamma^{(j-1) \alpha} x_{j}^{\alpha}}
$$

Now to study how consumption changes in the short term, still using the example with three goods:

$$
I E S_{x 1} \frac{p_{1 t} x_{1}}{E_{l}}+I E S_{x 2} \frac{p_{2 t} x_{2}}{E_{t}}+I E S_{x: 3} \frac{p_{3 t} x_{3}}{E_{t}}
$$

with

$$
E_{t}=p_{1 t} x_{1}+p_{2 t} x_{2}+p_{3 t} x_{3}
$$

If markets are in equilibrium prices are equal for all goods in each period. We can insert the static solution for each period, producing an expression for $E_{t}$ which will be:

$$
\begin{gathered}
E_{t}=p_{1 t}^{*} x_{1}^{*}+p_{2 t}^{*} x_{2}^{*}+p_{3 t}^{*} x_{3}^{*}=p_{t}\left(1+\gamma+\gamma^{2}\right) \\
I E S_{x 1} \frac{1}{1+\gamma+\gamma^{2}}+I E S_{x 2} \frac{\gamma}{1+\gamma+\gamma^{2}}+\underbrace{I E S_{x 3} \frac{\gamma^{2}}{1+\gamma+\gamma^{2}}}_{\text {last good }}
\end{gathered}
$$

The last good is the onc which gets the highest proportion of incomes, thercforc plays the most important role in determining how incomes and savings react as the economy continues to grow.

Let us study the sign of the IES for the last good in $t=3$ :

$$
I E S_{x_{3}}=\frac{1}{1-\alpha} \frac{x_{1}+\gamma^{\alpha} x_{2}^{\alpha}+\gamma^{2 \alpha} x_{3}^{\alpha}}{x_{1}+\gamma^{\alpha} x_{2}^{\alpha}}
$$

Choosing $p_{t} x_{1}=1$ as the numeraire, the equation has the following form:

$$
I E S_{x_{3}}=\frac{1}{1-\alpha} \frac{\gamma+\gamma^{2 \alpha}+\gamma^{4 \alpha}}{\gamma+\gamma^{2 \alpha}}
$$

which could be also be written as:

$$
I E S_{x_{3}}=\frac{1}{1-\alpha}\left(1+\frac{\gamma^{4 \alpha}}{\gamma+\gamma^{2 \alpha}}\right)
$$

This expression dominates the dynamics of the IES in the short run for this case with three goods. The main difficulty of the model is that the last good, the one determining the dominant behaviour, continually changes. However we are able to calculate, when all markets are in equilibrium and after choosing the numeraire, the value of this dominant good:

$$
I E S_{x_{t t}}=\frac{1}{1-\alpha}\left(1+\frac{\gamma^{2 t \alpha}}{1+\gamma^{2 \alpha}+\ldots+\gamma^{2(t-1) \alpha}}\right)
$$


The function will give us the value of the short-term IES, at any time $t$, for the last good. With a $\gamma$ greater than one and positive $\alpha$ less than one, this term is always positive and greater than one.

\section{The IES in the long run}

If we calculate the limit of cxpression 3.40 as $\mathrm{t}$ goes to infinity:

$$
\lim _{t \rightarrow \infty} I E S_{x_{t t}}=\lim _{t \rightarrow \infty} \frac{1}{1-\alpha}\left(1+\frac{\gamma^{2 t \alpha}}{1+\gamma^{2 \alpha}+\ldots+\gamma^{2(t-1) \alpha}}\right)=\frac{1}{1-\alpha}\left(\gamma^{2 \alpha}\right)
$$

Solution 3.41 of this limit is the value of the IES in the long run for the dominant good, for any $\mathrm{t}$, and with a $\gamma$ greater than one and positive $\alpha$.

$$
\underbrace{\frac{1}{1-\alpha}\left(1+\frac{\gamma^{2 t \alpha}}{1+\gamma^{2 \alpha}+\ldots+\gamma^{2(t-1) \alpha}}\right)}_{\left(I E S_{s r}\right)}>\underbrace{\frac{1}{1-\alpha}\left(\gamma^{\alpha^{2}}\right)}_{\left(I E S_{l r}\right)}
$$

This is the third case, when people save less and less as income increases. ${ }^{11}$ This suggests that the marginal propensity to consume increases with time. It is a logical result since we have modelled a technological effect that makes people need more goods as innovations arrive.

\subsection{Conclusion}

To understand what is happening in this economy let us turn to figure 3.4. Arrows show how the different actors are related.

Consumers get income from work they do in one of the two sectors as well as profits from the shares they have in both sectors. They get the returns on their savings. With this income they decide how much to save and how much to consume. The savings go to the financial markets; the markets will use this money to grant loans to the R\&D and final goods sectors.

Final goods firms get profits from selling the final goods to consumers. Each of them produces a different good for which they have total control over the knowledge involved in its production. To have this right they must buy the patent from the R\&D sector. To pay the initial cost they borrow money from the financial markets.

\footnotetext{
${ }^{11}$ We have compared the value of the dominant goods in the short run and in the long run. It is possible to show that even if we work with the sum of all IES for all existing goods the relation holds in both cases. The limit of the value of each good's IES as $t$ goes to infinity is zero for all goods, except for the two most recent ones. We have shown above the calculation for the most recent good; for its predecessor the short-term IES's limiting value is $\frac{1}{I-\alpha}$. For earlier goods in the chain of goods, in the short run we always have a positive value, while in the long run the limit is zero. Therefore the relation holds even if we work with all the goods simultaneously.
} 


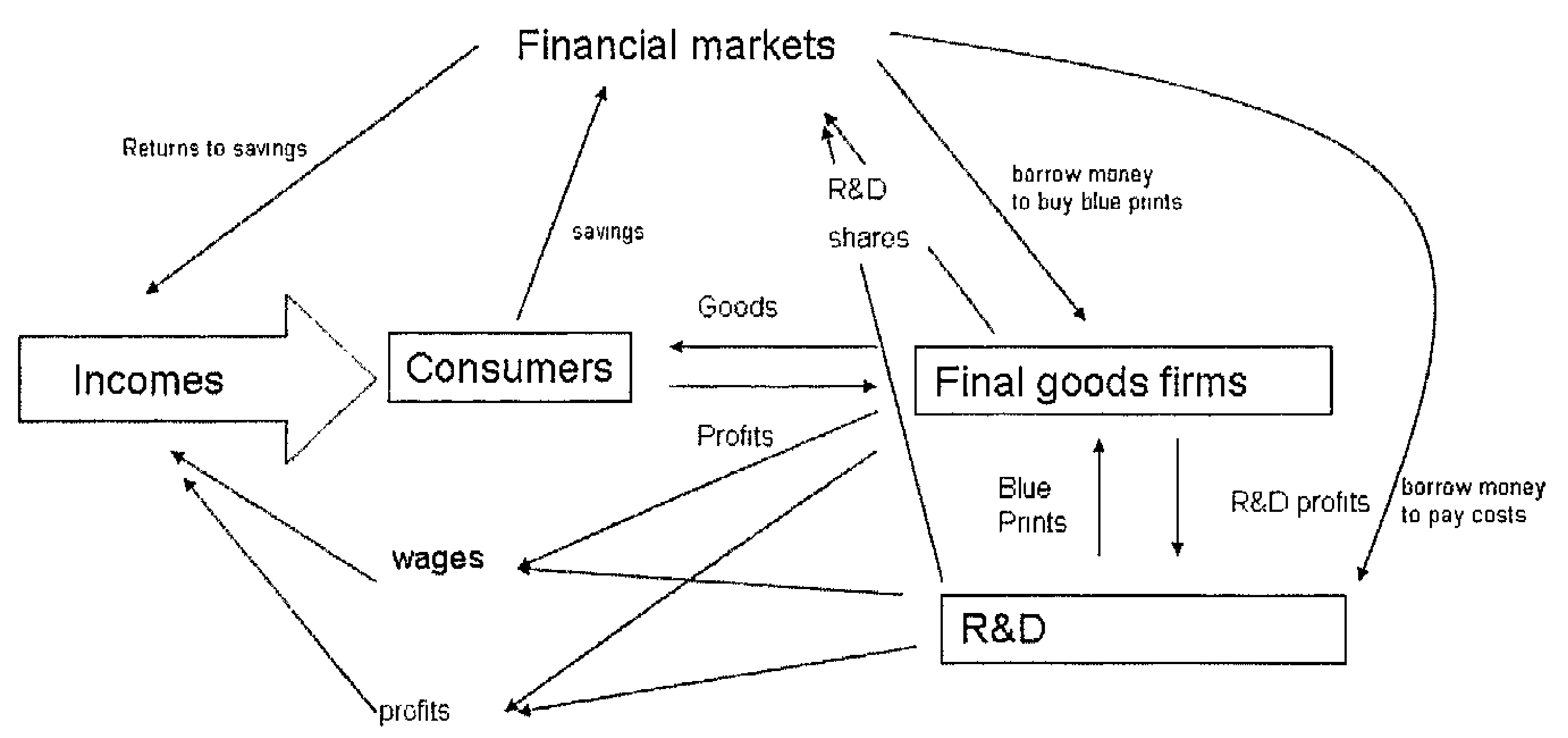

Figure 3.4: Interaction of agents

The R\&D sector produces a single blueprint in each time interval. To pay the labour cost of generating the next innovation they ask for credit from the financial sector. The financial sector in return has some form of investment in the R\&D activity which it distributes equally across all individuals. The value of the innovation is determined by the total labour devoted by the society to development of blueprints.

Each time an innovation arrives there will be an increase in the value of the final goods produced. Knowledge has the effect of creating new blueprints. Because this knowledge is profitable there will be an increase in incomes which will be translated into growth of the society's wealth and of the utility experienced by its consumers.

The main implication of the model is that economic growth is generated based on an active role of demand. The production coefficients are fixed, which means total production is always constant, labour is the only production factor and there is no population growth. The only factor that shows increasing returns to scale is knowledge, through the activities of the R\&D sector. Every time period the same amount of people working in the R\&D comes up with an idea which has higher value for the consumers than that of all earlier exploited ideas.

At the macroeconomic level two things permitting growth occur. At each time step a worthwhile innovation arrives whose value is recognised by the final 
3.6. Conclusion

goods sector. When this idea is bought money (equal to the value of the patent) is injected in the economy. At the same time the average propensity to consume increases since there is a new good that is sought after by all the economy. Together the two effects allow the economy to present a self sustaining growth process. 


\section{NATIONAL SYSTEMS OF INNOVATION AND THE ROLE OF DEMAND: A COMPARISON ACROSS COUNTRIES}

\subsection{Introduction}

In the previous chapter we used a neoclassical framework to analyse the relevant role of demand in a growth model. In this chapter we shall attempt to set some of the ideas discussed in the previous analysis in a more evolutionary framework. We shall highlight the relevance of demand and its impact on the knowledge economy. Three concepts of demand will be used to distinguish demand innovation activity across countries: habit formation, novelty, and consumption per capita. The analysis will be based on composite indicators.

The National System of Imnovation (NSI) is a broad concept which enjoys growing popularity among scholars and policy makers. The popularity of this concept is due to its capacity to reduce some of the difficulties related to technological change. To understand this success we have, on the one hand, to recognise knowledge as the main driver of a nation's wealth. On the other hand, we have to resist simplistic ways of introducing technology into neoclassical growth models. The NSI is a more systematic approach which takes into account the various interrelationships between the actors of society (firms, consumers, universities, institutions...).

Let us briefly comment on two ideas related to this opposition to the simplistic view of technology in the neoclassical framework. Firstly, why demand is rele- 
vant in a systematic view and, secondly, the notion of complementarity among the cconomy's different factors as a key point for successful innovation processes. The relevance of demand in this systemic framework can be seen as a continuation of demand pull theories to explain innovation processes. In the early 1970s Schmookler (1971) argued that society, through its market mechanism, affects the allocation of economic resources dedicated to innovation and therefore shapes the evolution of technological change. Rosenberg (1969) concentrates his argument on process innovation, writing about how demand for new techniques emerges and evolves. Many other arguments from the supply side were suggested as being relevant. This gave rise to the debate known as "demand pull:" versus "supply push". Perhaps the systemic view could be interpreted as an eclectic position to this debate in which demand plays a role. In the words of Edquist:

One consequence of the interdependent and non-linear view which characterizes the systems of innovation approach is that it is natural also to bring in demand as a determinant of innovation. (Edquist, 1997, p.21)

The second idea we want to stress is the importance of complementarities. The tradition of economic research is based on trade-off. For example, to find an optimal solution there is always some form of trade-off between spending and saving. Spending gives instantaneous satisfaction but is risky for the future, so the individual tries to take a balanced decision. The NSI approach is slightly different. This literature remarks that it is not just a trade-off between educating the population to a higher level and doing more research, but that these decisions complement each other. R\&D output will be much more efficient if the population is more highly skilled. This paper attempts to define four important dimensions of the NSI and to study the complementarities among them. Having done that, the paper presents a means of detecting in which dimension the system is weak, by which we mean one that is not generating the expected complementarity with the others.

From our point of view, the role of demand has still not been studied. Scholars recognise the roles of human capital and knowledge in improving the the country's production capacity. But how is demand affected by these factors? Are knowledge and dernand complementary in any way? These are the main concerns of this research.

The literature on NSI covers very different aspects and uses very different methodologies, going from case studies to input-output tables. Recently from one branch of the literature is emerging a quantification, based on composite indicators, of the system which permits comparisons between countries (Porter and Stern (2001), Furman et al. (2002), Chang and Shih (2005) and others); we continue this quantitative approach. However, we differ from other studies by explicitly including the role of demand into the system.

One contribution of this chapter is to bring some light onto the composite indicator methodology (for a discussion of the main issues concerning indicators see Nardo et al. (2005)). The main notion is that when research attempts to build 
a composite indicator, many decisions concerning missing data, normalization and weighting techniques need to be taken. These decisions affect the value of the final indicator. Despite the fact that a sensitivity analysis should be carried out, there is no clear answer on how to decide which is the best indicator. A growing literature is covering this topic and we suggest the "best" way to build a composite indicator is by using a technique we call "minimizing the distance to median".

The next section will make a selective review of the literature based on the role of demand and quantification methods for NSI, section 4.3 will discuss the methodology and the analysis carried out in the frame of composite indicators, section 4.4 comments on the results and some policy indications. The final section of the chapter forms the conclusion.

\subsection{Review of the literature}

A detailed review of all that has been written about national systems of innovation is beyond the scope of this chapter; Montobbio (2001) and Lundvall (2005) provide a detailed introduction to the history and different approaches. This section will review the role of demand in the NSI literature and then comment on different attempts to quantify NSI.

\subsubsection{The role of demand}

Here we shall review what are the important demand characteristics as seen by different authors; we narrow it down to the relevance and importance of demand in the concept of NSI. Some authors have focused their attention on the role of international demand, some on national demand and some argue that both are relevant. The unit of analysis is the country, therefore international demand is the demand of the rest of the world. Demand affects the system in many ways.

In one of the first articles using the concept of NSI, Freeman (1982) discusses the role of international demand. He argues that a firm that innovates and successfully exports its innovation enjoys an export monopoly that can exploited until imitators come into the market. Posner (1961) introduced the argument that the monopoly occurs because foreign demand develops faster than foreign supply, thus giving for a time a competitive advantage to the initiating country. For example, the Italian demand for mobile telephones developed faster than Italian supply; Norway, which introduced the innovation, took competitive advantage of this time lag. One might expect this monopoly to be erased by imitation sooner or later. Posner finds several arguments for this lag to continue in time. For example he says that initially it is the new product which generates the competitive advantage in an international environment, but the international leadership can be held for a long period due to the sequence of future process innovation linked with the new article. It is the time lag between the international demand and the national supply which allows a country to be more competitive. The time lag effect was further developed in relation with technical change and international trade by the 
literature (see for cxample Hufbauer (1970) or, more generally, Dosi et al. (1990)). In these relations demand does not play a prominent role, so we shall not discuss them hore.

A different perspective is taken by Dalum (1992) when he looks at how the diffcrent export specialization patterns of 21 OCDE countries affects the performance of the NSI. He implicitly gives international demand a greater weight than the national one, and he tries different specialization patterns with a sectorial focus. He notes how national sectors are present in the international distribution of exports. Even though all countries have access to international trade, they specialize in different sectors for historical or cultural reasons. Behind his arguments we find that international demand plays a role of specialization of the national capacity.

The recognition of a different demand segment is a key factor to understanding international competition and the finding of a now demand niche. Here we argue that the study of international demand is used as a source of information. The recognition of a new need in international demand allows the country to take an advantage. It can be the creation of a new good or a new niche within an existing demand. Perez $(1985,1988)$ suggests that the international advantage originates by analysing the new technological paradigm and domestic demand and deciding where the highest innovation potential lies. She suggests using the information given by the domestic demand and adjusting it to the new paradigm so that national supply can satisfy the needs of the national households. For Porter, finding a new niche can explain why some countries have leapfrogged over others in particular sectors. He gives the example of the competition in the copier machine industry between America and Japan. The Japanese discovered a new segment of demand, small machines, and developed a new strategy to approach the buyer. This new strategy allowed them to leapfrog the USA which was previously the principal seller in the sector. (Porter, 1990, p. 36).

To summarize, we found three main roles in international demand: information, specialization and a time lag. The intemational demand is used as a source of information to identify new needs, it affects the sectorial specialization of the country and, since it develops faster than international supply, allows the country to enjoy monopoly income during this time lag.

Some authors have centred their attention on national demand and its effects on the general overall performance of the NSI. The first interesting idea comes from (Porter, 1990, p.98). He points out that national needs anticipate those of the rest of the world. This fact can explain why a nation first moves into an industry and how it can enjoy the monopoly income of which Freeman (1982) wrote. It is the time lag between national needs being fulfilled versus the rest of the world that explains the superior national performance.

The role of specialization due to national demand is pointed out by Freeman (1995). He also highlights differences in national demand as one of the reasons against globalisation. He argnes that the differences in some industries might not 
4.2. Review of the literature

be important but are in others. There are some national needs that from his point of vicw can never be satisfied by international supply. He highlights climate differences that affect the performance of machines, instruments, materials... and also cultural aspects that cannot be ignored without consequences in segments like food, clothing and personal services. For example, take two firms producing takeaway pizzas, one Italian and one American. The one in Italy probably produces pizzas more to the liking of Italians than ones imported from the American firm.

The information capacity of national demand is recognized as a key factor for various reasons. Lundvall (1992) points to the relations between users and producers. These strong links help producers meet the needs of the different users. Out of these links the producer can find new ideas for production or to improve designs. Von Hippel goes one step further, and attributes all the innovation process, in some specific areas, to what he calls the "lead user" (von Hippel (1986), von Hippel (1988)). This idea is also important for Porter when he says that sophisticated and demanding buyers allow firms to increase the quality of the product. Although more than information it seems to be that demand helps national capacity building power (Porter, 1990, p.89). He also emphasises the fact that a large number of independent buyers help to increase variation, which is a major concern for many evolutionary economists. The same idea, taken from a supply side perspective, is enunciated by Metcalfe (1995).

A stream of the literature has contemplated simultaneous national and international demand dynamics as a possible explanation for differences in national capacity to compete. Fagerberg (1992) centres on testing the home market hypothesis. A strong home market means the producer's production patterns are allowed to grow faster, making a strong competing national sector in the international market. The role of dernand is information about the cvolution of consumer needs, plus the capacity building associated with this demand, which affects the international competitiveness of the supply. The capacity building issue is also discussed by Freeman (2002) who points out that after the Second World War when European research analyses productivity gaps with USA, the size of the domestic market is always acknowledged as one reason for the gap. Not only the size of the demand but also its growth seems to be important. For Porter even more relevant is the growth of domestic demand. But Porter also points out that the advantage of a large domestic market can be contradictory and for some countries low demand has forced competition into the international market. Porter comments that independently of the size of the market or the growth of demand, an early saturation of the domestic demand is a prerequisite for internationalisation of sales.

An interesting point regarding demand is raised when the public sector is considered as a determinant consumer. It is determinant in the sense of the proportion of the economy's consumption. Gregersen (1992) centres her attention on the public sector as a huge consumer, thereby introducing the capacity of 
the government to affect the innovative process from the demand side. The same point is met by Edquist (1995), analysing the role of the government as a sophisticated user, and by Malerba (2004) when he recognized that the demand is not onc homogeneous consumer but composed of very heterogeneous consumers, one of them being the public sector. This way of thinking is very much connected to another branch of the literature, military $\mathrm{R} \& \mathrm{D}$, where the public sector is the main determinant and consumer.

At this moment one could wonder if demand has not been sufficiently analysed in the contest of NSI. But in our view there arc threc principal roles that have not yet been studied:

- The importance of habit formation. When thinking of innovation as one of the main drivers of economic growth it is impossible to ignore this point. It is not just the fact that we need novelty, but something that is useful in the long run allows an innovation to affect the growth of the country. There is a branch of the literature that has long recognised the value of this situation (see for example Duesenberry (1949), Pollak (1970), Ryder and Heal (1973) and Scitosvky (1977)). But it is not until recently that there is a group of economists concerned by the habit formation hypothesis and growth: Carroll et al. (1997), AlonsoCarrera et al. (2004), Alvarez-Cuadrado et al. (2004), Carroll et al. (1997) and Fuhrer (2000).

- The causality from growth to savings. Opposing the formal neoclassical view that more savings generates more growth, the introduction of demand provides an argument to reverse the causality. In the orthodox framework savings are always invested, generating more capacity to acquire new technologies, which is then translated into more output. However, this argument is biased towards supply. By introducing demand there is room for proposing a different causality. More consumption generates more growth and more savings. If we include this idea in a technological change framework, nobody will disagree that an environment with an active demand will favour the appearance of innovations. An interesting empirical work trying to prove this reverse causality has been presented by Carroll and Weil (1994) and Carroll et al. (2000).

- Novelty and marketing expenditure. The concept of marketing as important for innovation has been pointed out by many scholars, such as Freeman (1995). To understand why the effort a nation makes in marketing is a determinant of innovation we must understand how marketing expenditure affects an individual consumer. Discarding the idea that preferences are constant (see chapter 2) novelty plays a determinant role. In this chapter novelty is related to the effort invested by the firm to make its innovation known to consumers. Therefore it is possible to study how marketing affects preferences. If an individual is offered two equivalent options it is normal that the one in which a higher marketing effort is done is more likely to be chosen. If we assume that growth can be caused 
4.2. Review of the literature

by an increase in consumption, a higher consumption pattern will be followed by the nation in which marketing expenditures are superior. The relation between growth and marketing expenditures has been analysed by Benhabib and Bisin (2000).

Having reviewed the different roles of demand in the NSI literature, the next subsection will look at the research being done to quantify different characteristics of the systems. The main goal of this quantification is to simplify comparisons of national performance.

\subsubsection{Attempts to quantify National Systems of Innovation}

Although NSI was initially a qualitative approach to innovation, as Godhino et al. (2005) argued, several factors that were impossible when the concept was born allow us to make a quantification of the NSI. An important generation of indices appeared after the publication of the Oslo Manual. Several new indicators have been created either by EUROSTAT or OECD statistical offices.

The first step before trying to quantify a NSI is to decide which dimensions of the system should be taken in consideration. Already Lundvall in 1992 argued that there are five interesting dimensions that any study considering this issue should analyse: the internal organization of the firms, inter-firm relationships, the role of the public sector, the institutional set-up of the financial sector and R\&D intensity and organization. The same five dimensions are used by Montobbio (2000), though recognizing that not only the internal organisation of the firm is important but also the vertical links of the firm with clients and suppliers. Making slight variations to the original division by Lundvall, avoiding the internal organization of the firms and studying the regulations in the sector instead, Kaiser and Prange (2004) analyse these dimensions in the German biotechnology sector. Dang Nguyen and Jolles (2005) take the division as stated by Montobbio and add two new ones: social cohesion and access to Information and Communication Technologies (ICT).

A different approach is taken by Furman et al. (2002) and by Porter and Stern (2001). They propose looking at three dimensions: common innovation infrastructure, national cluster conditions and the linkages between these two. Although agreeing on the same number, Nasierowski and Arcelus (1999) propose looking at the inputs of innovations, at their outputs and at the moderators between the two. Godhino et al. (2005) follow this research, though looking also at the preconditions for innovation; the moderators are renamed "structural organization". A even closer division is made by Liu and White (2001). They explain that their division evolved from a detailed study of the literature concerning technical change. This is relevant for us because these are the dimensions that best fit our research. They propose taking into consideration: research, implementation, end-use, linkages and education.

Having seen the dimensions, what techniques and methodologies can be used for quantified comparisons? One group are the studies that build composite indicators. 
Porter and Stern (2001) use regression techniques to build up a composite indicator that measures the national innovative capacity, ranking the countries according to this index. In line with this research is the work done by Furman et al. (2002), but they use the composite indicator to run regressions on Total Factor Productivity (TFP) and attempt to explain the contribution of each index in the creation of innovations. Among their concerns is the intention to link NSI and the endogenous growth literature. Dang Nguyen and Jolles (2005) work with eleven variables that are initially divided among 7 dimensions, beforc they use a principal component factor analysis to reduce them to two principal components. They study the dynamics of the countries based on these two factors. Godhino et al. (2005) used 29 variables to make 4 dimensions from the indicators. They use these indicators to perform a cluster analysis; based on the results they propose a taxonomy of NSI.

Nasierowski and Arcelus (1999) study the NSI in a different way. They use a set of eleven indices that they classify as inputs, moderators and outputs. Afterwards they proceed with different settings of a system of simultaneous equations to see how the linkages among inputs, moderators and outputs of innovations are best related. Chang and Shilh (2005) used an input-output matrix to study R\&D intersectorial relations, and diffusion of innovations. They compared the systems of Taiwan and China. An interesting point is raised by Coombs et al. (1996) when suggesting a new way of accessing innovation performance, that of counting innovations published in specialized journals. More oriented toward the business literature, Chiesa and Manzini (1998) classify the NSI according to the various strategies that firms use when they decide to innovate.

We are going to base our analysis on composite indicators. Some decisions on the techniques use to build such indicator affect the final value of the indicator. In other to be sure that our indicator is robust with respect to the building process we introduce in the next section a discussion on the methodology to construct composite indicators.

\subsection{Methodology to construct composite indica- tors}

Most of the discussion that follows is based on a benchmark analysis using composite indicators. In this section we analyse the effects on the value of the final indicator of different index-building techniques. Since this is the principal tool used in the discussion we consider it important to study these techniques. We are interested in studying four dimensions of the system. As stated in section 4.1 our study is very similar to that of Liu and White (2001). We use four of their five dimensions, for each of which we consider a set of three variables. In this section we describe how we built the composite indicators.

In total we have twelve variables, presented in Table 4.1. Initially we want to make a composite indicator for each dimension. We study fourteen European 
4.3. Methodology to construct composite indicators

countries: Austria, Belgium, Germany, Denmark, Spain, Finland, France, Greece, Ireland, Italy, Netherlands, Portugal, Sweden and the United Kingdom - all the countries of the EU-15 group excepting Luxembourg. This country was eliminated from the sample duc to the poor quality of its statistics. We are interested in the evolution of the system's dynamics, therefore we tried to get variables for as many years as possible. The period of the study initially goes from 1993 to 2003 inclusive. For each variable we have a panel data structure of 14 countries times 11 years. At most, assuming no missing values, we shall have a total of 154 data per variable.

\begin{tabular}{lll} 
DIMENSION & VARIABLES & SOURCES \\
\hline \multirow{2}{*}{ Human Capital } & \% of work pop. with tertiary education & EUROSTAT \\
& $\begin{array}{l}\text { Life Long Learning } \\
\text { Total Expenditures in Education (as \% GDP) }\end{array}$ & EUROSTAT \\
\hline Creation of & Public Expenditure R\&D (as \% GDP). & EUROSTAT \\
Knowledge & Number of scientific publications (as \% pop) & CORDIS \\
\hline Innovation & Bnternet users per capita. & WTI \\
Capacity of & labor productivity & EUROSTAT \\
Supply & high tech exports over total exports & EUROSTAT \\
\hline Innovation & Total expenditures on Mobiles per capita. & WUROSTAT \\
Capacity of & Consumption (as \% GDP) & WDI \\
Demand & Marketing expenditures (as \% GDP) & EUROSTAT \\
\hline
\end{tabular}

Table 4.1: Dimensions and variables

For each dimension we have a composite indicator made from three variables. To discuss the issues raised by composite indicator techniques we focus our attention on one year and one country in one dimension. For example, let us talk about Austria in 1993 in the human capital dimension. For this point we have three variables: the proportion of the population working in 1993 having received tertiary education, life-long learning, and expenditure on education for this year. The reasons why we chose these variables instead of othors will be discussed in the next section when we introduce the economic sense of each dimension.

Now, to build the indicator we have at least three steps: imputation of missing values, normalization of the data and weighting techniques. We follow some of the suggestions in the Handbook of Composite Indicators published by the OECD. We are interested in comparing how countries perform, but not simply in a annual ranking of countries. Instead we are looking for an indicator that varies within a meaningful range. For each step we found these methodologies relevant:

- For the imputation of missing values: no imputation, mean year imputation and regression imputation.

- When normalizing the data: distance to the mean, standardization and rescaling.

- Concerning weights: Equal weights, Factor Analysis (FA) based on correlation matrix, FA based on variance covariance matrix, and benefit of the doubt. 


\section{NSI AND THE ROLE OF DEMAND}

With three imputation techniques, three possible normalizations and four methods for setting weights there are 36 possible values for each year and each country. Now, the OECD manual tells us to take all these permutations so as to know which are the possible outcomes. There is no formal suggestion on how to choose the best combination of techniques. One possible way to choose "the best" combination of techniques to build the indicator would be to calculate the mean of these 36 values and choose the combination which is closest to the mean. But with so much variation in the process, the distribution of the outcomes could be very skewed, and if this were the case it would be better to use the median rather than the mean.

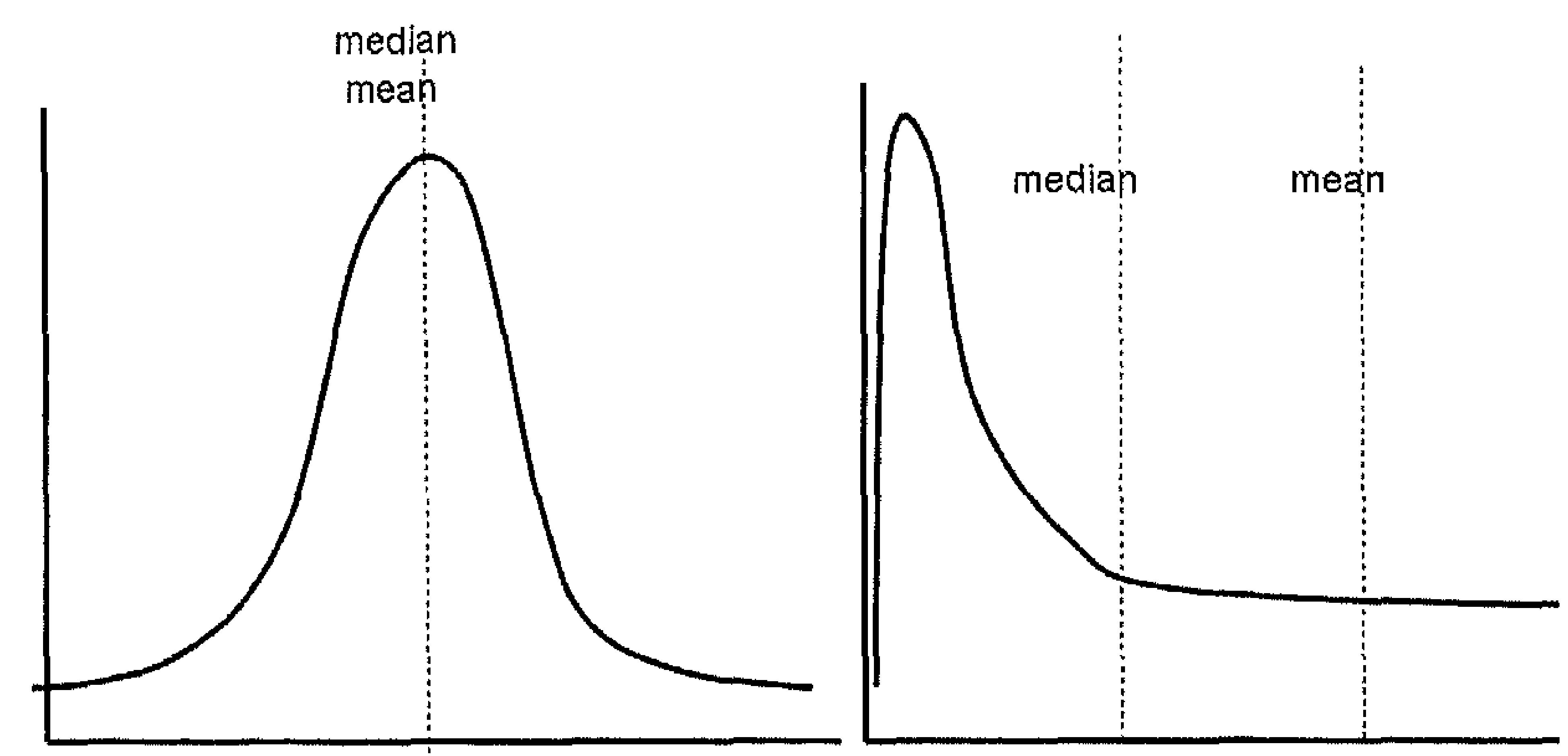

Figure 4.1: Mean and median: symmetric vs. skewed distributions

If the distribution is symmetrical the values of the median and the mean will be close so we could use either without affecting the results. But in case of very skewed distributions, as on the right of figure 4.1, the median might better capture our idea of a stable indicator. The best method to build the composite indicator is the one that is least affected by changes in the procedure, i.e. the method that remains closest to the median. Our object is not to satisfy a country's government with our outcome but to find the most effective way to explain the relations between variables and to explain the outcomes of the national system of innovation of the different countries. Therefore a procedure like "benefit of the doubt" will be no use to us unless it is most stable one. We are searching for a way to take into account all possible variations in the indicators created by the different building techniques and to minimise them.

The object of this chapter is to produce a methodology to choose the most consistent way of producing a composite indicator. We argue that the distance to the median can help us understand the effect of each step on the final outcome. We generate all possible outcomes numerically, calculate the median, and calculate the distance of each method from the median. One possible technique would be to 
choose the minimal distance to the median indicator as we know this is the most stable procedure. This "bcst" method takes into consideration, and minimises, all possible variations. This provides us with the most stable indicator, the one least sensitive to variations in procedures of construction.

Having described what we want to do, we shall explain the reasons behind each step taken, bearing in mind that we wish to obtain the best indicator by minimising its distance from the median.

\subsubsection{Imputation}

Imputation deals with decisions concerning treatment of missing values. Three options are considered. In our panel structure of the data the missing values do not depend on the variable of interest therefore they are missing completely at random $(\mathrm{MCAR})^{1}$, under the classification given by the OECD. Due to the structure of the data, we have three imputation options:

1. No imputation of missing values. The blank spaces are left empty.

2. Mean year imputation. The values of the years in between two real data are filled in with their mean value, leaving the rest as blanks. So if we have for example the data for Austria 1994 and 1996, we calculate Austria 1995's value as the mean value of the indicators, though leaving empty Austria 1993 since there were no earlier data with which to calculate a mean value.

3. Regression imputation. We calculate the trend of the data over the years for each country and impute all the missing values. This method of imputation provides us with complete tables.

It is important to realise that if we have missing values, it affects the total number of outputs per indicator that we have for the year. Imagine for example that 1995's value for Austria is missing but we have it for 1994 and 1996. Using the first imputation method, it will remain empty, but using the second or third there will be an outcome. In subsequent steps if we have no data we cannot construct indicators, which will affect the total number of outcomes per year and country. If for that year the country has no missing data then it will have 60 outcomes, if the missing data was filled by mean imputation it will have 40 outcomes, and 20 if only regression imputation was a valid option for imputation.

\subsubsection{Normalization}

The variables that compose each indicator vary within very different ranges. Therefore a normalization process is required to homogenize these ranges before creating totals.

Taking into account different normalization methods that are suitable for our purposes, we initially consider:

\footnotetext{
${ }^{1}$ see discussion of Nardo et al. (2005)
} 
1. Distance to the European mean by year. The range of the normalization is from 0 to $+\infty$

$$
x_{i t}^{N}=\frac{x_{i t}}{\overline{E U_{t}}}
$$

2. Standardization (or z-scores). We do this year by year in a cross-section of the countries. The range in this case goes from $-\infty$ to $+\infty$

$$
x_{i t}^{N}=\frac{x_{i t}-\overline{E U_{t}}}{\sigma_{E U t}}
$$

3. Rescaling. This system gives 0 to the minimum value, and 1 to the maximum.

$$
x_{i t}^{N}=\frac{x_{i t}-\min _{i t}\left(x_{i t}\right)}{\max _{i t}\left(x_{i t}\right)-\min _{i t}\left(x_{i t}\right)}
$$

4. Standardization and rescaling. Regarding the first three normalization processes, and assessing how each would perform in relation to their proximity to the median, a z-scored normalization will produce greater variation than other procedures. The other two normalization processes produce a smaller range of values and arc therefore more likely to be close to the median than z-scores. But it could be interesting to see whether standardisation followed by rescaling gives useful values. Hence we rescaled the values of the z-score to bring them back to a scale 0 to +infinity, giving the value 1 to the mean. Where $z_{i}$ is the result of the standardization process

$$
z_{i t}^{N}=\frac{x_{i t}-\overline{E U_{t}}}{\sigma_{E U t}}
$$

Rescaling is performed by:

$$
r_{i t}^{N}=\frac{z_{i t}-\overline{M i n z_{i t}}}{\overline{M i n z_{i t}}}
$$

\subsubsection{Weighting}

Any scalar indicator that combines several components must somehow weight those inputs relative to each other, for which here there are four reasonable options:

1. Equal weight to the three variables. In other words, calculate an arithmetic mean.

2. Factor analysis based on the correlation matrix. To get these weights we work with the correlation matrix. For every year, we calculate the correlation matrix using the three values of each variable, then calculate the eigenvalues of the correlation matrix. The weights based on these eigenvalues are taken as indicated by the OECD. 
4.3. Methodology to construct composite indicators

3. Factor analysis based on the variancc-correlation matrix. The procedure is similar to the previous one, but instead of a correlation matrix we use a covariance matrix. This gives weights that are based on the actual value of the variance instead of the correlation coefficients.

4. The 'benefit of the doubt' approach (BOD). The idea behind this technique is to choose the weights that maximize the value of the indicator. The best way to maximize it is to give the weight 1 to the maximum value of the three normalized variables. But, since we also want a composite indicator in which the three values are present, we constrain the maximization. The OECD report proposes the fixed weights of $0.5,0.4$ and 0.1 to restrict the maximization. With these weights we give a weight of 0.5 to the normalized variable that has the highest score and a weight of 0.4 to the second best; the lowest variable has a weight of 0.1 . This should give a better score than with the other weighting systems. But a closer look at the weights of the factor analysis gave us values which were near $0.8,0.15$ and 0.05 , and in some extreme cases even higher than these. Therefore in our maximisation calculations we use values of $0.75,0.2$ and 0.05. These three constraint values assure us that the scores of the indicators will be at a maximum in most cases, while keeping a reasonable presence of the three ingredients of the composite indicator. For a more detailed discussion of the advantages of this approach see Saisana et al. (2005), Bowen and Moesen (2005) and Cherchye et al. (2004)

5. The opposite of BOD. As with the benefit-of-the-doubt approach, this method is built to produce the best output. One can see that a bias is generated when BOD is included, especially on the median, since by creating so many BOD indicators the median is raised. To avoid this effect we include in the analysis an opposite of BOD; with a parallel procedure and the same weights we made the country score the minimum value.

We never calculated the indicator if any of the three indices were missing because we had already taken missing values into account by imputation. So the average (equal weights) has been calculated only if all three values were present. We consider this to be the most consistent way to proceed with the analysis. In the case of equal weights one possible alternative would be to recalculate the weights so as to get an arithmetic mean. For example, if the weights when we have threc indicators is $1 / 3$ for each, but if we are missing one, we could create the index using the weight $1 / 2$ for the remaining information. However to be consistent in the analysis we should follow a similar approach as that of the FA techniques to recalculate weightings, and this confuses the outcomes too much. Therefore to be consistent we have only calculated the output when none of the three variables had missing values. 


\subsubsection{Evaluation of performance based on the distance : the median}

In our uncertainty analysis we take thrce methods for imputing the data, fou malization procedures and five weighting techniques. Because we have add normalization process and one weighting technique to the OECD manual si tions, instead of 36 we have a maximum of 60 different outcomes for every cc for every year.

If data are missing the minimum number of outcomes will be 20; in thi we have information for this point only through regression imputation. This mation with four normalizations and 5 possible weighting systems gives $20 \mathrm{p}$

Every possible outcome will be determined by combinations from tabl When talking of indicator 311, we mean that we used regression imputation putation 3), the normalization procedure 1 (distance from the European $\mathrm{r}$ and we are using no weights (weighting 1 ).

\begin{tabular}{|l|c|l|}
\hline PROCEDURE & & TECHNIQUE \\
\hline \hline \multirow{3}{*}{ Imputation } & 1 & No imputation \\
\cline { 2 - 2 } & 2 & Mean imputation \\
\cline { 2 - 2 } & 3 & Regression imputation \\
\hline \multirow{3}{*}{ Normalization } & 1 & Distance from the European Mean \\
\cline { 2 - 2 } & 2 & Standardization \\
\cline { 2 - 2 } & 3 & Rescaling \\
\cline { 2 - 2 } & 4 & Standardization and rescaling \\
\hline \multirow{5}{*}{ Weighting } & 1 & No weights \\
& 2 & FA weights correlation matrix \\
\cline { 2 - 2 } & 3 & FA weights covariance matrix \\
\cline { 2 - 2 } & 4 & Benefit Of the Doubt \\
\cline { 2 - 2 } & 5 & Opposite Benefit Of the Doubt \\
\hline
\end{tabular}

Table 4.2: Different indicator outcomes 


\subsection{Methodology to construct composite indicators}

Each country in each year has either 20,40 or 60 outcomes as it was explained in subsection. We calculated the median for each country and year across methods. For every year and country we will have a single median. Then calculated the distance of each method to the median for that specific country and year with the following formula:

$$
d_{i t}^{c}=\sqrt{\left(x_{i t}^{c}-M e d i a n_{t}^{c}\right)^{2}}
$$

Where $c$ is a country, $t$ the year and $i$ a mothod. As we have said, the median was done on a country and yearly basis, the distance being calculated for each point. The values were summed for each method $(111$ - 345) to see which is the most stable one. Wc could do this for each of the four dimensions or try to find a single method that works best for each dimensions. We calculated both alternatives and the results where quite similar. Therefore we present the general case which sums up for all four dimensions.

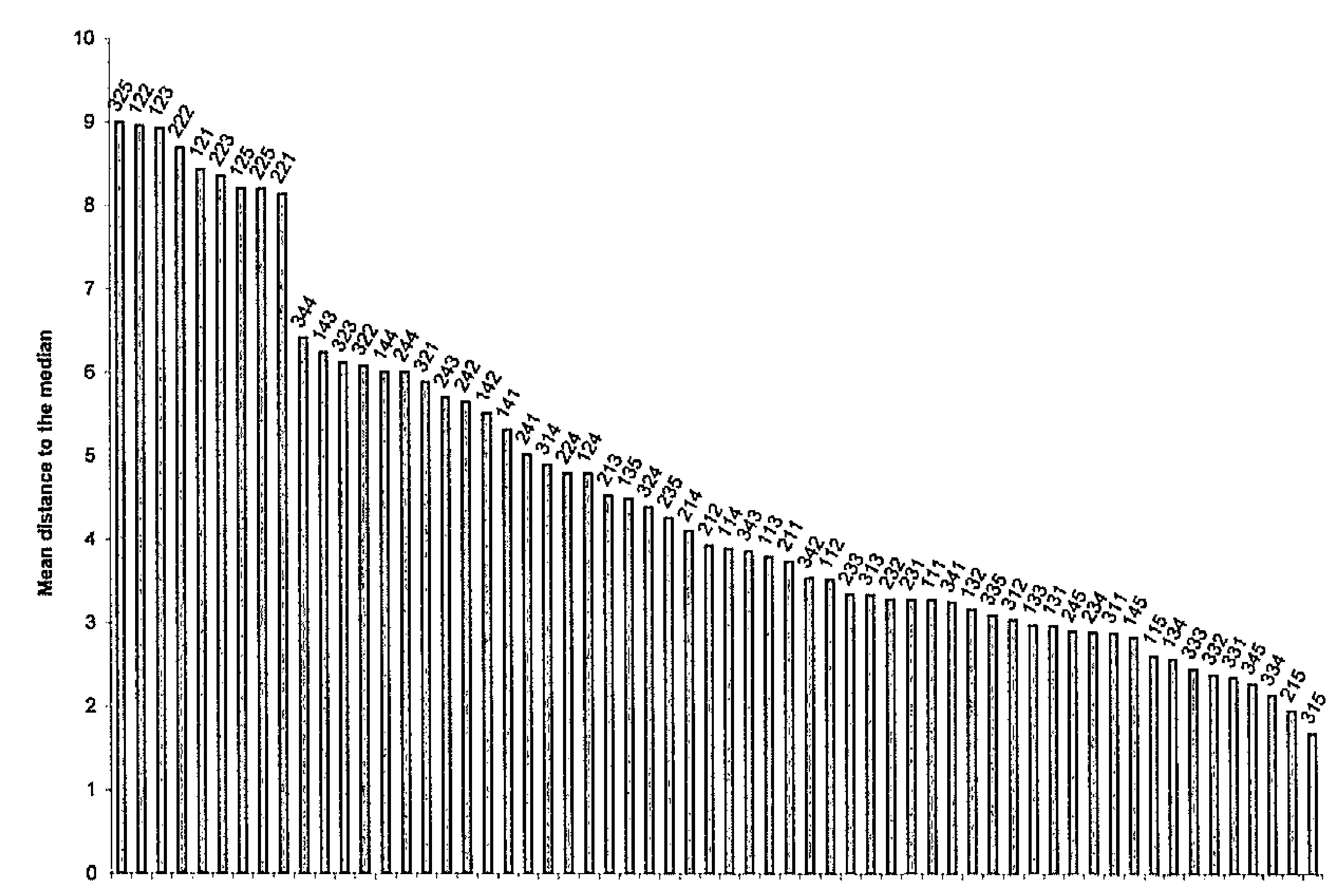

Figure 4.2: Results of the mean distance to median approach

The results of the analysis are presented in descending order in figure 4.2. Each column is the average distance to the median of the particular method. We could just look at this graph and choose the one that has the lowest score. This is 


\section{NSI AND The Role of Demand}

procedure 315 , which table 4.2 translates as: regression imputation, distance from the European mean, and Opposite to BOD approach (minimal weights).

Rather than rushing to a quick decision we thought it worthwhile to group every outcome according to the different steps taken. The first point is to consider how well the different imputation methods perform. The results are plotted in figure 4.3 according to the three different imputational methods and sequenced in descending order. The line across the bars is the average performance of each group. We immediately see that regression imputation is the techniquc that on average, taking into account all the uncertainty coming from the other procedures, scores closest to the median.

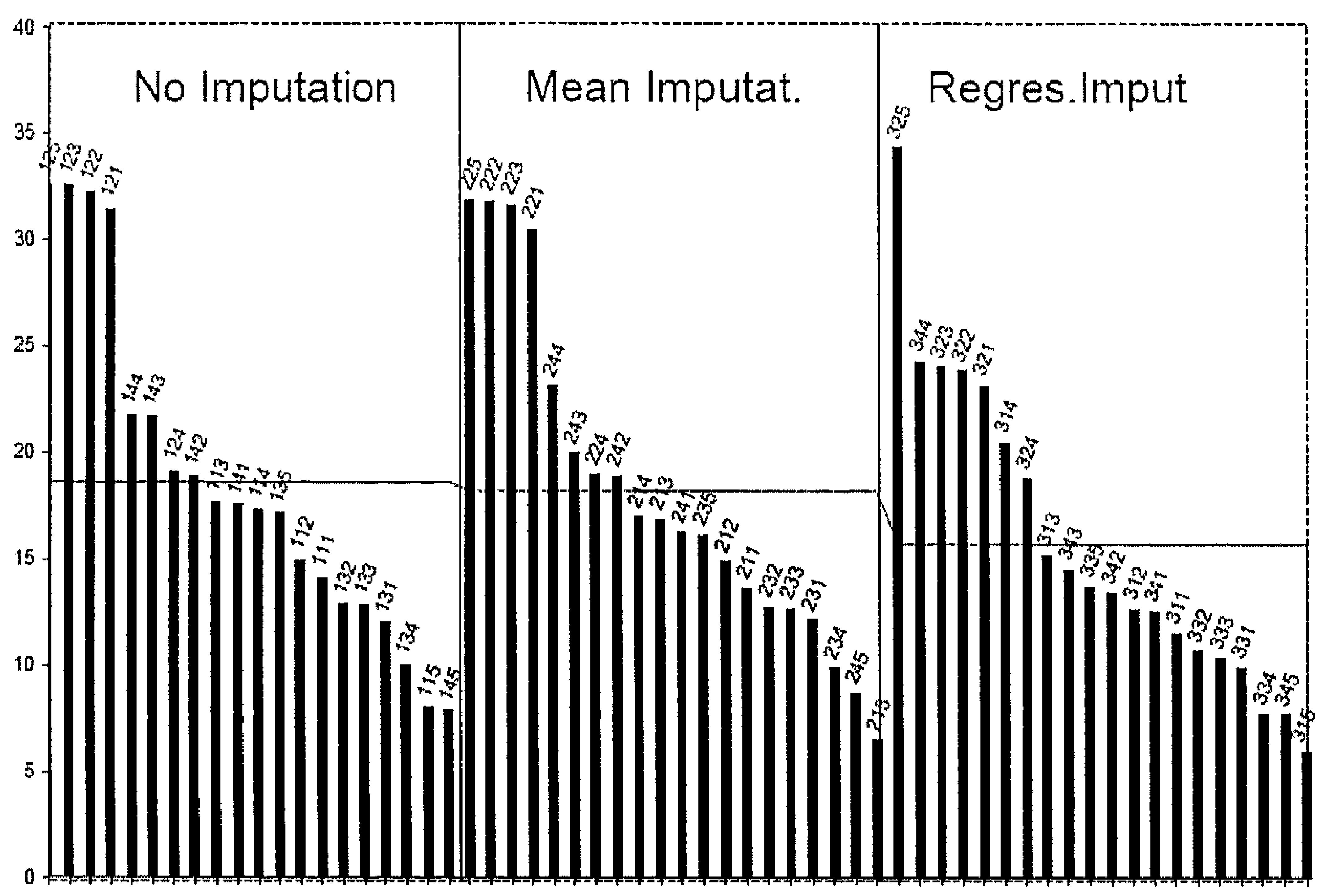

Figure 4.3: Imputation techniques

We did the same for the different normalization techniques, as presented in figure 4.4. In this case it is important to remember in which range the values of the different techniques oscillate. The distance to the mean changes in theory between 0 and $+\infty$, giving 1 to the mean value. But in reality no indicator scores zero under this normalization technique. And it is hard to imagine any country scoring the double of the mean. The real values of our exercise vary within the range $0.3-2$. The standardization in theory varies within a range of $-\infty$ and $+\infty$, though in the implementation of the exercise it ranges from -3.5 to 3.5 . This may be one reason why the average distance to the mean is so large. This also explains why rescaling seems to scorc so well, because the maximum variation 
lies within the range 0-1. The extra normalization process that we introduce in the analysis, ranges within $0-+\infty$. This makes it comparable to the distance to the mean process because the ranges are similar, but the dispersion in the second case is bigger due to its coming from the standardization process. When we chose this last method, we took the output of the standardization ranging from $[-\infty$ and $+\infty]$ and rescaled it to $[0++\infty]$ giving the mean the value 1 . Probably if we rescaled to $[0,1]$ the average behaviour would have remained more constant to the median value.

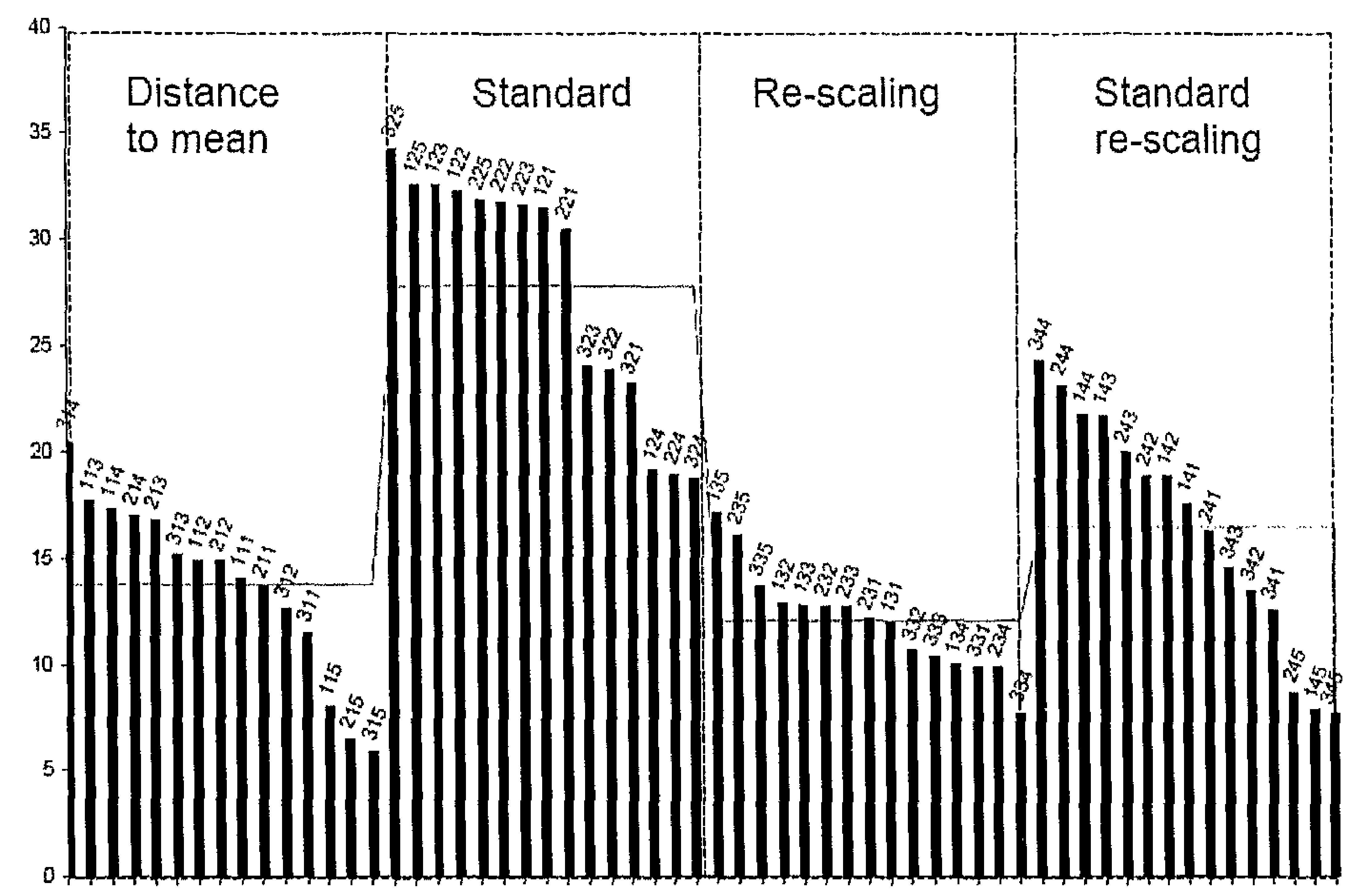

Figure 4.4: Normalization techniques

For the best normalization process we could either choose the distance to the mean or rescaling. But since we want to have some economics results and study the implications for each system, it is more intuitive to work with the distance to the mean. It makes our analysis easier to explain.

A first look at figure 4.5 seems to put the different weighting systems in very similar positions. It is interesting to look at the artificial minimum weight system. The procedures 325,125 and 225 have a very high clistance to the median, because we are using a standardization process which give us very high negative values and which, through the weighting system, makes the indicator score low. So probably these indicators are very far from the median. With the BOD approach, or maximum weight, the behaviour seems to be more moderate. The weights that 


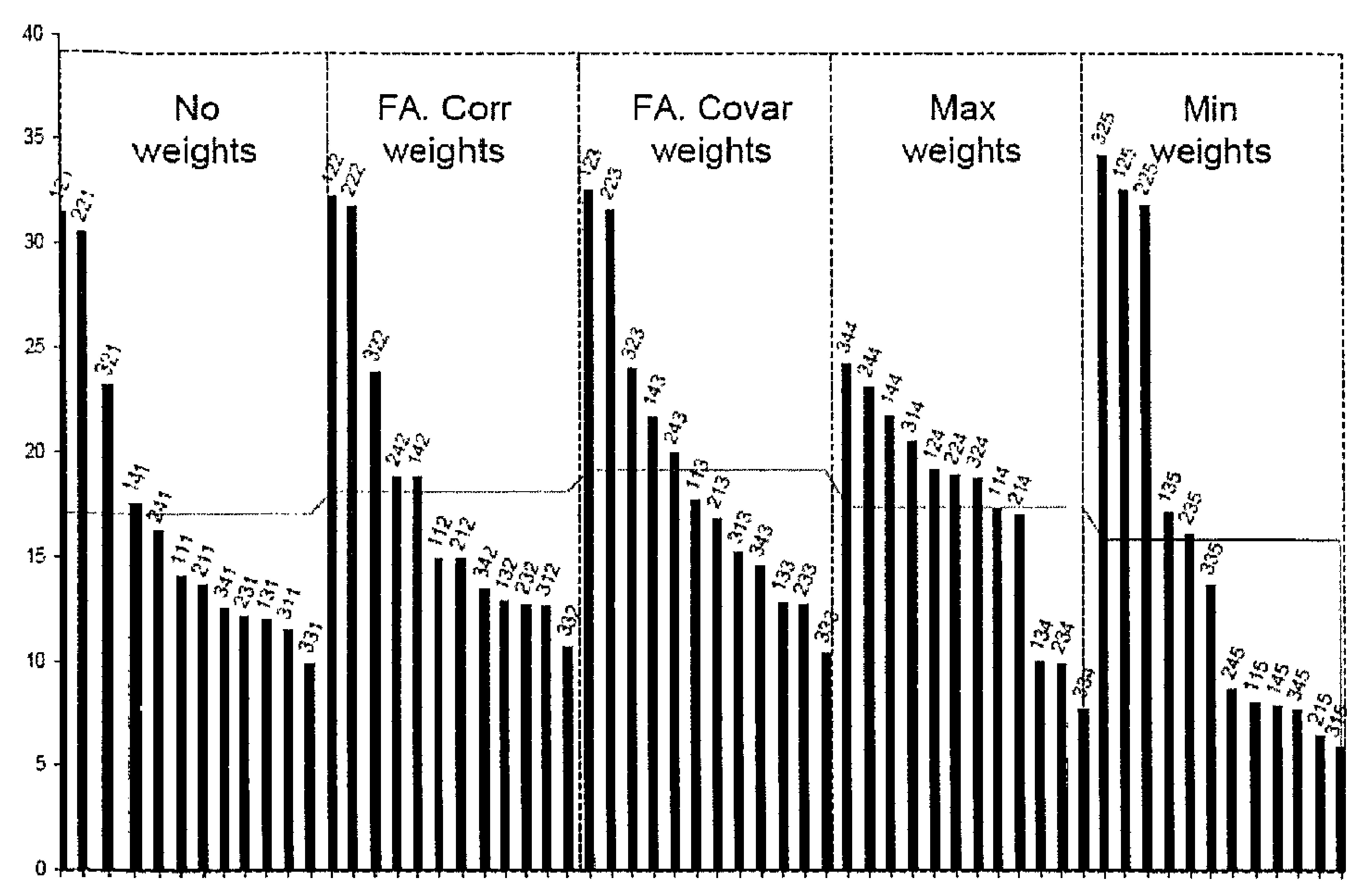

Figure 4.5: Weighting techniques

we used were $0.75,0.20$ and 0.05 . Decreasing these weights, using for example the limits to the weights suggested by the $\operatorname{OECD}(0.5,0.4$ and 0.1$)$ will reduce the mean behaviour of this procedure. The simple average, or no weighting system, seems to perform just as well as the others. So for simplicity and clarity of interpretation we chose this one.

Let us recapitulate our conclusions. The goal is to combine different variables to construct a composite indicator; several options are presented in table 4.2. To understand what happens we decided to compute all the options and carry out a sensitivity analysis. To assess the best choice we computed the distance of each combination to the median, as presented in Figure 4.2. A discussion of the effect of each decision concerning missing values, normalization and weighting clarifies the effect of each of this step on the final variation of the index when compare with a median average of all of them. The highest disturbances are introduced in the normalization step. The imputation of missing values and component weighting seem to have little effect on the final value of the index. The overall procedure which gives the lowest scores is 315 (regression imputation, distance from the European mean and Opposite to the BOD weights). However the Opposite of the BOD technique had been introduced to compensate for the biasing effects of the BOD (Benefit Of the Doubt). Therefore, the low score of this procedure is artificially generated. If we disregard indexes that have used the Opposite of the BOD approach, and we choose the best ten choices we have: $334,331,332,333$, 
4.4. The economic implication of the indicators

$134,311,234,131,133$ and 312 . Which means that the combination of regression imputation and rescaling or mean normalization in general produce results that are closer to the median and indicates that such combinations of techniques in general are quite stable and introduce very little disturbances. The ranking might vary with the data set. However any of these combinations produces a indicator that in terms of distance to the mean are very similar. We shall choose procedure 311. The choice is based firstly on its rather stable behaviour, secondly on the economic interpretation of the index, and in relation with the exercise that we are going to do. We want to compare economic performance of European countries. If we choose 311 we will be comparing with the European average, which has an economic interpretation. So our choice is among the most stable techniques while useful for our next section. Therefore the decision of choosing the procedure for us in this case is a combination of the performance of the index and of its economic interpretation.

\subsection{The economic implication of the indicators}

Before considering the economic implication of these indicators directly, we shall first reflect on what innovation means for a knowledge society. An innovation is nothing but the creation of value out of an idea. If the idea is associated with the concept of invention, the innovation is the economic value of the invention. For value to be created the new idea has to be connected to the market through new goods or services, or through better ways of producing, marketing and delivering the goods. The final acceptance of the value of the innovation comes from the market, the interaction between the two forces of demand and supply. We shall study the links between the different aspects that we consider essential for a National System of Innovation to function well. The idea of this paper is to compare the whole process for each country in the sample.

Knowledge seems to be the key word in the process, and therefore we speak of a knowledge econorny as being the central input in the production of wealth. It is generally accepted among economists that there are two forms of knowledge: embodied or tacit and codified or disembodied. Embodied knowledge is present in people's experience and is hard to transmit. Codified knowledge is presented in a form that someone else can understand, such as a patent, a publication or a book. We shall look at the relation between these two forms of knowledge, embodied and disembodied, and try to see how these two dimensions affect the generation of value in the interaction between supply and demand.

\subsubsection{The four dimensions and their variables}

We can now take a more detailed view of how we built the indicators and why we chose each of the variables in the composite indicators. The four dimensions are:

- Human Capital: The quality and quantity of human capital are fundamental 
to innovation system performance in that it is through this that knowledge can be transformed into inventions and later into innovations: new processes and products. We are interested not only in the capacity that a country has to educate its population but also in spreading existing knowledge. Therefore we use three variables for this compositc indicator. They are a mixture of input and output variables related to the national effort to build up human capital. As an input of the national effort we use expenditure in education as a proportion of GDP. As an output variable to indicate how well the population is educated we use the percentage of the working population with tertiary education. We do not imply that tertiary education is the only relevant factor but take it as the tip of the iceberg of the education system. The third component is the proportion of the working population involved in life-long learning to keep up-to-date with evolving knowledge.

- Knowledge: in this dimension we wish to assess the effort realised by the nation to push forward the frontier of knowledge and how much the nation is using this knowledge. The three variables that we consider herre are: public expenditure on $R \& D$ as an indication of the national capacity to contribute to basic research or basic knowledge, the number of scientific publications per capita as an output indicator of knowledge performance showing how well the resources are used to produce codified knowledge, and the number of internet users per capita as a measure of how quickly knowledge diffuses in each country. It is not only scientific knowledge but also information about new products that is diffused more rapidly via the internet. ${ }^{2}$

- Supply Innovation Capacity: In this dimension we want to understand the national capacity to use human capital and existing production knowledge in more efficient ways. We consider here the labour productivity index, thinking of the reduction of cost (increase in productivity index) as a result of the capacity of the nation to take advantage of human capital and knowledge, business R\&D (with objectives other than basic research) as a private effort to generate the specific knowledge that the production needs and the proportion of high-tech exports as a measure of how competitive the specific country is in its exporting capacity.

- Demand Innovation Capacity: This is a parallel concept to the previous one; we are interested in the capacity that knowledge and human capital has to increase the sophistication and needs of the nation. We try to assess the impact of a society, more qualified and with greater access to an increasing stock of knowledge, to create a more favourable environment for the creation of innovations. To compare this dimension across countries we use the total expenditure in mobile

\footnotetext{
${ }^{2}$ Eurostat is producing a new indicator that is proportion of internet users who have used the net to find out characteristics of new products or services. This indicator will be much more accurate, but the time period is very short and hard to get the information we need for our interests. Both indicators were highly correlated.
} 
4.4. The economic implication of the indicators

phones per capita in order to understand how the habit of a new innovation varies across countries. We also take national marketing expenditure as a percentage of GDP as a national effort to diffuse new products and the proportion of GDP spent on final consumption, the notion being that a nation more ready to spend is more likely to generate new products. This dimension has a strong link with Chapters 2 and 3 of the thesis. In Chapter 2 we concluded that habit formation and novelty were the kcy to understanding preference evolution. For this reason we introduce the total expenditure in mobile phones per capita as a measurement of habit formation for innovations. To capture the intensity of the effect of novelty in the demand for innovation we introduce a relative measurement of marketing. In chapter 2 wc also concluded that an increasing number of habits has an effect on the propensity to consume; to capture this effect we introduce national consumption relative to GDP. Therefore the most important results of those chapters are being used in the composition of this index.

The first step that we take is to study the relationships among the four indicators. For figure 4.6 we pooled together all the data for all years and countries and plotted in a scatter graph the four dimensions against each other, adding a linear regression line. The graph quickly shows that the first three dimensions of the NSI are highly correlated, while the indicator on demand innovation capacity is not. We review briefly the theories behind these relations.

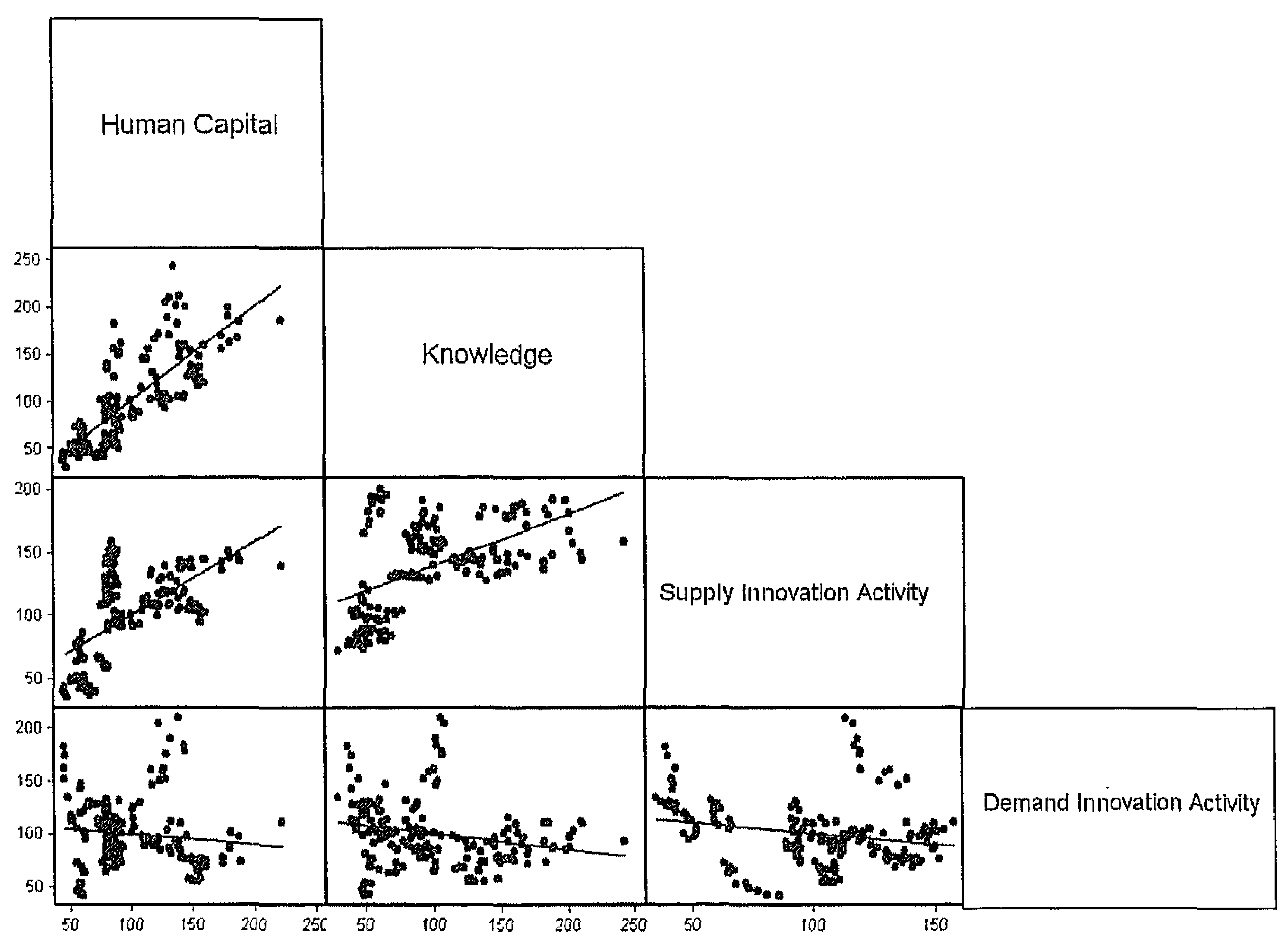

Figure 4.6: Correlations among the four dimensions 
The first square shows a very strong positive relation between the two indicators of a nation's human capital and its capacity to increase knowledge. This is supported by the idea that a highly educated population will have a higher possibility to push the frontier of knowledge. The square below shows the relation between human capital and the capacity that the working population has to improve the productive capacity of the country. We can see that here the relation is also quite strongly positive. Looking at the relation betwcen knowledge and supply, it can also be seen the relation is positive but less strong than the previous one. The slope of the regression lines of supply innovation activity show human capital has a stronger relationship with it than knowledge attainment. It is possible that the impact of knowledge runs through the human capital capacity to have its effect on the production side. The most surprising graphs are the three last correlations. In all three, demand is either not related to the other indicators or is negatively related. In principle, we would expect that a population with higher education contains more sophisticated consumer's. Also a positive relation would be expected between demand and knowledge bccause knowledge in principle should be transformed into better things which the consumer needs in order to have a more pleasant life, but from the graphs this relationship is not apparent. A closer look at the figure shows that the cloud of points is subdivided into several small cloudlets, each probably from a different country. Therefore we decided to look at the relations at the country level. The next section shows a clearer view of this demand effect. The explanation is that there is a very positive relation for some countries while a very weak relation for others.

\subsubsection{The four dimensions at the country level}

The database is constructed as a panel data structure, which means we have evolution of the countries over time. In our sample we have European countries for the period 1993-2003. For every country we have a total of 10 years. The annual index is the position of the country relative to the EU-15 mean, therefore it need not always increase. The value of the indicator in each dimension should be interpreted in relation with the mean, so if a country's index for one dimension is constantly increasing over time then its position relative to the EU-15 average has been improving over the years.

The following graphical analysis allows us to understand the evolution of each dimension related to the European mean. As a first examplc we use the Dutch case; the data are prescnted in figure 4.7. The left-hand side of the figure plots the evolution of the indicator over time. The right side shows the relations among the four dimensions and how are they linked in their evolution.

The left-hand column of four graphs presents the evolution in time of each of the dimensions: Human Capital (HK), Knowledge Creation (KN), Supply Innovation (SI) and Demand Innovation (DI). In each square there is a red line marking the level of the European mean. The line remains constant over time because it 
4.4. The economic implication of the indicators

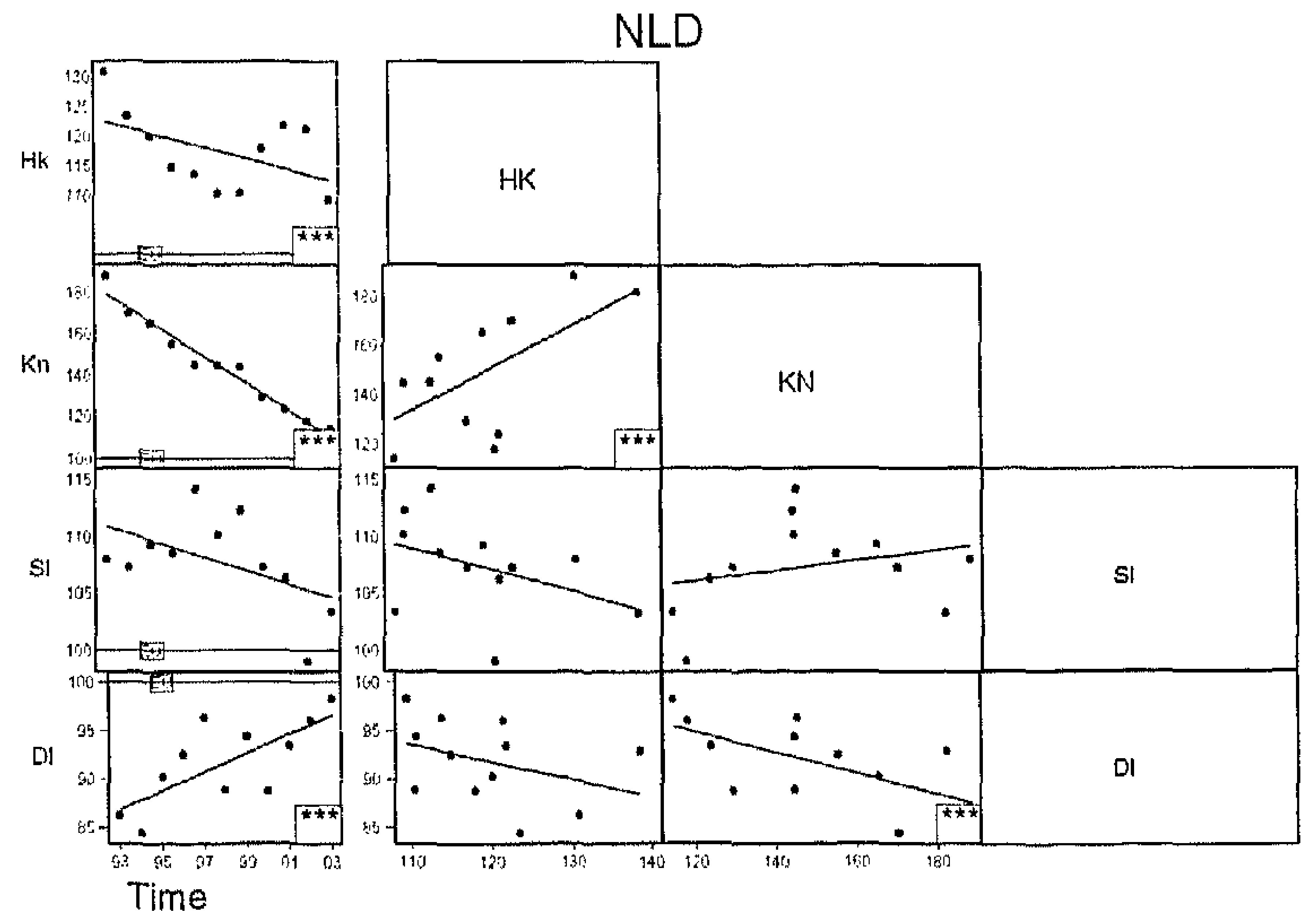

Figure 4.7: Netherlands - National System of Innovation

has been used as a base to build the indicators. Each point is the value that the indicator takes for a given year. The line between the points is a linear regression ${ }^{3}$, where we regress the value of the indicator over time to get the linear trend. If the indicator's trend is statistically different from zero at the $1 \%$ level three stars appear at bottom right; two if it is significant at $5 \%$, one star if it is significant at $10 \%$, and no stars in any other case. For example, let us concentrate on the top left graph, which presents the evolution of HK over the years. In figure 4.7 human capital over the years is approaching the level of the European Union. This means that there is some convergence in this dimension toward the European average for this country. The three stars show this tendency is statistically different from zero at the $1 \%$ level. The same can be said for Knowledge Creation. But if we look at the supply innovation capacity of the country, even though we see that the trend is negative and moving towards the European mean from above, it is not significant. In this case we observe that the level of the country remains constant over the period of study. Such stability explains the non-significant coefficient.

On the right of the figure a matrix of plots is presented. In each of them the variables are being regressed to each other ${ }^{4}$. The linear regression line is also plotted and the stars explain the significance level on the same pattern as that presented in the previous paragraph. In this figure we can see that the movement in the dimension of human capital is related to the creation of knowledge, but we

\footnotetext{
${ }^{3}$ It is a regular OLS regression in which we regress the values of the indicator over a linear time trend. The significant level is related to the beta coefficient of such an exercise.

${ }^{4}$ Similar to the previous OLS case but now we regress one indicator against another. The level of significance of the beta coefficient of such a regression is represented by the number of stars.
} 
find no significant relation between this indicator and the changes in supply and demand innovations.

The Dutch case is a typical case of convergence, in which all the variables are moving towards or are close to the EU mean. The indicator's explanatory significance is reduced if the country always remains very close to the mean. Despite that, the graph of the Netherlands could be a good example of a good pattern of evolution in all dimensions.

\subsubsection{Weak links}

We consider that a country is doing well if the country is growing in each of the dimensions. European countries differ in their initial value of each index. We define a weak link as a dimension which is below the European mean and is decreasing over time. To shorten the analysis we shall select just three representative countries in which only one dimension seems to be weak. The rest of the graphs are presented in appendix D.1.

In these cases we suggest that policy should focus on the weak dimension. We cannot define the policies that should be applied; we only identify the area in which the country needs to make the most effort. Let us have a look at three specific cases: Ireland, Spain and Sweden.

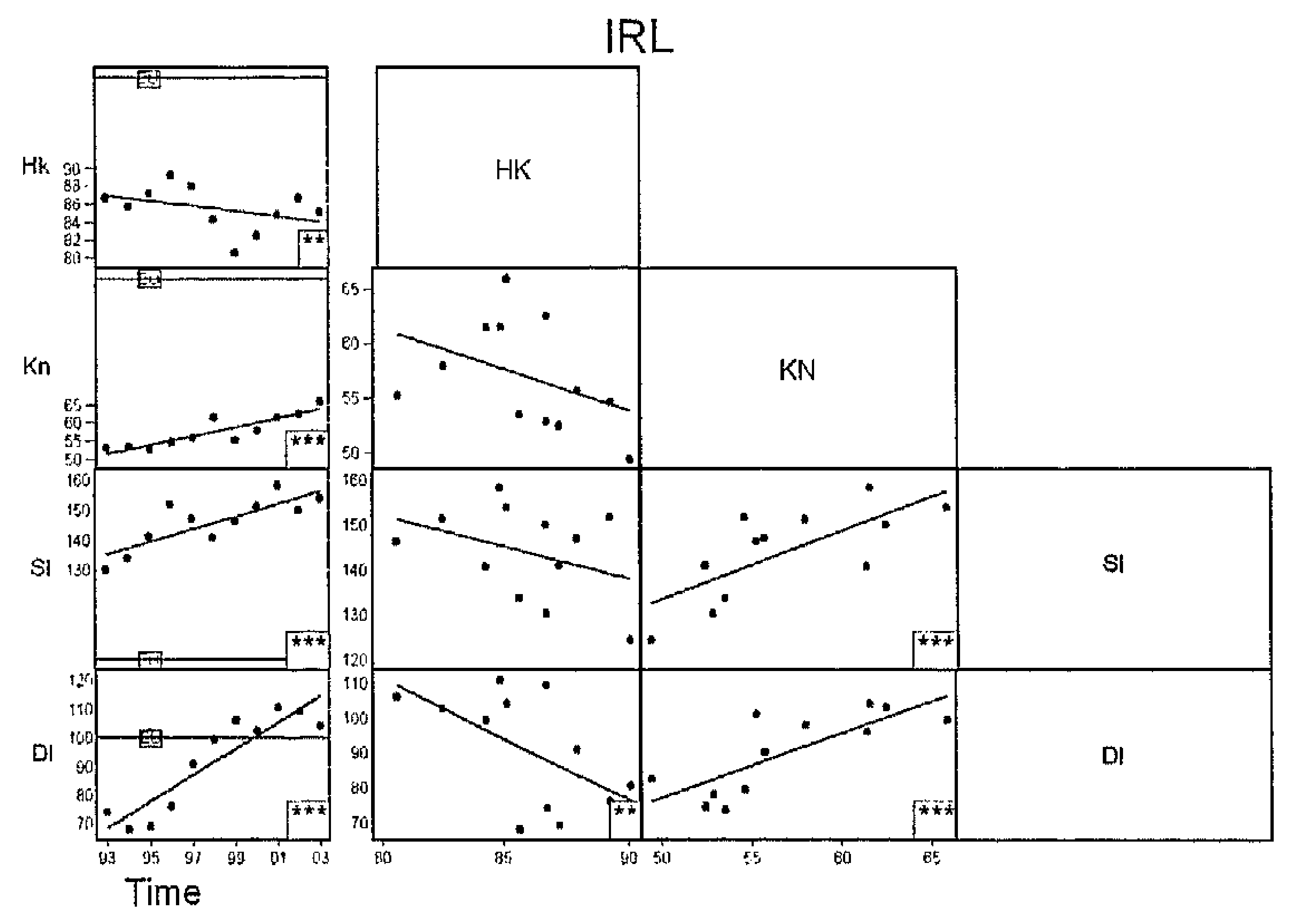

Figure 4.8: Ireland - National System of Innovation

The Irish system is presented in fig 4.8. Out of the four dimensions human capital is the weak link. Knowledge, even though behind the rest of the countries, is significantly approaching the average. The capacity to use knowledge to produce, i.e. the innovation capacity from the supply, is above the average of the EU and presents a divergent tendency. The demand capacity is also positively growing. 
4.4. The economic implication of the indicators

The weak link appears to be the formation of human capital. In the first square we can see the tendency to fall behind the other countries. Clearly out of this brief analysis the policy recommendation would be to strengthen ways to generate human capital.

One possible answer comes from considering that what is being represented here is the national effort to educate their population. One might wonder how to generate knowledge if the people are insufficiently educated. In the Irish case one possible answer is drawing in highly educated immigration. That international effects of each dimension are not represented in the graphs is a shortcoming of the study. At the same time we observe that the national creation of knowledge has a positive impact on the demand and supply of innovations.

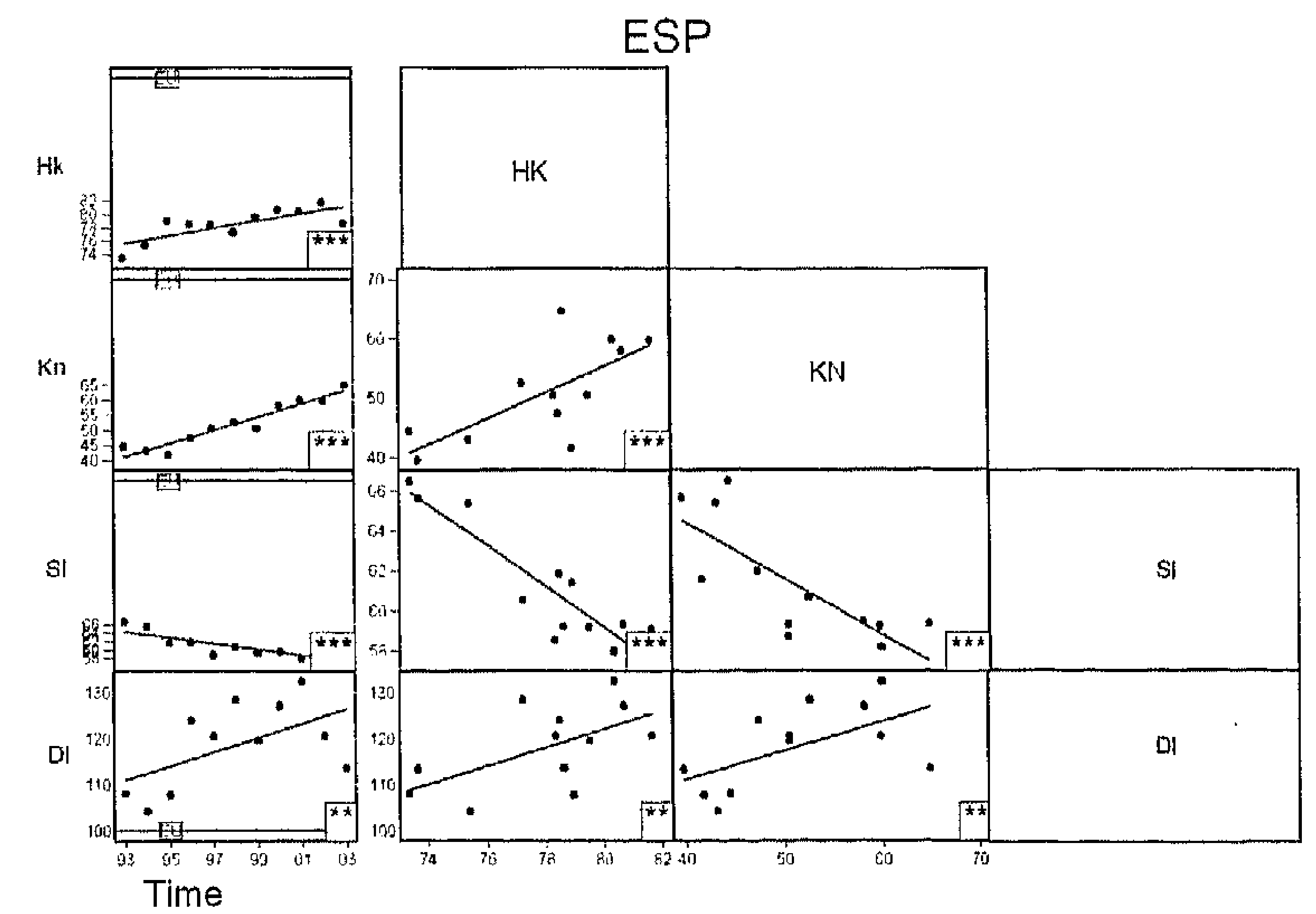

Figure 4.9: Spain - National System of Innovation

In the next example, the Spanish case (figure 4.9), the weakness of the system comes from the incapacity of supply to use knowledge. However, we see a positive tendency for creation of knowledge, human capital formation, and demand innovation. The supply innovation variable lags behind the EU average and cloes not show any tendency to converge. The interlinks presented in the matrix of correlations shows that knowledge, in both tacit and codified forms, has a positive impact on the evolution of demand but it lacks the capacity to boost the innovation on the supply side. Clearly in this case policy should be focussed on linking the existing knowledge with the improvement of the production process.

The last case presented is Sweden, figure 4.10. In the first three dimensions they are converging from above towards the European mean. In human capital, the tendency to fall is insignificant, which means that Sweden has found ways to maintain its superior education. In knowledge production it presents a tendency 


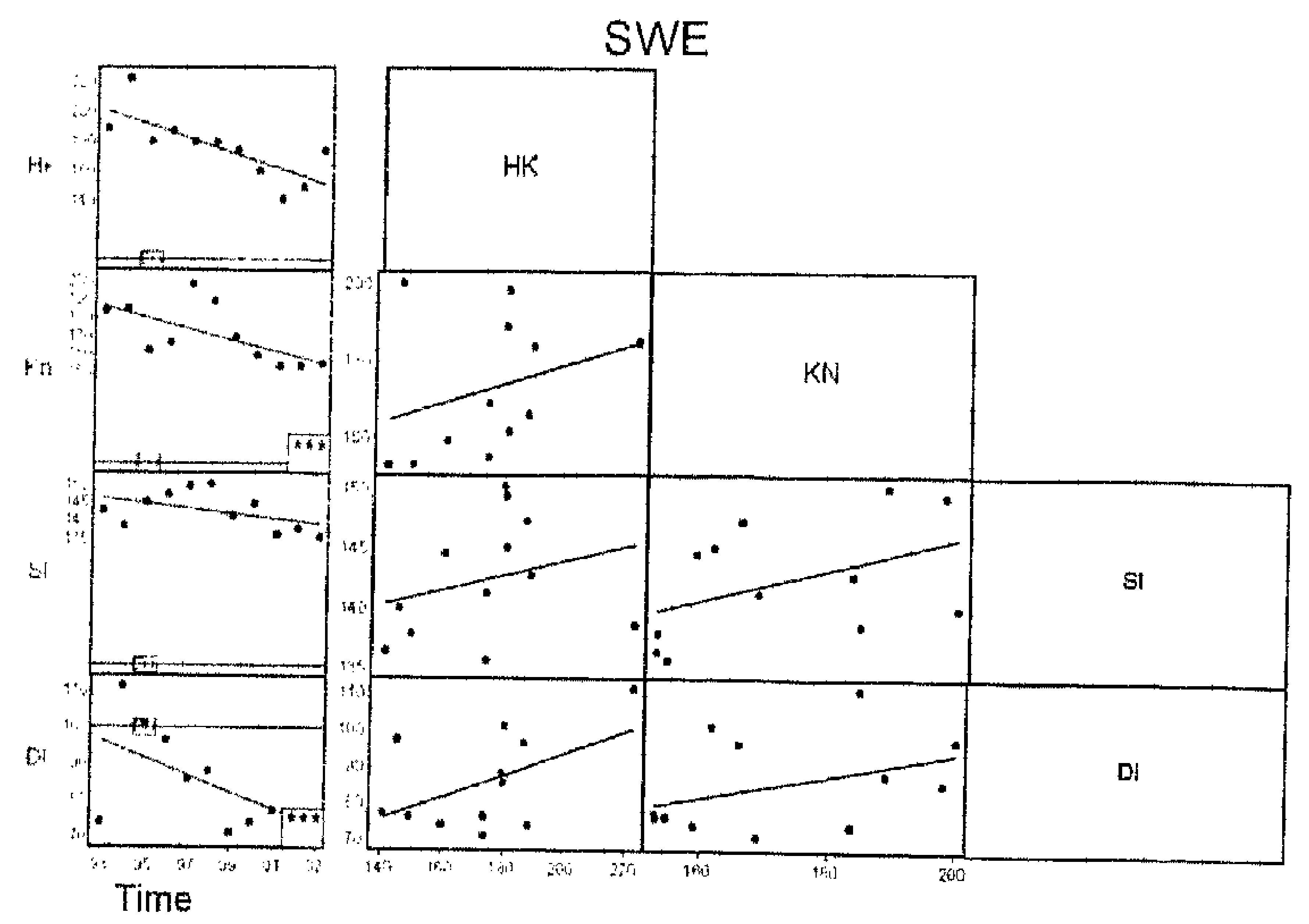

Figure 4.10: Sweden - National System of Innovation

to reach the European mean, but from above the average. The supply innovation capacity also shows a stable case of superior capacity. This country presents its weakness on the demand side, where it is not only below the mean but falling: behind. A possible explanation, as in the Irish case, is that this country relies on international demand instead of national demand. However, this dimension it is not captured by the statistics.

\subsubsection{Country Groups}

After a detailed analysis of the bchaviour of each country we are able to find some commonalities. First of all, we present a group of countries formed by Austria, France, the Netherlands and Italy, which show, in figure 4.11, a significant convergence towards the EU mean in most dimensions either from above or below. The best case is the Netherlands. Austria presents perfect behaviour, with a capacity to push the frontier of knowledge much faster than the rest of the countrics. France and Italy lag behind in human capital formation.

The Scandinavian countries make up the next group. In figure 4.12 we see that three countries, Sweden, Finland and Denmark, have strong patterns in three dimensions: human capital, codified knowledge creation and in their capacity to use this knowledge for the supply side of the innovation. But also all three present a very weak pattern in demand innovation. They seem to lack the capacity to use the knowledge they have to activate the demand. One possible explanation could be that these countries are focussed towards international demand rather than the national one.

In figure 4.13 we have Ireland, Portugal, Greece and Germany. The main com- 
4.4. The economic implication of the indicators

monality is their low capacity to produce knowledge. In both forms of knowledge, tacit and codified, they have weak links in their NSI. Very low trends for human capital and, with the exception of Greece, all of them seem to be lagging behind in this dimension. A low standard also for codified knowledge although all present converging patterns. 

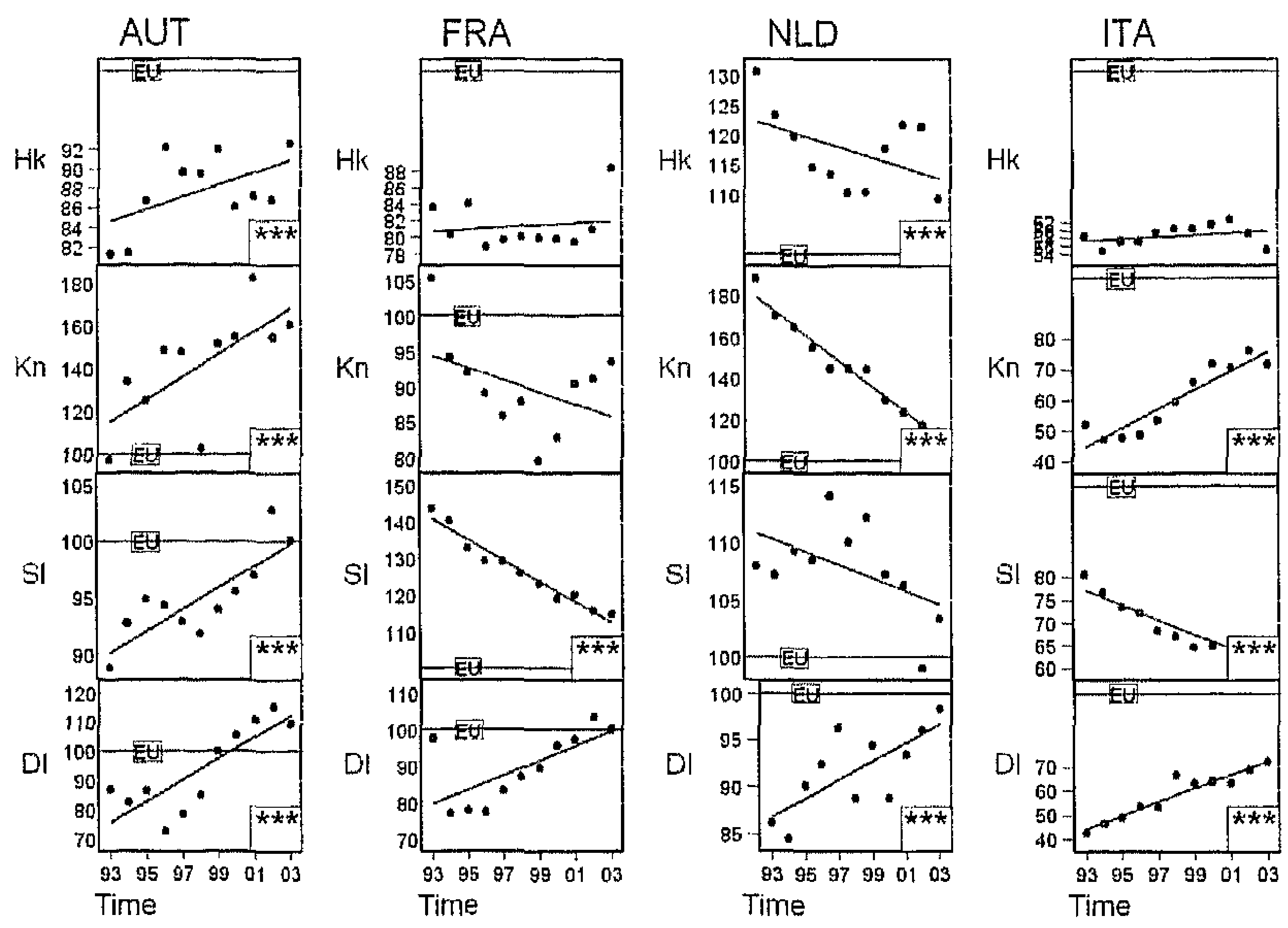

Figure 4.11: Countries presenting converging patterns
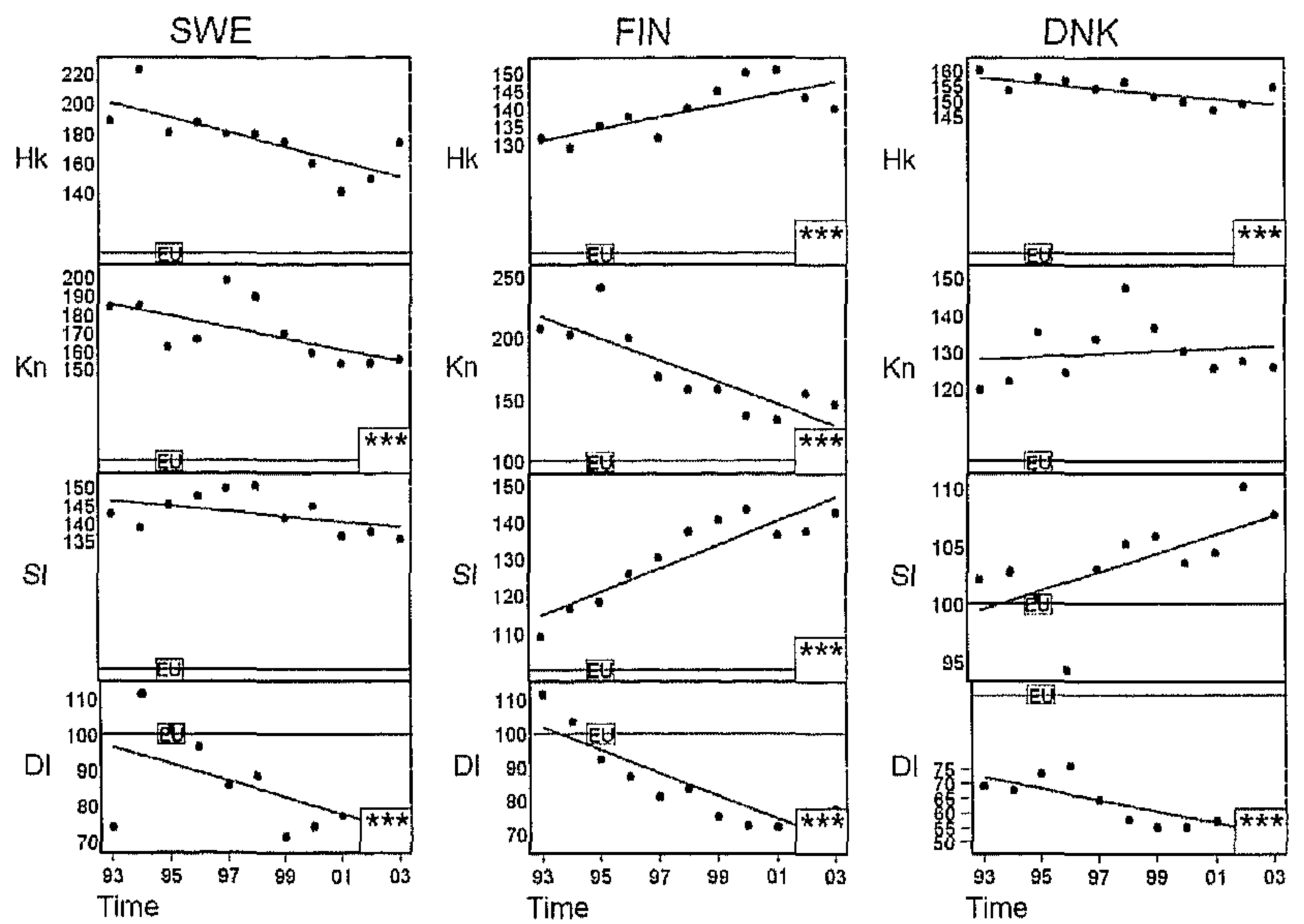

Figure 4.12: Scandinavian countries 

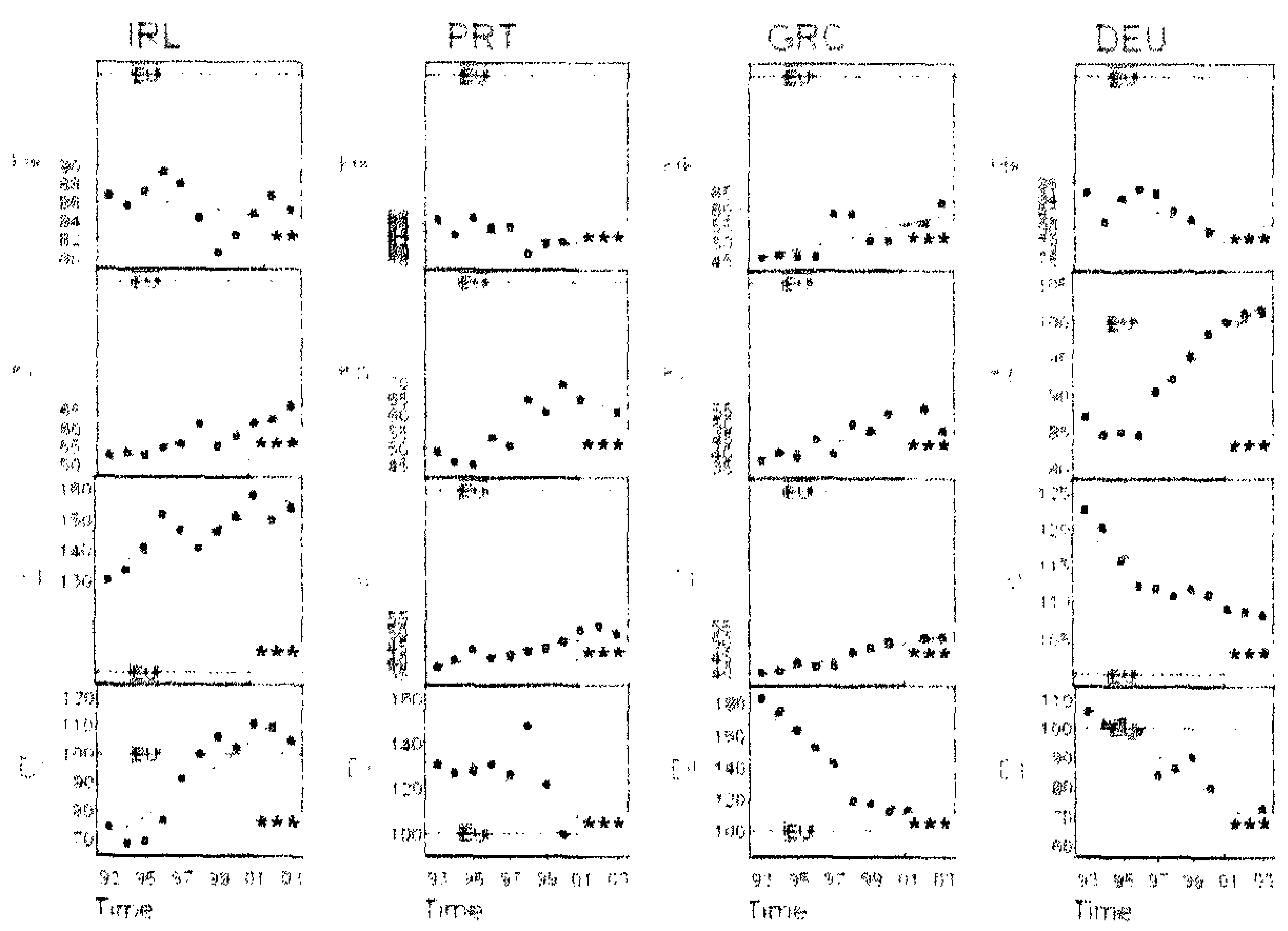

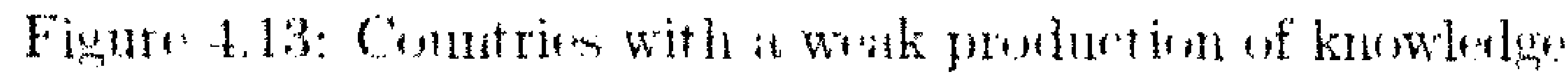
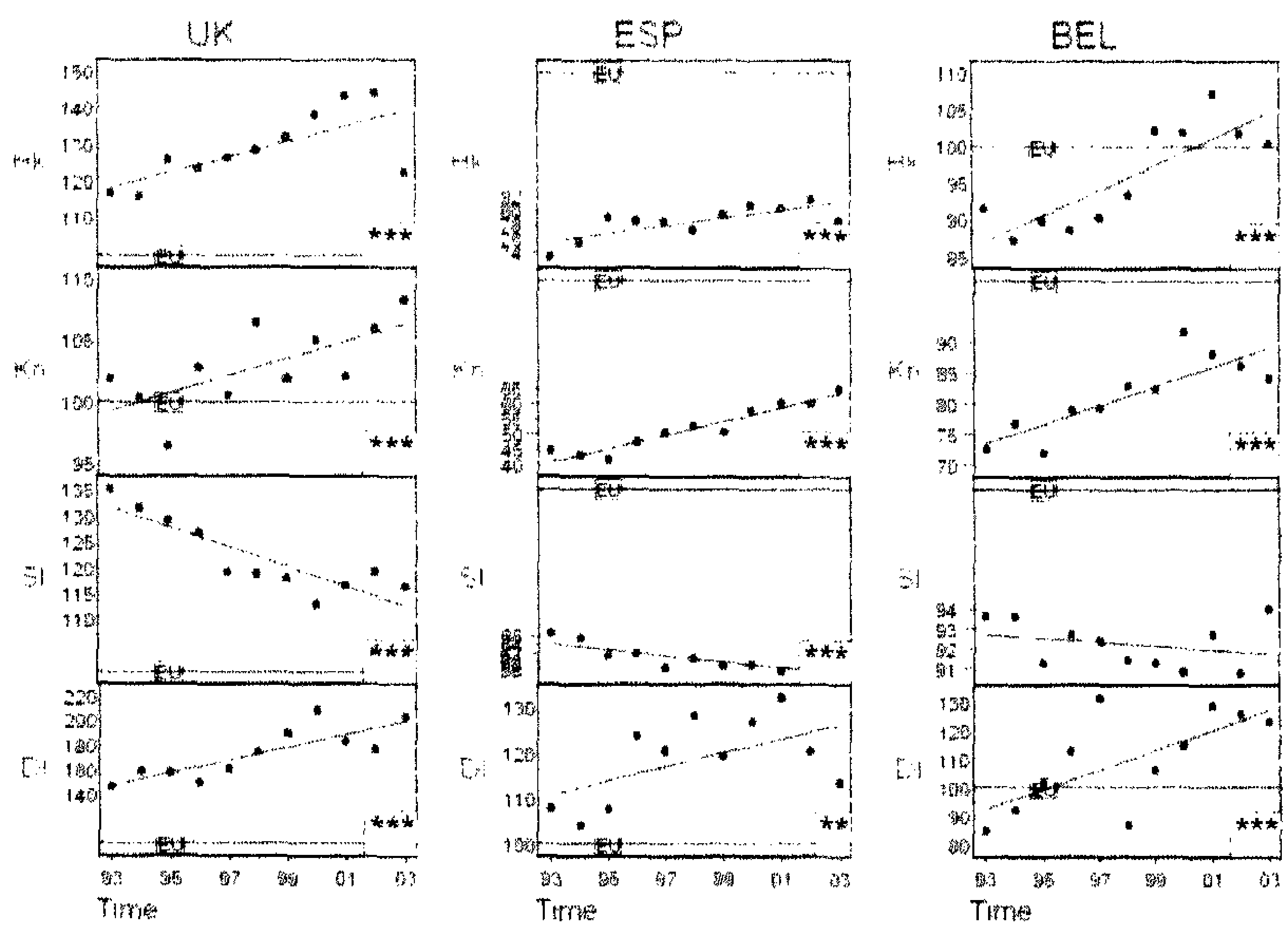

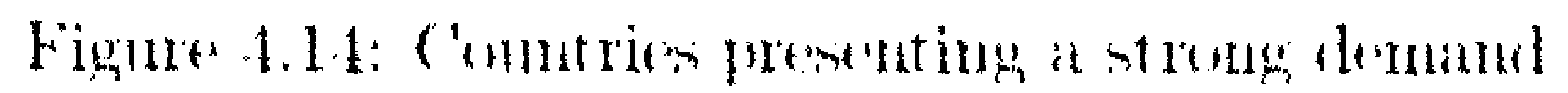




\section{NSI AND THE ROLE OF DEMAND}

The last group is formed by the United Kingdom, Spain and Belgium. They are represented in figure 4.14. Their common characteristic is the strong growth on the demand innovation side. The UK shows a very strong tendency to boost human capital which is the case of neither Belgium nor Spain. However, the latter two do not present a weak link, as we defined it, in human capital since both are converging toward the European average. Morc important, in their case, is the weak link in the supply innovation dimension, where policy should be focussed more intensely.

\subsection{Conclusions}

Exercises that have tried to quantify National Systems of Innovation have not brought dynamics into the discussion, most of them concluding with a single index and a ranking for each country in the index. In our exercise, presented here, we observe in more detail the shortcomings of each country. Not only the evolution of the index brings new light on the way that countries are progressing but it also highlights weak links of systems. These weak links are the points where policy action should be taken, assuming that each of the dimensions present some complementarities with the rest of the system. One conclusion of this chapter is that a healthy national system of innovation is one that is able to generate synergies by linking different segments of society. We were able to study the interaction of four of these dimensions.

The inclusion of demand as a more active component of the system brings us some interesting conclusions. First, Scandinavian countries, that normally stand above the European average in innovation activities, present a very weak demand side. Others such as the UK, Spain and Belgium present very strong growth in this dimension. With the analysis we have also seen that the EU-15 countries present very different capacities in their NSI.

Another important conclusion deals with the methodology of building indicators. We have presented a sensitivity analysis on a possible way to choose the best technique to build an indicator, which was then applied to a NSI framework. However the "minimum distance from the mean" is a solution which could help decide how to build indicators in many other areas.

Our analysis is limited by the availability of data and the difficulties presented by any exercise using indicators rather than values. The availability of data limited our capacity to study the effect of international forces on national systems, as in the case of Ireland where international human capital may be playing a very significant role which our framework does not capture. Further analysis and further development of economic indicators would be useful to clarify the implication of the relations that we found. 


\section{THE IMPACT OF GOVERNMENT FUNDING ON R\&D AND INNOVATION}

\subsection{Introduction ${ }^{1}$}

In the previous chapter we analysed the dynamics of different National Systems of Innovation. By studying the evolution of four dimensions we were able to identify weak links in some countries. In this chapter we wish to understand whether direct policy measures affect a country's innovation and if they have any impact on demand. Therefore we shall concentrate on product innovation as an intention to move towards "innovation aimed at demand". The effect on demand is approximated by the percentage of firms' total sales formed by new products. In a way, this percentage measures how close the innovation is to consumers' needs.

The input side of innovation is measured by the intensity of $R \& D$ expenditure. The output of innovation (our demand effect) is measured by the share of total sales due to innovative products, i.e. new or substantially modified products. Moreover, the share in sales of new products can relate to products new to the firm or new to the market. The former includes both true innovation and imitation, the latter

\footnotetext{
${ }^{1}$ This study was financed by the European Commission in preparation for the Competitiveness Report.

It was elaborated in collaboration with Pierre Mohnen.

We thank Heinz Hollenstein, Jordi Jaumandreu, Georg Licht, Jacques Mairesse and the participants of the final IEEF workshop in Madrid for many helpful comments. We also thank Martin Falk for running the programs for us with the original data at WIFO.
} 


\section{GOVERNMENT Funding AND R\&D}

only true innovations. Both types of innovation will be examined.

The goal is to evaluate how government intervention affects innovation. Arc firms that receive government support more successful than those that receive no public funding for innovation? Are funded firms closer to consumers' needs? The public support can be related to R\&D expenditure (as with R\&D tax credits) or also to help for other activities allied to innovation such as promoting new products and providing informational assistance for the introduction of new products. We shall not distinguish here between tax incentives and direct support measures. However, we shall examine the relative effectiveness of national versus EU-originating public support.

The present analysis is based on Austria, using the microdata of the Community Innovation Survey ${ }^{2}$, CIS 3, covering the years 1998-2000. Micro data are much richer in informational content than macro data; they yield information on innovators and non-innovators and they are characterised by a substantial heterogeneity, not only across industries but also across individual firms. It is then possible, and indeed necessary in order to get consistent estimates, to examine the effect of government support both on the propensity to be innovative and on the amount of innovation.

The analysis presents some shortcomings due to data availability. We shall analyse a cross-scction as habit-tracking is not possible. Neither have we introduced any idea of novelty ${ }^{3}$. Our results provide very limited measurable information of the effect on demand of funding policies.

The remainder of the chapter is organised as follows: section 5.2 presents the data and describes the relative importance of various funding sources for innovation in Austria, section 5.3 introduces the econometric methods that we use to infer the impact of funding for innovation and the reasons why we use them, section 5.4 presents and discusses the results of the estimation and section 5.5 provides a conclusion.

\subsection{Data}

The analysis is based on the microdata of the third Community Innovation Survey (CIS3) in Austria, covering the years 1998-2000. The CIS survey collects information on innovation output and R\&D and, at least for the firms that are innovative,

\footnotetext{
${ }^{2}$ The Community Innovation Survey contains information on another (wider) definition of innovation inputs, the expenditures on innovation, comprising intramural and extramural R\&D, acquisition of machinery and equipment for the production of new goods, the costs of acquisition of patents, licenses, know-how, etc., of training for innovalion, design and market introduction of new products. Statisticians do not consider these responses very reliable and report many non-responses to the questions. It was therefore decided to consider only R\&D expenditure as a measure of innovation input.

${ }^{3}$ In the CIS we find a question on R\&D expenditure which is close to our idea of novelty: market introduction of new products. But in addition to the reasons mentioned in the previous footnote the definition of this variable is not a clear measure of novelty. It is composed of marketing expenditure and expenses on market research. Although marketing expenditure is close to our idea of novelty, market research is not. Therefore we have not used it.
} 
it also asks respondents whether they received government support for innovation from local, regional, national and $\mathrm{EU}$ sources.

\subsubsection{Frequency of innovation in Austria in 1998-2000}

After a few identifying questions, respondents are faced with the following central questions:

- During the period 1998-2000, has your enterprise introduced on the market any new or substantially improved products?

- During the period 1998-2000, has your enterprise introduced any new or substantially improved production process?

- By the end of 2000, did your enterprise have any ongoing innovation activities?

- During the period 1998-2000, did your enterprise have any innovation activities that were abandoned?

A first way to characterize innovators is to consider as innovators those that have responded "yes" to any of those four questions. This is in the spirit of the CIS survey, where those who have responded "no" to all four questions are considered as non-innovators and do not have to respond to most of the other questions in the survey. We have therefore only scant information about non-innovators, an important point to which we shall return when we come to the econometric handling of the data. We can also be more precise and consider different types of innovators; are product innovators those who have responded affirmatively to the first question, are process innovators those who have responded affirmatively to the second question, and potential innovators those who had either ongoing but incompleted innovation activities or those who were not successful in their innovation activities in the three year time-span. Moreover, among the product innovators, we can distinguish innovators with products new to the firm but not to the market, who can be assimilated as imitators, and those with products new to the market, who can be regarded as true innovators.

After some basic cleaning of the dataset ${ }^{4}$, we end up with 1287 observations. Of those, 42 percent declare themselves as innovators. Among those, 77 percent are product innovators offering products new to the firm and a lower fraction, 35 percent, have come up with products new to the market, 63 percent come up with new processes, 75 percent are unsuccessful or not yct successful innovators, and 12 percent have had to abandon some innovation projects (see table 5.1). Of course, a firm may belong to various groups of innovators. Almost half of the Austrian innovators are both product and process innovators, and many successful

\footnotetext{
${ }^{4}$ The original dataset has been cleaned by eliminating 18 firms, 3 which report zero turnover or employment, 11 which belong to the primary sector and to NACE codes 37 and 73 because of insufficient data per industry, and 4 that have an R\&D over sales ratio greater then $48 \%$, which are suspected to be firms specializing in $R \& D$. Missing values for $R \& D$ and all explanatory variables such as sources of information or sources of government funding are set equal to zero.
} 


\section{Government Funding And R\&D}

\begin{tabular}{|c|c|c|c|}
\hline & $\begin{array}{l}\text { Number } \\
\text { observations }\end{array}$ & $\begin{array}{l}\text { Percentages } \\
\text { of all firms }\end{array}$ & $\begin{array}{l}\text { Percentages } \\
\text { of innovators }\end{array}$ \\
\hline Total & 1287 & $100 \%$ & \\
\hline Innovators & 546 & $42 \%$ & $100 \%$ \\
\hline \multicolumn{4}{|c|}{ Product innovators } \\
\hline New to firm & 418 & $32 \%$ & $77 \%$ \\
\hline New to market & 190 & $15 \%$ & $35 \%$ \\
\hline Process innovators & 346 & $27 \%$ & $63 \%$ \\
\hline Ongoing innovation & 409 & $32 \%$ & $75 \%$ \\
\hline Abandoned imnovation & 63 & $5 \%$ & $12 \%$ \\
\hline
\end{tabular}

Table 5.1: Distribution of innovator types in Austria, 1998-2000

innovators during the 1998-2000 period have ongoing innovation activities, which might turn out new products or new processes in the future.

The focus in the remainder of the analysis will be on product innovators because the CIS 3 dataset contains quantitative data on innovation only for this segment.

\subsubsection{Distribution of various sources of government support for innovation}

In the CIS 3 dataset, firms are asked about four sources of public support for innovation: from the local and regional government, from the central government, from the EU, and in particular from the EU 4th and 5th Framework Programmes for Research and Technical Development (RTD). The central government, including agencies working for the central government, is the most frequently cited source of public support for innovation, followed by local government, the EU and the Framework Programmes for RTD, be it for innovators, R\&D performers, new to firm or new to market product innovators. Again a firm may receive various kinds of public support.

\begin{tabular}{|c|c|c|c|c|c|c|c|c|}
\hline \multirow[b]{2}{*}{ Funding } & \multicolumn{2}{|c|}{$\begin{array}{c}\text { All } \\
\text { Innovators }\end{array}$} & \multicolumn{2}{|c|}{$\begin{array}{c}\text { R\&D } \\
\text { Performers }\end{array}$} & \multicolumn{2}{|c|}{$\begin{array}{l}\text { New to Firm } \\
\text { Product } \\
\text { Innovators }\end{array}$} & \multicolumn{2}{|c|}{$\begin{array}{c}\text { New to Market } \\
\text { Product } \\
\text { Innovators }\end{array}$} \\
\hline & Num. & $\%$ & Num. & $\%$ & Num. & $\%$ & Num. & $\%$ \\
\hline Local Gov't & 113 & 20.7 & 78 & 25.8 & 89 & 21.3 & 56 & 29.5 \\
\hline Central Gov't & 172 & 31.5 & 150 & 49.7 & 145 & 34.7 & 91 & 47.9 \\
\hline EU & 64 & 11.7 & 51 & 16.9 & 51 & 12.2 & 32 & 16.8 \\
\hline 4th or 5 th RTD & 46 & 8.4 & 40 & 13.2 & 39 & 9.3 & 22 & 11.6 \\
\hline
\end{tabular}

Table 5.2: Distribution of government support among innovators, Austria, 19982000 
A comparison of the percentage distribution of sources of funding among all innovators, R\&D performers and the two types of product innovators reveals that the $R \& D$ performers are more likely to get support for innovation than all innovators together (see table 5.2). Support for innovation is thus more concentrated on the input side than on the output side of innovation. It is also noticeable that new to market product innovators are more likely (higher percentages) to receive public support of some kind than new to firm product innovators.

\subsection{Methodology}

The question is whether government support for innovation from its various sources affects innovation activity. Are firms that receive government support more innovative than those that receive no governmental support? Two sides of the innovation process can be examined: on the input side, the $R \& D$ expenditures, and on the output side, the share of innovative sales. Figure 5.1 illustrates the relation between government intervention and innovation activities. R\&D feeds into the innovation process, which yields new products. Government intervention can affect the input and/or the output side of innovation.

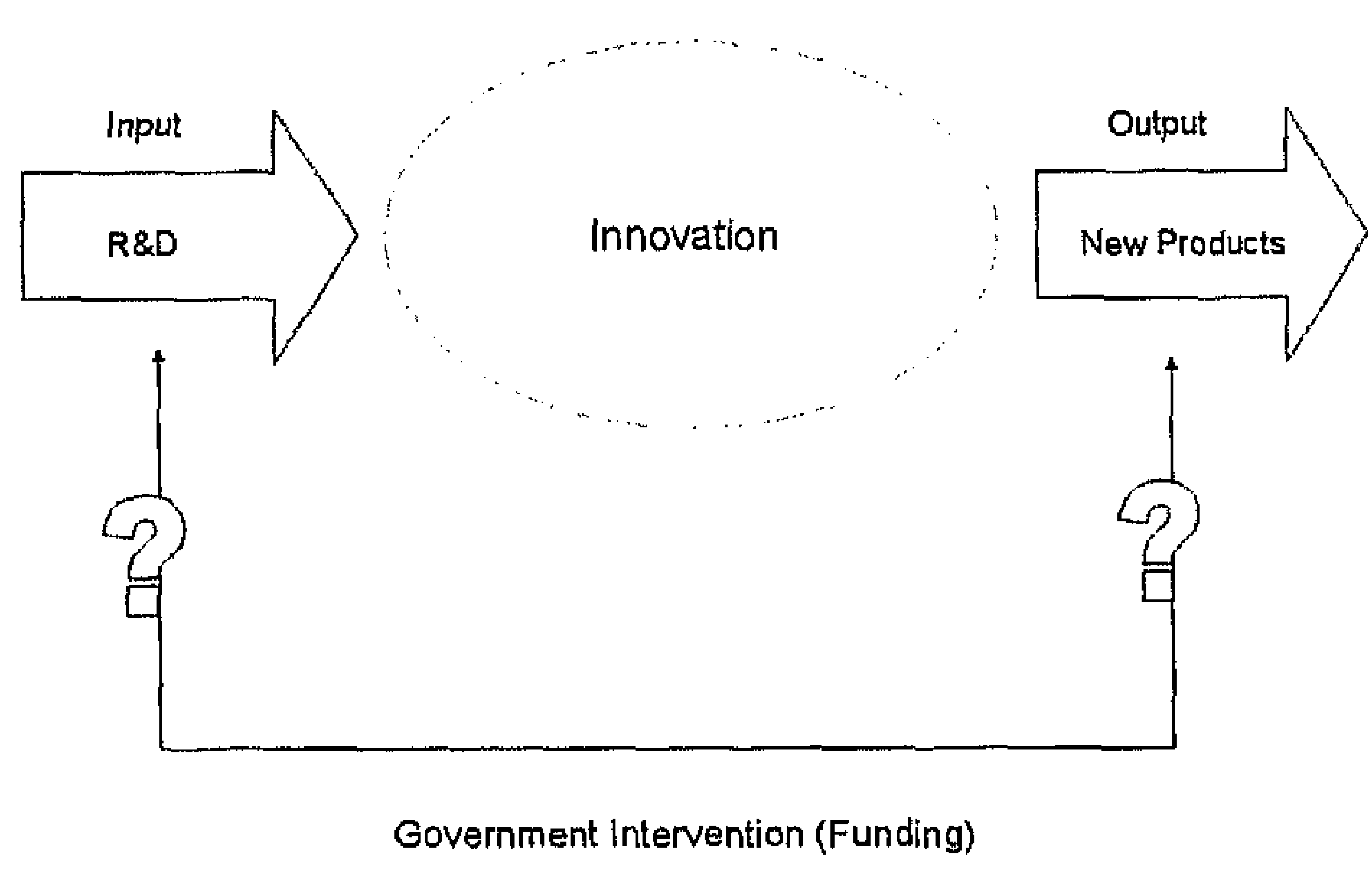

Figure 5.1: Government Funds and Innovation Activity

\subsubsection{Econometric model}

It is not sufficient to compare the means of the respective variables for supported and non-supported firms. We should at least check whether other values have also varied and hence affected the innovation activity variables. Moreover, the 
support variables themselves are endogenous, that is, there may be a systematic attribution of government funding for imnovation related to such things as firm size, past success and promise of future success as revealed by the patent portfolio.

Anyway, since in the CIS 3 questionnaire only imnovators are asked about sources of government funding, we cannot compare the means of innovation output between supported and non-supported firms. We can only compare thosc means among innovators of different types. This leaves us with too few observations to proceed to a matching estimator where each firm receiving support is matched to a similar firm receiving no support, thereby controlling for other determinants like size, network or industry affiliation. We therefore have to turn to a modeling of the endogencity of innovation and of public support.

A model is set up where government support, R\&D and innovative sales are endogenized. More precisely, the model is composed of four equations. The first two explain the determinants of government support for innovation. Two sources of support are considered: those emanating from the central govermment and those emanating from the European Union ${ }^{5}$. As modelled in Gonzalez et al. (2005), firms form expectations about government funding for innovation from domestic and EU sources. These expectations (through the effect of latent variables) then enter the $R \& D$ and innovation output equations. The second equation relates to the determinants of (intramural and extramural) R\&D. Since not all firms are R\&D performers, we could have a selection bias if we only considered firms that perform R\&D. In fact, we have a concentration of data with zero R\&D. To correct for selectivity, we use a tobit model which posits a latent variable that explains simultaneously the $R \& D$ intensity equation and the observed non-R\&D performing enterprises for which the latent variable falls below a critical tireshold. The third equation pertains to inmovation output. The focus is on product innovations for which the dataset provides both qualitative and quantitative information, as opposed to process innovation for which there is no quantitative measure in the dataset. Since we have both innovators and non-innovators, we have again a tobit model with a latent variable that is equal to the observed intensity of innovation for innovators and which falls below the innovation threshold for non-innovators. We have two models, one in which the innovation output is composed of products new to the firm (corresponding to imitators and true innovators) and one in which it is composed of products new to the market (characterizing true innovators). The latent variable for $R \& D$ enters the latent variable for innovation. The more R\&D firms do, the higher the chance they come up with a new product. Government support for innovation can thus affect innovation output directly, or indirectly by stimulating $R \& D$.

\footnotetext{
${ }^{5}$ The CIS 3 dataset for Austria is too small separately to analyse the four sources of government support contained in the CIS 3 questionnaire: local government support, central government support, EU funding and funding from the 4 th and 5 th framework programmes.
} 


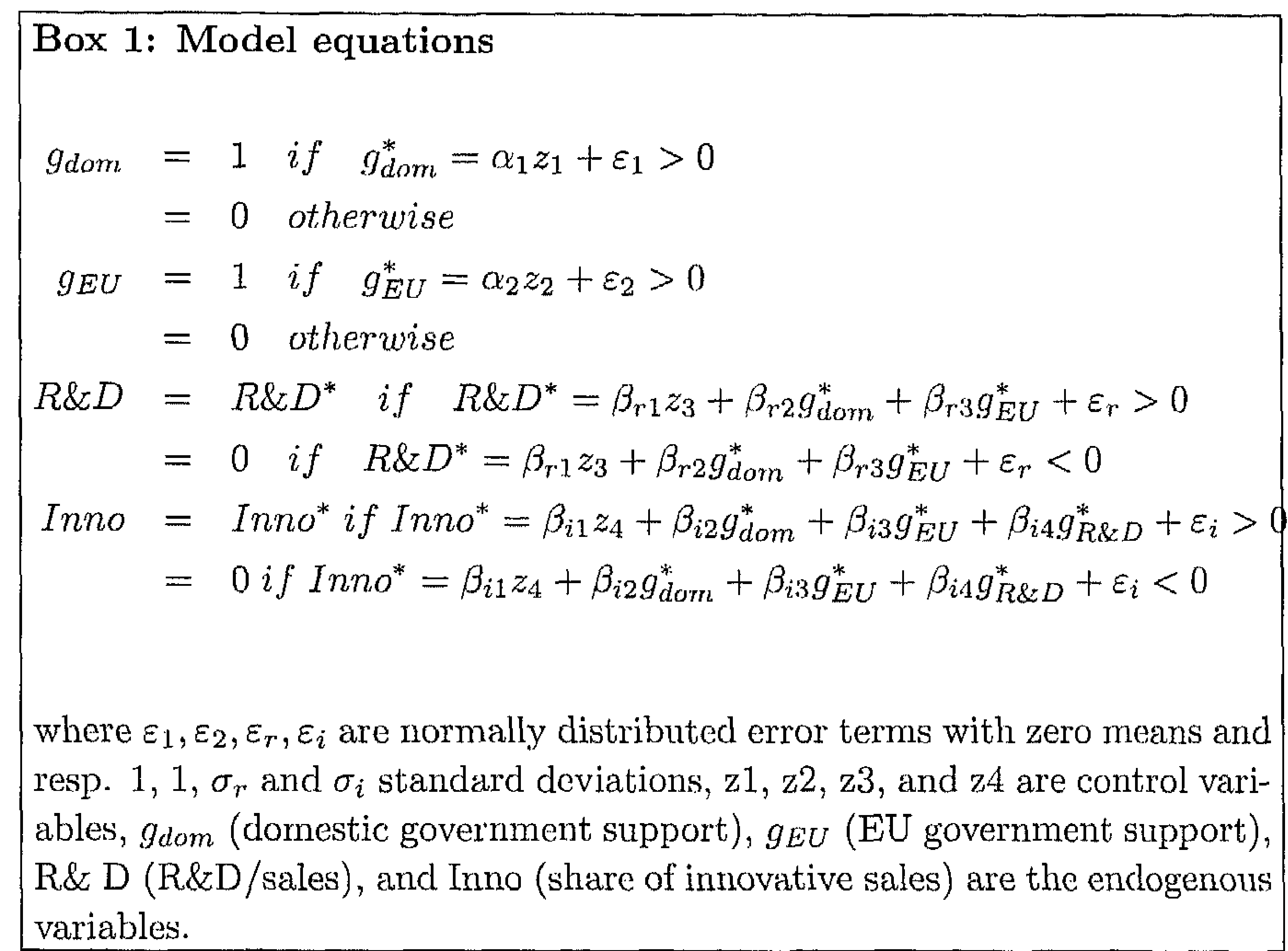

The model thus allows one to analyse which type of government support has a significant effect on innovation, and whether it affects innovative sales directly or via $R \& D$. Endogeneity and selectivity are explicitly taken into account in the estimation of the model. Box 1 recapitulates the model in a formal way and specifies the distribution assumptions about the random error terms. Box 2 presents the asymptotic least squares estimation procedure that is used to estimate this model.

Firms that have not introduced a product, or a process, and that have no unfinished or abandoned innovation activities are asked to respond to only a few identifying questions. Relevant information for trying to explain what makes a firm a candidate for government support, what makes it reach the threshold level for $R \& D$ or for innovation, and what determines the intensities of $R \& D$ and innovation, is only available for the $42 \%$ of firms in the sample that are innovative in some way. We therefore run the analysis only on this subsample of innovating firms. 


\section{Government Funding and R\&D}

Box 2: Asymptotic Least Squares

We are in the presence of a system of simultaneous equations with limited dependent variables as in Crepon et al. (1998). The government funding variables are dichotomous variables, and the $R \& D$ and innovation intensities are censored variables. The econometric model is estimated by using the method of asymptotic least squares (also known as the minimum distance estimator). In a first stage, the reduced form equations of the model are estimated consistently by running a probit on the two sources of government funding, and a simple tobit model for the $R \& D$ and innovation output equations. In the second stage (if there are overidentifying restrictions) the parameters of the structural form are estimated by minimizing the distances between the estimated reduced form parameters and those predicted by the model from the identifying constraints, weighted by the estimated variance-covariance matrix of the reduced form parameters (see Gourieroux et al. (1985)). Identification is generally assured by way of exclusion restrictions. Asymptotic least squares yield convergent and asymptotically normal estimates.

\subsubsection{Control variables}

In each equation, we control for a number of determinants other than the policy and innovation variables. The choice and the location of the control variables in the model is not a trivial one. To identify the parameters of the model we have to impose exclusion restrictions, i.e. exclude some explanatory variables in some of the equations in order to identify the other ones. The choice of exclusion restrictions is partly motivated on theoretical grounds (sources of information are more likely to determine innovation directly than through government support), and partly based on the significance of estimated coefficients. Non-significant coefficients might be bad instruments to identify other key parameters of the model.

The main variables and their position in the model are in order:

- Industry Dummies: The object of using dummy variables is to account for some industry-specific effects in each equation. Governments may be more willing to foster certain industries, such as biotechnology, because they have promised to invest in new technologies. There are not enough observations per NACE twodigit industry codes to control for each of the corresponding industries. We thus classified the industries in three industry clusters: the high-tech cluster (vehicles, chemicals, machinery, electrical products, plastics, telecommunications, computer services, engineering services, support auxiliary transport activities and industries not otherwise classified), the low-tech cluster (food, textiles, wood, non-metallic mineral products, basic metals, supplies, finance and transportation), and the wholesale industry, which is strongly represented in the sample.

- Domestic Group: Government may be less willing to intervene if firms belong to a group because it is expected that these firms benefit from group support. 


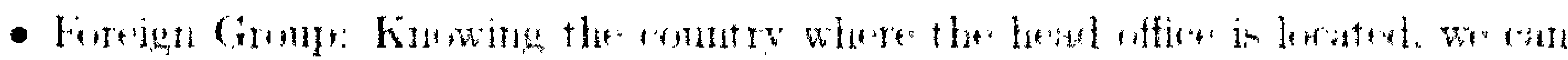

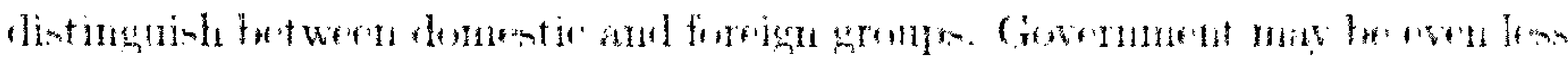

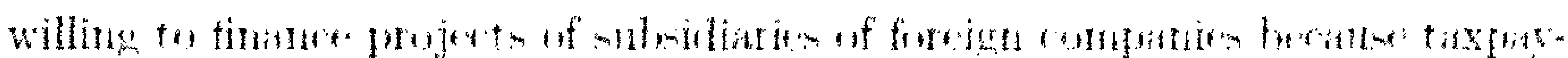

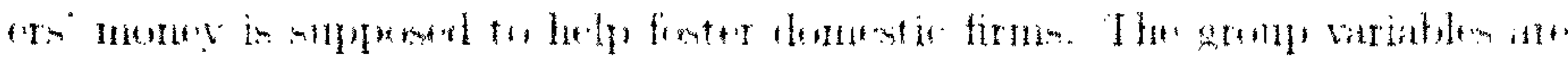

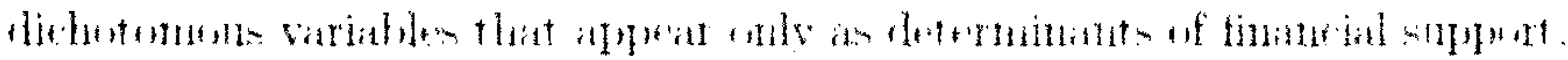

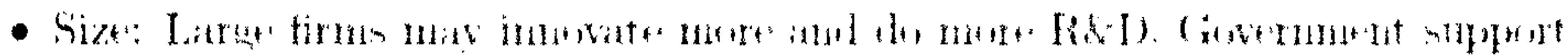

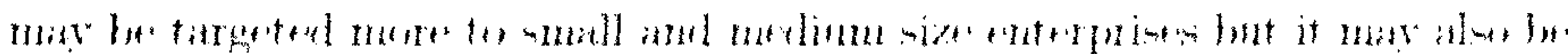

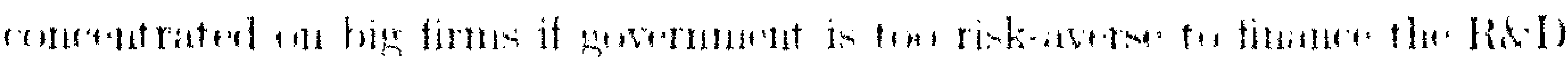

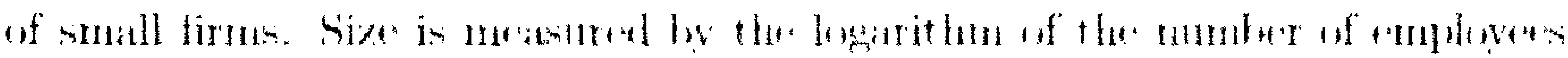

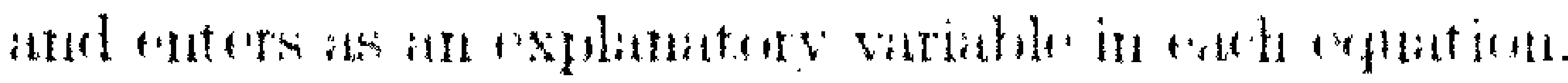

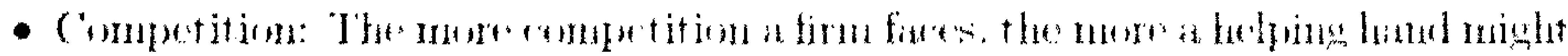

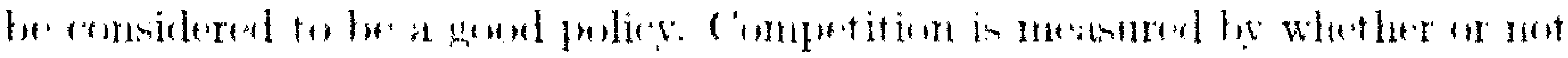

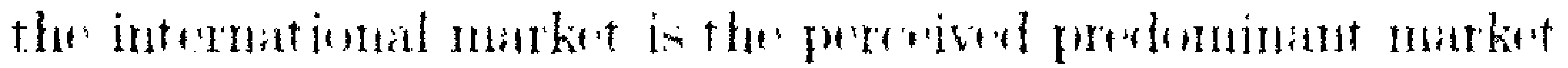

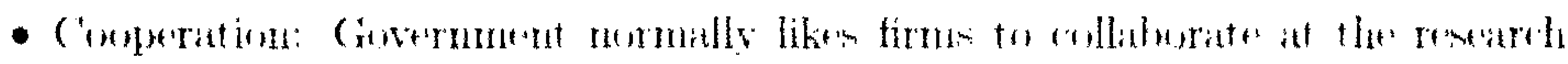

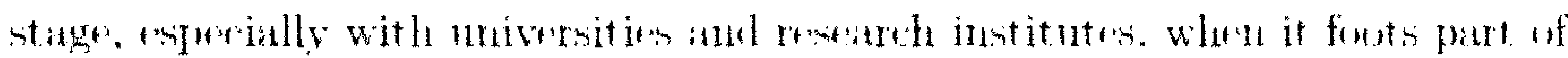

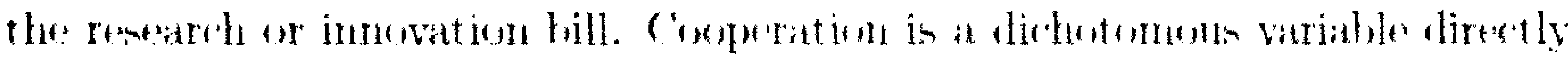
berrowed from CIS 3. Compention and cooperation atfent RdD and innowat iom only thromgh gowernment mpport.

- Human Capital: The higher the qualitent ion of workers, the higher the caparity

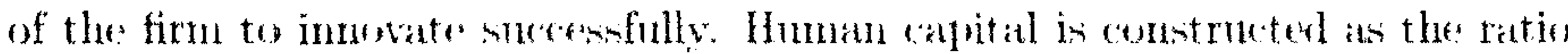
of the manker of workers with higher edneation divided hy the total monber of workers in the firm. It antres as a determinant of R\&D intensitx.

- Appropriability prohlems: The "itparity to appropriate the ontput of research. be it by patenting. by secrece or other means, is regarded as a significant desterminant of $\mathrm{Rd} D$ D for Cohen and Levin (1989)). Appropriahility problems are proxied by the perceived importane of ecomomic risk as an obstade to innovation.

- Financial difficultirs: Bermse of the market failure of information goonds. innowators may have difficulty finding appropriate financing for their innowation. Financial difficulties are measured be the perceived difficulty of areess to finance as an olmtacle to inuvation.

- Externalities from science: The other posibible important somere of information that we wonld like to control for ary the extermalities deriving from basic research performed at miversitios and public research institntions. Appropriability. ateress to finame and externalities are transformed from catcogorical to binary valiables be asserdatiug at one to any positive respense, and a zero to zero

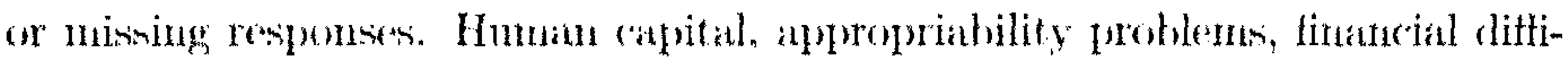

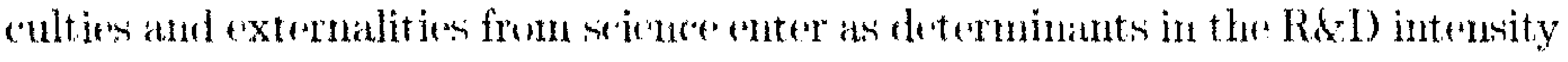
equliation. 


\section{Government Funding and R\&D}

- Externalities from clients: Clients are often recognized as an important source of information to convey the needs felt by market demand (see von Hippel (1988)). Since we concentrate on product innovations, it seems reasonable to expect information from clients to influence product innovation.

\begin{tabular}{rrr} 
Variable name & Mean & Std Dev \\
\hline Hich-tech industries & 0.291 & 0.455 \\
Low-tech industries & 0.504 & 0.5 \\
Wholesale industry & 0.205 & 0.404 \\
Domestic group & 0.447 & 0.498 \\
Foreign group & 0.198 & 0.399 \\
Competition & 0.462 & 1.59 \\
Size (log nb of employees & 0.495 \\
Human capital & 0.052 & 0.085 \\
Cooperation & 0.236 & 0.425 \\
Appropriability problems & 0.756 & 0.43 \\
Financial difficulties & 0.643 & 0.48 \\
Externalities from clients & 0.788 & 0.409 \\
Externalities from science & 0.463 & 0.499 \\
Central government support & 0.315 & 0.465 \\
EU innovation support & 0.117 & 0.322 \\
National innovation support & 0.375 & 0.485 \\
Overall EU innovation support & 0.137 & 0.345 \\
Doing R\&D & 0.553 & 0.498 \\
R\&D over sales & 0.028 & 0.06 \\
$>0$ new to firm innov. share & 0.258 & 0.252 \\
$>0$ new to market innov. share & 0.165 & 0.203 \\
\hline
\end{tabular}

Number of observations: 546

Table 5.3: Descriptive statistics on control variables, Austria, 1998-2000, CIS 3

Table 5.3 presents some descriptive statistics. From the 546 innovative enterprises in our sample, 29.1 percent belong to the high-tech industry cluster, 50.4 percent belong to the low-tech industry cluster, and 20.5 percent to the wholesale trade sector. Almost half of the enterprises in our sample belong to an Austrian group and almost 20 percent to a foreign group; 42.9 percent consider the international market as their most important market, and are thus likely to face stiff competition; on average 5.2 percent of the employees have a vocational school or university degree; 23.6 percent declare that they cooperate to innovate; a large fraction declare having difficulties with appropriability (75.6 percent) or with access to finance (46.3 percent). If we aggregate local and central government support on the one hand, and EU and RTD support on the other, we get percentages of supported firms not unlike the percentages receiving central government and EU support; 55.3 percent of the innovators do some R\&D with an average R\&D inten- 
sity with respect to total sales of 2.8 percent. The product innovators with new to firm innovations have on average 25.8 percent of their total turnover accounted for by new products, and those with products new to the market 16.5 percent.

\subsection{Results}

We have estimated the model with two measures of product innovation. Table 5.5 reports the estimation results obtained with the broad measure of innovation in products now to the firm, i.e. mixing true product innovators and imitators. Table 5.6 reports those with the narrower measure of innovation in products new to the market, corresponding to true product innovators. As we would expect, the major difference between the two models is in the innovation equation. Since the model for true innovators selects a more homogeneous set of firms, the estimates of model 2 are slightly more precise. In both cases, the Sargan test of overidentifying restrictions does not reject the null hypothesis that the overidentifying restrictions hold, even with a $10 \%$ margin of error, when government support is explained by the model. In this sense the data do not reject the model specification. When government support is treated as exogenous, however, the Sargan test rejects the model specification at the $5 \%$ level.

Table 5.4: Marginal effects of determinants of various sources of innovation support, Austria, 1998-2000, CIS 3, probit estimation

\begin{tabular}{|c|c|c|c|}
\hline $\begin{array}{l}\text { Support } \\
\text { Variables }\end{array}$ & Central & European & $\begin{array}{l}\text { National Sources } \\
\text { (Local or Central) }\end{array}$ \\
\hline Variables & Government & Union & ( Local or Central) \\
\hline
\end{tabular}

\begin{tabular}{rrrrr}
\hline \hline High-tech sectors & $-0.513^{* * *}$ & $-0.389^{* * *}$ & $-0.470^{* * *}$ & $-0.408^{* * *}$ \\
Low-tech sectors & $-0.624^{* * *}$ & $-0.419^{* * *}$ & $-0.586^{* * *}$ & $-0.435^{* * *}$ \\
Wholesale trade & $-0.598^{* * *}$ & $-0.363^{* * *}$ & $-0.530^{* * *}$ & $-0.379^{* * *}$ \\
Austrian group & $-0.141^{* * *}$ & $-0.084^{* * *}$ & $-0.197^{* * *}$ & $-0.085^{* * *}$ \\
Foreign group & $-0.126^{* * *}$ & $-0.121^{* * *}$ & $-0.216^{* * *}$ & $-0.122^{* * *}$ \\
Size & $0.077^{* * *}$ & $0.046^{* * *}$ & $0.083^{* * *}$ & $0.048^{* * *}$ \\
Competition & $0.152^{* * *}$ & - & $0.180^{* * *}$ & - \\
Cooperation & $0.129^{* * *}$ & $0.113^{* * *}$ & $0.121^{* * *}$ & $0.111^{* * *}$ \\
Financial difficulties & $0.105^{* * *}$ & - & $0.117^{* * *}$ & -
\end{tabular}

* significant at $10 \%,{ }^{* *}$ significant at $5 \%,{ }^{* * *}$ significant at $1 \%$

Table 5.4 contains the magnitude and the direction of the marginal effects of the explanatory variables on the probability of receiving government support for innovation. When a firm shifts from a low-tech industry to a high-tech industry it increases its probability of getting government support. For example, support from the central government increases in that case by 11.1 percentage points, EU support by only 3 percentage points. In Austria the wholesale trade sector is more likely to get support from the national government or the $\mathrm{EU}$ than the low-tech sectors. Firms that belong to a group are less likely to get innovation 


\section{GOVERNMENT Funding AND R\&D}

support, probably becausc they are supposed to have access to resources emanating from the group. The central government is even more adverse to financing firms belonging to foreign groups, probably because taxpayers' money is supposed to help domestic firms. The national government prefers funding firms of a certain size that are independent and operate mostly in foreign markets, that cooperate but experience difficulty in financing their innovation. Firms facing international competition have a probability 15 percentage points higher to be funded by central government when evaluated at the mean of all the other covariates. Enterprises which cooperate in innovation are more likely to get help from both national and EU sources. A one pcrcent increase in size increases by 7.7 percentage points the probability of receiving central government support and by 4.6 percentage points the probability of receiving EU support for innovation. Support is more responsive from national than from EU sources. There is not a great difference in the factors determining local and central government support or EU and RTD support for innovation, but there is some difference between national and EU support in general. 


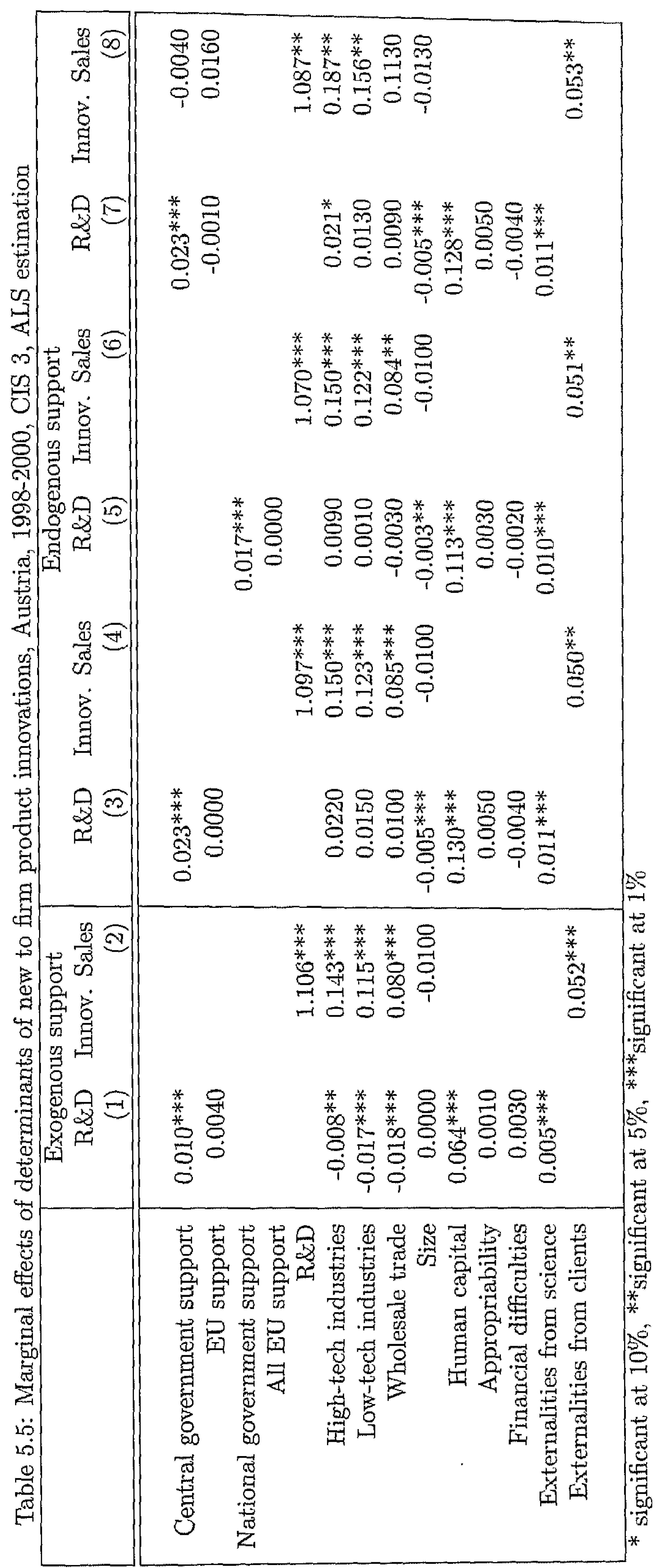




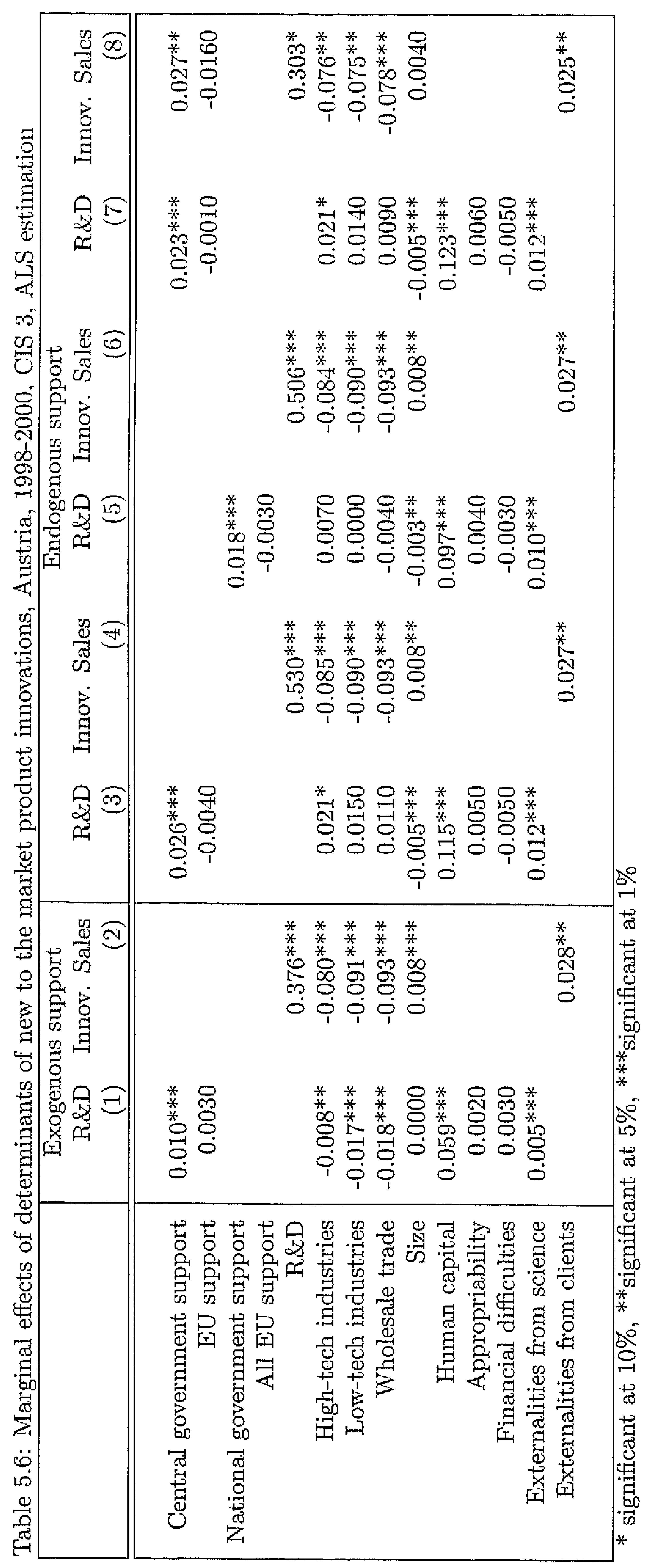


As a comparison of columns 1 and 3 of table 5.5 reveals, when government support is treated as endogenous, as it should be, the effect of contral government support, human capital and science externalities doubles. Previously these variables were in part picking up the negative effcct of size. Central government support appears to be one of the most important determinants of R\&D. Receiving central govermment support incrcases by 2.3 percentage points the intensity of $R \& D$, which is a high figure if we recall that the mean $R \& D$ intensity is 2.8 percent. A one percent increase in the number of employees decreases R\&D intensity by half a percentage point. One percentage point increase in human capital, which is large given the mean value of human capital of 5.2 percentage points, is connected to only one tenth of a percentage point increase in R\&D intensity. The only other significant effect comes from the science push: firms that benefit from information emanating from universities or government labs have a 1.1 percentage point higher R\&D intensity ceteris paribus.

The proper treatment of the endogeneity of government support measures has little bcaring on the estimates of the innovation equation. R\&D has a significant effect on innovation. The rate of return of $R \& D$ in terms of innovative sales is of the order of $10 \%$ ( 1 Euro of R\&D yields a net 1.1 Euro increase in innovative sales, hence a net revenue of 10 Eurocents). The externalities coming from clients increase the innovation intensity by half a percentage point. The higher intensity of innovation in high-tech than low-tech and in low-tech compared to wholesale trade reflects and confirms our ad-hoc classification.

Since collinearity would probably not allow the estimation of the separate effects of all four sources of innovation support, an alternative is to merge central and local government support and EU and RTD support from the 4th and 5th Framework Programmes. The results of this experiment are reported in columns 5 and 6 . The effects are of similar magnitude as when only two of the four measures are singled out (previous columns 3 and 4 ).

The last two columns of table 5.5 report the results of the experiment when government support measures are allowed to affect innovation directly in addition to their indirect effect going through $R \& D$. The direct effects are not significant.

It is noticeable that the EU support always turns out to be non-significant. A large fraction of firms that receive central government support also get EU support. So it may be that the effects of the latter are confounded with those of the former. It may even be that some $E U$ money is handed out by national ministeries and has the appearance of being nationally funded. Financial difficulties and appropriability problems play no significant role on R\&D, nor does size on innovation.

In table 5.6 are reported the marginal effects of the explanatory variables for the new-to-market product innovations. An increase in the marginal effects when the public support measures are treated as endogenous is again apparent, also in the effect of $R \& D$ on productivity. The robustness of the results to the use of two specific versus two amalgamated government support measures is also confirmed. The marginal effects of the explanatory variables on new to market product in- 
novations are similar to those on new to firm product innovations except for the rate of return on R\&D; in terms of the new to market product innovative share this drops to 5.3 percent. The major difference between true innovators and the amalgamation of true innovators and imitators is in the specification of the last two columns in table 5.6, namely when direct effects of government support on innovation are allowed for. Central government support leads to an increase of 2.7 percentage points in innovative sales in addition to the $0.7(0.023 \times 0.303)$ percentage point due to the indirect effect through $\mathrm{R} \& \mathrm{D}$. The total effect of central government support measures amounts to 3.3 percent.

\subsection{Conclusion}

This chapter has examined the extent and the effects of government support for innovation in Austria under CIS 3. The central government, including agencies working for it, is the most frequently cited source of public support for innovation, followed by local government, the EU and the Framework Programmes for RTD. Support for innovation is more concentrated on the input side (R\&D) than on the output side of innovation (share of innovative sales) which also means it has very little effect on final demand. The firms receiving support do not come closer to consumers' needs. It is also noticeable that new to market product innovators are more likely to receive public support of some sort than new to firm product innovators.

To account for the endogeneity of government support for innovation, of R\&D and of product innovation, a system of simultaneous equations was estimated in which government support feeds on $R \& D$, which itself generates innovative sales. Two forms of innovative sales were distinguished: products new to the firm and products new to the entire market. The national government prefers to fund firms that are independent, that have a certain size, that operate principally in foreign markets, that cooperate with other firms and that experience difficulties in financing their innovation. Competition and financial difficulties are not significant when justifying EU support for innovation.

Receiving central government support increases the intensity of $R \& D$ by 2.3 percentage points. There is no great difference in the factors determining local and central government support or EU and RTD support for innovation, but there is some difference between national and EU support in general. EU support is never significant once national support is taken into account. The rate of return of $R \& D$ in terms of innovative sales in products new to the firm is of 10 percent. Central government support thus generates a 2.5 percentage point increase in the share of new to firm product innovative sales. When new to market product innovations are considered, central government support leads to a direct increase of 2.7 percentage points in innovative sales in addition to the 0.7 percentage point due to the indirect effect through R\&D. The total effect of central government support on the share of new to market innovative sales amounts to 3.3 percent. 


\section{CONCLUSION}

This thesis is a research study in which demand in general plays a crucial role in technical change. We have linked technical change to human needs and argued that demand should be a key to understanding successful innovations.

If we agree on the role of knowledge and technology in society, and that this knowledge generates value only if it is useful to people, then demand is a cornerstone. Hence demand and demand dynamics becomes an area of research that should be fostered and further developed. Especially in Economics very little is known about the role played by demand in the selection of successful innovations.

From the ideas put forward in chapter 2, especially from the psychological introduction concerning the reasons why we form habits and seek novelty, we understand that humans are always searching for difference and novelty. It is in this eternal search that technology and inventions have a chance to become real innovations. The value of these inventions has to be related to changes in the standard of living, by affecting consumption habits. Also from this chapter we understand that there is a need for coordination between innovation and marketing strategies. For example, from a policy perspective, if the government targets funding to a group of firms the funding should also include some help towards marketing the new products. Otherwise very good inventions may fail simply because insufficient people hear of them thus wasting the costly innovation effort.

With chapter 3 we introduce a conclusion different from mainstream growth theories: that growth comes from a constant increase in consumption levels. Each new period the same amount of people is able to come up with better innovations needed by consumers. By combining the same amount of labour with the right knowledge a wealthier society can expand the utility without using extra resources. Despite the very strong assumptions that have been used to build the 


\section{CONCLUSIONS}

model, the idea behind it is quite simple: technology changes consumer's needs. And once people are used to these inventions there is no going back. Our model is focused on rich societies in which R\&D's main problem is coming up with new goods that people need to buy.

In chapter 4 a systemic view of imnovation process is aligned with the previous discussion about demand. Using benchmarking techniques, it is shown that demand dynamics are very different across European countries, and so is their interaction with other system dimensions we have identified as relevant: human capital, knowledge, and supply. The evaluation of national innovation performance is modified when demand is included. Of special interest are the Scandinavian countries with a weak demand link. The analysis is entitled to help police maker focus their attention on weak links in the national system of innovations.

The final empirical exercise undertaken in chapter 5 analyses the relationship between a policy and the capacity of firms to come up with new goods. The CIS data used in this analysis are not the best when analysing the effect of demand. None of the variables can be used for evaluating the utility value of an innovation for a person. The best proxy is the percentage of innovative sales. Therefore a better data structure should be created to analytically understand the whole picture of technical change. Despite the difficulties, we were able to conclude that there is only a subtle indirect effect of external government funding on innovative sales. Funding affects the R\&D expenditures, which positively affects innovative sales.

In all these chapters we have looked from the side of consumers and with different techniques have tried to understand how technology affects their lives. With such differentiated techniques we hope our work has opened up new areas of research and contributed a new perspective to study the influence of demand on technology in particular and on society in general.

\subsection{Final remarks}

We concludc by highlighting some general facts. First, the research revealed that in order to gain important insights on the role of demand in the technological process, it is critically important to consider the process of preference formation in consumer theory. An analysis that is based on constant preferences limits the capacity to understand product innovation; it does not offer the possibility of selecting a new product. By taking into account the process of preference formation in relation with habits and novelty, an interesting conclusion was drawn: very good innovation, in the sense that is portrays a high potential for fulfilling the needs 
6.1. Final remarks

of a population, may not attain the minimum level of required novelty. Such an outcome may be interpreted as the result of a poor marketing strategy by the firm. It may also be viewed as resulting from a lack of adequate public support in the innovation's marketing phase. However, it is noteworthy that if firms that receive public support also face financial difficulties in $R \& D$ investment, it may be deduced that they also encounter financial difficulties in marketing their innovations.

Sccond, the model presented in chapter 2 on habit formation and novelty illustrates how indifference curves change over time. The aim of the model was to link classical consumer theory to a more flexible and dynamic demand. This more dynamic setting allows the consumer to make decisions which reflect the impact of new goods on previous purchasing habits.

In the macroeconornic framework, we focus on habit formation. A third point is raised: if demand is expected to play a substantial role in the growth process, nonhomothetic preferences must be taken into account. In other words, if technical change creates new products, more flexibility is required on the demand side in order to understand the effect of such new products. The consumer's ability to vary the proportion of income devoted to each innovation with income growth is crucial. In such a setting, demand may be seen as playing a more realistic role in the general equilibrium.

The fourth remark pertains to the model presented in chapter 3 . This is one of the few models in which technical change simultaneously generates a vertical as well as a horizontal differentiation of final products. Consequently, the latest products have associated higher utility; the effect of technical change over time may be interpreted as an increase in the (average) marginal propensity to consume. Furthermore, the characteristics of our model allows us to draw a link between our research and the branch of literature, which propounds that the causality that runs from more savings to more growth should be reversed. Contrary to neoclassical theories, which assume that savings generate higher growth, our model illustrates the opposite: more consumption produces higher rates of growth. Put differently, even if the growth rate of savings diminishes with time, the economy presents perpetual growth.

Fifth, we note that we have mainly focused on habit although an analysis of novelty may have also raised important insights. For example, a focus on novelty may have made it possible to gain a better understanding of the role of marketing expenditure and publicity in the growth of modern economies.

The analysis that is carried out in chapter 4 provides some evidence of the evolution of demand and its influence on European NSI. Some countries present a very strong national demand, which may be driving the evolution of technical change. Other countries present very poor dynarnics on the demand side. Demand is represented by three composite variables that attempt to capture different elements: the first one attempts to capture habit formation as a result of an innovation, the second onc the national marketing effort, and the third one the evolution of average national consumption. The selection of these three variables is based on the conclusions drawn from the previous chapters. The sixth point that merits 
attention is that the different demand evolutions across the selected countries indicate that demand dynamics vary significantly at the national level and in the ways in which they affect the NSI.

In chapter 5, while acknowledging the poor quality of data, we find very little evidence of any effect of public support on the final demand. The main conclusion here is that public policies for supporting innovations have a weak effect on the final demand. This conclusion may be tied in with the previous view that funding for innovation does not adequately consider the role of demand in the technological process: it is designed to support firms in the $R \& D$ phase and pays little interest if any to the commercialisation of innovations. Good inventions may not show their full potential because they are unknown to consumers.

The general conclusion that emerges from this research is that consumers as well as their choices play a very important role on technical change. They select innovations, choose between existing goods and decide how to redistribute their income between old goods and new ones. The reasons behind these decisions play an important part in explaining the differences between successful and unsuccessful innovations. Demand for innovations, therefore, needs to be further explored in order to improve our understanding of the role of technology in society. As mentioned earlier, the thesis does not intend to provide a final word on the role of demand; it is an attempt to open up new areas of discussion in which the role of demand is sufficiently acknowledged so that our understanding of technical change may become more relevant to society. 


\section{KEYNESIAN MULTIPLIER}

The multiplier theory, as found in any text book ${ }^{1}$, states that at the macro level consumption is a constant proportion of the total income:

$$
C_{t}=c_{1} Y_{t-1}
$$

Constant $c_{1}$ is the (marginal and average) propensity to consume. For a single period, $t$, investment is divided in two parts

$$
I_{t}=I_{0}+\Delta I
$$

$I_{0}$ is the initial level of investment. The increase in the investment, principally coming from public expenditure, is also known as an exogenous demand shock.

$$
\Delta I=G
$$

The equilibrium condition is

$$
Y_{t}=C_{t}+I_{t}
$$

Simple substitution yields the following differential equation:

$$
Y_{t}=c_{1} Y_{t-1}+I_{0}+\Delta I
$$

By trying $Y_{t}=Y_{t-1}=\bar{Y}$ a particular solution is found:

$$
\bar{Y}=\frac{I_{0}+\Delta I}{1-c_{1}}
$$

The logic is the following: for the economy an increase in government expenditure (G) means an increase in investment that will increase demand in that period and pay the salary of the workers hired to satisfy this increase in demand. They,

\footnotetext{
${ }^{1}$ For this part we are following the discussion presented in Gandolfo (1980) Chapter 4.
} 


\section{APPENDIX A}

at the same time, will use part of their salaries on consumption. The total effect on the economy, the new level of national income that is reached after the shock, is presented in the previous equation. The increase in national income $\Delta Y$, is proportional to the initial increase in $\Delta I$ :

$$
\Delta Y=\frac{1}{1-c_{1}} \Delta I
$$

Now we repeat the steps, using the assumption that the government intervention funds $R \& D$. This sector creates new innovations which arrive in the economy and generate habits in the society, thus raising the average and marginal propensity to consume

$$
C_{t-1}=c_{1} Y_{t-2}
$$

In the initial situation (without the new technology) the consumption rate is $c_{1}$. At time $t$ a radical innovation arrives that makes evcrybody increase consumption to $c_{2}$ with $0<c_{1}<c_{2}<1$; at $\mathrm{t}$ consumption will be

$$
C_{t}=c_{2} Y_{t-1}
$$

and similarly for all following periods

$$
C_{t+1}=c_{2} Y_{t}
$$

The investment equation remains with the two previous parts

$$
I_{t}=I_{0}+\Delta I
$$

$\Delta I$ is assumed to be mainly public expenditure which, in this case, is fully used in the $R \& D$ sector and so has as consequence the arrival of the radical innovation:

$$
\Delta I=G
$$

The equilibrium is the same

$$
Y_{t}=C_{t}+I_{t}
$$

Now, substituting, we get:

$$
\bar{Y}=\frac{I_{0}+\Delta I}{1-c_{2}}
$$

and

$$
\Delta Y=\frac{1}{1-c_{2}} \Delta I
$$

Thus whenever $c_{1}<c_{2}$

$$
\frac{\Delta I}{1-c_{1}}<\frac{\Delta I}{1-c_{2}}
$$


Therefore we can conclude that the multiplier effect in the second case is higher. When expenditure is used on $R \& D$ and results in new products that are wanted by the society it has a positive impact on the national income level. 


\section{DYNAMIC CONSPICUOUS CONSUMPTION}




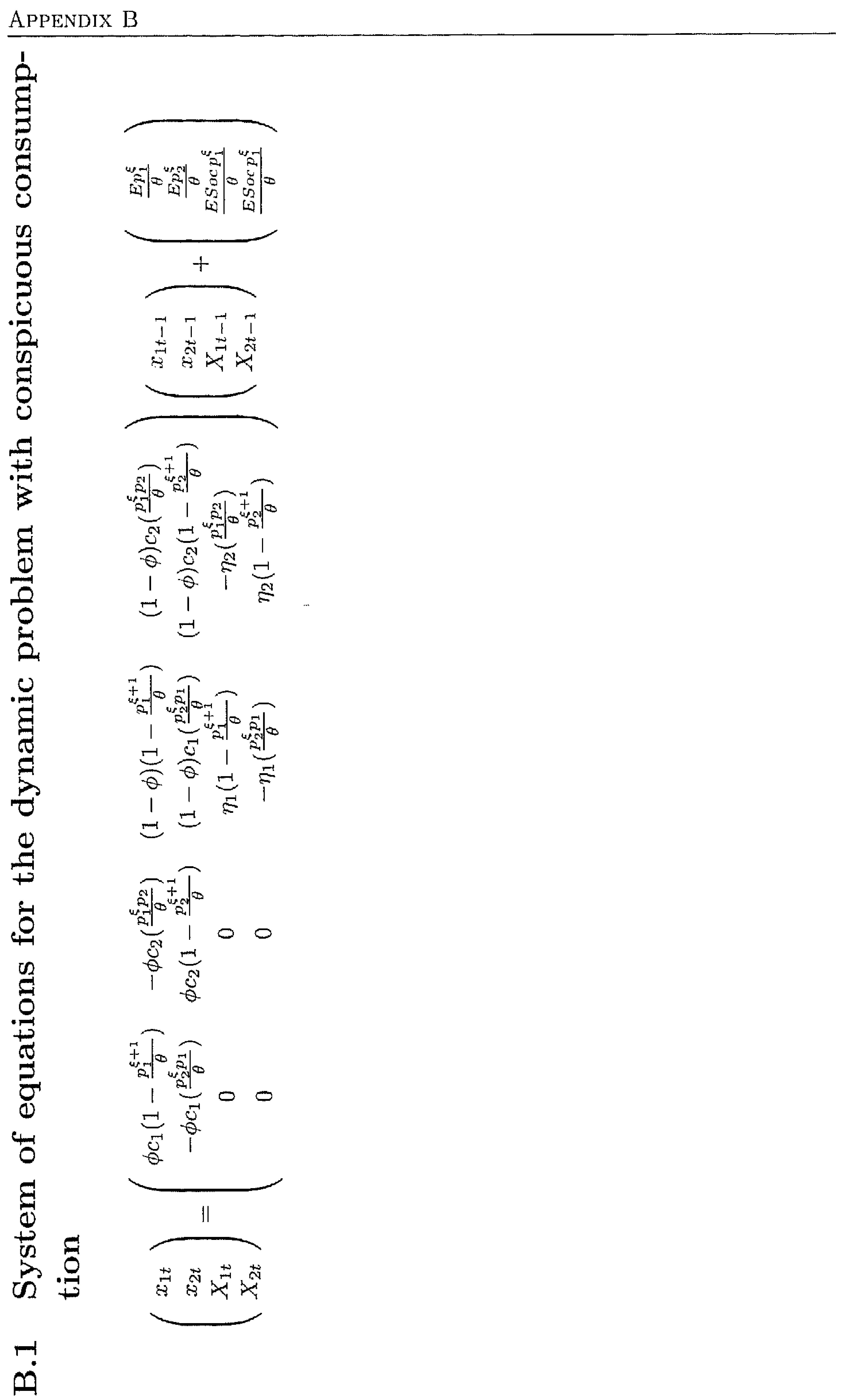




\section{TECHNICAL NOTES}

\section{C.1 Technical Notes}

\section{C.1.1 STEP 1: Maximization of the static utility for prices} of the within period in the long run

The problem can be stated:

$$
\begin{aligned}
\operatorname{Max} & U=\left(\sum_{\mathrm{i}=1}^{\mathrm{n}}\left(x_{i}-z_{i}\right)^{\alpha}\right)^{1 / \alpha} \\
\text { s.t } & \sum_{\mathrm{i}=1}^{\mathrm{n}} x_{i} p_{i}=E
\end{aligned}
$$

We build up the Lagrangian:

$$
L\left(x_{1}, x_{2} \ldots x_{n}, \lambda\right)=\left(\sum_{\mathrm{i}=1}^{\mathrm{n}}\left(x_{i}-z_{i}\right)^{\alpha}\right)^{1 / \alpha}-\lambda\left(\sum_{\mathrm{i}=1}^{\mathrm{n}} x_{i} p_{i}-E\right)
$$

Calculating the first order condition for each $x_{i}$, and for $\lambda$, we have that

$$
\frac{\partial L}{\partial x_{i}}=\left(x_{i}-z_{i}\right)^{\alpha-1}\left(\sum_{\mathrm{i}=1}^{\mathrm{n}}\left(x_{i}-z_{i}\right)^{\alpha}\right)^{1 / \alpha-1}-\lambda p_{i}=0
$$

or, taking into account the definition of $U$ in equation C.1 and the fact that $1 / \alpha-1=(1-\alpha)(1 / \alpha)$, we arrive at:

$$
\frac{\partial L}{\partial x_{i}}=\left(x_{i}-z_{i}\right)^{\alpha-1} U^{(1-\alpha)}-\lambda p_{i}=0
$$


Solving for $p_{i}$ we have

$$
p_{i}=\frac{\left(x_{i}-z_{i}\right)^{\alpha-1} U^{(1-\alpha)}}{\lambda}
$$

To remove the lambda the following steps are taken. First multiply both sides of the equation C.6 by $x_{i}$

$$
\begin{aligned}
p_{i} x_{i} & =\frac{\left(x_{i}-z_{i}\right)^{\alpha-1} x_{i} U^{(1-\alpha)}}{\lambda} \\
E & =\sum_{i=1}^{n} x_{i} p_{i} \\
E & =\sum_{i=1}^{n} \frac{\left(x_{i}-z_{i}\right)^{\alpha-1} x_{i} U^{(1-\alpha)}}{\lambda}
\end{aligned}
$$

Dividing C.7 by C.9 we arrive at

$$
\frac{p_{i} x_{i}}{E}=\frac{\frac{\left(x_{i}-z_{i}\right)^{\alpha-1} x_{i} U^{(1-\alpha)}}{\lambda}}{\sum_{j=1}^{n} \frac{\left(x_{j}-z_{j}\right)^{\alpha-1} x_{j} U^{(1-\alpha)}}{\lambda}}
$$

Simplifying in equation C.10 we find

$$
p_{i}=\frac{\left(x_{i}-z_{i}\right)^{\alpha-1}}{\sum_{j=1}^{\mathrm{n}}\left(x_{j}-z_{j}\right)^{\alpha-1} x_{j}} E
$$

This is the furthest we can go without defining $z_{i}$. If we define it as above, $z_{i t}=c_{i} x_{i t-1}$, then we have

$$
p_{i t}=\frac{\left(x_{i t}-c_{i} x_{i t-1}\right)^{\alpha-1}}{\sum_{j=1}^{t}\left(x_{j t}-c_{j} x_{j t-1}\right)^{\alpha-1} x_{j t}} E_{t}
$$

This can only be solved at equilibrium. Because we have assumed sufficient time to reach the within solution in every period, in this case the quantities of consecutive subperiods are equal: $x_{i t}=x_{i t-1}$. So, using the definition of technology from equation 3.1 :

$$
p_{i t}=\frac{\left(1-c_{i}\right)^{\alpha-1} x_{i}^{\alpha-1}}{\sum_{j=1}^{\mathrm{t}}\left(1-c_{j}\right)^{\alpha-1} x_{j t}^{\alpha}} E_{t}
$$

Writing the prices as a function of the $\gamma$ parameter we have:

$$
p_{i t}=\frac{\gamma^{(i-1)(\alpha-1)} x_{i}^{\alpha-1}}{\sum_{j=1}^{\mathrm{t}} \gamma^{(j-1)(\alpha-1)} x_{j t}^{\alpha}} E_{t}
$$


C.1. Technical Notes

C.1.2 STEP 2: Intratemporal utility maximization. The Euler Rule.

Rewriting the intertemporal maximization problem using the indirect utility function, and using the definition of $s_{t}$, we have:

$$
\begin{aligned}
\underset{E_{t}, d_{t+1}}{\operatorname{Max}} & \sum_{t=1}^{\infty} \beta^{t}\left(\sum_{i=1}^{t}\left(\frac{\gamma^{i-1} p_{i} \xi}{\sum_{i=1}^{t} \gamma^{i-1} p_{i} \xi+1}\right)^{\alpha}\right)^{\frac{1}{\alpha}} E_{t} \\
\text { s.t. } & E_{t}+\frac{d_{t+1}}{\left(1+r_{t}\right)}=d_{t}+\Pi_{t}+w_{t}
\end{aligned}
$$

Building up the Lagrangian:

$$
\begin{aligned}
L\left(E_{t}, d_{t+1}\right)= & \beta^{t}\left(\sum_{i=1}^{t}\left(\frac{\gamma^{i-1} p_{i t} \xi}{\sum_{i=1}^{t} \gamma^{i-1} p_{i t}{ }^{\xi+1}}\right)^{\alpha}\right)^{\frac{1}{\alpha}} E_{t} \\
& -\beta^{t} \lambda_{t}\left(E_{t}+\frac{d_{t+1}}{\left(1+r_{t}\right)}-d_{t}-\Pi_{t}-w_{t} L_{t}\right)
\end{aligned}
$$

Writing the first order conditions of the Lagrangian,

$$
\begin{array}{cl}
F O C_{E_{t}}: & \frac{\partial L}{\partial E_{t}}=0 \\
F O C_{d_{t+1}}: & \frac{\partial L}{\partial d_{t+1}}=0 \\
F O C_{\lambda_{t}}: & \frac{\partial L}{\partial \lambda_{t}}=0
\end{array}
$$

To make it as simple as possible the example uses an increase in the utility function from two goods to three goods. The main difference between the two periods is that in the latter there will be one more good and therefore the utility function will have increased by one good. Building the Lagrangian for $t=2$ and $t=3$ :

$$
\begin{aligned}
L_{t=2}= & \beta^{t}\left(\left(\frac{p_{1 t}^{\xi}}{p_{1 t}^{\xi+1}+\gamma p_{2 t}^{\xi+1}}\right)^{\alpha}+\left(\frac{\gamma p_{2 t}^{\xi}}{p_{1 t}^{\xi+1}+\gamma p_{2 t}^{\xi+1}}\right)^{\alpha}\right)^{1 / \alpha} E_{t} \\
& -\beta^{t} \lambda_{t}\left(E_{t}+\frac{d_{t+1}}{\left(1+r_{t}\right)}-w_{t}-d_{t}-\Pi_{t}\right) \\
L_{t=3} \quad=\beta^{t+1} & \left(\left(\frac{p_{1 t}^{\xi}}{p_{1 t}^{\xi+1}+\gamma p_{2 t}^{\xi+1}+\gamma^{2} p_{3 t}^{\xi+1}}\right)^{\alpha}+\left(\frac{\gamma p_{2 t}^{\xi}}{p_{1 t}^{\xi+1}+\gamma p_{2 t}^{\xi+1}+\gamma^{2} p_{3 t}^{\xi+1}}\right)^{\alpha}+\left(\frac{\gamma^{2} p_{3 t}^{\xi}}{p_{1 t}^{\xi+1}+\gamma p_{2 t}^{\xi+1}+\gamma^{2} p_{3 t}^{\xi+1}}\right)^{\alpha}\right)^{1 / \alpha} .
\end{aligned}
$$




$$
-\beta^{t+1} \lambda_{t+1}\left(E_{t+1}+\frac{d_{t+1}}{\left(1+r_{t}\right)}-w_{t+1}-d_{t+1}-\Pi_{t+1}\right)
$$

Now we present the equations from the first order conditions ${ }^{1}$,

- From FOC $E_{t}$

$$
\left(\left(\frac{p_{1 t}^{\xi}}{p_{1 t}^{\xi+1}+\gamma p_{2 t}^{\xi+1}}\right)^{\alpha}+\left(\frac{\gamma p_{2 t}^{\xi}}{p_{1 t}^{\xi+1}+\gamma p_{2 t}^{\xi+1}}\right)^{\alpha}\right)^{1 / \alpha}=\lambda_{t}
$$

- From $F O C_{E_{t}+1}$

$$
\left(\left(\frac{p_{1 t}^{\xi}}{p_{1 t}^{\xi+1}+\gamma p_{2 t}^{\xi+1}+\gamma^{2} p_{3 t}^{\xi+1}}\right)^{\alpha}+\left(\frac{\gamma p_{2 t}^{\xi}}{p_{1 t}^{\xi+1}+\gamma p_{2 t}^{\xi+1}+\gamma^{2} p_{3 t}^{\xi+1}}\right)^{\alpha}+\left(\frac{\gamma^{2} p_{3 t}^{\xi}}{p_{1 t}^{\xi+1}+\gamma p_{2 t}^{\xi+1}+\gamma^{2} p_{3 t}^{\xi+1}}\right)^{\alpha}\right)^{\alpha}=\lambda_{t+1}
$$

- From $F O C_{d_{t+1}}$

$$
\lambda_{t} \frac{1}{\left(1+r_{t}\right)}-\beta \lambda_{t+1}=0
$$

To understand the meaning of the last equation, we rearrange terms in the following way:

$$
\frac{\lambda_{t}}{\left(1+r_{t}\right)}=\beta \lambda_{l+1}
$$

The meaning of $\lambda_{t}$ is the extra utility that will be experienced by the consumer if we reduce marginally the budget constraint in $t$. The consumer ensures that if she saves this extra unit and waits one period to consume it, it will be equal to the present discount utility if she consumes it in the future.

Solving for all this we get the following Euler rule:

$$
\frac{\left(\left(\frac{p_{1 t}^{\xi}}{p_{1 t}^{\xi+1}+\gamma p_{2 t}^{\xi+1}+\gamma^{2} p_{3 t}^{\xi+1}}\right)^{\alpha}+\left(\frac{\gamma p_{2 t}^{\xi}}{p_{1 t}^{\xi+1}+\gamma p_{2 t}^{\xi+1}+\gamma^{2} p_{3 t}^{\xi+1}}\right)^{\alpha}+\left(\frac{\gamma^{2} p_{3 t}^{\xi}}{p_{1 t}^{\xi+1}+\gamma p_{2 t}^{\xi+1}+\gamma^{2} p_{3 t}^{\xi+1}}\right)^{\alpha}\right)^{\alpha}}{\left(\left(\frac{p_{1 t}^{\xi}}{p_{1 t}^{\xi+1}+\gamma_{2 t}^{\xi+1}}\right)^{\alpha}+\left(\frac{\gamma p_{2 t}^{\xi}}{p_{1 t}^{\xi+1}+\gamma p_{2 t}^{\xi+1}}\right)^{\alpha}\right)^{1 / \alpha}}=\frac{1}{\left(1+r_{t}\right) \beta}
$$

Now writing the same relation for the general case of going from $t$ to $t+1$ we have:

$$
\frac{\left(\sum_{i=1}^{t+1}\left(\frac{\gamma^{i-1} p_{i t}^{\xi}}{\sum_{i=1}^{t+1} \gamma^{i-1} p_{i t}^{\xi+1}}\right)^{\alpha}\right)^{1 / \alpha}}{\left(\sum_{i=1}^{t}\left(\frac{\gamma^{i-1} p_{i t}^{\xi}}{\sum_{i=1}^{t} \gamma^{i-1} p_{i t}^{\xi+1}}\right)^{\alpha}\right)^{1 / \alpha}}=\frac{1}{\left(1+\gamma_{t}\right) \beta}
$$

\footnotetext{
${ }^{1}$ We maximize using the Lagrangian technique. To read more about this technique see Ferguson and Lim (2003), Judd (1998) or Chow (1997).
} 
C.1. Technical Notes

Choosing the numeraire in such a way that expenditure on the first good is always equal to one,

$$
p_{1 t} x_{1 t}=1 \forall t
$$

We insert the solution of the within period for the quantity (sol 3.7),

$$
p_{1 t} \frac{p_{1 t}^{\xi}}{\sum_{i=1}^{t} \gamma^{i-1} p_{1 t}^{\xi+1}} E_{t}=1
$$

Knowing that prices are equal for all goods in each period

$$
p_{t} \frac{p_{t}^{\xi}}{\sum_{i=1}^{t} \gamma^{i-1} p_{t}^{\xi+1}} E_{t}=1
$$

the Euler rule can be expressed as:

$$
\left(\frac{1+\gamma^{\alpha}+\ldots+\gamma^{\alpha(t)}}{1+\gamma^{\alpha}+\ldots+\gamma^{\alpha(t-1)}}\right)^{1 / \alpha} \frac{E_{t}}{E_{t+1}} \frac{p_{t}}{p_{t+1}}=\frac{1}{\left(1+r_{t}\right) \beta}
$$

\section{C.1.3 Evolution of quantities and profits over time as new innovations arrive}

In this annex we explain a series of tables to explain the general evolution of quantities produced for each good every period of time:

We find in table 3.1 a diagonal structure; in each period of time a new good arrives. In table C.1 we divide these quantities by the quantity of the first good produced in each period.

\begin{tabular}{|c||ccccccc|}
\hline Sector & $\begin{array}{c}\text { Time } \\
\mathbf{1}\end{array}$ & $\mathbf{2}$ & $\mathbf{3}$ & {$[\ldots]$} & $\mathbf{t}$ & $\mathbf{t + 1}$ & {$[\ldots]$} \\
\hline \hline & & & & & & & \\
$\mathbf{1}$ & $x_{11} / x_{11}$ & $x_{12} / x_{12}$ & $x_{13} / x_{13}$ & $\ldots$ & $x_{1 t} / x_{1 t}$ & $x_{1 t+1} / x_{1 t+1}$ & $\ldots$ \\
$\mathbf{2}$ & & $x_{22} / x_{12}$ & $x_{23} / x_{13}$ & $\ldots$ & $x_{2 t} / x_{1 t}$ & $x_{2 t+1} / x_{1 t+1}$ & $\ldots$ \\
$\mathbf{3}$ & & & $x_{33} / x_{13}$ & $\ldots$ & $x_{3 t} / x_{1 t}$ & $x_{3 t+1} / x_{1 t+1}$ & $\ldots$ \\
{$[\ldots]$} & $\ldots$ & $\ldots$ & $\ldots$ & $\ldots$ & $\ldots$ & $\ldots$ & $\ldots$ \\
$\mathbf{i}$ & $\ldots$ & & & $\ldots$ & $x_{i t} / x_{1 t}$ & $x_{i t+1} / x_{1 t+1}$ & $\ldots$ \\
$\mathbf{i}+1$ & & & & $\ldots$ & & $x_{i+1} / x_{1 t+1}$ & $\ldots$ \\
{$[\ldots]$} & $\ldots$ & $\ldots$ & $\ldots$ & $\ldots$ & $\ldots$ & $\ldots$ & $\ldots$ \\
\hline$\ldots$
\end{tabular}

Table C.1: Transformation in relative quantities to the quantity of the first good

We can now write all the relative quantities in relation to the quantity produced of the first good, this is done in table C.2. 


\begin{tabular}{|c||ccccccc|}
\hline & Time & & & & & & \\
Sector & $\mathbf{1}$ & $\mathbf{2}$ & $\mathbf{3}$ & {$[\ldots]$} & $\mathbf{t}$ & $\mathbf{t}+\mathbf{1}$ & {$[\ldots]$} \\
\hline \hline & & & & & & & \\
1 & 1 & 1 & 1 & $\ldots$ & 1 & 1 & $\ldots$ \\
2 & & $\gamma$ & $\gamma$ & $\ldots$ & $\gamma$ & $\gamma$ & $\ldots$ \\
3 & & & $\gamma^{2}$ & $\ldots$ & $\gamma^{2}$ & $\gamma^{2}$ & $\ldots$ \\
{$[\ldots]$} & $\ldots$ & $\ldots$ & $\ldots$ & $\ldots$ & $\ldots$ & $\ldots$ & $\ldots$ \\
$i$ & & & & $\ldots$ & $\gamma^{i-1}$ & $\gamma^{i-1}$ & $\ldots$ \\
$i+1$ & & & & $\ldots$ & & $\gamma^{i}$ & $\ldots$ \\
{$[\ldots]$} & $\ldots$ & $\ldots$ & $\ldots$ & $\ldots$ & $\ldots$ & $\ldots$ & $\ldots$ \\
\hline
\end{tabular}

Table C.2: Relatives quantities expressed in relation to the quantity of the first good

If we multiply by the solution of the first good in each period we shall again find the total production. This idea is presented in table C.3.

\begin{tabular}{|c||ccccccc|}
\hline Sector & $\mathbf{1}$ & $\mathbf{2}$ & $\mathbf{3}$ & {$[\ldots]$} & $\mathbf{t}$ & $\mathrm{t}+\mathbf{1}$ & {$[\ldots]$} \\
\hline \hline & & & & & & & \\
$\mathbf{1}$ & $x_{11}$ & $x_{12}$ & $x_{13}$ & $\ldots$ & $x_{1 t}$ & $x_{1 t+1}$ & $\ldots$ \\
2 & & $\gamma x_{12}$ & $\gamma x_{13}$ & $\ldots$ & $\gamma x_{1 t}$ & $\gamma x_{1 t+1}$ & $\ldots$ \\
$\mathbf{3}$ & & & $\gamma^{2} x_{13}$ & $\ldots$ & $\gamma^{2} x_{1 t}$ & $\gamma^{2} x_{1 t+1}$ & $\ldots$ \\
{$[\ldots]$} & $\ldots$ & $\ldots$ & $\ldots$ & $\ldots$ & $\ldots$ & $\ldots$ & $\ldots$ \\
$\mathrm{i}$ & & & & $\ldots$ & $\gamma^{i-1} x_{1 t}$ & $\gamma^{i-1} x_{1 t+1}$ & $\ldots$ \\
$\mathbf{i}+1$ & & & & $\ldots$ & & $\gamma^{i} x_{1 t+1}$ & $\ldots$ \\
{$[\ldots]$} & $\ldots$ & $\ldots$ & $\ldots$ & $\ldots$ & $\ldots$ & $\ldots$ & $\ldots$ \\
\hline
\end{tabular}

Table C.3: Total quantities in relation to the first good 
C.1. Technical Notes

Using the distribution of labour presented in equation 3.19, this matrix can be written as a function of the total labour used in each period:

\begin{tabular}{|c|c|c|c|c|c|c|c|}
\hline Sector & $\begin{array}{c}\text { Time } \\
1 \\
\end{array}$ & 2 & 3 & {$[\ldots]$} & t & $t+1$ & {$[\ldots]$} \\
\hline 1 & $\frac{1}{1} a L_{F G}$ & $\frac{1}{1+\gamma} a L_{F G}$ & $\frac{1}{1+\gamma+\gamma^{2}} a L_{F G}$ & · & 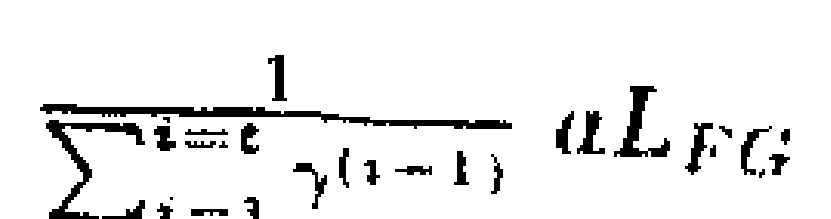 & $\frac{1}{\Gamma^{2+1-1}, T_{1}+1,} a I_{F G}$ & \\
\hline 2 & & $\frac{\gamma}{1+\gamma} a L_{F G}$ & $\frac{\gamma}{1+\gamma+\gamma^{2}} a L_{F G}$ & $\cdots$ & $\frac{L_{i=3}}{\sum_{i=1}^{i=1} \gamma(1-1)} a L_{F G}$ & $\frac{\sum_{a=1} f^{\prime 2 l 1}}{\sum_{i=+1}^{(z-1)}} a L_{F G}$ & \\
\hline 3 & & & $\frac{\gamma^{2}}{1+\gamma+\gamma^{2}} a L_{F G}$ & $\cdots$ & 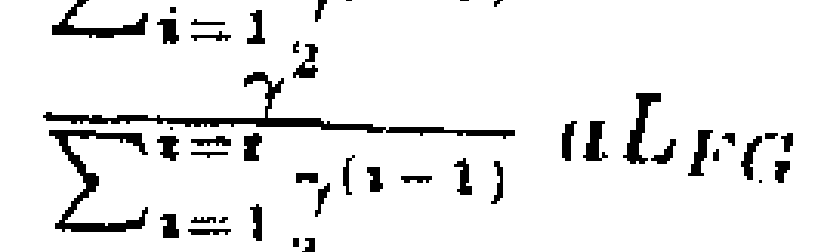 & $\frac{\sum_{1} \cdot y^{2}}{\sum_{i=1}^{i=1} \gamma^{(a-1}} a L_{F G}$ & \\
\hline 4 & & & & $\ldots$ & $\frac{\gamma^{3}}{\sum_{\substack{i=1 \\
t=1}}^{(2-1)}} a L_{F G}$ & 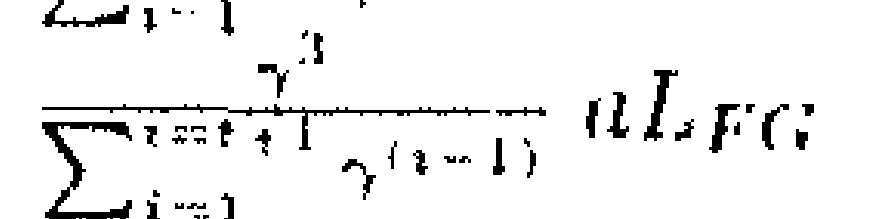 & \\
\hline 5 & & & & $\ldots$ & $\frac{y^{4}}{\sum_{i=t^{i}}^{\gamma^{(i-1)}}} a L_{F G}$ & 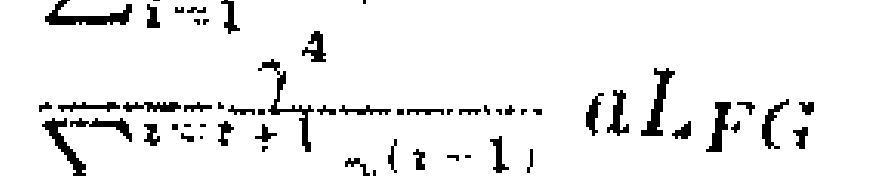 & \\
\hline$[\ldots]$ & $\ldots$ & .. & ... & $\cdots$ & & & \\
\hline $\mathbf{i}$ & & & & .. & 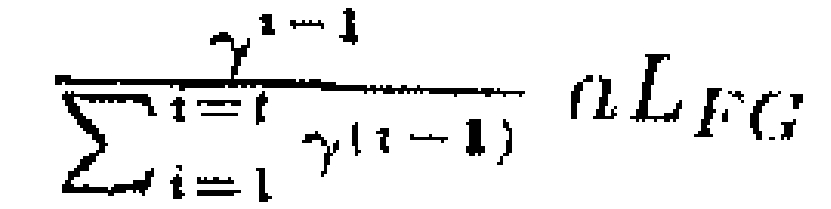 & $\frac{y^{t+1}}{\sum^{1+1} y^{k-1}} a L_{F G}$ & \\
\hline $\mathrm{i}+1$ & & & & $\ldots$ & & 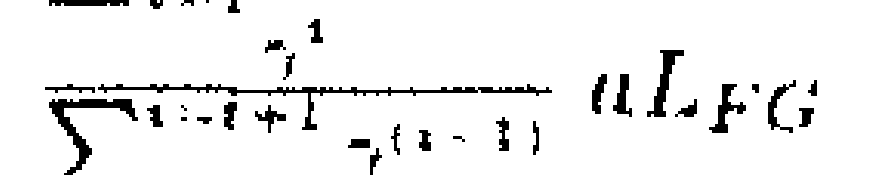 & \\
\hline$[\ldots]$ & & $\ldots$ & & $\ldots$ & & & \\
\hline
\end{tabular}

Table C.4: Production of quantities in relation to the labour used in the sector of final goods

Since the distribution between $L_{F G}$ and $L_{R \& D}$ is known and constant, which means that distribution of labour across the two sectors of the economy is constant, then table C. 4 shows that the total quantity produced of each good reduces as time goes on and new goods arrive. Choosing the first good as an example and following the resulting quantity in time we have:

$$
\begin{aligned}
& x_{11}=a L_{F G 1} \\
& x_{12}=a \frac{1}{1+\gamma} L_{F G} \\
& x_{13}=a \frac{1}{1+\gamma+\gamma^{2}} L_{F G} \\
& x_{1 t}=a \frac{1}{\sum_{i=1}^{i=t} \gamma^{(i-1)}} L_{F G}
\end{aligned}
$$

An easy transformation of the former table, making use of the equation 3.20 , will give us the value of the profits depending on salaries and quantitics of labour employed in the final goods sector: 


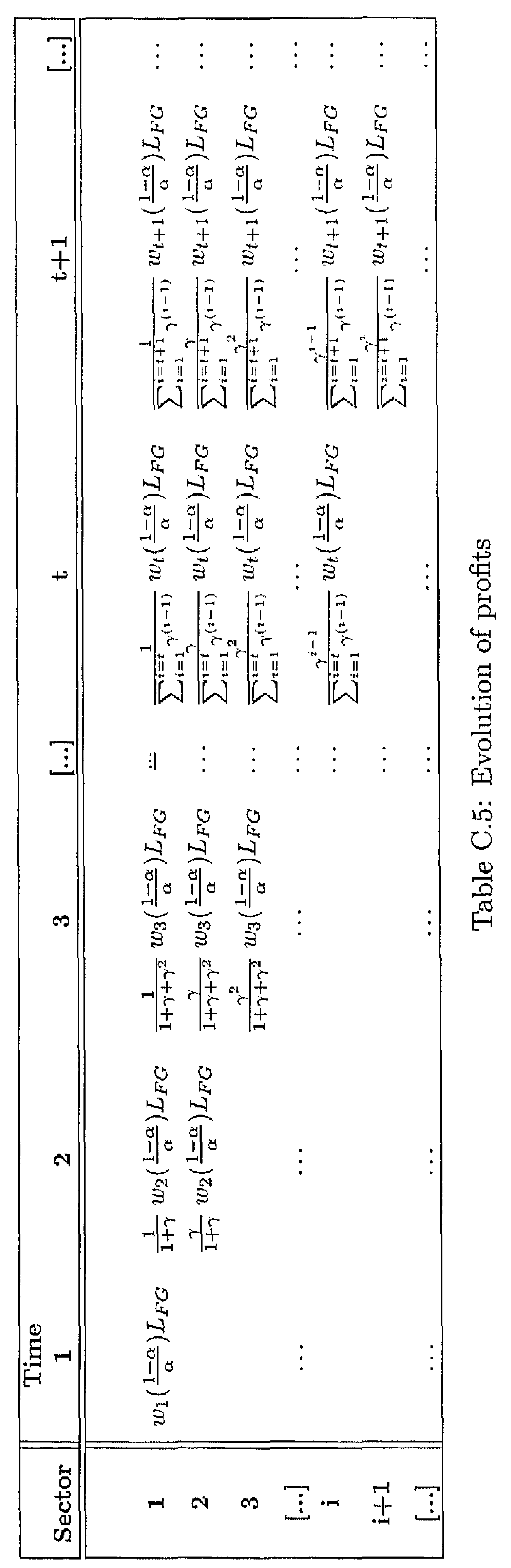




\section{C.1.4 Calculus of the value of the sum}

The limit of the following fraction when t goes to infinity is:

$$
\lim _{t \rightarrow \infty} \frac{1+\gamma+\gamma^{2}+\gamma^{3}+\ldots . \gamma^{t-1}+\gamma^{t}}{1+\gamma+\gamma^{2}+\gamma^{3}+\ldots . \gamma^{t-1}}
$$

Transforming this formula in the following way we have:

$$
\frac{1+\gamma\left(1+\gamma^{2}+\gamma^{3}+\ldots+\gamma^{t-1}\right)}{1+\gamma+\gamma^{2}+\gamma^{3}+\ldots+\gamma^{t-1}}=\frac{1}{1+\gamma+\gamma^{2}+\gamma^{3}+\ldots+\gamma^{t-1}}+\gamma
$$

The limit of a sum is the sum of the two limits:

$$
\lim _{t \rightarrow \infty}\left(\frac{1}{1+\gamma+\gamma^{2}+\gamma^{3}+\ldots+\gamma^{t-1}}+\gamma\right)=0+\gamma
$$

Therefore we can say that

$$
\lim _{t \rightarrow \infty} \frac{1+\gamma+\gamma^{2}+\gamma^{3}+\ldots . \gamma^{t-1}+\gamma^{l}}{1+\gamma+\gamma^{2}+\gamma^{3}+\ldots . . \gamma^{t-1}}=\gamma
$$

Following similar algebra, we can deduce

$$
\begin{gathered}
\lim _{t \rightarrow \infty} \frac{1+\gamma^{\alpha}+\gamma^{2 \alpha}+\gamma^{3 \alpha}+\ldots . \gamma^{\alpha(t-1)}+\gamma^{\alpha t}}{1+\gamma^{\alpha}+\gamma^{2 \alpha}+\gamma^{3 \alpha}+\ldots . \gamma^{\alpha(t-1)}}=\gamma^{\alpha} \\
\lim _{t \rightarrow \infty} \frac{\gamma^{t}}{1+\gamma+\gamma^{2}+\gamma^{3}+\ldots . \gamma^{t-1}}=\gamma-1 \\
\lim _{t \rightarrow \infty} \frac{\gamma-1}{1+\gamma+\gamma^{2}+\gamma^{3}+\ldots . \gamma^{t-1}}=\frac{\gamma-1}{\gamma}
\end{gathered}
$$

\section{The limit of the sum in the transition}

Let us analyse the value of the limits when we depart from a different value of the labour distribution to the one in the equilibria, and we will assume that it takes the economy $n$ periods to reach labour distribution of the equilibrium. In such a case we will be getting the different gammas, until $t=n$, in $t=n+1$ we will be already in the equilibrium

$$
\begin{aligned}
& \gamma_{(2)}=\phi L_{R \& D, t=2} \\
& \gamma_{(3)}=\phi L_{R \& D, t=3} \\
& \cdots \\
& \gamma_{(n)}=\phi L_{R \& D, t=n} \\
& \gamma_{(* *)}=\phi L_{R \& D, t=n+1} \\
& \cdots \\
& \gamma_{(* *)}=\phi L_{R \& D, t=\infty}
\end{aligned}
$$




$$
\lim _{t \rightarrow \infty}\left(\frac{1+\gamma_{(2)}+\left(\gamma_{(2)} \gamma_{(3)}\right) \ldots+\left(\gamma_{(2)} \gamma_{(3)} \ldots \gamma_{(n)} \gamma_{(* *)}^{(t-n)}\right)}{1+\gamma_{(2)}+\left(\gamma_{(2)} \gamma_{(3)}\right) \ldots+\left(\gamma_{(2)} \gamma_{(3)} \ldots \gamma_{(n)} \gamma_{(* *)}^{(t-n-1)}\right)}\right)
$$

We need the value of this limit, which applying l'Hôpital (t-n-1) times with respect to $\gamma_{(* *)}$, will give us the value of the limit,

$$
\left(\frac{(t-n-1) !\left(\gamma_{(2)} \gamma_{(3)} \ldots \gamma_{(n)}\right) \gamma_{(* *)}}{(t-n-1) !\left(\gamma_{(2)} \gamma_{(3)} \ldots \gamma_{(n)}\right)}\right)=\gamma_{(* *)}
$$

Equation C.23 can be transformed into,

$$
\begin{gathered}
\lim _{t \rightarrow \infty}\left(\frac{1+\gamma_{(2)}+\left(\gamma_{(2)} \gamma_{(3)}\right) \ldots+\left(\gamma_{(2)} \gamma_{(3)} \ldots \gamma_{(n)} \gamma_{(* *)}^{(t-n)}\right)}{1+\gamma_{(2)}+\left(\gamma_{(2)} \gamma_{(3)}\right) \ldots+\left(\gamma_{(2)} \gamma_{(3)} \ldots \gamma_{(n)} \gamma_{(* *)}^{(t-n-1)}\right)}\right)= \\
\lim _{t \rightarrow \infty}\left(\frac{1+\gamma_{(2)}+\left(\gamma_{(2)} \gamma_{(3)}\right) \ldots+\left(\gamma_{(2)} \gamma_{(3)} \ldots \gamma_{(n)} \gamma_{(* *)}^{(t-n-1)}\right)+\left(\gamma_{(2)} \gamma_{(3)} \ldots \gamma_{(n)} \gamma_{(* *)}^{(t-n)}\right)}{1+\gamma_{(2)}+\left(\gamma_{(2)} \gamma_{(3)}\right) \ldots+\left(\gamma_{(2)} \gamma_{(3)} \ldots \gamma_{(n)} \gamma_{(* *)}^{(t-n-1)}\right)}\right)= \\
\lim _{t \rightarrow \infty}\left(\begin{array}{c}
\left.1+\frac{\left(\gamma_{(2)} \gamma_{(3)} \ldots \gamma_{(n)} \gamma_{(* *)}^{(t-n)}\right)}{1+\gamma_{(2)}+\left(\gamma_{(2)} \gamma_{(3)}\right) \ldots+\left(\gamma_{(2)} \gamma_{(3)} \ldots \gamma_{(n)} \gamma_{(* *)}^{(t-n-1)}\right)}\right)= \\
1+\lim _{t \rightarrow \infty}\left(\frac{\left(\gamma_{(2)} \gamma_{(3)} \ldots \gamma_{(n)} \gamma_{(* *)}^{(t-n)}\right)}{1+\gamma_{(2)}+\left(\gamma_{(2)} \gamma_{(3)}\right) \ldots+\left(\gamma_{(2)} \gamma_{(3)} \ldots \gamma_{(n)} \gamma_{(* *)}^{(t-n-1)}\right)}\right)
\end{array}\right)=\gamma_{(* *)}
\end{gathered}
$$

Therefore the limit of

$$
\lim _{t \rightarrow \infty}\left(\frac{\left(\gamma_{(2)} \gamma_{(3)} \ldots \gamma_{(n)} \gamma_{(* *)}^{(t-n)}\right)}{1+\gamma_{(2)}+\left(\gamma_{(2)} \gamma_{(3)}\right) \ldots+\left(\gamma_{(2)} \gamma_{(3)} \ldots \gamma_{(n)} \gamma_{(* *)}^{(t-n-1)}\right)}\right)=\gamma_{(* *)}-1
$$

The last limit we calculate is the one coming from the Euler Equation for this especific case of having at the beginning of the process different gammas,

$$
\lim _{t \rightarrow \infty}\left(\frac{1+\gamma_{(2)}^{\alpha}+\left(\gamma_{(2)} \gamma_{(3)}\right)^{\alpha} \ldots+\left(\gamma_{(2)} \gamma_{(3) \ldots \gamma_{(n)}} \gamma_{(* *)}^{(t-n) \alpha}\right)}{1+\gamma_{(2)}^{\alpha}+\left(\gamma_{(2)} \gamma_{(3)}\right)^{\alpha} \ldots+\left(\gamma_{(2)} \gamma_{(3)} \ldots \gamma_{(n)} \gamma_{(* *)}^{(t-n-1) \alpha}\right)}\right)^{1 / \alpha}
$$

As before applying l'Hôpital (t-n-1) times with respect to $\gamma_{(* *)}$, will give us the value of the limit, 


$$
\left(\frac{(t-n-1) ! \alpha^{(l-n-1)}\left(\gamma_{(2)} \gamma_{(3)} \cdots \gamma_{(n)}\right) \gamma_{(* *)}^{\alpha}}{(t-n-1) ! \alpha^{(t-n-1)}\left(\gamma_{(2)} \gamma_{(3)} \cdots \gamma_{(n)}\right)}\right)^{1 / \alpha}=\gamma_{(* *)}
$$

With this calculation we have demostrated that the value of the limit is not affected by intial variation in the values of the $\gamma \mathrm{s}$.

\section{C.1.5 Relation between salary ratios and income ratios}

Starting from the definition of expenditure:

$$
E_{t}=\sum_{i} x_{i t} p_{i t}
$$

We know that prices are equal in each period for all goods:

$$
E_{t}=p_{t} \sum_{i} x_{i t}
$$

Since there is a constant amount of labour devoted to final goods:

$$
\sum_{i} x_{i t}=a L_{F G}
$$

Therefore $E_{t}$ can be written as

$$
E_{t}=p_{t} a L_{F G}
$$

Using the relation given by solution 3.16 we can write:

$$
E_{t}=\frac{w_{t}}{\alpha} L_{F G}
$$

And, repeating the procedure,

$$
E_{t+1}=\frac{w_{t+1}}{\alpha} L_{F G}
$$

Finally dividing the previous two equations, we find the following relation:

$$
\frac{E_{t+1}}{E_{t}}=\frac{w_{t+1}}{w_{t}}
$$

\section{C.1.6 Growth of the utility function in the long run}

Starting from our utility function Equation 3.9:

$$
\left.U_{t}=\left(\sum_{i=1}^{t} \gamma^{(i-1) \alpha} x_{i t}^{(x)}\right)\right)^{1 / \alpha}
$$




\section{APPENDIX C}

we shall calculate the following growth rate:

$$
\frac{U_{t+1}-U_{t}}{U_{t}}
$$

For simplicity, choosing $t=2$, the ratio will be:

$$
\frac{U_{3}-U_{2}}{U_{2}}
$$

Writing down the explicit utility function for each period:

$$
\frac{\left[\left(x_{1}\right)^{\alpha}+\left(\gamma x_{2}\right)^{\alpha}+\left(\gamma^{2} x_{3}\right)^{\alpha}\right]^{1 / \alpha}-\left[\left(x_{1}\right)^{\alpha}+\left(\gamma x_{2}\right)^{\alpha}\right]^{1 / \alpha}}{\left[\left(x_{1}\right)^{\alpha}+\left(\gamma x_{2}\right)^{\alpha}\right]^{1 / \alpha}}
$$

Choosing as the numeraire the total expenditure on the first good, these transformations follow:

$$
\begin{aligned}
& p_{t} x_{1}=1 \\
& p_{t} x_{2}=\gamma p_{t} x_{1}=\gamma \\
& p_{t} x_{3}=\gamma^{2} p_{t} x_{1}=\gamma^{2} \\
& p_{t+1} x_{1}=1
\end{aligned}
$$

The previous expression can be transformed into:

$$
\frac{\left[\left(\frac{1}{p_{t+1}}\right)^{\alpha}+\left(\gamma^{2} \frac{1}{p_{t+1}}\right)^{\alpha}+\left(\gamma^{4} \frac{1}{p_{t+1}}\right)^{\alpha}\right]^{1 / \alpha}-\left[\left(\frac{1}{p_{t}}\right)^{\alpha}+\left(\gamma^{2} \frac{1}{p_{t}}\right)^{\alpha}\right]^{1 / \alpha}}{\left[\left(\frac{1}{p_{t}}\right)^{\alpha}+\left(\gamma^{2} \frac{1}{p_{t}}\right)^{\alpha \alpha}\right]^{1 / \alpha}}
$$

Working on the algebra of this expression,

$$
\begin{aligned}
& \frac{\frac{1}{p_{t+1}}\left[1^{\alpha}+\gamma^{2 \alpha}+\gamma^{4 \alpha}\right]^{1 / \alpha}-\frac{1}{p_{t}}\left[1^{\alpha}+\gamma^{2 \alpha}\right]^{1 / \alpha}}{\frac{1}{p_{t}}\left[1^{\alpha}+\gamma^{2 \alpha}\right]^{1 / \alpha}} \\
& \frac{p_{t}}{p_{t+1}} \frac{\left[1^{\alpha}+\gamma^{2 \alpha}+\gamma^{4 \alpha}\right]^{1 / \alpha}}{\left[1^{\alpha}+\gamma^{2 \alpha}\right]^{1 / \alpha}}-1 \\
& \frac{p_{t}}{p_{t+1}}\left(\frac{1^{\alpha}+\gamma^{2 \alpha}+\gamma^{4 \alpha}}{1^{\alpha}+\gamma^{2 \alpha}}\right)^{1 / \alpha}-1
\end{aligned}
$$

In the long run, we can substitute the fractions for the value they will have as $t$ goes to infinity (see C.1.4),

$$
\lim _{t \rightarrow \infty} \frac{1^{\alpha}+\gamma^{2 \alpha}+\gamma^{4 \alpha}+\ldots+\gamma^{(t+1) 2 \alpha}}{1^{\alpha}+\gamma^{2 \alpha}+\gamma^{(t) 2 \alpha}}=\gamma^{2 \alpha}
$$

Substituting the value of the limit:

$$
\frac{p_{t}}{p_{t+1}}\left(\gamma^{2 \alpha}\right)^{1 / \alpha}-1
$$

Since we are in equilibrium prices grow at a constant rate (see the end of section 
$3.5)$ :

$$
\frac{1}{\gamma}\left(\gamma^{2 \alpha}\right)^{1 / \alpha}-1
$$

Therefore we can conclucle that in the long run equilibrium the utility is growing at this rate:

$$
\frac{U_{t+1}-U_{t}}{U_{t}}=\gamma-1
$$




\section{D.1 European National System of Innovation in four dimensions \\ D.1.1 Converging Countries}

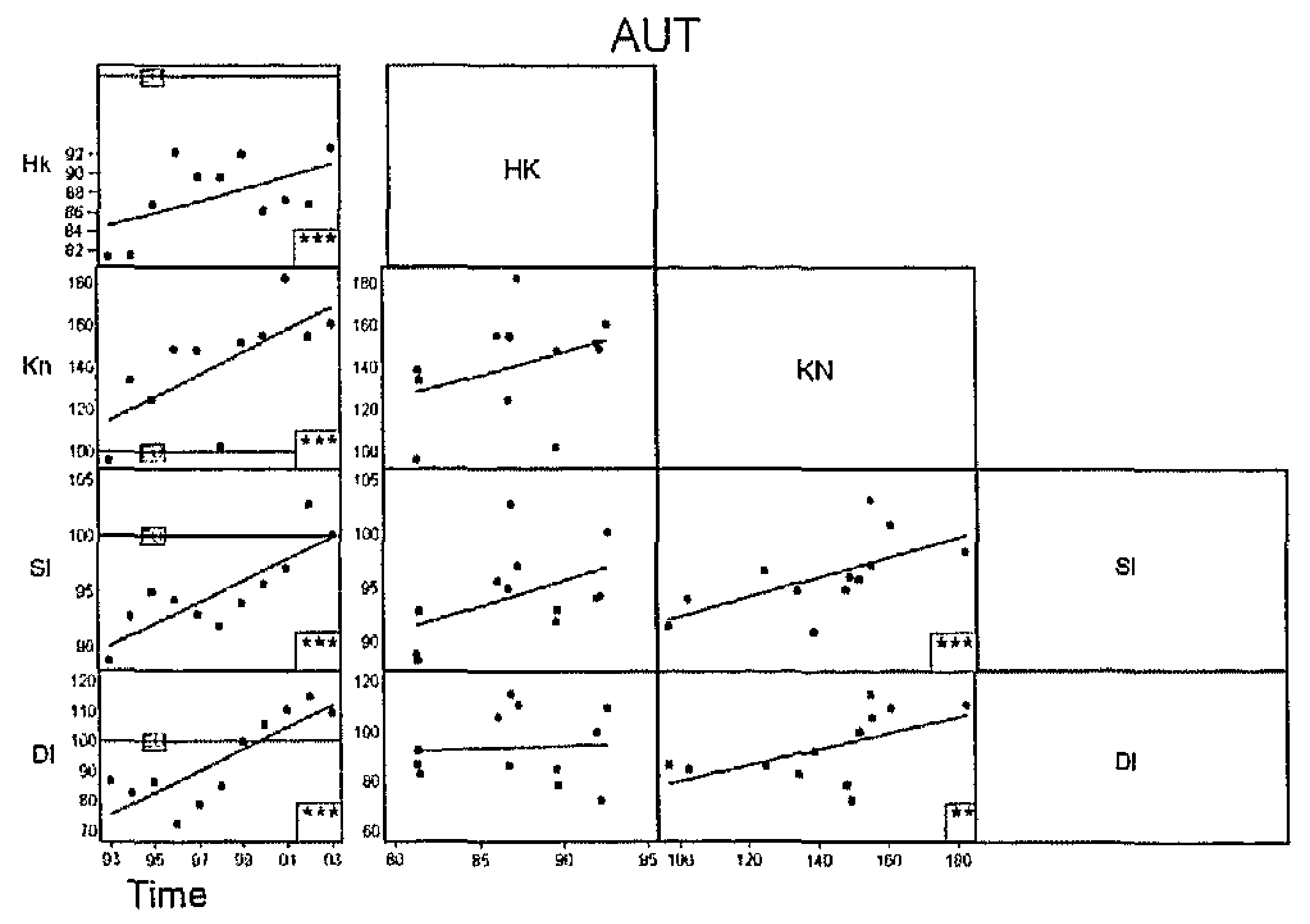

Figure D.1: Austria - National System of Innovations 


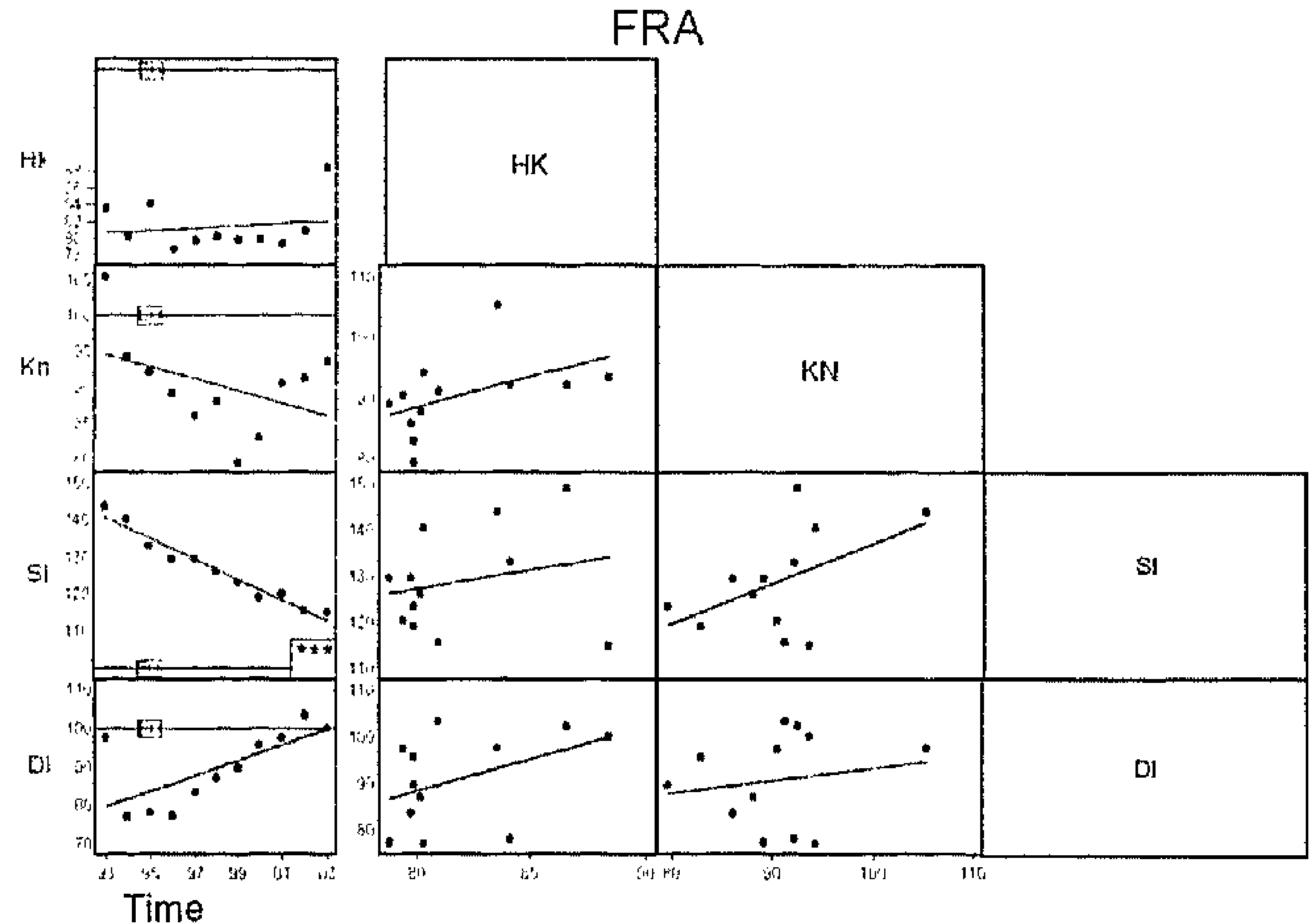

Figure D.2: France - National System of Innovations

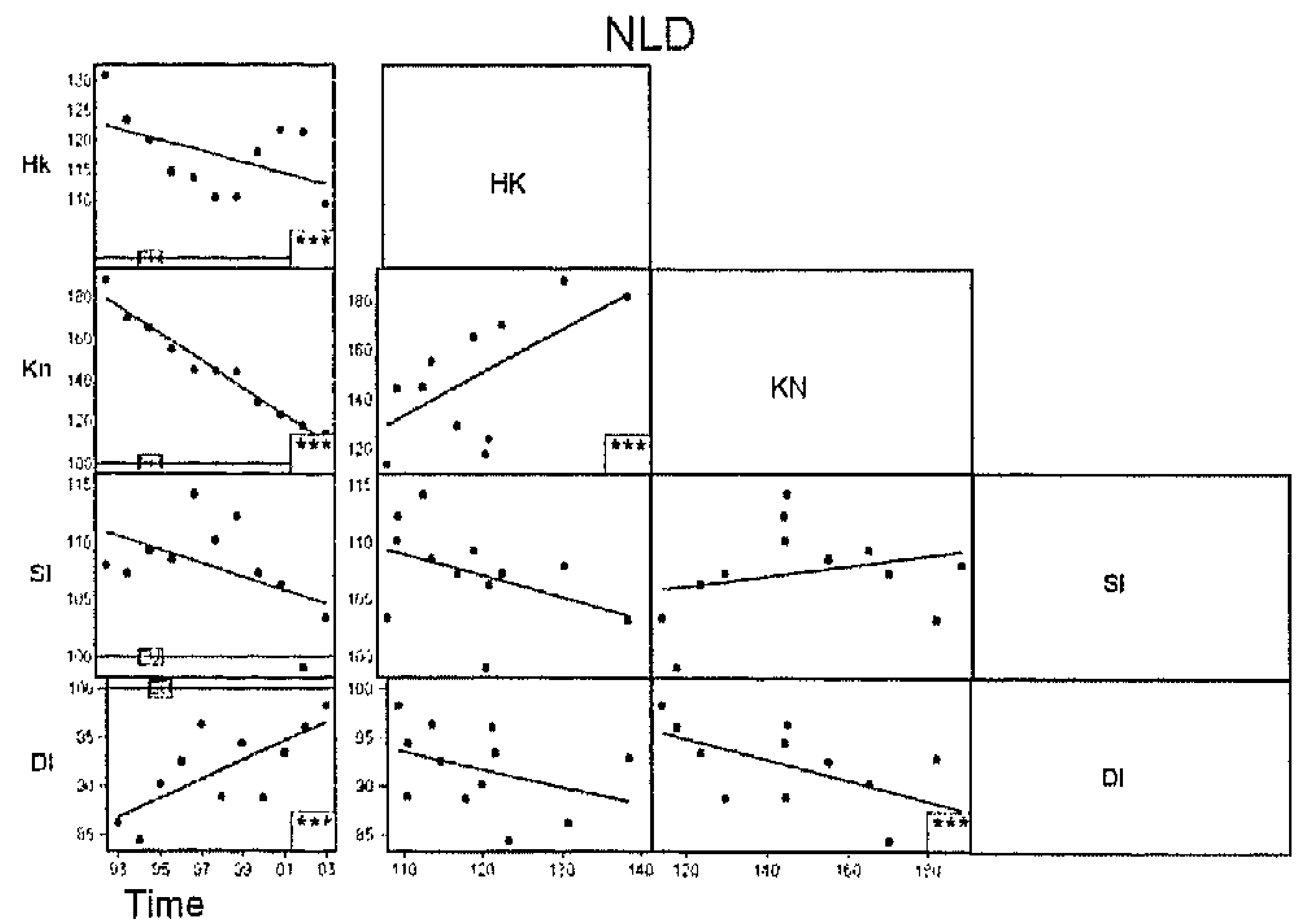

Figure D.3: Netherlands - National System of Innovations 


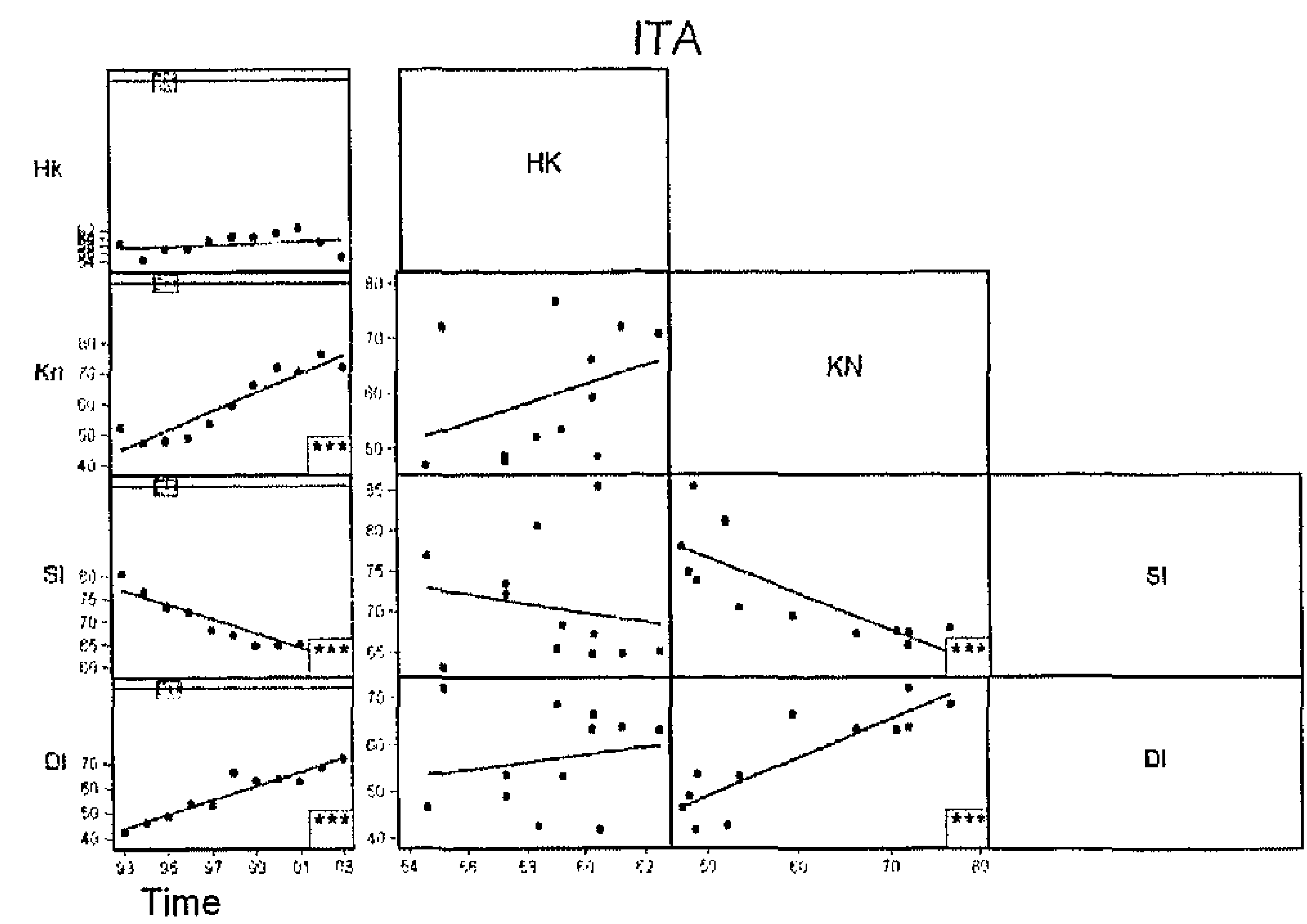

Figure D.4: Italy - National System of Innovations 


\section{D.1.2 Scandinavian Countries}

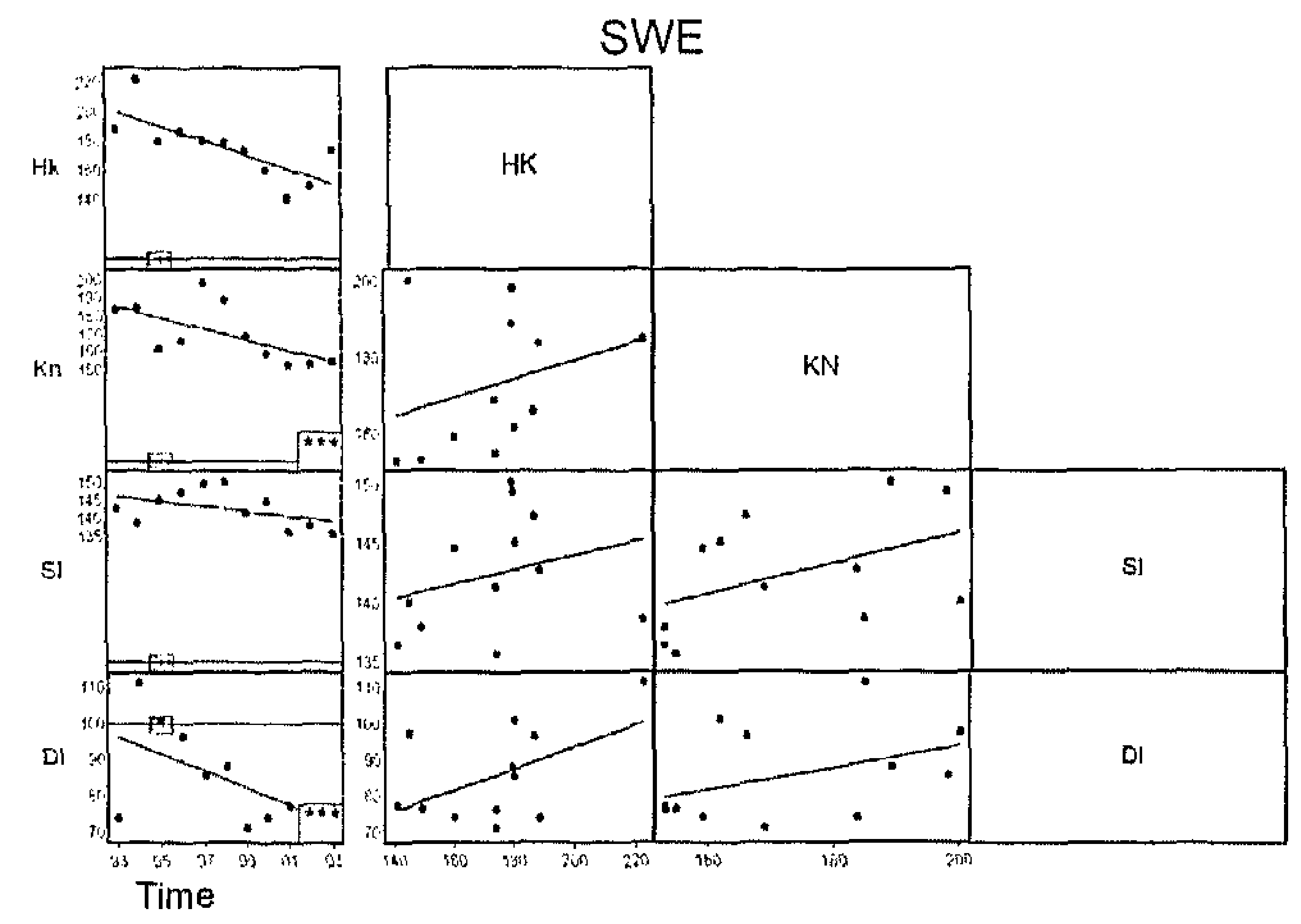

Figure D.5: Sweden - National System of Innovations

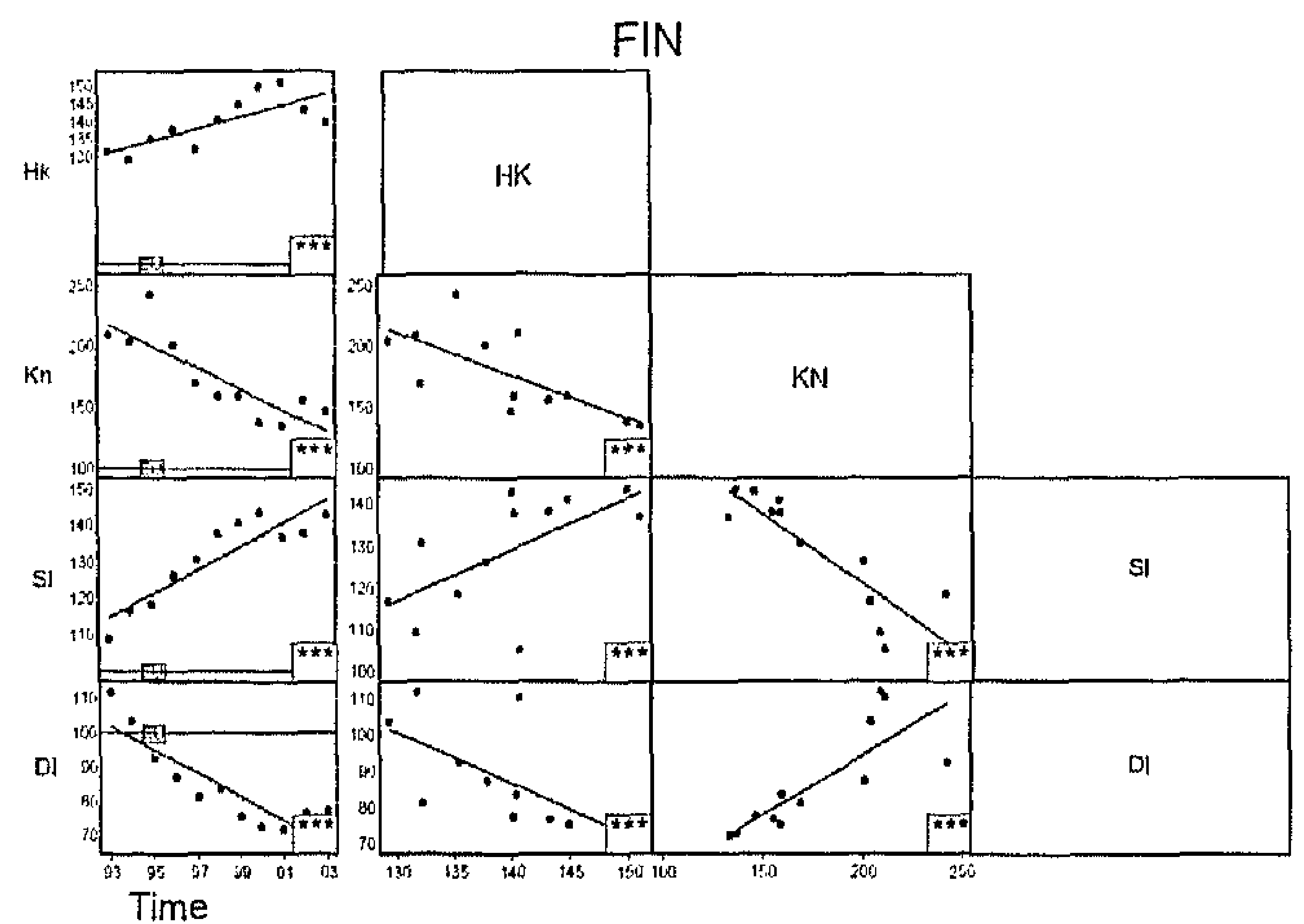

Figure D.6: Finland - National System of Innovations 


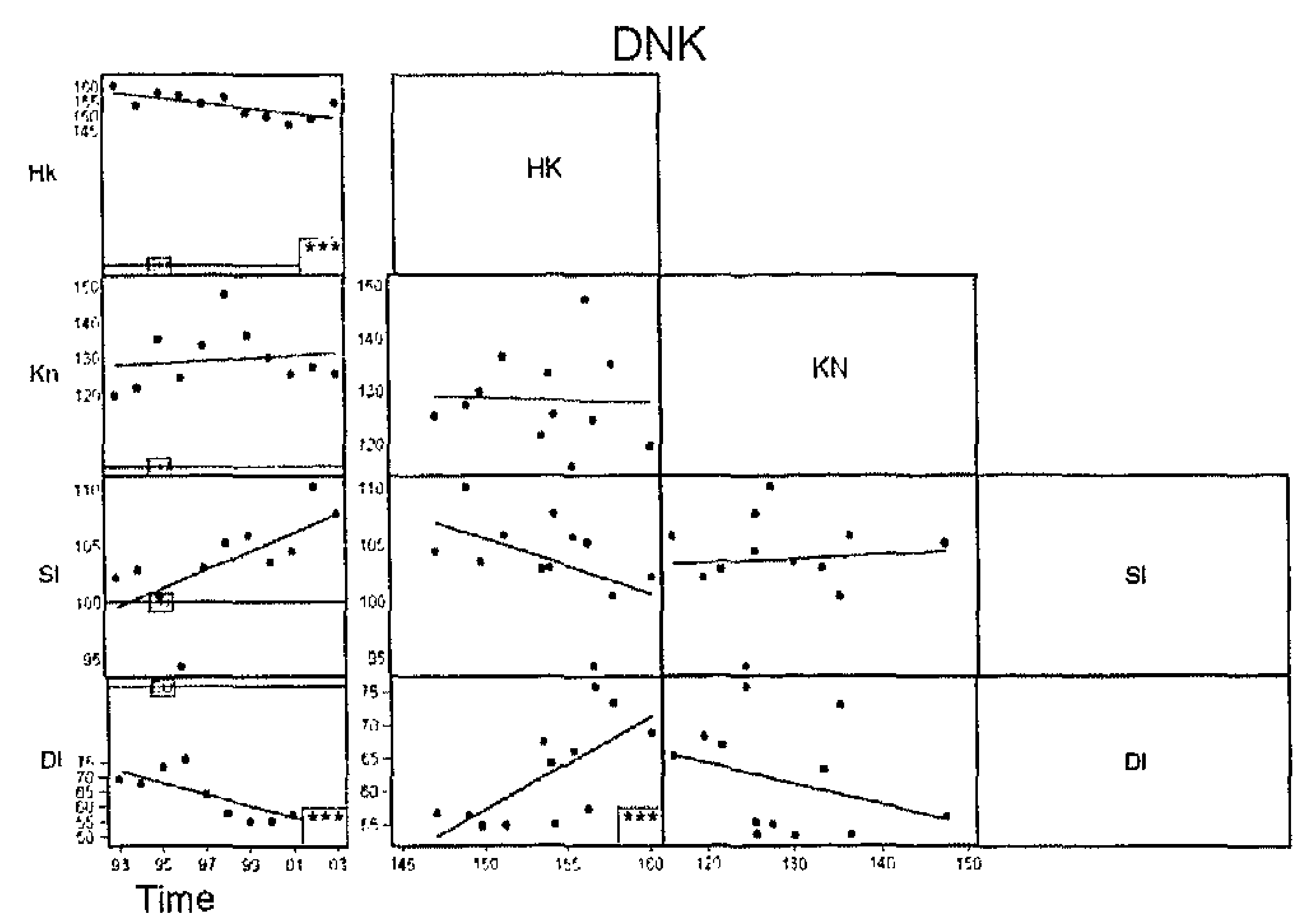

Figure D.7: Denmark - National System of Innovations 


\section{D.1.3 Low Knowledge}

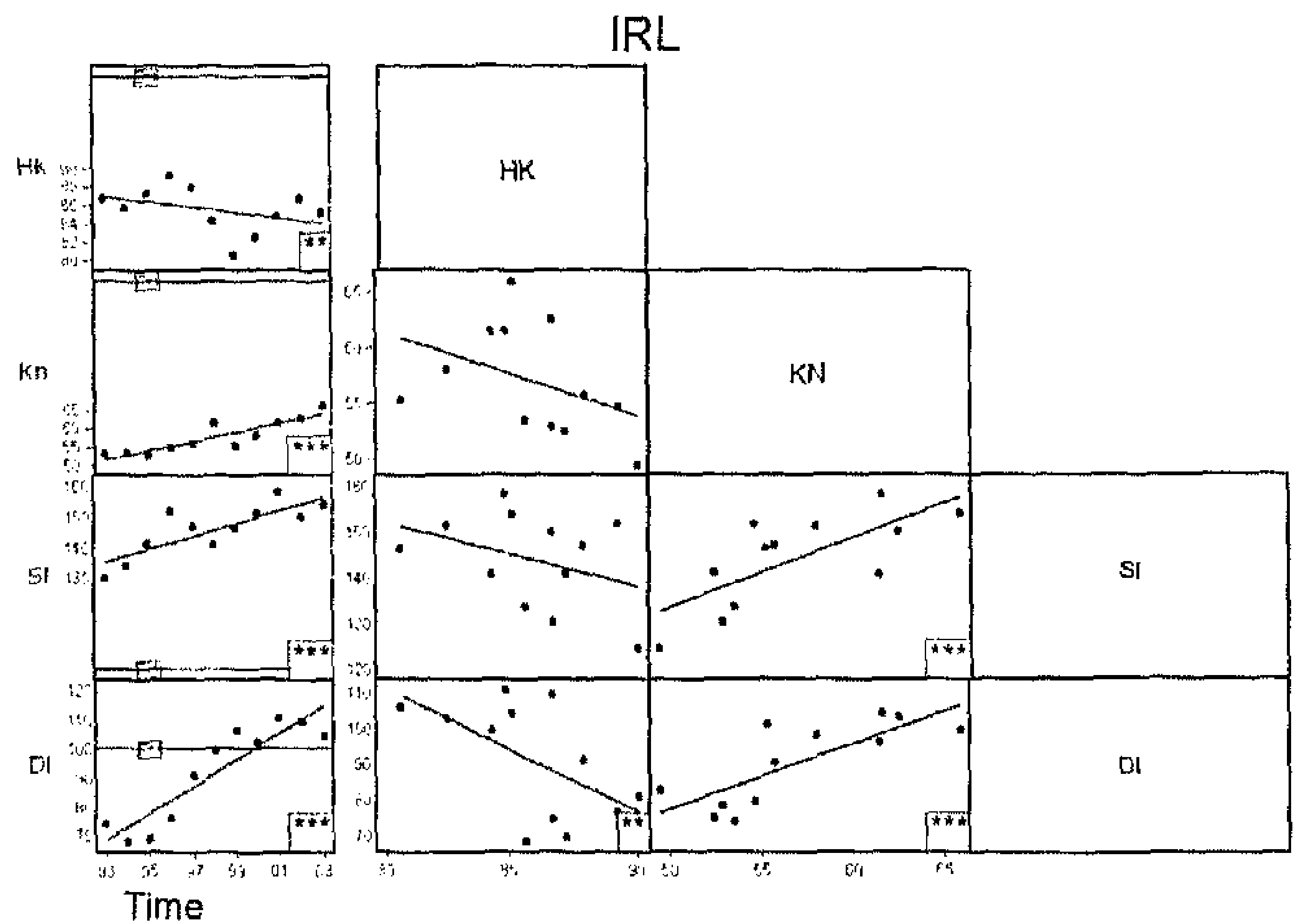

Figure D.8: Ireland - National System of Innovations

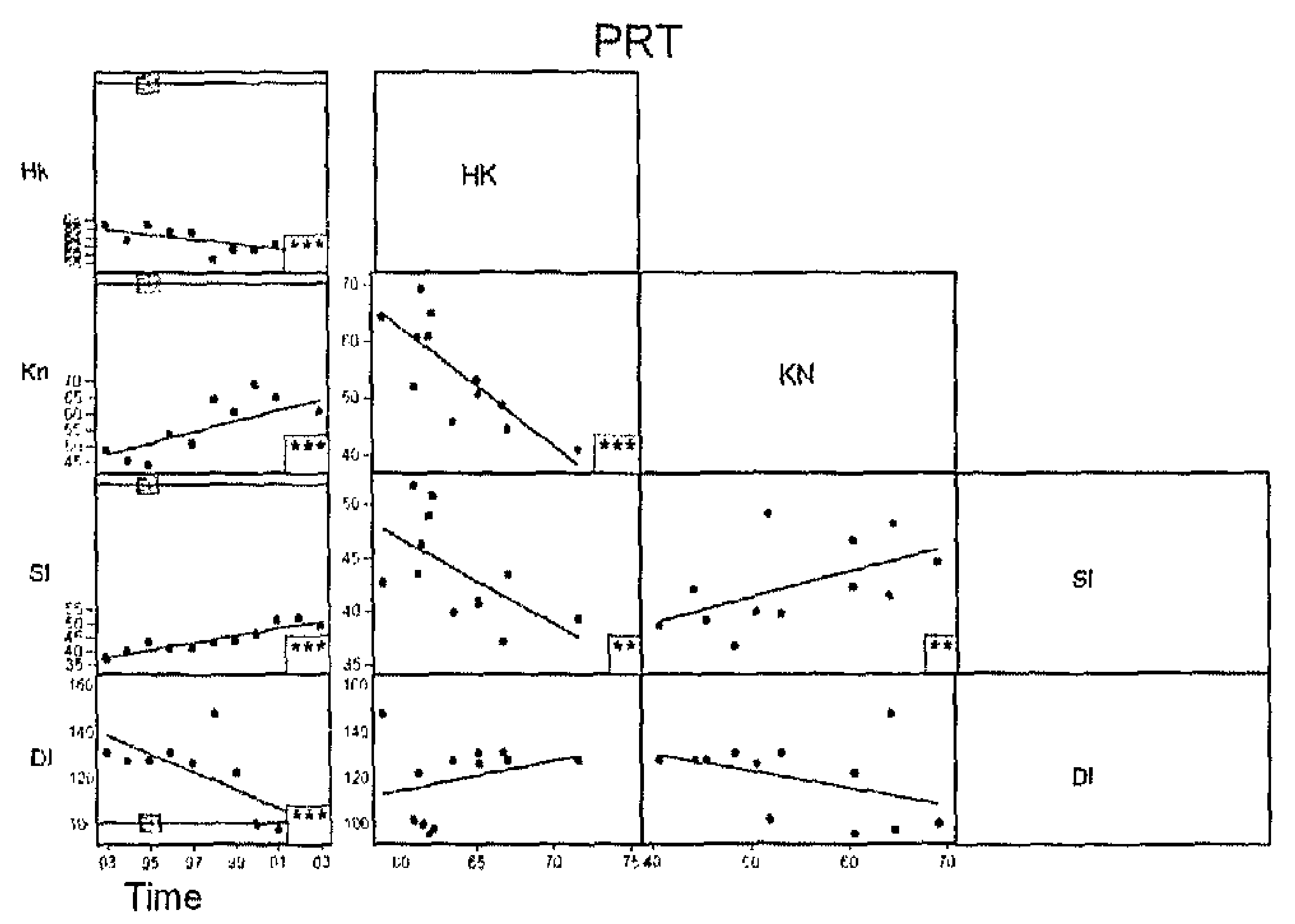

Figure D.9: Portugal - National System of Innovations 


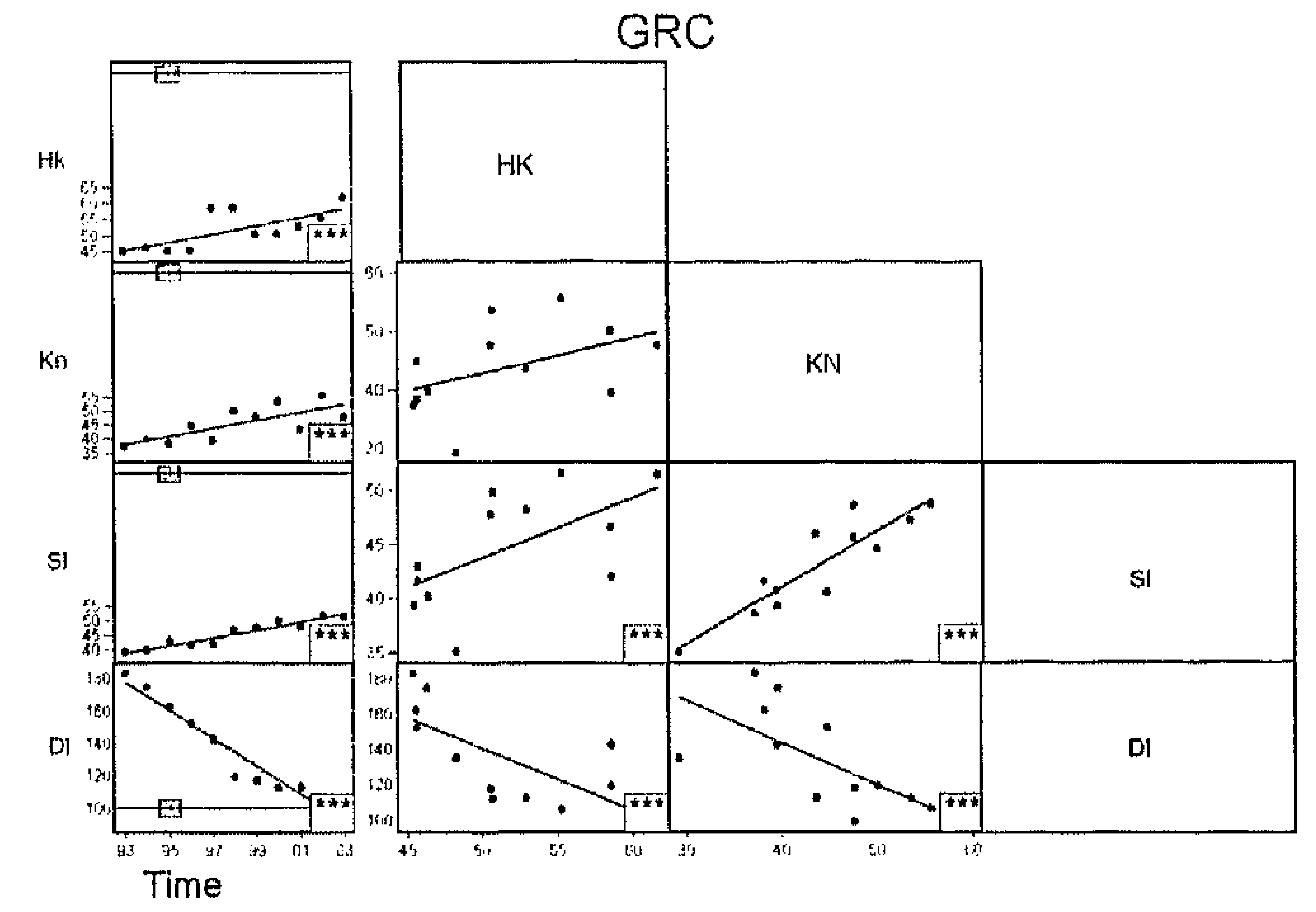

Figure D.10: Greece - National System of Innovations

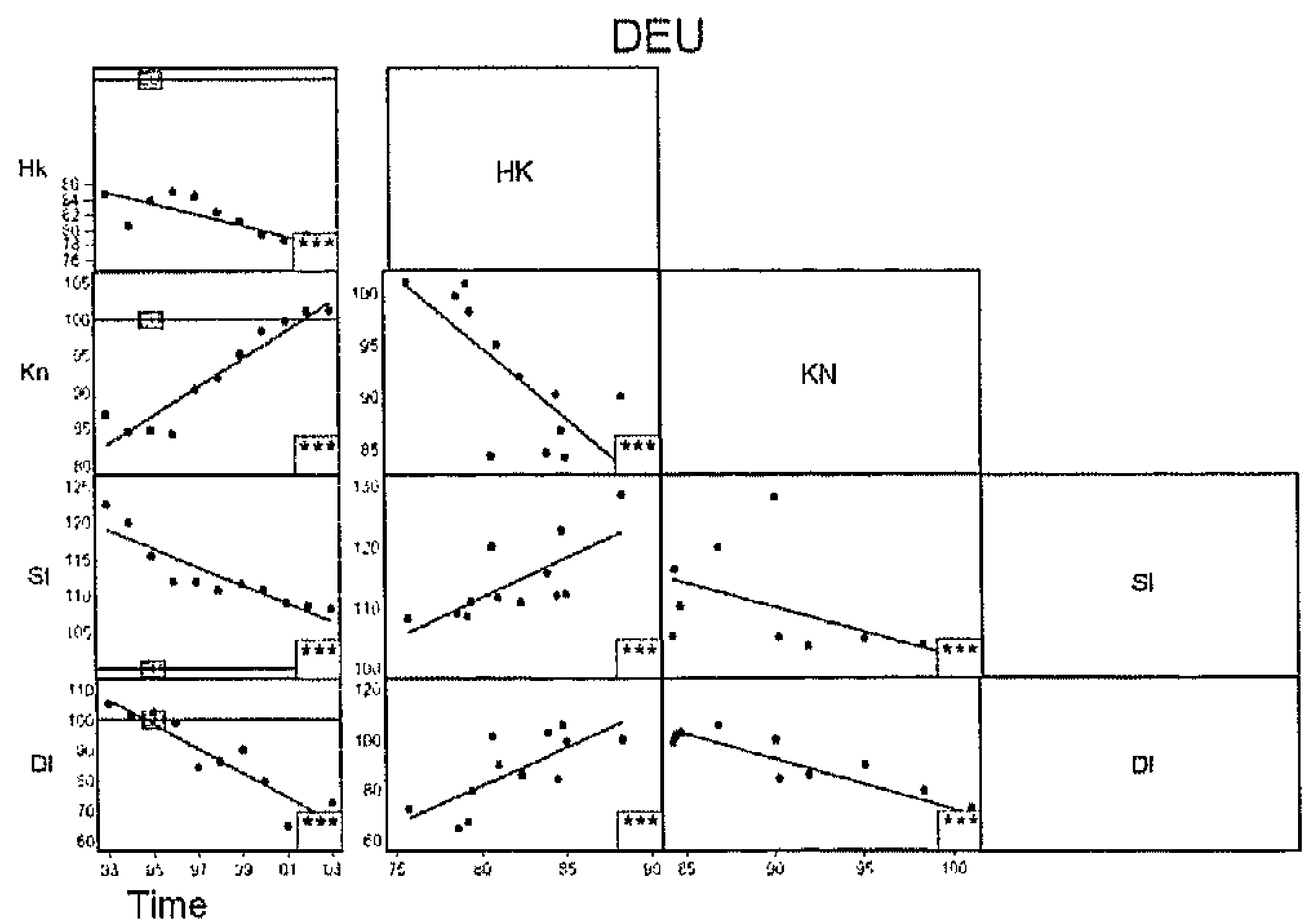

Figure D.11: Germany - National System of Innovations 


\section{D.1.4 Strong Demand}

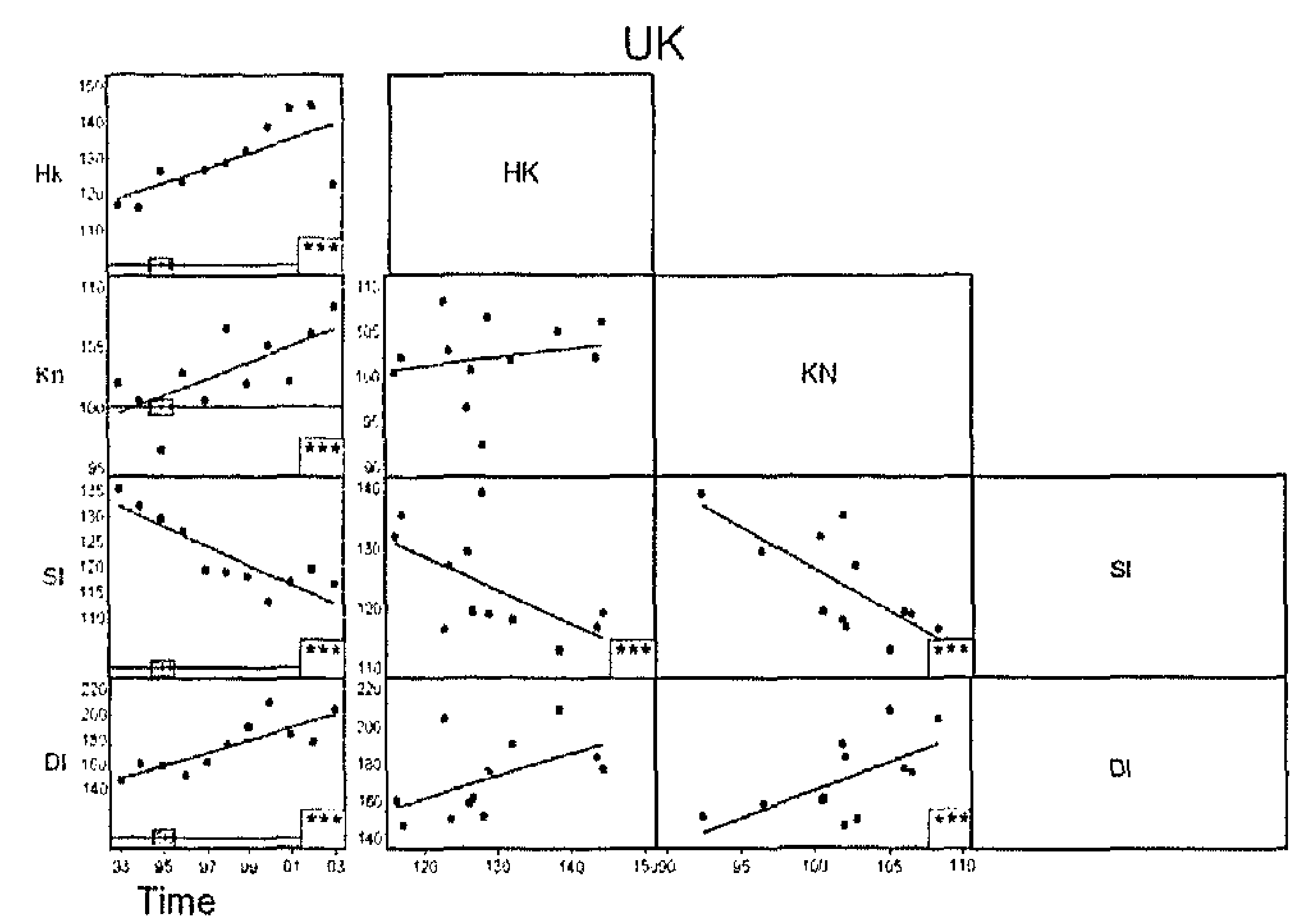

Figure D.12: United Kingdom - National System of Innovations

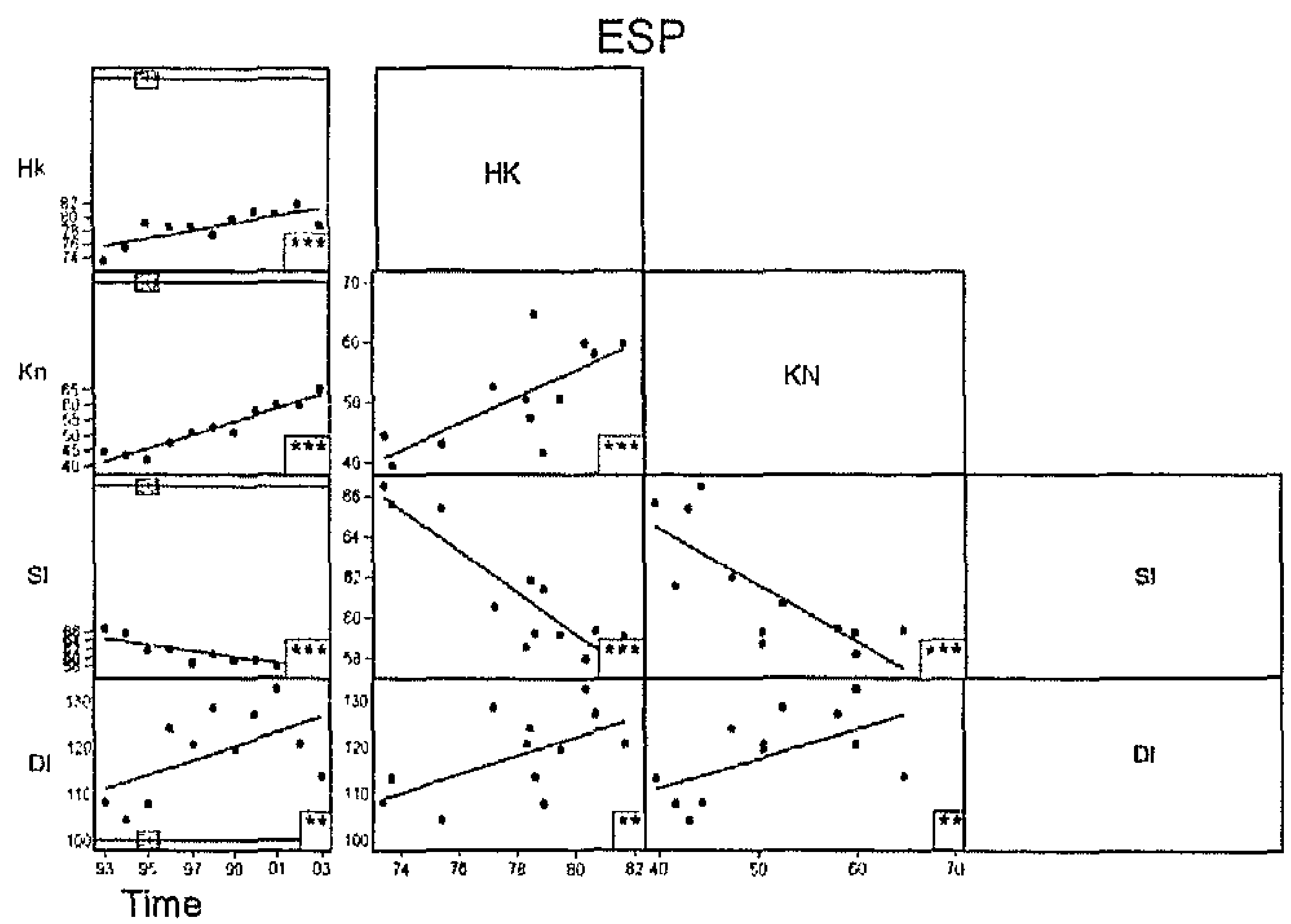

Figure D.13: Spain - National System of Innovations 


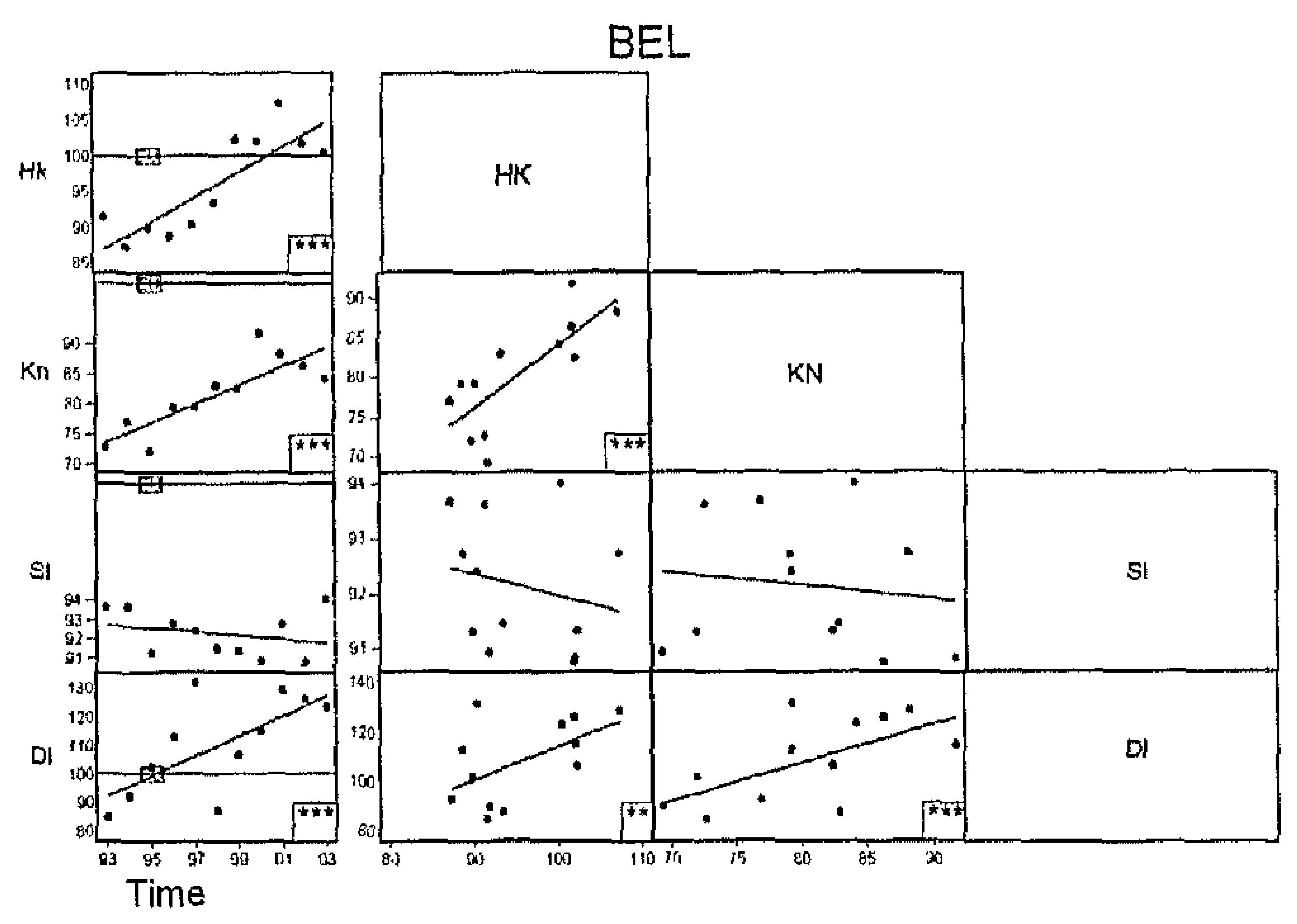

Figure D.14: Belgium - National System of Innovations 


\section{BIBLIOGRAPHY}

Aghion, P. and P. Howitt (1992). A model of growth through creative destruction. Econometrica: Journal of the Econometric Society 60(2), 323-351.

Ainslie, G. (1975). Specious reward: A behavioral theory of impusiveness and impulse control. Psychological Bulletin 82(2), 463-496.

Ainslie, G. (1991). Derivation of "rational" economic behavior from hyperbolic discount curves. The American Economic Revicw 81 (2, Papers and Proceedings of the Hundred and Third Annual Meeting of the American Economic Association), 334-340.

Ainslie, G. (1992). Picoeconomics: The Strategic Interaction of Successive Motivational States within the person. Cambridge: Cambridge University Press.

Alonso-Carrera, J., J. Caballe, and X. Raurich (2004). Consumption externalities, habit formation and equilibrium efficiency. Scandinavian Journal of Economics 106(2), 23151.

Alvarez-Cuadrado, F., G. Monteiro, and S. J. Turnovsky (2004). Habit formation, catching up with the joneses, and economic growth. Journal of Economic Growth 9(1), $47-80$.

Aoki, M. and H. Yoshikawa (2002). Demand saturation-creation and economic growth. Journal of Economic Behavior and Organization 48(2), 127-54.

Arrow, K. J. (1962). The economic implications of learning by doing. The Review of Economic Studies 29(3), 155-173.

Attanasio, O. P., L. Picci, and A. E. Scorcu (2000). Saving, growth, and investment: A macroeconomic analysis using a panel of countries. Review of Economics and Statistics 82(2), 182-211.

Barro, R. J. and X. Sala-i Martin (1995). Economic Growth. New York: McGraw-Hill.

Benhabib, J. and A. Bisin (2000). Adverstising, mass consumption and capitalism. http://www.econ.nyu.edu/user/benhabib/research.htm February.

Bentham, J. (1907). An Introduction to the Principles of Morals and Legislation. Oxford: Claredon Press. 
Bergemann, D. and J. Valimalsi (2006). Dynamic pricing of new experience goods. Journal of Political Economy 114(4), 713-743.

Berlyne, D. (1974). Studies in the new experinemental aesthetics: steps toward an objective psychology of aesthetic appreciation. Washington Hemisphere Pub. Corp.

Bianchi, M. (1998). The Active Consumer. London: Routledge.

Bianchi, M. (2002). Novelty, preferences, and fashion: When goods are unsettling.

Bowen, H. P. and W. Moesen (2005). Benchmarking the competitiveness of nations: Nouniform weighting and non-economic dimensions. (Mimeo).

Carroll, C. D., J. Overland, and D. N. Weil (1997). Comparison utility in a growth model. Journal of Economic Grouth 2(4), 339-67.

Carroll, C. D., J. Overland, and D. N. Weil (2000). Saving and growth with habit formation. American Economic Review 90(3), 341-55.

Carroll, C. D. and D. N. Weil (1994). Saving and growth: A reinterpretation. CarnegieRochester Conference Series on Public Policy 40(0), 133-92.

Chang, P.-L. and H.-Y. Shih (2005). Comparing patterns of intersectoral innovation diffusion in taiwan and china: A network analysis. Technovation 25, 155-196.

Cherchye, L., W. Moesen, and T. Van Puyenbroeck (2004). Legitimately diverse, yet comparable: On synthesizing social inclusion performance in the eu. Journal of Common Market Studies 42(5), 919-55.

Chiesa, V. and R. Manzini (1998). Towards a framework for dynamic technology strategy. Technology Analysis and Strategic Management 10(1), 111-29.

Chow, G. (1997). Dynamics Economics. New York: Oxford University Press.

Cohen, W. M. and R. C. Levin (1989). Empirical studies of innovation and market structure.

Coombs, R., P. Narandren, and A. Richards (1996). A literature-based innovation output indicator. Research Policy 25, 403-413.

Crepon, B., E. Duguet, and J. Mairesse (1998). Research, innovation and productivity: An econometric analysis at the firm level. Economics of Innovation and New Technology 7(2), 115-58.

Dalum, B. (1992). Export specialisation, structural competitiveness and national systems of innovation.

Dang Nguyen, G. and M. Jolles (2005). Does the european union create the foundations of an information society for all? Bruges European Economic Policy Briefings 11.

Dasgupta, P. and E. Maskin (2005). Uncertainty and hyperbolic discounting. American Economic Review 95(4), 1290-1299. 
Dixit, A. K. and J. E. Stiglitz (1977). Monopolistic competition and optimum product diversity. The American Economic Revicw 67(3), 297-308.

Domar, E. D. (1946). Capital expansion, rate of growth, and employment. Econometrica, Journal of the Econometric Society 14(2), 137-147. FLA 00129682 George Banta Publishing Company EN Copyright 1946 The Econometric Socicty.

Dosi, G., K. Pavitt, and L. Soete (1990). The Economics of Technical Change and Interantional Trade. Harvest Wheatsheaf.

Duesenberry, J. S. (1949). Income, Saving and the Theory of the Consumer Behaviour. Cambridge Mass.: Harrod University Press.

Echevarria, C. (1997). Changes in sectoral composition associated with economic growth. Inlernational Economic Review 38(2), 431-52. TY - JOUR Accession Number: 0423505 . Keywords: Economic Growth; Growth; Technological Change. Publication Type: Journal Article. Update Code: 199709.

Edquist, C. (1995). Government technology procurement as an instrument of technology policy. In M. J. M. Teubal, D. Foray and E. Zucovitch (Eds.), Technological Infrastructure Policy (TIP). Dordrecht-Boston London: Kluger.

Edquist, C. (1997). Systems of innovation approaches-their emergence and characteristics. In Systems of Innovation, pp. 1-35. London (UK): Series Editor: John de la Mothe.

Fagerberg, J. (1992, 1992///). The home market hypothesis re-examined: The impact of domestic user-producer interaction on export specialisation. TY - GEN Accession Number: 0367394 . Editor: Lundvall, Bengt-Ake, ed.. Keywords: Exports. Geographic Descriptors: OECD. Publication Type: Collective Volume Article. Update Code: 199512.

Falkinger, J. and J. Zweimuller (1997). The impact of income inequality on product diversity and economic growth. Metroeconomica $48(3), 211-37$.

Faruk, G. and P. Wolfgang (2005). The revealed preference theory of changing tastes. Review of Economic Studies 72, 429-448.

Felice, G. and L. Bonatti (2004). Endogenous Growth and Changing Sectoral Composition in Advanced Economies. Ph. D. thesis, University of Pavia (ITALY) WP. Paper No. 162.

Ferguson, B. and G. Lim (2003). Dynamic Economic Models in Discrete Time. London: Routledge.

Foellmi, R. and J. Zweimuller (2002). Structural Change and the Kaldor Facts of Economic Growth. C.E.P.R. Discussion Papers, CEPR Discussion Papers: 3300.

Foellmi, R. and J. Zweimuller (2004). Inequality, market power, and product diversity. Economics Letters 82(1), 139-45.

Foellmi, R. and J. Zweimuller (2006). Income distribution and demand induced innovations. Review of Economic Studies 73. 
Frank, R. H. (1999). Luxery Fever. New York: The Free Press.

Frederick, S., G. Loewenstein, and T. O'Donoghue (2002). Time discounting and time prefercnce: A critical review.

Freeman, C. (1982). Technological infraestructure and international competitiveness. Reprint for The First Globelics Conference. Draft paper submitted to the OECD.

Freeman, C. (1995). The 'national system of innovation' in historical perspective. Cambridge Journal of Economics 19(1), 5-24.

Freeman, C. (2002). Continental, national and sub-national innovation systemscomplementarity and economic growth. Research Policy 31(2), 191-211.

Fuhrer, J. C. (2000). Habit formation in consumption and its implications for monetarypolicy models. American Economic Review 90(3), 367-90.

Furman, J. L., M. E. Porter, and S. Stern (2002). The determinants of national innovative capacity. Rescarch Policy 31(6), 899-933. TY - JOUR Accession Number: 0614999 - Geographic Descriptors: Selected Countries. Publication Type: Journal Article. Update Code: 200208.

Galbraith, J. K. (1958). The Affluent Society. Penguin Books.

Gandolfo, G. (1980). Economics Dynamics. Berlin-Heidelberg: Springer.

Geary, R. (1950). A note on a constant utility index of the cost of living. Review of Economic Studies 18, 65-66.

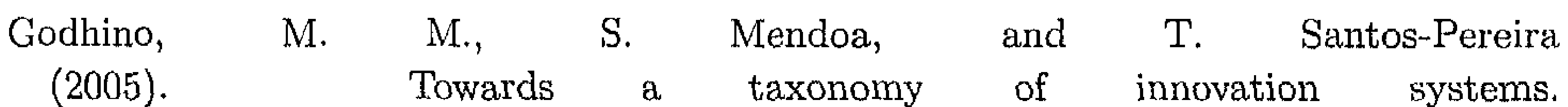
http://pascal.iseg.utl.pt/depteco/iseg_ecosemin0405_mmgodinhopaper.pdf WP 13/2005/DE/CISEP(ISEG-UT Lisabon University).

Gollier, C. and R. Zeckhauser (2005). Aggregation of heterogeneous time preferences. Journal of Political Economy 113(4), 878-896.

Gonzalez, X., J. Jaumandreu, and C. Pazo (2005). Barriers to innovation and subsidy effectiveness. RAND Journal of Economics 36(4), 930-950.

Gourieroux, C., A. Monfort, and A. Trognon (1985). Moindres carres asymptotiques. (asymptotic least squares. with english summary.). Annales de l'INSEE 0(58), 91122.

Granger, C. W. J. and L.-l. Huang (1997). Evaluation of panel data models: Some suggestions from time series.

Greenwood, J. and G. Uysal (2004). New goods and the transition to a new economy. TY - UNPB Accession Number: 0745243 . Publication Type: Working Paper. Update Code: 200410.

Gregersen, B. (1992). The public sector as a pacer in national systems of innovation. 
Grossman, G. and E. Helpman (1991). Innovation and Growth. Massachusetts: The MIT press.

Harrod, R. F. (1939). An essay in dynamic theory. The Economic Journal 49(193), 14-33. FLA 00130133 MacMillan and Co. Limited Copyright 1939 Royal Economic Society.

Hebb, D. (1955). Drives and the c.n.s. ( conceptual nervous system)". THe Psychological Review 62(4), 243-254.

Hicks, J. R. and R. G. D. Allen (1934a). A reconsideration of the theory of value part i. Economica 1(1), 52-76.

Hicks, J. R. and R. G. D. Allen (1934b). A reconsideration of the theory of value part ii. a mathematical theory of individual demand functions. Economica 1(2), 196-219. FLA 200130427 London School of Economics and Political Science Copyright 1934 The London School of Economics and Political Science.

Hufbauer, G. (1970). The impact of national characteristics and technology on the commodity composition of trade in manufactured goods. In R. Vernon (Ed.), The Technology Factor in International Trade. New York: Harvard University Press.

Ito, T. and J. T. Cacioppo (1999). The psychophysiology of utility appraisals. In Kahneman Ed. (1999) Well being : the foundations of Hedonic Psychology..

Jevons, W. (1871). The Theory of Political Economy. London: New York Macmillan.

Jones, C. I. (1995a). R\&d-based modesl of economic growth. Journal of Political Economy 103(4), 759-784.

Jones, C. I. (1995b). Time series test of endogenosu growth models. Quartely Journal of Economics 110(2), 495-525.

Judd, K. (1998). Numerical Methods in Economics. Massachusetts: The MIT press.

Judd, K. L. (1985). On the performance of patents. Econometrica: Journal of the Econometric Society 53(3), 567-586. FLA 00129682 The Econometric Society EN Copyright 1985 The Econometric Society.

Kahneman, D., E. Diener, and N. Schwarz (Eds.) (1999). Well being: the foundations of Hedonic Psychology. New York: Russell Sage Foundation.

Kahneman, D. and A. Tversky (1979). Prospect theory: An analysis of decision under risk. Econometrica: Journal of the Econometric Society 47(2), 263-292.

Kahneman, D., P. P. Wakker, and R. Sarin (1997). Back to bentham? explorations of experienced utility. The Quarterly Journal of Economics 112(2, In Memory of Amos Tversky (1937-1996)), 375-405.

Kaiser, R. and H. Prange (2004). The reconfiguration of national innovation systems-the example of german biotechnology. Research Policy 33(3), 395-408.

Keynes, J. M. (1936). The general theory of employment, interest and money. London: Macmillan [etc.] for the Royal Economic Society. 
Kongsamut, P., S. Rebelo, and D. Xie (2001). Beyond balanced growth. Review of Economic Studies 68(4), 869-82.

Koszegi, B. and M. Rabin (2006). A model of reference-dependent preferences. Quarterly Journal of Economics CXXI(4), 1133-1165.

Lancaster, K. (1966). Change and innovation in the technology of consumption. The American Economic Review 56(1/2), 14-23.

Liu, X. and S. White (2001). Comparing innovation systems: A framework and application to china's transitional context. Research Policy 30(7), 1091-1114. TY - JOUR Accession Number: 0590474 . Geographic Descriptors: China. Publication Type: Journal Article. Update Code: 200112.

Loewenstein, G., T. O'Donoghue, and M. Rabin (2000). Projection bias in predicting future utility.

Loewenstein, G. and D. Prelec (1991). Negative time preference.

Loewenstein, G. and D. Prelec (1992). Anomalies in intertemporal choice: Evidence and an interpretation.

Lucas, R. (1988). On the mechanisms of economic develpment. Journal of Monetary Economics 22, 3-42.

Lundvall, B.-A. (1992). User-producer relationships, national systems of innovation and internationalisation.

Lundvall, B.-A. (2005). National innovation systems- analytical concept and development tool. Paper to be presented at the DRUID tenth Anniversary Summer Conferences..

Malerba, Franco, e. (2004). Sectoral systems of innovation: Concepts, issues and analyses of six major sectors in Europe. Cambridge; New York and Melbourne: Cambridge University Press.

Mandler, M. (2006). Cardinality versus ordinality: A suggested compromise. American Economic Review 96(4), 11141136.

Markowitz, H. (1952). The utility of wealth. The Journal of Political Economy 60(2), 151-158.

Marshall, A. (1890). Principles of Economics.

Metcalfe, J. S. (1995). Technology systems and technology policy in an evolutionary framework. Cambridge Journal of Economics 19(1), 25-46.

Mill, J. S. and G. Sher (1979). Utilitarianism. Indianapolis: Hackett Pub. Co.

Montobbio, F. (2000). Instituzioni e attivita innovativa: i sistemi inovativi. In F. Malerba (Ed.), Economia dell' Innovazione.

Montobbio, F. (2001). The Dynamics of Industries: Essays on Structural Change, Technological Spillovers and Patterns of International Specialisation. Ph. D. thesis, University of Manchester (UK). 
Nardo, M., M. Saisana, A. Salteli, S. Tarantola, A. Hoffman, and E. Giovannini (2005). Handbook on constructing composite indicators: Methodology and user guide. OCDE Slatistic Working Paper 3.

Nasierowski, W. and F. Arcelus (1999). Interrelationsships among the elements of national innovation systems: A statistical evaluation. European Journal of Operational Reserach 119, 235-253.

Ngai, L. R. and C. A. Pissarides (2007). Structural change in a multisector model of growth. American Economic Review 97(1), 429443.

Osborn, D. R. (1988). Seasonality and habit persistence in a life cycle model of consumptio n. Journal of Applied Econometrics 3(4), 255-66.

Pasinetti, L. (1981). Structural Change and Economic Growth: a Theoretical Essay on the Dynamics of the Wealth of Nations. New York: Cambridge University Press.

Perez, C. (1985). Microelectornics, long waves and world structural change: New perspectives for developing countries. World Development 13(3), 441-463.

Perez, C. (1988). New technologies and development. In C. Freeman and B.-A. Lundvall (Eds.), Small Contires Facing the Technological Revolution. London: Biddle of Guildford.

Pollak, R. A. (1970). Habit formation and dynamic demand functions. The Journal of Political Economy 78(4, Part 1), 745-763.

Porter, M. E. (1990). The competitive advantage of nations. The Macmillan Press LTD.

Porter, M. E. and S. Stern (2001). National innovative capacity. The Global Competitiveness Report 2001-2002 http://www.isc.hbs.edu/Innov_9211.pdf.

Posner, M. (1961). International trade and technical change. Oxford Economic Papers October.

Ramsey, F. P. (1928). A mathematical theory of saving. The Economic Journal 38(152), 543-559. FLA 00130133 MacMillan and Co. Limited Copyright 1928 Royal Economic Society.

Ravn, M., S. Schmitt-Grohe, and M. Uribe (2006). Deep habits.

Robbins, L. (1935). An essay on the Nature and Significance of Economic Science. London: Macmillan.

Romer, P. M. (1990). Endogenous technological change. Journal of Political Economy 98(5, Part 2: The Problem of Development: A Conference of the Institute for the Study of Free Enterprise Systems), S71-S102.

Rosenberg, N. (1969). The direction of technological change: Inducement mechanisms and focusing devices. Economic Development and Cultural Change 18(1), 1-24.

Ryder, Harl E., J. and G. M. Heal (1973). Optimal growth with intertemporally dependent preferences. The Review of Economic Studies 40(1), 1-31. 
Saisana, M., A. Salteli, and S. Tarantola (2005). uncertainty and sentitivity analysis techniques as tools for the quality assessment of composite indicators. Journal of Royal Statistical Society 168(part 2), 307-323.

Samuelson, P. A. (1938). A note on the pure theory of consumer's behaviour: An addendum. Economica 5(19), 353-354.

Samuelson, P. A. (1952). Probability, utility, and the independence axiom. Econometrica: Journal of the Econometric Society 20(4), 670 678.

Schmookler, J. (1971). Economics sources of inventive capacity. in N. Rosemberg(ed) The Economics of Technological Change.

Scitosvky, T. (1977). The joyless economy : an inquiry into human satisfaction and consumer dissatisfactionn. Oxford University Press.

Smith, A. (1723). History of astronomy. In W. B. a. Ross (Ed.), Essays in Philosophical Subjects. Oxford University Press.

Solomon, R. (1980). The opponent process theory of adquired motivation. American Psycologist 35(8), 691-712.

Solow, R. M. (1956). A contribution to the theory of economic growth. The Quarterly Journal of Economics 70(1), 65-94.

Stigler, G. J. and G. S. Becker (1977). De gustibus non est disputandum. The American Economic Review 67(2), 76-90.

Stone, R. (1955). Consumers' Expendilure in the United Kingdom, 1900-1919., Volume 22 of Economica.

Swann, P. (2002). There's more to economics of consumption tha (almost) unconstrained utility maximization. In M. T. Andrew McMcekin, Keen Green and V. Walsh. (Eds.), Innovation by the demand, pp. 23-41. Manchester: Manchester Universtity Press.

Thaler, R. (1981). Some empirical evidence on dynamics inconsistency. Economic Letters 8, 201-07.

Tversky, A. and D. Kahneman (1986). Rational choice and the framing of decisions.

Tversky, A. and D. Kahneman (1991). Loss aversion in riskless choice: A referencedependent model.

Van de Stadt, H., A. Kapteyn, and S. van de Geer (1985). The relativity of utility: Evidence from panel data. The Review of Economic Statistics 67(2), 179-187.

von Hippel, E. (1986). Lead users: A source of novel product conccpts. Management Science 32(7), 791-805.

von Hippel, E. (1988). The sources of innovation. Oxford University Press.

Weinreb, F. (1936). Statistische Bepaling van de vraagcurve. Ph. D. thesis, Nederlandsch Economisch Instituut. N 17. 
Witt, U. (2001a). Economic growth. what happens on the the demand side? Journal of Evolutionary Economics 11(1), 1-5.

Witt, U. (2001b). Learning to consume-a theory of wants and the growth of demand.

Zweimuller, J. (2000). Schumpeterian entrepreneurs meet engel's law: The impact of inequality on innovation-driven growth. Journal of Economic Growth 5(2), 185-206. 
SAMENVATTING

Dit proefschrift analyseert de invloed van technologische verandering op de vraag naar consumentengoederen. Gebruikmakend van een scala aan technieken en benaderingen wordt besproken hoe succesvolle innovaties de opties van consumenten veranderen. Hoewel dit proefschrift de nadruk legt op productinnovatie, bestaat het uit vier onafhankelijke artikelen.

Allereerst kijken we vanuit een microeconomisch perspectief naar de evolutie van preferenties. Een microeconomisch model wordt gentroduceerd waarin de consument zijn of haar nut maximeert en waarbij er interactie is tussen nieuwe mogelijkheden en eerdere koopgewoonten. Het ontstaan van gewoonten en de nieuwheidswaarde van producten zijn twee concepten die dit dynamische consumentengedrag verklaren. Het model verklaart een situatie waarin een technisch hoogwaardig innovatief product kan falen doordat het een lage nieuwheidswaarde heeft.

Het ontstaan van gewoonten wordt geanalyseerd in een macroeconomisch groeimodel. Uitgaande van niet-homothetische voorkeuren in een Dixit-Stiglitz opzet, introduceert het model creatieve destructie aan de vraagkant. Er zijn twee sectoren: een finale goederensector en een Onderzoek en Ontwikkeling (O\&O) sector. De laatste sector ontwikkelt elke periode een blauwdruk voor een nieuw product welke superieur is aan alle eerdere blauwdrukken betreffende het vermogen om gewoonten te ontwikkelen. In elke periode verschilt het nieuwe product van alle bestaande producten, zowel in horizontale als in verticale zin. Een interessante conclusie is dat productinnovatie de marginale (en gemiddelde) neiging om te consumeren verhoogt.

De vraagkant wordt ook bestudeerd vanuit een evolutionair perspectief door zijn rol in het Nationaal Systeem van Innovaties te bespreken. Vier dimensies van het systeem worden gekwantificeerd met gebruik van samengestelde indicatoren: creatie van kennis, menselijk kapitaal en aanbod- en vraaggerelatecrde innovatiecapaciteit. De innovatiecapaciteit hangt af van de mate waarin vraag en aanbod met de andere twee dimensies correleren. De evolutie van veertien Europese landen over tien jaar wordt besproken in een poging om de zwakke schakels in het systeem van ieder land te identificeren.

Het laatste empirische hoofdstuk maakt gebruik van CIS gegevens om vast te stellen of overheidsuitgaven een effect hebben op de vraag naar nieuwe goederen. Met behulp van een minimumafstand schatter wordt een systeem van vergelijkingen gemaakt waarin overheidsuitgaven zowel invloed hebben op zowel de kosten van innovatie (R\&D) als op de opbrengsten (vraag naar nieuwe producten). We vinden een licht positief effect van het ontvangen van overheidsuitgaven op de hoeveelhcid O\&O. Het effect van uitgaven op de vraag naar nieuwe producten is echter veel kleiner, en werkt alleen via de toename 
van O\&O.

Het belangrijkste doel van het proefschrift is on door deze vier gezichtspunten nieuwe gebjeden aan te dragen voor discussie over de rol van de vraagkant op technische verandering. De hoofdconclusic van dit proefschrift is dat we menselijke behoeften en do vraag naar innovatie in overweging moeten nemen wanneer we de economie van technologische verandering beschouwen. Dit kan alleen gedaan worden door een dynamisch perspectief op de vraagkant te introduceren. 


\section{About the Author}

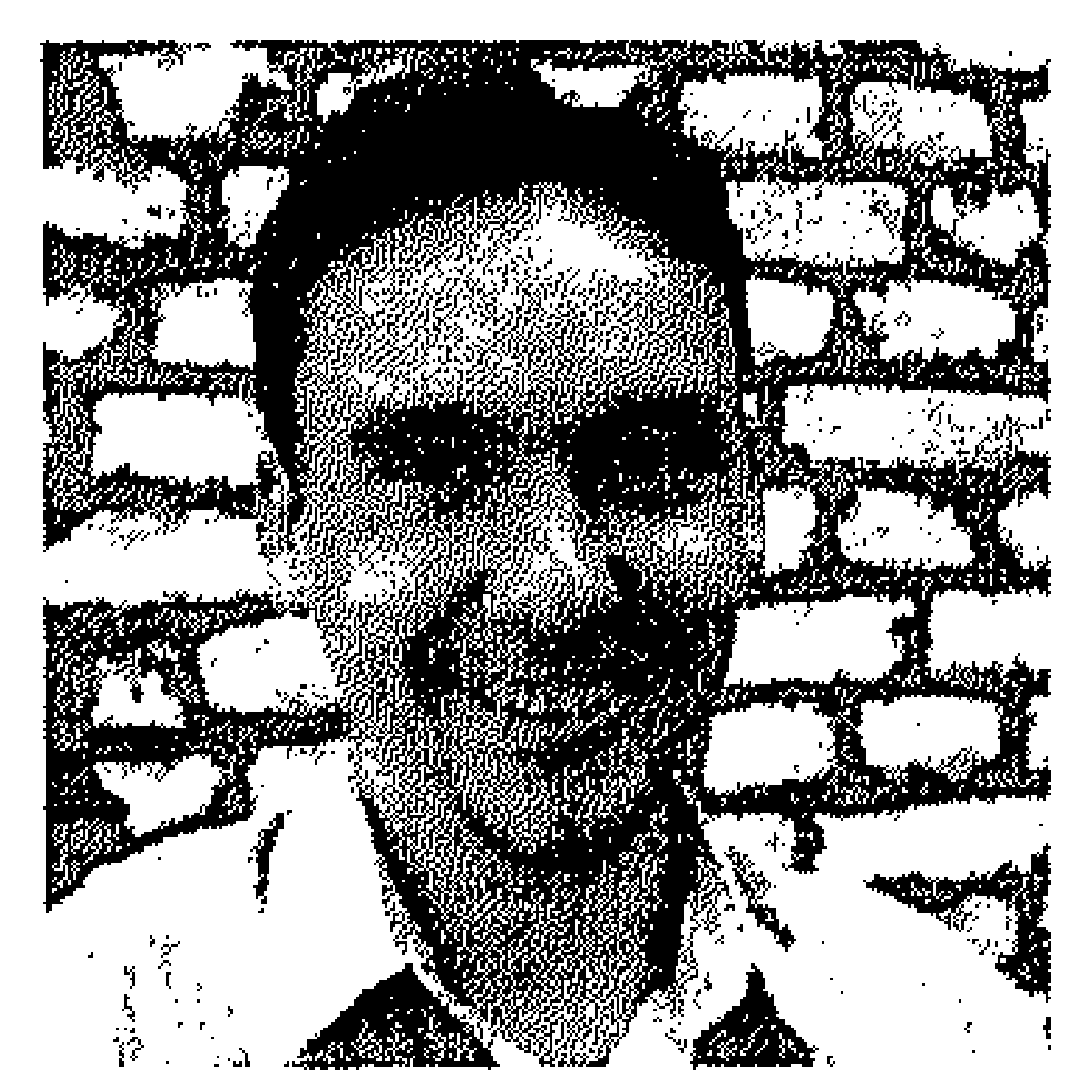

Abraham Garcia was born in Cordoba, Spain. He joined the MERIT/UNU-INTECH (now UNU-MERIT) PhD programme in 2001. Before commencing at this programme he acquired a wealth of multinational experience, working as an Analyst in Germany and Spain. He obtained a Bachelor of Science degree in Economics from the University of Seville in 1998.

At UNU-MERIT he has been working as a Research Assistant in a variety of projects which have enriched his analytical and research skills in European science, technology and innovation policies. The range of topics in which he was involved varies from studying the impact of Open Source Software in a less developed region in Spain, to understanding the dynamics of sectoral innovation across Europe. The last year he has been working as an associate researcher in CEMI- EPFL, Lausanne Switzerland. 